\title{
Incorporación de la Psicología Social al Proceso de Elicitación de Requerimientos de Software
}

Autor: Claudio Alejandro Torre

Directora: Mg. Natalia Andriano

Codirector: Dr. Gustavo Rossi

Tesis presentada para obtener el grado de magíster en Ingeniería de Software.

Facultad de Informática

Universidad Nacional de La Plata - República Argentina

Abril de 2013 


\section{$\underline{\text { Tabla de Contenidos }}$}

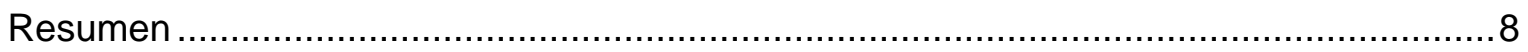

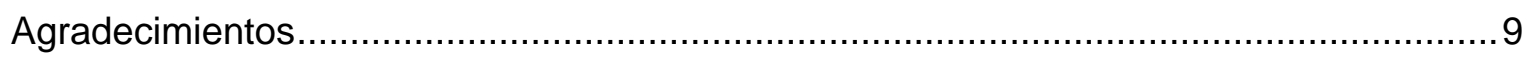

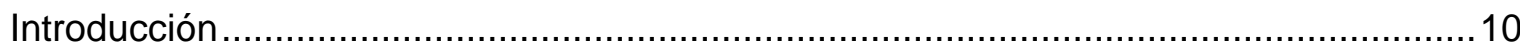

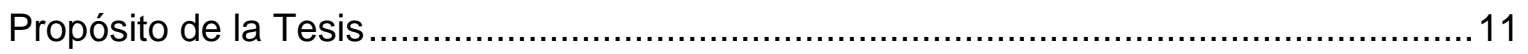

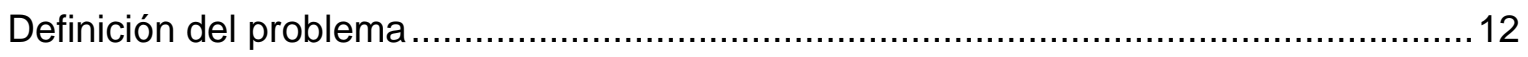

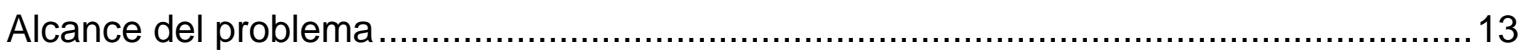

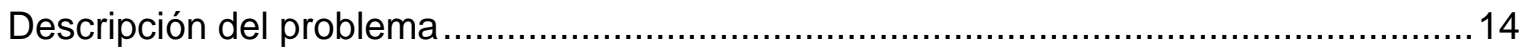

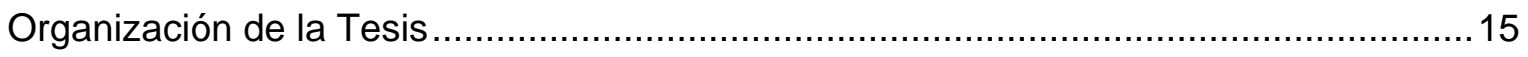

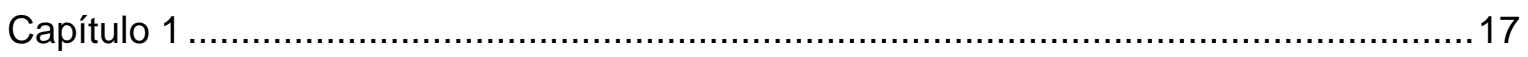

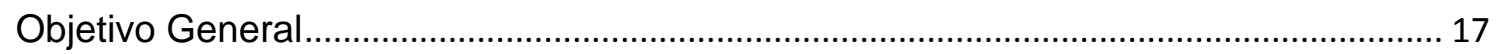

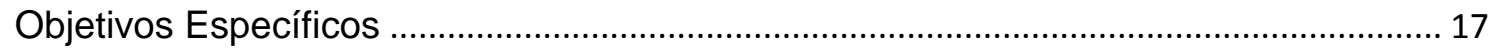

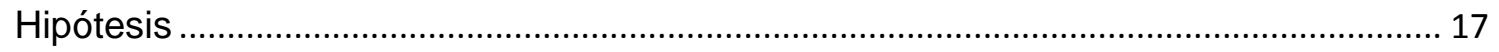

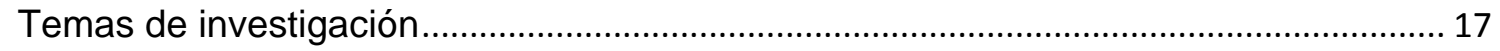

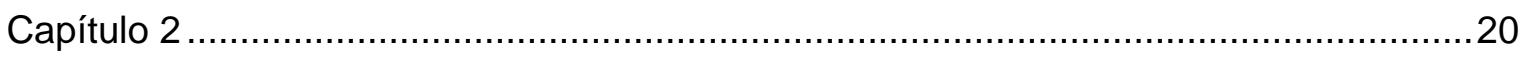

Presentación del marco teórico, estado del arte y Revisión de la literatura relacionada acerca de los factores psicosociales para la implementación de proyectos de software

Estudio de la personalidad - Principales Escuelas Psicológicas ....................................... 20

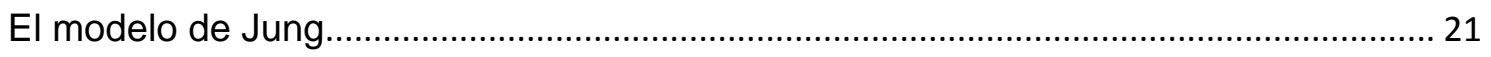

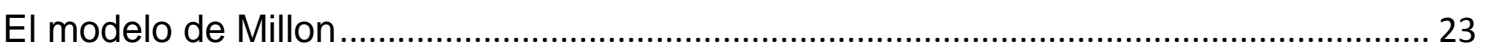

2.1 Cohesión - Interacción de estilos de personalidad dentro del equipo de

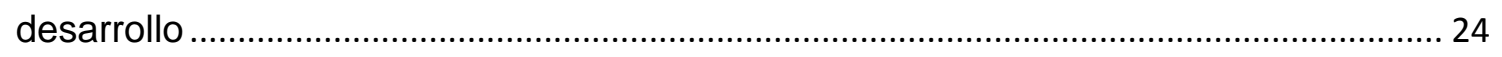

2.2 Comunicación entre el equipo de desarrollo y el usuario ......................................... 28

Método de Observación de Robert F Bales (Interaction Process Analysis IPA) ....................... 30

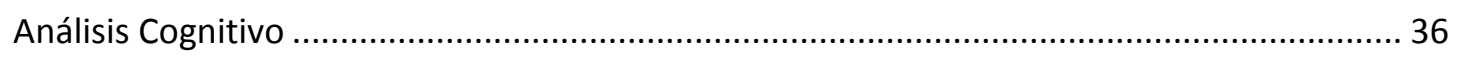

Determinación del valor cognitivo ILS para técnicas de elicitación de requerimientos .......... 37 
Principales trabajos en la temática 39

2.3 Nivel de Consenso para implementar el proyecto de software .............................. 43

2.4 Estilo de mando: Estilos de Priorización de Requerimientos ................................ 44

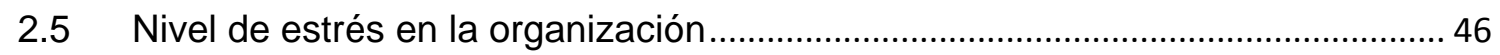

2.6 Participación - Actitud de los Usuarios Claves ....................................................... 49

2.7 Nivel de conflictos en la organización ................................................................... 53

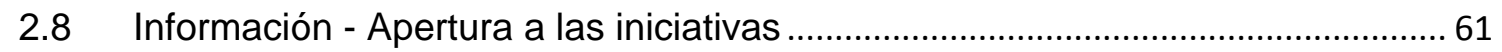

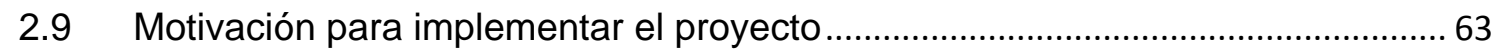

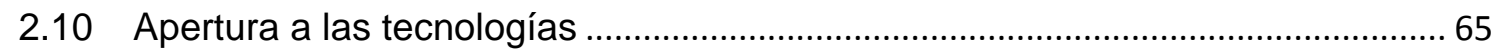

2.11 Formación - Acceso de los usuarios a la capacitación ........................................... 67

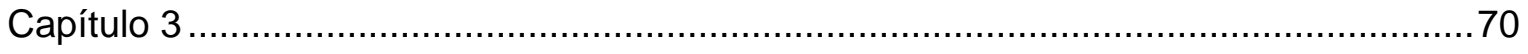

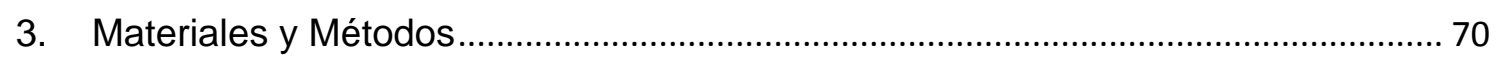

3.1.1 Arquitectura de la encuesta de opinión.......................................................... 70

3.1.2 Implementación de la encuesta y métodos de análisis ...................................... 71

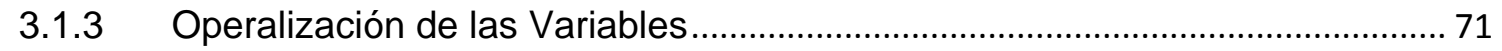

3.1.4 Esquema de evaluación de los resultados de la encuesta................................ 72

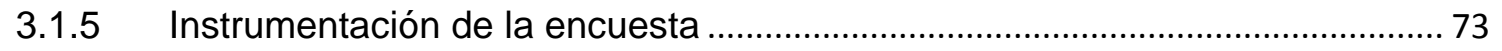

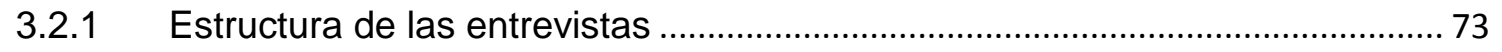

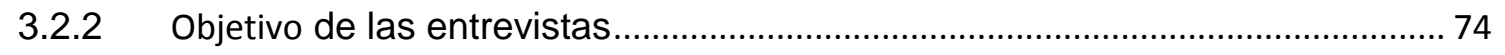

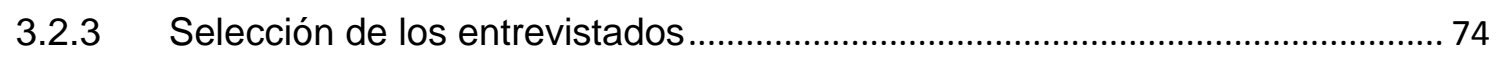

3.3.1 Herramienta de diagnóstico psicosocial sobre el proyecto................................. 75

3.3.2 Descripción de las variables: riesgo psicosocial ................................................ 77

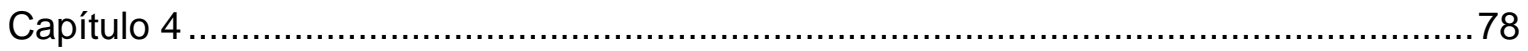

Análisis e Interpretación de los resultados de la encuesta de opinión ............................. 78

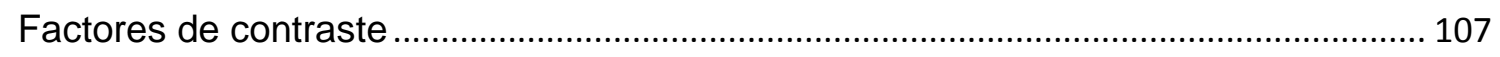

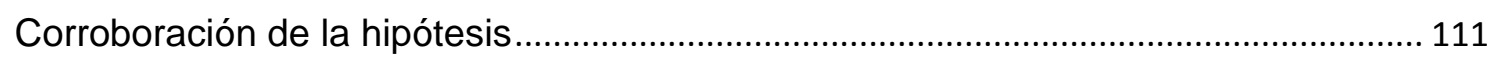


Análisis de los Factores Psicosociales como una buena práctica para la Implementación de Proyectos de Software

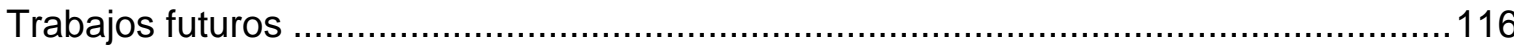

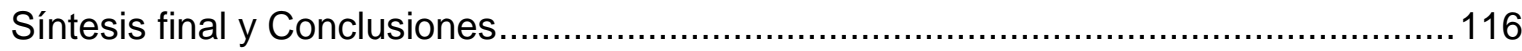

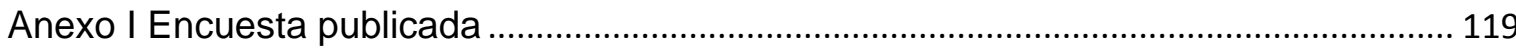

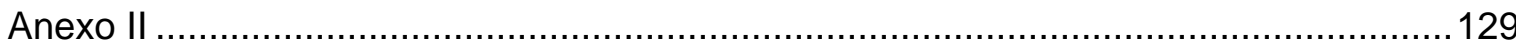

Herramienta para diagnosticar riesgos psicosociales en el desarrollo e implementación

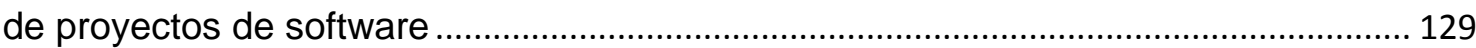

Cuestionario de diagnóstico de riesgo psicosocial en proyectos de software ............... 132

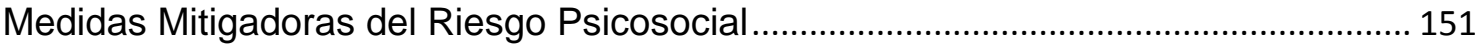

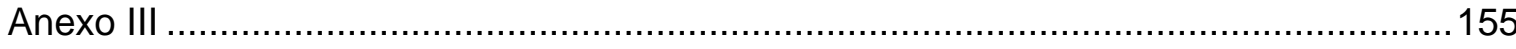

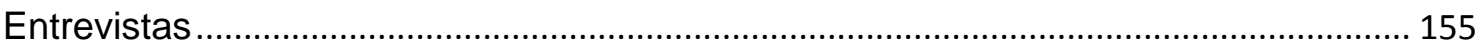

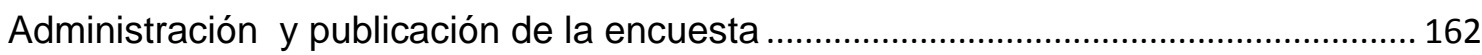

Glosario de Definiciones, Términos y abreviaturas ........................................................ 165

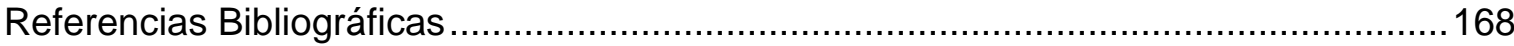

\section{$\underline{\text { Tabla de Figuras }}$}

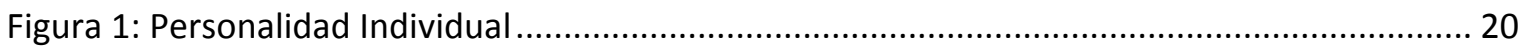

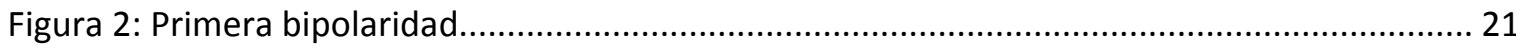

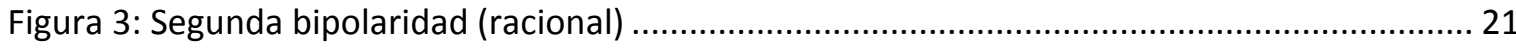

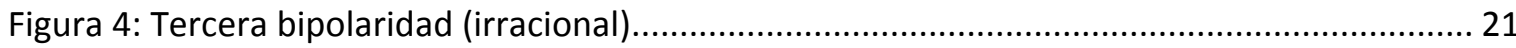

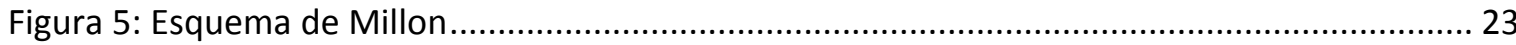

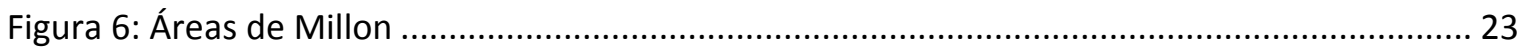

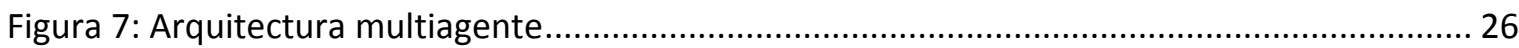

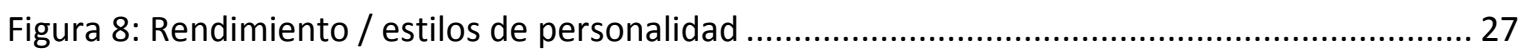

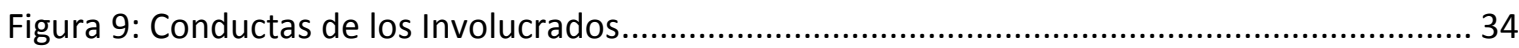

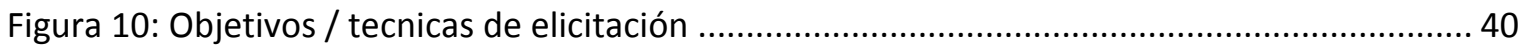




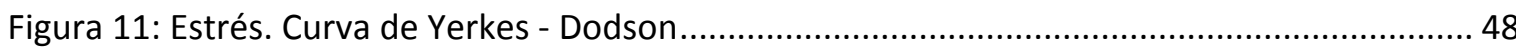

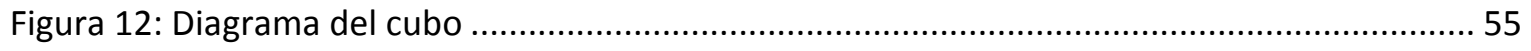

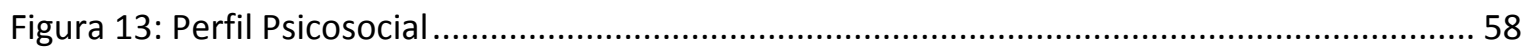

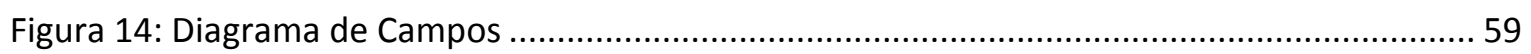

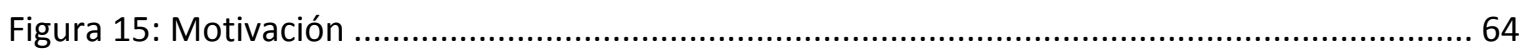

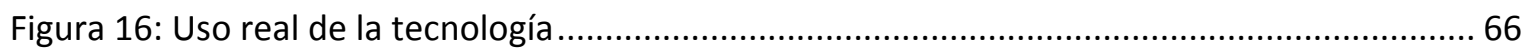

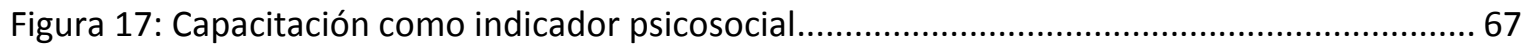

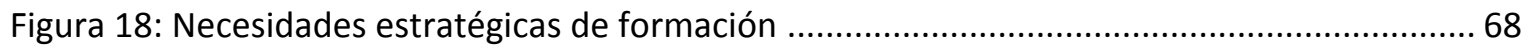

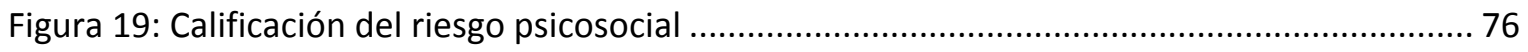

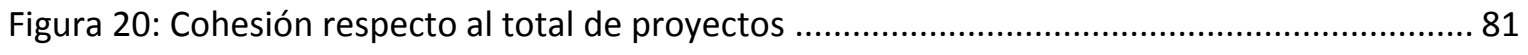

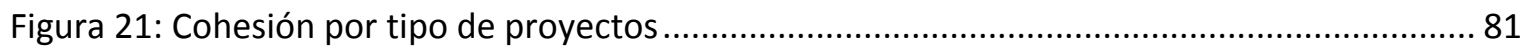

Figura 22: Comunicación con el usuario respecto al total de proyectos ....................................... 83

Figura 23: Comunicación con el usuario por tipo de proyectos PI/PNI ........................................... 83

Figura 24: (Consenso para la implementación respecto al total de proyectos) ………………..... 85

Figura 25: (Comunicación con el usuario por tipo de proyecto PI / PNI) ........................................ 85

Figura 26: (Estilo de mando/Priorización de requerimientos respecto al total de proyectos)........87

Figura 27: (Estilo de mando/priorización de requerimientos por tipo de proyecto $\mathrm{PI} / \mathrm{PNI}$ ) .......... 88

Figura 28: Nivel de estrés en la organización respecto al total de proyectos ................................ 90

Figura 29: Nivel de estrés en la organización por tipo de proyecto PI/PNI ..................................... 91

Figura 30: Participación. Actitud de los usuarios claves respecto al total de proyectos ................. 93

Figura 31: Participación. Actitud de los usuarios claves por tipo de proyecto PI/PNI ..................... 93

Figura 32: Nivel de conflictos en la organización respecto al total de proyectos........................... 96

Figura 33: Nivel de conflictos en la organización por tipo de proyecto PI/PNI .............................. 96

Figura 34: Información. Apertura a las iniciativas respecto al total de proyectos ...........................98

Figura 35: Información. Apertura a las iniciativas por tipo de proyecto $\mathrm{PI} / \mathrm{PNI}$............................... 99

Figura 36: Motivación para implementar el proyecto sobre el total de proyectos ........................ 100 
Figura 37: Motivación para implementar el proyecto por tipo de proyecto PI/PNI 101

Figura 38: Apertura a la tecnología respecto al total de proyectos. 103

Figura 39: Apertura a la tecnología por tipo de proyecto PI/PNI 104

Figura 40: Formación. Acceso de los usuarios a la capacitación respecto al total de proyectos . 105

Figura 41: Formación. Acceso de los usuarios a la capacitación por tipo de proyecto PI/PNI ..... 106

Figura 42: Incidencia de aspectos de naturaleza técnica sobre PI/PNI 108

Figura 43: Incidencia de aspectos de naturaleza económica/financiera sobre PI/PNI..... 109

Figura 44: Incidencia del tamaño de la organización sobre PI/PNI..... 110

Figura 45: Resumen de valores de contraste de hipótesis

Figura 46: Análisis de opiniones sobre incorporar como buena práctica al análisis de los factores psicosociales. 115

\section{Índice de Tablas}

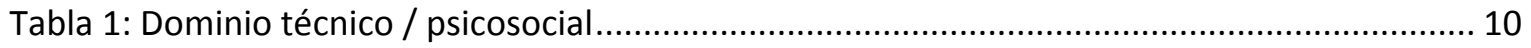

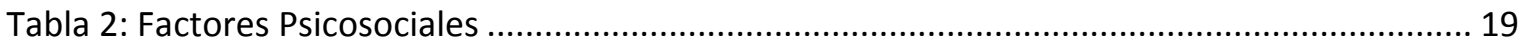

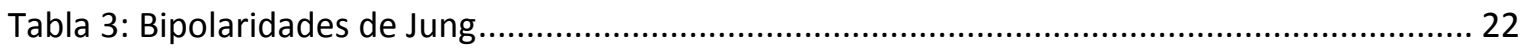

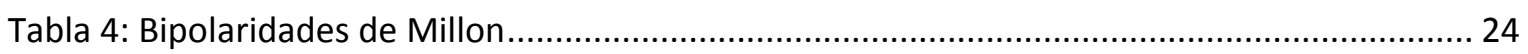

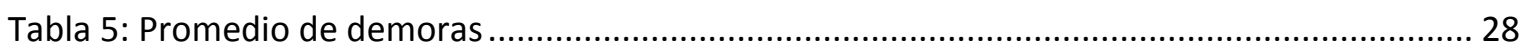

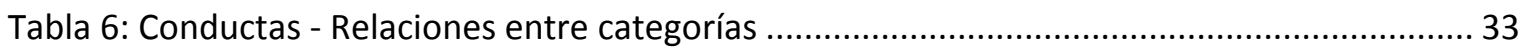

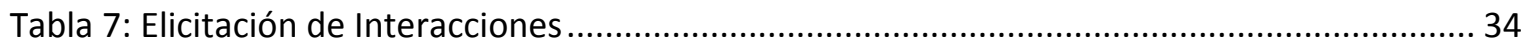

Tabla 8: Estilos cognitivos / técnicas de elicitación ......................................................................... 38

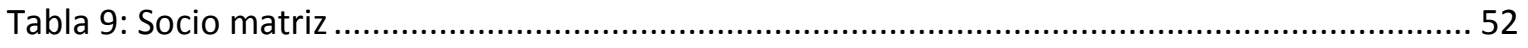

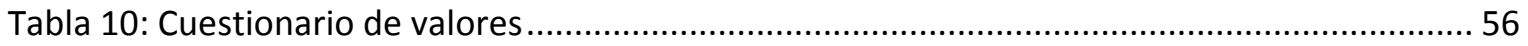

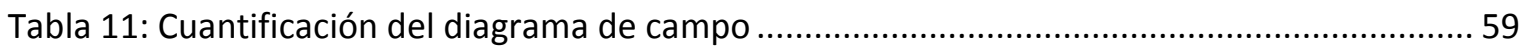

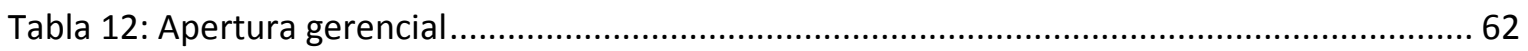

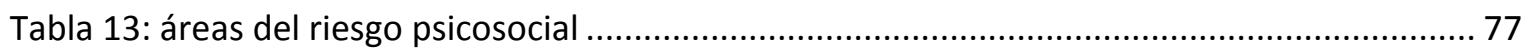

Tabla 14: Análisis de Factores psicosociales ....................................................................... 78 
Tabla 15 : de contingencia (Cohesión de personalidades).......................................................... 80

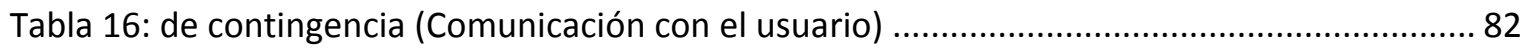

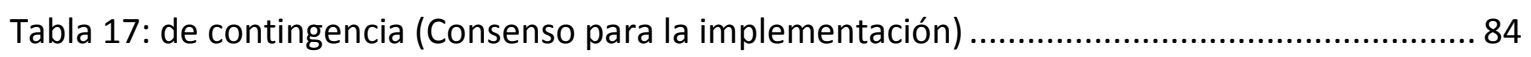

Tabla 18: de contingencia (estilo de mando / priorización de requerimientos)............................... 86

Tabla 19: de contingencia (nivel de estrés en la organización.) ………………............................ 89

Tabla 20: de contingencia (Participación. Actitud de los usuarios claves)...................................... 92

Tabla 21: de contingencia (Nivel de conflictos en la organización) ……....................................... 95

Tabla 22: de contingencia (Información. Apertura a las iniciativas) ............................................... 97

Tabla 23: de contingencia (Motivación para implementar el proyecto) ….................................... 100

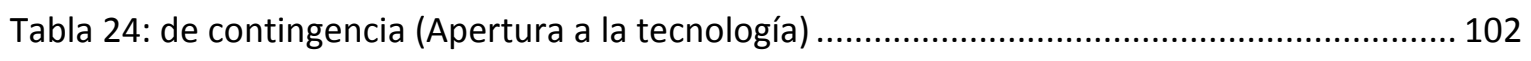

Tabla 25: de contingencia. Formación. (Acceso de los usuarios a la capacitación) ........................ 105

Tabla 26 de contingencia (Incidencia de aspectos de naturaleza técnica) ................................... 108

Tabla 27: de contingencia (Incidencia de aspectos de naturaleza económica/financiera sobre

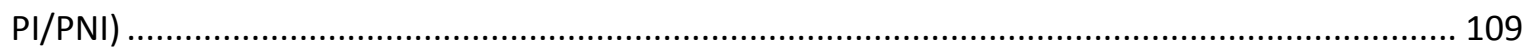

Tabla 28: de contingencia (Incidencia del tamaño de la organización sobre PI/PNI) ................... 110

Tabla 29: de contingencia (ejemplo para cálculo de proporciones) ............................................ 112

Tabla 30: de contingencia (Análisis de opiniones de incorporar como buena práctica al análisis de

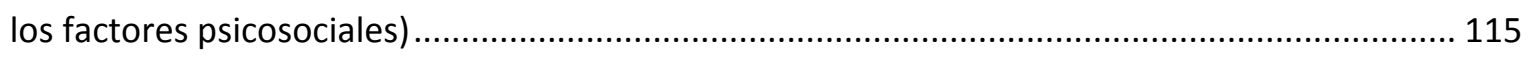

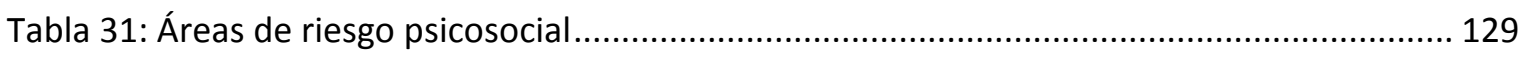




\section{Resumen}

La presente investigación tiene como objetivo indagar en la cuestión por qué determinados proyectos de software se logran implementar sin inconvenientes en algunas organizaciones, mientras que los mismos proyectos fracasan en otras organizaciones de características similares.

Existen distintos enfoques que abordan este tema desde el ámbito de la psicología social.

Por ejemplo, [Martínez Carod et al., 2005] lo plantea desde las motivaciones cuando establece: "la intencionalidad política para que un requerimiento se implemente o se omita en un proyecto de software, suele estar influida por la dinámica del grupo en el que éste se inserta, involucrando complejas relaciones interpersonales entre los involucrados".

Por su parte [Tastle, et al., 2010] propone analizar el problema desde el disenso, al sostener: "Ignorar el nivel de disenso en una etapa de índole investigativa como lo es la elicitación, lleva implícito un riesgo que puede propagarse hacia etapas posteriores del proceso de desarrollo de software".

La hipótesis planteada como parte de este trabajo coincide con los argumentos de los autores citados y los refuerza aún más, sosteniendo la necesidad de incrementar el conocimiento del factor humano durante el proceso de desarrollo de software, especialmente durante la elicitación de requerimientos. Mediante métodos y técnicas provenientes de la psicología social resultaría posible mejorar la implementación de proyectos de software.

Creemos que la diferencia entre alcanzar el éxito y fracasar en la implementación podría diagnosticarse si se dispusiera de herramientas para diagnosticar la evolución de ciertos aspectos vinculados al comportamiento humano y la conducta social como por ejemplo la personalidad, la comunicación, el estrés, los conflictos, el acceso a la información y la organización informal, entre otros.

Palabras claves: personalidad individual, estilos cognitivos, dinámica de grupos, factores psicosociales, implementación de software. 


\section{$\underline{\text { Agradecimientos }}$}

Sería un grave error de mi parte pasar por alto las contribuciones efectuadas por distintas personas que desinteresadamente aportaron su experiencia y conocimiento para que este trabajo pudiera finalizarse.

En primer lugar quiero agradecer el tiempo y el aporte intelectual brindado por mis directores, la Magíster en Ingeniería de Software Natalia Andriano y el Doctor en Ciencias Informáticas Gustavo Rossi.

También es mi intención agradecer a todas aquellas personas que contribuyeron con su grano de arena, ya sea colaborando explícitamente con su opinión en la encuesta y en las entrevistas efectuadas, como así también cooperando de manera implícita, al asesorar o expresar sus puntos de vista.

Por último quiero agradecer a mi esposa Claudia, a mis hijos Patricio, Manuel y Agustín, y a mis padres, por apoyar esta iniciativa, la cual requirió de mí un tiempo de trabajo significativo.

A todos ellos, muchas gracias. 


\section{Introducción}

El punto de partida de esta investigación ha surgido por un trabajo de investigación realizado en la Universidad de Giessenn, Alemania, en el cual se describe la injerencia del contexto laboral sobre la calidad del producto software y su proceso de desarrollo. [Frese et al., 1995]

El trabajo denominado IPAS, comprendió la realización de una encuesta de opinión en la que se analizaron 29 proyectos de software implementados por 19 firmas de origen germano y suizo, realizados por equipos cuyo tamaño medio fue de 10 desarrolladores. El tamaño de la muestra fue de 200 encuestados, a los cuales se les suministró un cuestionario y se le efectuaron una serie de entrevistas.

En el estudio se cruzaron 3 variables del dominio técnico con 5 factores psicosociales, conformando así la siguiente matriz de evaluación.

Tabla 1: Dominio técnico / psicosocial

\begin{tabular}{|l|c|c|c|}
\hline & $\frac{\text { Relación con el }}{\text { usuario }}$ & Desarrollo & $\frac{\text { Métodos y }}{\text { herramientas }}$ \\
\hline Complejidad & $\mathrm{X}$ & $\mathrm{X}$ & $\mathrm{X}$ \\
\hline Comunicación & $\mathrm{X}$ & $\mathrm{X}$ & $\mathrm{X}$ \\
\hline Discreción & $\mathrm{X}$ & $\mathrm{X}$ & $\mathrm{X}$ \\
\hline Calificación & $\mathrm{X}$ & $\mathrm{X}$ & $\mathrm{X}$ \\
\hline Estrés & $\mathrm{X}$ & $\mathrm{X}$ & $\mathrm{X}$ \\
\hline
\end{tabular}

Los resultados confirmaron algunas hipótesis. Por ejemplo, las opiniones evidenciaron que las tareas de desarrollo se vieron favorecidas por la preminencia del factor comunicación y fueron perjudicadas por la presencia de estrés.

Curiosamente, el estudio reveló que la programación constituye sólo una parte pequeña del desarrollo de software, aproximadamente el $10 \%$ del tiempo, mientras que las actividades sociales, como por ejemplo, intercambio de información, asesoramiento, reuniones de equipo, etc., acaparan un porcentaje mucho mayor de su jornada de trabajo, evidenciando que las tareas de desarrollo son socialmente orientadas.

Desde el punto de vista de las organizaciones en general, [Cequea, et al., 2011] sostienen que las personas evidencian comportamientos de índole individual y grupal que afectan a la productividad. Dichos comportamientos provienen de procesos sociológicos y psicosociales. Los 
primeros son fenómenos producidos por la actividad social de los seres humanos dentro de un contexto, mientras que los psicosociales derivan de la organización y las condiciones del trabajo.

Por su parte, para [OIT-OMS, 1984], los factores psicosociales "consisten en interacciones entre, por una parte, las capacidades del trabajador, sus necesidades, su cultura y su situación personal, y por la otra, el trabajo, el medio ambiente y las condiciones de la organización, todo lo cual, a través de percepciones y experiencias, pueden influir en la salud, el rendimiento y la satisfacción en el trabajo".

En este trabajo se seguirá la línea de pensamiento de [OIT-OMS, 1984] y las posiciones de [Frese et al., 1995] y [Cequea, et al., 2011].

Recordemos, el primero sostiene que en las tareas de desarrollo de software existe preminencia de actividades sociales y el segundo, concluye que se produce afectación de productividad por variación de comportamientos individuales y grupales de los desarrolladores.

Pero no será posible avanzar sin antes definir el término "Elicitación de requerimientos". La definición que más se ajusta al contexto de este trabajo de investigación la aporta [Brooks, et al., 1995] cuando establece al proceso de elicitación como "la tarea de adquirir todo el conocimiento relevante necesario para producir un modelo de requerimientos del dominio del problema."

El siguiente párrafo de Sommerville resume nuestro punto de vista acerca de la importancia que adquiere la gestión de los factores psicosociales para la implementación de proyectos de software.

"El software no existe en forma aislada: se lo utiliza dentro del contexto social propio de la organización. Los requerimientos se originan y restringen dentro de ese contexto. La razón por la cual frecuentemente se desarrolla software que nunca es utilizado proviene del hecho de desestimar la importancia de ese contexto".

\section{Propósito de la Tesis}

Durante la exposición de trabajos presentados en la edición 2009 del Curso - GROUPWARE y SOFTWARE SOCIAL - dictado en el Postgrado de la Facultad de Informática de la Universidad Nacional de La Plata, surgió la siguiente disyuntiva como tema de debate: 
- ¿Es suficiente abordar el proceso de elicitación de requerimientos de software aplicando únicamente las herramientas de elicitación clásicas (tormenta de ideas, casos de uso, entrevistas, etc.)?, o;

- ¿Resulta conveniente complementar dichas técnicas recurriendo a métodos útiles que registren aspectos del contexto socio-técnico como por ejemplo, la personalidad, la comunicación, las motivaciones, y los conflictos entre los involucrados que conforman la organización del cliente?

Lo que este trabajo persigue es realzar la idea que los requerimientos en los sistemas socio-técnicos, además de implementarse por su naturaleza racional, también se implementan producto de valoraciones subjetivas de los involucrados con el proyecto, generadas por estímulos sensoriales, emotivos e interpersonales provenientes de su entorno, es decir por todo aquello que conforma el perfil psicosocial de la organización.

\section{Definición del problema}

Si bien es cuantiosa la bibliografía ([Alvarez, 2002], [Christel et al., 1992], [Hickey, et al., 2004], [Jacobson, 1992], [Loucopoulos, et al., 1995], [Mullery, 1979], [Sindre, et al., 2000], [Sommerville, et al., 1997], [Durán Toro, et al., 2002], [Zowghi, et al., 2005] ) que trata un amplio espectro en la teoría y aplicación de las técnicas de elicitación de requerimientos, no sucede lo mismo cuando se pretende medir el impacto de los factores psicosociales sobre la implementación de proyectos de software.

Lo que pretendemos es trabajar en la intersección de dos (2) áreas, es decir: utilizar herramientas de la psicología social como dinámica de grupos, análisis del estrés laboral y métodos de resolución de conflictos, por ejemplo, y aplicarlas dentro del campo de la ingeniería de requerimientos para mejorar la implementación de proyectos de software.

El enfoque dado pretende incorporar conocimiento que le facilite al equipo de desarrollo reunir mayor y mejor información acerca del riesgo proveniente de la conducta social, evaluando los factores psicosociales, tanto en la organización donde funcionará el software, como en aquella que lo desarrolla. 


\section{Alcance del problema}

Según [OIT-OMS, 1984]: "La evaluación de riesgos es un paso necesario para detectar, prevenir y/o corregir las posibles situaciones problemáticas provocadas por los factores psicosociales. Dicha evaluación debe ser multifactorial e incluirá aspectos propios de la tarea, de la organización, del ambiente, del desempeño y del puesto de trabajo."

Según [Cequea, et al., 2011] a los factores psicosociales se los puede clasificar de acuerdo a la siguiente taxonomía:

Factores Psicosociales $\left\{\begin{array}{l}\text { Individuales } \\ \text { Grupales } \\ \text { Organizacionales }\end{array}\right.$

Uno de los hitos fundamentales de la investigación es corroborar si existe relación estadísticamente significativa entre la implementación de proyectos de software y la afectación de los factores psicosociales mencionados.

Cada vez con mayor frecuencia se aprecia que las técnicas utilizadas durante el proceso de elicitación de requerimientos (tormenta de ideas, entrevistas, escenarios, etc. [Durán Toro, et al., 2002]) se introducen más en el terreno de las ciencias sociales como la sociología organizacional, la psicología y otras disciplinas emergentes relacionadas con éstas. [Tastle, W. , 2010].

[Whitworth, E et al., 2007] sostiene: "actualmente existe carencia de investigación básica en el campo socio-psicológico de los individuos que integran equipos de desarrollo de software."

En función de estas líneas de pensamiento, hemos incluido dentro del alcance del presente trabajo el diseño de una herramienta de diagnóstico destinada al proceso de elicitación de requerimientos para identificar el riesgo proveniente del área sociológica y 
psicosocial de la Organización, y su impacto sobre el proyecto de software. (Anexo II)

\section{Descripción del problema}

Para nosotros, dos cuestiones fundamentales definen el problema a resolver.

1. ¿Existe relación entre la implementación de proyectos de software y los factores psicosociales?

2. ¿De ser así, resulta posible complementar el proceso de elicitación de requerimientos mediante el uso de prácticas provenientes de la psicología social aplicadas para evaluar en forma sistemática, disciplinada y cuantificable los riesgos provenientes de los factores psicosociales?

Luego de efectuar un amplio análisis de la situación, nuestra conclusión es afirmativa para ambas cuestiones.

Ahora bien, la pregunta clave surge espontáneamente:

3. ¿También para otros autores, la deficiente gestión de los factores psicosociales resulta ser un problema para la implementación de proyectos de software?

Veamos algunas opiniones:

[Tastle, W. , 2010] sostiene que las causas principales del abordaje a las ciencias sociales se debe a la necesidad de elicitar el conflicto producido por posiciones de disenso entre los involucrados con el proyecto, cada uno de ellos motivados por su punto de vista particular.

Según [Boehm, B., 1998], "Ia Ingeniería de Requerimientos es la disciplina utilizada para desarrollar una especificación de software completa, consistente y no ambigua que servirá de base para establecer acuerdos entre las partes involucradas, describiendo las funciones que realizará el sistema".

En ese sentido, [Suárez, F., 1971] define: "la psicosociología de las organizaciones es la disciplina encargada de develar los factores, el contexto, los trasfondos y las fuerzas que operan, rodean y subyacen a las organizaciones como sistemas sociales en continua interacción con el ambiente". 
Una de las tareas que continúa siendo una recurrente fuente de error en la etapa de requerimientos es la equívoca identificación por parte los involucrados con el proyecto de sus propias necesidades. Generalmente este fenómeno se produce por puntos de vista distintos o posiciones encontradas [Tastle, $W$ et al., 2010] que el equipo de desarrollo no gestiona adecuadamente.

Por su parte [Madigan] sostiene que la complejidad del proceso de elicitación de requerimientos se asocia a una serie de dificultades en su implementación entre ellas, los problemas del comportamiento humano.

Para nosotros, estos problemas de comportamiento, generalmente minimizados en los equipos de desarrollo, adquieren injerencia crítica en el resultado final del proyecto de software.

\section{Organización de la Tesis}

Para que el lector pueda obtener una apreciación de alto nivel de los temas aquí tratados, a continuación se resumen las etapas desarrolladas y la temática general abordada en cada una de ellas.

Etapa 1 - Propósito del trabajo y definición del problema. Objetivo General y Objetivos específicos. Presentación de la hipótesis. Temas de investigación. (Capítulo 1)

Etapa 2 - Exploración: Presentación del marco teórico, estado del arte y revisión de la literatura relacionada.

Cuestiones teóricas más significativas en la temática "Aportes de la Psicología Social a la Ingeniería de Software". Principales trabajos realizados en la temática sobre Factores Psicosociales y desarrollo de software.

\section{Etapa 3 - Materiales y Métodos}

La encuesta de opinión. Especificación de los objetivos, alcances, variables, publicación de cuestionarios y recopilación de datos que permitieron corroborar la hipótesis que se postula. Entrevistas a psicólogos, desarrolladores y usuarios. (Capítulo 4).

Etapa 4 - Análisis de los resultados y demostración de la hipótesis. Presentación de los resultados y verificación de existencia de relación 
estadísticamente significativa entre los factores psicosociales y la implementación de proyectos de software.

Etapa 5 - Presentación de la herramienta de diagnóstico destinada al proceso de elicitación de requerimientos que identifique el riesgo proveniente del área sociológica y psicosocial de la Organización, y su impacto sobre el proyecto de software. (Anexo II). Elaboración de conclusiones. Identificación de futuros trabajos. 


\section{Capítulo 1}

\section{Objetivo General}

Desarrollar una herramienta de diagnóstico destinada al proceso de elicitación de requerimientos que identifique el riesgo proveniente del área sociológica y psicosocial de la Organización, y su impacto sobre el proyecto de software.

\section{Objetivos Específicos}

1. Evaluar aspectos de personalidad individual, estilos cognitivos y conducta grupal de los stakeholders que pudieren impactar sobre la implementación de proyectos de software.

2. Incrementar conocimiento sobre factores psicosociales como el estrés disfuncional, los conflictos y medir su influencia en las primeras etapas de los proyectos de software.

3. Introducir el uso de la herramienta describiendo sus principales funcionalidades y métricas utilizadas.

4. Mediante encuestas y entrevistas, corroborar la utilidad de incorporar instrumentos de la psicología social al proceso de elicitación de requerimientos, como una herramienta más de análisis.

\section{Hipótesis}

La hipótesis que trataremos de demostrar es que "Existe relación estadísticamente significativa entre la implementación de proyectos de software y los factores psicosociales aquí descriptos".

La aplicación de herramientas de diagnóstico y las buenas prácticas para gestionar los factores psicosociales en un proyecto de software, mejoran su implementación.

\section{$\underline{\text { Temas de investigación }}$}

Como ya se dijo, esta investigación propone incorporar temas propios del ámbito de la psicología social al proceso de elicitación de requerimientos. 
Para describir el estado de arte sobre la problemática planteada se recurrió a bibliografía proveniente, tanto del área de ingeniería de requerimientos como de la psicología social y la sociología de las organizaciones.

En ese campo de acción se tuvieron en cuenta investigaciones realizadas en el ámbito de la psicología tradicional, no clínica, las principales teorías de estudio de la personalidad individual, los estilos cognitivos y la dinámica de grupos. Desde el punto de vista de la ingeniería de software se evaluó la relación de la psicóloga social con la implementación de proyectos de software desde tres (3) modelos de referencia:

- El modelo de capacidad y madurez del Software (SW-CMMI 1.3) del Software Engineering Institute. [SEI, 2010]

- El modelo de desarrollo ágil, surgido del Manifiesto para el desarrollo ágil de software. Manifesto for Agile Development [Beck, 2001]

- El "Project Management Body of Knowledge" [PMBOK, 2003] Project Management Institute (PMI).

Para la selección de los factores psicosociales se consideraron como fuentes primarias a [Cequea, et al., 2011], por el documento "Factores grupales que inciden en la productividad", y a [Martín, et al., 2002] por el "Cuestionario de evaluación de factores psicosociales."

Los factores psicosociales extraídos fueron de:

- [Cequea, et al., 2011]: cohesión del grupo, consenso, conflicto y motivación;

- [Martín, et al., 2002]: comunicación, estilo de mando, estrés, participación, información, tecnología y formación.

Teniendo en cuenta que:

- no se han encontrado trabajos que traten la problemática de factores psicosociales específicos para la implementación de proyectos de software, y que;

- según los autores, los factores psicosociales mencionados son lo suficientemente genéricos para funcionar en dominios laborales diversos,

se propone especializar los factores psicosociales establecidos en [Cequea, et al., 2011] - [Martín, et al., 2002] contextualizándolos para la implementación de proyectos de software. 


\begin{tabular}{|l|l|}
\hline \multicolumn{2}{|l|}{$\begin{array}{l}\text { Factores Psicosociales } \\
\text { [Cequea, et al., 2011] - [Martín, et al., 2002] }\end{array}$} \\
\hline Cohesión & $\begin{array}{l}\text { Interacción de estilos de personalidad dentro } \\
\text { del equipo de desarrollo. }\end{array}$ \\
\hline Comunicación & $\begin{array}{l}\text { Comunicación entre el equipo de desarrollo y el } \\
\text { usuario. }\end{array}$ \\
\hline Consenso & $\begin{array}{l}\text { Nivel de consenso para implementar el proyecto } \\
\text { de software. }\end{array}$ \\
\hline Estilo de mando & Estilos de priorización de requerimientos. \\
\hline Estrés & Nivel de estrés en la organización. \\
\hline Participación & Actitud de los usuarios claves. \\
\hline Conflictos & Nivel de Conflictos en la organización. \\
\hline Información & Apertura a las iniciativas. \\
\hline Motivación & Motivación para la implementar el proyecto. \\
\hline Tecnologías & Apertura a las Tecnologías \\
\hline Formación & Acceso de los usuarios a la capacitación. \\
\hline
\end{tabular}




\section{Capítulo 2}

Presentación del marco teórico, estado del arte y Revisión de la literatura relacionada acerca de los factores psicosociales para la implementación de proyectos de software

Antes de abordar la descripción de los factores psicosociales detallados en el Capítulo I, surge necesario presentarle al lector una breve reseña sobre los antecedentes de las principales escuelas psicológicas que han estudiado los estilos de personalidad humana.

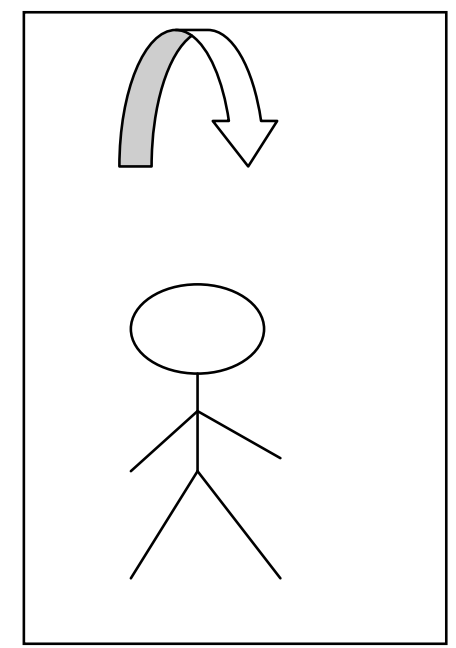

Figura 1: Personalidad Individual

\section{Estudio de la personalidad - Principales Escuelas Psicológicas}

A fines del siglo XVIII los pioneros en lo que hoy llamamos psicología establecieron la denominada "Teoría de la Personalidad". En ella, la personalidad se describía como un conjunto estructurado y dinámico de rasgos que caracterizaban a un individuo. Estos rasgos eran adquiridos por herencia, medio ambiente y experiencias personales. [Cooper et al., 2002].

La premisa consistía en explicar a través del estudio de la personalidad las causas por las cuales, ante los mismos estímulos, los hombres se comportaban de manera diferente. 
Entre las escuelas psicológicas que estudiaron la personalidad se destacaron las psicoanalíticas (Sigmund Freud, Melanie Klein), las fenomenológicas (Carl Rogers), las conductuales (John Watson, B. F. Skinner) y las de rasgos de personalidad (Hans Eysenck, Raymond Cattell, Carl Jung y Theodore Millon). Esta última teoría fue la que mejor se adaptó al campo de la psicología organizacional, sosteniendo que el comportamiento de un individuo puede ser interpretado como una combinación independiente de intensidades de diferentes rasgos.

A continuación se resumirán los aspectos teóricos más salientes con sus principales interlocutores.

\section{El modelo de Jung}

En su teoría, Carl Gustav Jung describió las diferencias de personalidad entre individuos utilizando las categorías fundamentales de introversión y extroversión. [Millon, 2008]. Es decir, la clasificación de un individuo de acuerdo a si éste guía sus acciones enfocando su mundo interno o su realidad externa.

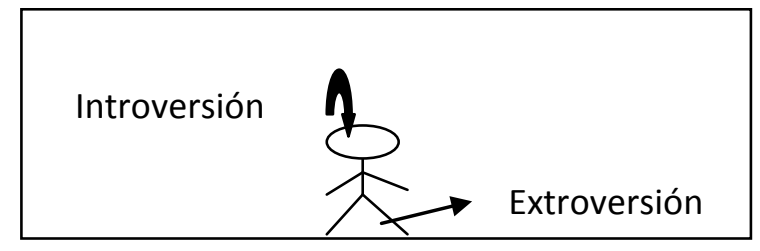

Figura 2: Primera bipolaridad

Pero esto no era suficiente. Lo que faltaba era establecer cómo el individuo trataba la información con su entorno es decir si lo hacía preferentemente con: el intelecto o el sentimiento, o con los sentidos o la intuición.

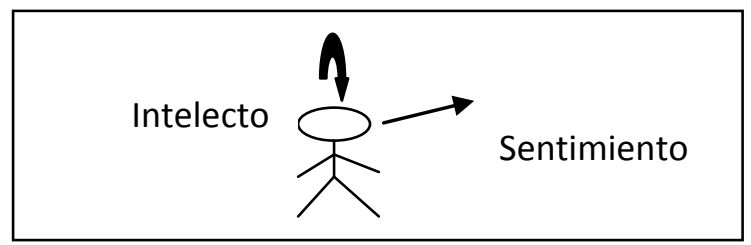

Figura 3: Segunda bipolaridad (racional)

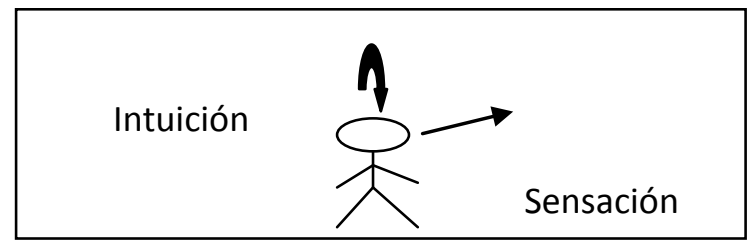

Figura 4: Tercera bipolaridad (irracional) 
Jung sostuvo que la prevalencia de los estilos racionales le permite al individuo deducir con mayor criterio y tomar decisiones más acertadas.

En cambio, las funciones irracionales le aportan al individuo la motivación necesaria para tomar las decisiones que debe afrontar.

Tabla 3: Bipolaridades de Jung

\begin{tabular}{|l|l|l|}
\hline \multicolumn{1}{|c|}{ ÁREA } & \multicolumn{2}{|l|}{ BIPOLARIDADES DE JUNG } \\
\hline \multirow{4}{*}{$\begin{array}{l}\text { Función Dominante } \\
1^{\circ} \text { Bipolaridad } \\
2^{\circ} \text { Bipolaridad }\end{array}$} & Introversión & Intelecto \\
\cline { 2 - 3 } & Introversión & Sentimiento \\
\cline { 2 - 3 } & Extraversión & Intelecto \\
\cline { 2 - 3 } & Extraversión & Sentimiento \\
\cline { 2 - 3 } & Introversión & Intuición \\
\cline { 2 - 3 } $1^{\circ}$ Bipolaridad & Introversión & Sensación \\
\cline { 2 - 3 } $3^{\circ}$ Bipolaridad & Extraversión & Intuición \\
\cline { 2 - 3 } & Extraversión & Sensación \\
\hline
\end{tabular}

La combinación de la primer bipolaridad (introversión y extroversión) con las dos siguientes bipolaridades (intelecto / sentimiento, sensación / intuición) determinan ocho estilos o rasgos de personalidad que representan la función dominante del individuo.

Para complementar esa función dominante Jung estableció una función auxiliar que cubre el comportamiento menos preferido del individuo. Dicha función presenta una estructura similar, es decir con los ocho estilos de la función dominante.

Según Jung, la función auxiliar es aquella que se activa cuando alguien decide trabajar en la dirección menos favorita y es usualmente opuesta a la función dominante. Por ejemplo si la función principal en un individuo es eminentemente racional (pensamiento o sentimiento), la auxiliar 
posiblemente sea irracional (sensación o intuición) o, viceversa.[Digman, 1990].

\section{El modelo de Millon}

En su teoría, Theodore Millon priorizó la importancia de factores biológicos, ambientales y de relación interpersonal en la composición de la personalidad. [Millon, 2008]. Durante la formación de la personalidad, un individuo recibe la influencia de factores biológicos y psicológicos que interactúan dinámicamente en un espiral iterativo, en el cual cada círculo del espiral se construye sobre las interacciones previas, creando de esta forma, nuevas bases para las próximas interacciones. [Campos et al., 2007]

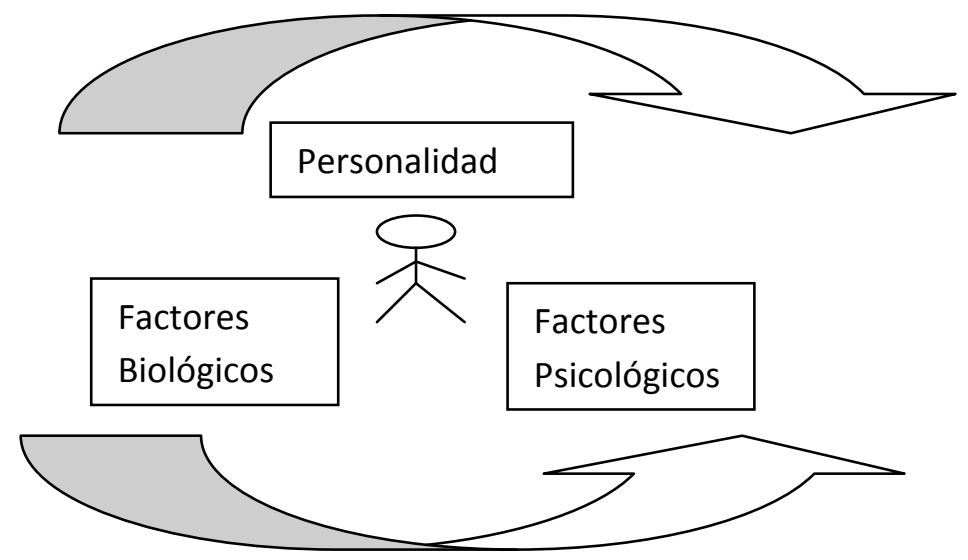

Figura 5: Esquema de Millon

Millon propuso una forma de medir la personalidad a través de este esquema, el cual se basa en el análisis de las acciones que un individuo realiza para lograr sus objetivos. Dichas acciones fueron enfocadas desde tres áreas principales:

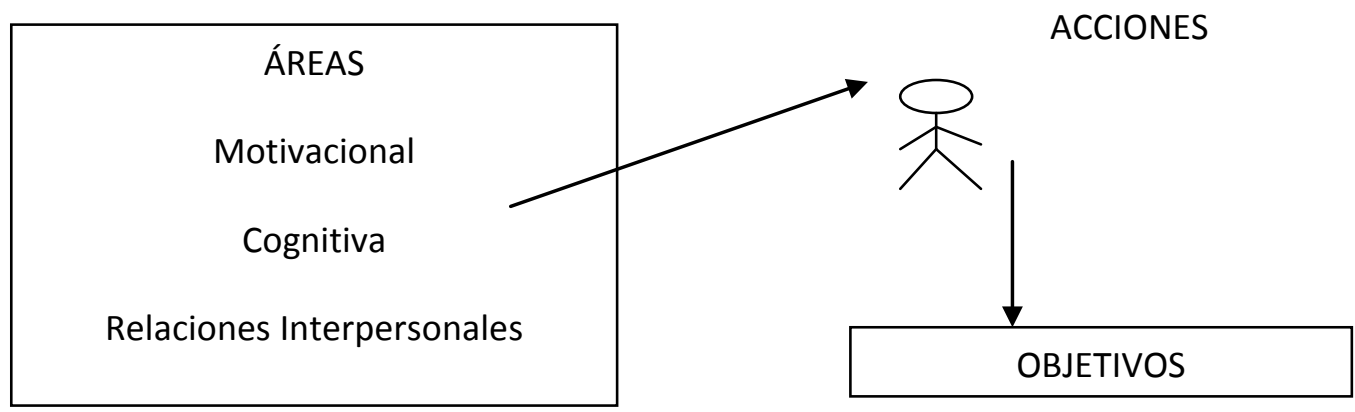

Figura 6: Áreas de Millon

El área motivacional comprende tres (3) bipolaridades que resumen la inclinación de un individuo a abrirse al mundo, hacerlo individualmente y 
tratar de modificarlo.

En el área cognitiva, Millon analizó al individuo en su interacción con el entorno, proponiendo cuatro (4) bipolaridades.

Finalmente, en el área de las relaciones interpersonales, incluyó cinco (5) modalidades que evidencian los individuos en su comunicación con los demás.

En síntesis, la combinación de las doce (12) bipolaridades (24 rasgos) propuestas por Millon, logran definir el estilo de personalidad de un individuo y por ende por qué tipo de tareas tendrá predilección.

A continuación se presenta un cuadro que resume la totalidad de bipolaridades.

Tabla 4: Bipolaridades de Millon

\begin{tabular}{|l|l|l|}
\hline \multicolumn{1}{|c|}{ ÁREA } & \multicolumn{2}{|c|}{ BIPOLARIDADES DE MILLON } \\
\hline \multirow{4}{*}{ MOTIVACIONAL } & Apertura & Preservación \\
\cline { 2 - 3 } & Individualismo & Protección \\
\cline { 2 - 3 } & Modificación & Acomodación \\
\hline \multirow{4}{*}{ COGNITIVA } & Introversión & Extroversión \\
\cline { 2 - 3 } & Intelecto & Sentimiento \\
\cline { 2 - 3 } INTECIONES & Sensación & Intuición \\
\cline { 2 - 3 } & Sistematización & Innovación \\
\hline & Timidez & Comunicatividad \\
\cline { 2 - 3 } & Indecisión & Seguridad \\
\cline { 2 - 3 } & Discrepancia & Conformidad \\
\cline { 2 - 3 } & Sumisión & Control \\
\cline { 2 - 3 } & Satisfacción & Insatisfacción \\
\hline
\end{tabular}

Descripción de los factores psicosociales de [Cequea, et al., 2011] y [Martín, et al., 2002] especializados por esta investigación como factores de riesgo para los proyectos de software

\subsection{Cohesión - Interacción de estilos de personalidad dentro del equipo de desarrollo}

"Si bien el diseño de software requiere una sólida base de tecnología, también este proceso se encuentra condicionado por aspectos intuitivos que manejan los desarrolladores. Ellos perciben en los requerimientos de los usuarios factores socio-técnicos y cognitivos ligados a la psicología, los cuales incorporan en sus especificaciones". $Y$ concluye el autor: "Las 
capacidades de la psicología social y antropología son aceptadas solo en una baja proporción en estos ambientes." [Grudin, J., 1994]

Ahora bien, nos preguntamos ¿resulta posible medir cómo repercuten los estilos de personalidad de los desarrolladores sobre el rendimiento de las actividades que se desarrollan en un proyecto de software?

Para [SommerVille, I., 2004] esto es factible. "La cohesión de los miembros de un grupo de desarrollo se puede estimar en cualquier etapa del proyecto de software".

Por su parte, Margerison and McCann, diseñaron el Team Management Index [Margerison et al., 1996] para medir el perfil de gestión de equipos. En base a un test de 60 preguntas es posible conocer quiénes serían los individuos que están psicológicamente mejor preparados para cohesionar grupos en una organización.

Como uno de los trabajos que mejor exponen el tema de investigación planteado, a continuación describiremos el marco de trabajo Sim Org [Campos et al., 2007], el cual permite simular el rendimiento de un equipo de desarrollo de software considerando los estilos de personalidad de sus integrantes.

La estructura elegida por [Campos et al., 2007] para la implementación de la herramienta SimOrg fue la denominada arquitectura multiagente.

Para [Gómez Álvarez, 2005], los sistemas multiagente (MAS) se componen de abstracciones software que evidencian responsabilidad y comportamiento proactivo y autónomo en la búsqueda de un objetivo común, en este caso, el desarrollo e implementación de un proyecto de software.

Para [Hayes-Roth et al., 1998], el uso de personalidad en simulaciones basadas en sistemas multiagente pretende adicionar realidad para representar más fielmente los sistemas sociales.

El término agente se aplica específicamente a un miembro del equipo de desarrollo de software, con estilo de personalidad definido y varias tareas que son de su responsabilidad. [Campos et al., 2007]

La arquitectura basada en sistemas multiagente que implementó SimOrg contiene los siguientes módulos. 


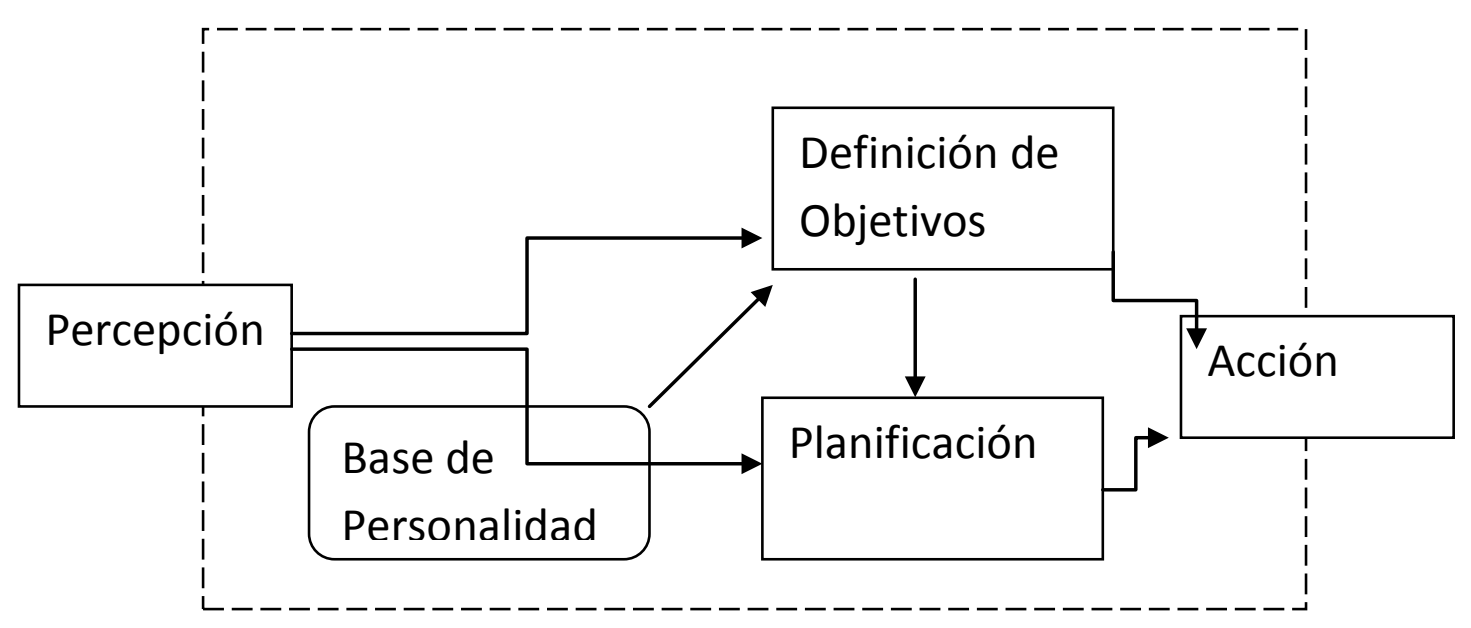

Figura 7: Arquitectura multiagente

Dependiendo de la escuela psicológica que se desea configurar para la simulación, los atributos que se involucran pueden diferir. Por ejemplo, si se configura en base al modelo Millon, el módulo Base de Personalidad incluirá las áreas motivacionales, cognitivas y de relaciones interpersonales.

En su diseño, el marco de trabajo establece como principal heurística que, en el desarrollo de software existen rasgos de personalidad "ideales" para la ejecución de determinadas tareas. El método prevé como condición necesaria la realización de un test para determinar el estilo de personalidad de cada integrante del equipo de desarrollo.

El objetivo es encontrar la mejor curva de rendimientos en base a los estilos de personalidad que se evidenciaron en el test.

Los autores incluyeron en el modelo la función auxiliar de personalidad de Jung (e) para compensar los desvíos producidos cuando los individuos deciden actuar de modo diferente a lo que les sugiere su estilo de personalidad dominante.

Como resultado final, el modelo permite simular el rendimiento $(r)$ de cada integrante del equipo de desarrollo luego de haber analizado su estilo de personalidad $\mathrm{p}$.

$r=f(p, e)$. 
El gráfico siguiente, extraído de [Campos et al., 2007], muestra los resultados de una simulación en la que se tomaron tres diseñadores, cada uno con su estilo de personalidad definido: el A (perfeccionista), el B (individualista) y el C (cooperativo).

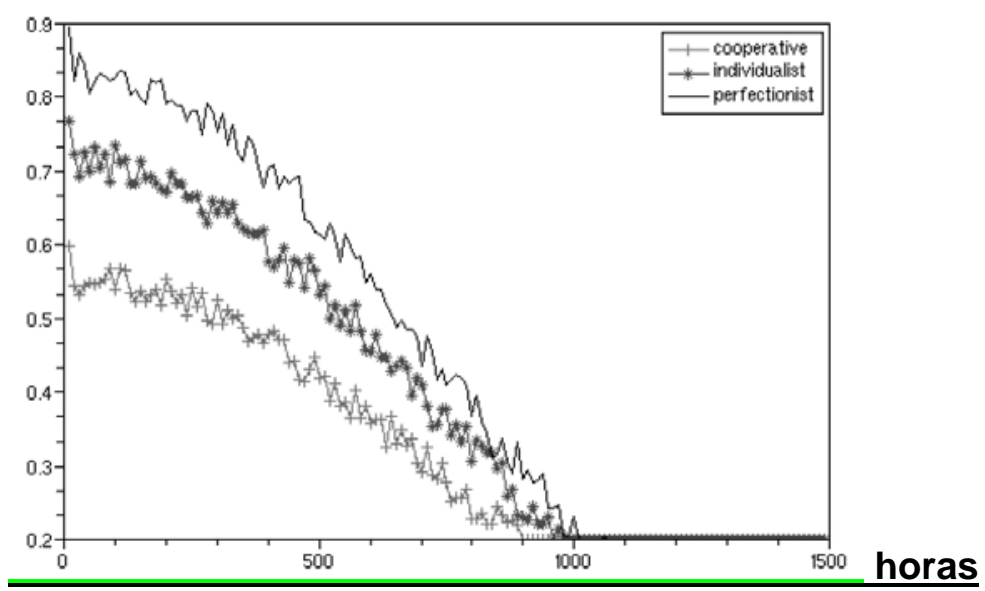

Figura 8: Rendimiento / estilos de personalidad

Se aprecia que el integrante que mejor se ha ajustado al estilo de personalidad ideal es el A. Aunque el nivel de calidad decae en todos en torno a las 1.000 horas, la curva presenta en todo el dominio de tiempo t. niveles más altos para A que para el resto.

En relación a la variable tiempo, se muestra en el siguiente cuadro [Campos et al., 2007], en color negro, la demora promedio en finalizar la tarea de diseño.

En la barra superior se representa la demora de los empleados con mejor rendimiento, es decir, aquellos que presentaron mayor concordancia psicológica respecto a la personalidad ideal para la tarea diseño.

Las simulaciones que permite el Framework SimOrg varían en términos de rendimiento, siendo la variable tiempo su indicador principal, dependiendo éste de los estímulos y sobrecargas que se le impongan a los agentes en la simulación. 
Tabla 5: Promedio de demoras

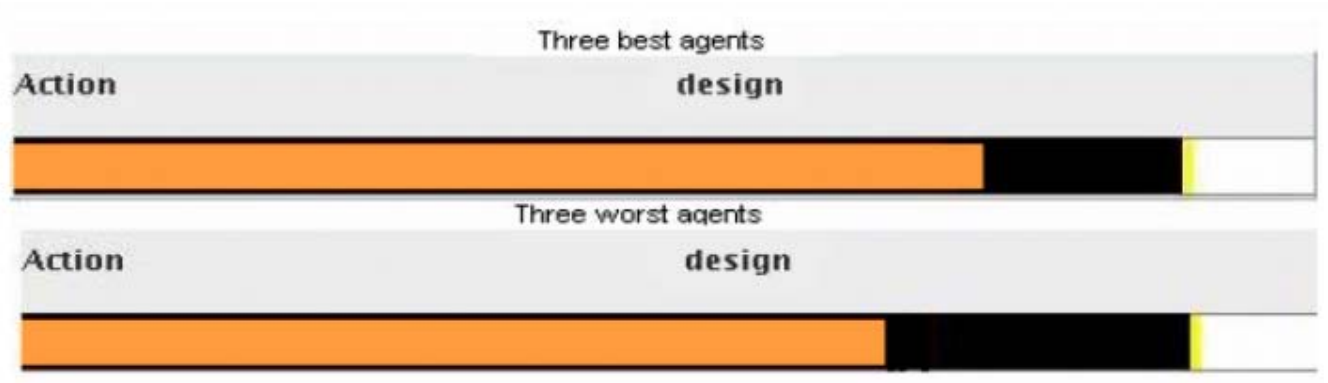

Los autores recomiendan la aplicación de SimOrg en escenarios en donde el modelo de desarrollo de software seleccionado a aplicar sea un proceso iterativo basado en metodologías ágiles [Highsmith, 2002]. En ese modelo, las comunicaciones que se producen entre los agentes son intensas al principio, debiéndose monitorear tanto las interacciones formales como las informales, estas últimas producidas por afinidad o intereses fuera del organigrama formal.

\subsection{Comunicación entre el equipo de desarrollo y el usuario}

Desde hace tiempo se ha reconocido que existe una brecha en la comunicación entre desarrolladores y usuarios en las diferentes etapas por la que atraviesa un proyecto de software. [Parry et al., 1995]. A esta brecha se la ha denominado con diferentes términos, y se han propuesto distintas alternativas para reducirla. Sin embargo, a pesar de los esfuerzos, el problema continúa apareciendo, y los intentos han sido limitados en su eficacia. Para este autor, las causas de esta brecha se produce debido a que, tanto los desarrolladores como los usuarios, adolecen del suficiente conocimiento del dominio de su contraparte, generando con ello un obstáculo en la de comunicación entre ambos.

Para [Bice, 2010] existe una gran cantidad de proyectos de software que fracasan por falta de comunicación durante la elicitación de requerimientos: "Por ser el software un objeto intangible, a menudo se producen desconexiones entre los usuarios y los desarrolladores. A diferencia de la fabricación de un producto concreto, el desarrollo de software se basa en descripciones particulares que realizan los clientes, descripciones éstas que cuando son ambiguas, no logran ser interpretadas como requerimientos." 
[Barañano, 2005] sostiene: "la fluidez en la comunicación entre desarrolladores y usuarios permite el lanzamiento de innovaciones con éxito."

En general, los desarrolladores de software tienen, como sucede en todas las disciplinas, su propia cultura y su manera particular de resolver los problemas. Frecuentemente esa cultura está fuertemente arraigada y obstaculiza la apertura a la cultura de los usuarios, caracterizada por tiempos y prioridades diferentes. Esa diferencia de culturas se amplifica cuando ambos grupos se encuentran en lugares geográficamente diferentes. [Kwan et al., 2006]

Ahora bien, ¿cuáles han sido los instrumentos que la tecnología ha propuesto para atenuar esa brecha?

Las soluciones parecen apuntar hacia dos direcciones.

- las metodologías de desarrollo ágiles como Programación Extrema (XP) o Scrum. [Schwaber et al., 2006]

- las herramientas colaborativas como CSCW (Computer-Supported Cooperative Work) o Groupware. [Grudin, J., 1994]

[Canós, J, 2005] sostiene "XP se basa en la realimentación continua entre el cliente y equipo de desarrollo, comunicación fluida entre todos los participantes, simplicidad en las soluciones implementadas y coraje para enfrentar los cambios."

En ese sentido, el Software Engineering Institute (SEI), a través de CMMI® for Development, Version 1.3 [SEI, 2010], establece como fuente de origen de riesgos en los proyectos, el manejo inadecuado de las comunicaciones con los reales o potenciales clientes o sus representantes.

Tanto las herramientas colaborativas, con facilidades vía web de edición y gestión de requerimientos en sesiones compartidos, como las metodologías de desarrollo ágil imponen el rol de un negociador como elemento clave para reducir la brecha de comunicación y potenciar las relaciones interpersonales como clave de éxito.

Ahora bien, [Driskell, et al., 2006] sostiene que los productos de software colaborativo hubieran exhibido aún mayor efectividad, si se hubiesen incorporado para el negociador aspectos provenientes del campo de la psicología social como por ejemplo la dinámica de grupos. 
En lugar de ello, se le asignó mayor prioridad a cuestiones vinculadas al detalle estético del producto software que en la mejora del conocimiento del usuario.

En esa misma dirección apunta [Grudin, 1994] cuando se pregunta:

“¿Y dónde está el grupo?”.

Para él, la mayoría de las investigaciones que profundizaron sobre la brecha comunicacional provienen de áreas ligadas a la psicología. A pesar de ello, concluye el autor, "Las capacidades de la psicología social y antropología son aceptadas solo en una baja proporción en estos ambientes."

Para esta investigación la brecha de comunicación entre desarrolladores de software y usuarios representa un factor psicosocial clave que debe ser gestionado durante todo el ciclo de desarrollo de software, pero muy especialmente durante el proceso de elicitación de requerimientos. De no reducirse convenientemente ese riesgo, la misma puede transformarse en un factor crítico para el éxito de la implementación del proyecto.

Por lo tanto, a continuación se describirá un método proveniente de la dinámica de grupos con el objeto de acercar instrumentos para evaluar la fluidez de la comunicación usuario - equipo de desarrollo.

Método de Observación de Robert F Bales (Interaction Process Analysis $\underline{\text { IPA) }}$

[Bales, 1950] partió de dos supuestos fundamentales:

En los grupos de personas que interactúan entre sí, sus integrantes reaccionan de diferente manera a las situaciones externas, produciéndose dos particularidades: dada una tarea, las personas evidencian problemas relacionados con la meta que persigue esa tarea (dimensión instrumental de la interacción social). Además, dichas personas también presentan problemas de índole social y emocional producidos por el contacto entre ellos (dimensión socioemocional de la interacción social). [Huici Casal et al., 2004] 
En función de ello, todo individuo del grupo puede ser analizado en función del impacto que ejerce sobre los problemas de tarea, sociales $y / 0$ emocionales.

El modelo parte de la premisa de la necesidad de registrar sistemáticamente las relaciones que tienen lugar dentro de un grupo, con el fin de mejorar sus pautas de comportamiento.

En esencia, la idea base consiste en que las interacciones que ocurren dentro del grupo revelan las características y la naturaleza del mismo, los puntos de liderazgo y las relaciones con el entorno. [Huici Casal et al., 2004]. El método codifica la interacción de los integrantes de un grupo en tres categorías a saber:

- Área Socio emocional Positiva (AEP)

- Área de Tarea (AT)

- Área Socio emocional Negativa (AEN)

Cada una de esas categorías presenta indicadores de conducta que el equipo de desarrollo deberá registrar y analizar si pretende elicitar la forma de interactuar de los stakeholders.

A continuación se detallan conductas típicas de cada área.

AEP

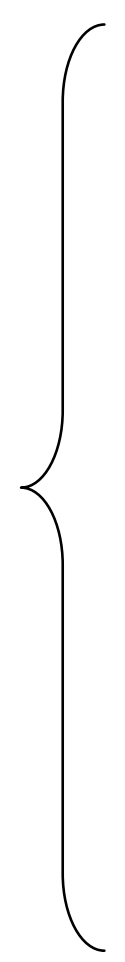

a. Demostrar Solidaridad para implementar el proyecto (aumentar el estatus de los otros stakeholders, cooperar, conciliar).

b. Mostrar Liberación de Tensión (reírse, mostrar satisfacción, adherirse al cambio, apoyar la reducción de tensión en el grupo manteniendo los objetivos de la implementación).

c. Estar de Acuerdo (No se busca imponer los requerimientos propios, mostrar aceptación pasiva, comprender, coincidir, aceptar los requerimientos ajenos si éstos son lógicos, reconocer errores propios). 
d. Sugerir mejoras en los requerimientos (dirigir, orientar a otros, tratar que el resto de los stakeholders entiendan su postura pero sin imponerla).

e. Dar Opiniones (expresión de puntos de vista o emisión de juicios de valor que suponen análisis previo, exteriorización de sentimientos y deseos).

f. Dar Orientación (informar, explicar lo que se persigue con un determinado requerimiento $\mathrm{u}$ objetivo, atraer la atención de los demás para emitir un concepto, repetir un concepto para reafirmarlo).

g. Pedir Orientación (requerir información, aclaraciones o confirmaciones, emitir preguntas directas que requieran respuestas concretas).

h. Pedir Opinión (requerir aclaración sobre puntos de vista e interpretación de lo que ha ocurrido en una determinada situación. Se pretende averiguar algo sobre sentimientos, pensamientos, actitudes y valores del resto de los stakeholders.).

i. Pedir Sugerencias (solicitud de modos de acción para lograr un objetivo o requerimientos del grupo. No se incluyen el pedido de sugerencias que van acompañados de aspectos emocionales, estos se incluirían en "Mostrar tensión/Antagonismo).

k. Estar en Desacuerdo (mostrar resistencia a la implementación, retener recursos, evadir preguntas, evitar reuniones, no comprometerse, indiferencia, manifestar desacuerdo, desconfianza, incredulidad.

I. Mostrar Tensión (Tirantez, ansiedad, impaciencia, frustración, sentimiento de culpa, demostración de aislamiento).

m. Antagonismo (devaluar el estatus del otro, autoafirmación a expensas de los demás stakeholders, autoritarismo y control limitando2 la libertad de los demás). 
El método propone que a través de la elicitación de las relaciones entre las categorías es posible construir un conjunto de índices que reflejen problemas o conflictos entre los stakeholders durante la etapa de requerimientos.

Tabla 6: Conductas - Relaciones entre categorías

\begin{tabular}{|l|l|}
\hline Índice & Relaciones \\
\hline Comunicación & $\mathrm{g} / \mathrm{f}+\mathrm{g}$ \\
\hline Evaluación & $\mathrm{h} / \mathrm{h}+\mathrm{e}$ \\
\hline Control & $\mathrm{i} / \mathrm{i}+\mathrm{d}$ \\
\hline Toma de decisiones & $\mathrm{j} / \mathrm{j}+\mathrm{c}$ \\
\hline Tensión & $\mathrm{k} / \mathrm{k}+\mathrm{b}$ \\
\hline Integración & $\mathrm{l} / \mathrm{l}+\mathrm{a}$ \\
\hline
\end{tabular}

Por ejemplo, para medir el nivel de positividad (NP) se involucran a los siguientes índices:

$N P=$ Demostrar solidaridad (a) + Mostrar Liberación de Tensión (b) + Estar de Acuerdo (c)+Sugerir Mejoras (d) + Dar Opiniones (e) + Dar Orientación (f) $/ 6$.

[Huici Casal et al., 2004] sostiene: "Se podrían calcular otro tipo de índices como los de Positividad General o de Negatividad General."

En la siguiente tabla extraída del mismo autor se muestra un ejemplo de las observaciones registradas por el equipo de desarrollo durante el proceso de elicitación de requerimientos de un sistema de ventas en donde dos (2) sectores, empaque y marketing interactúan por los conflictos que trae la implantación de una nueva tecnología.

Las filas de la tabla representan las doce conductas, desde la a hasta la I. Sobre la tabla, la línea horizontal cortada por líneas verticales indican las intervenciones en el tiempo de los stakeholders. En cada una de las líneas verticales se refleja un evento. 
Tabla 7: Elicitación de Interacciones

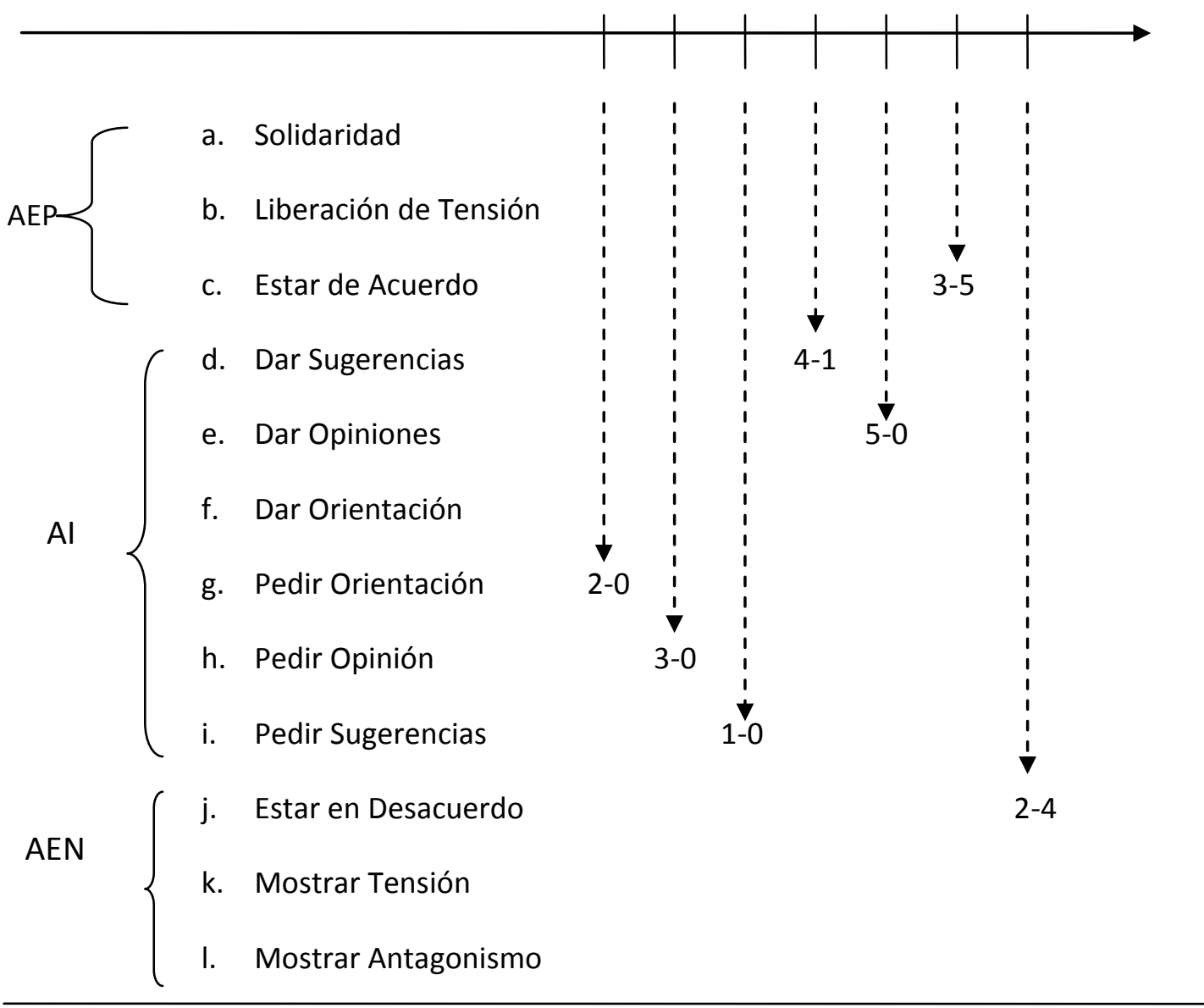

\section{Premisas:}

El equipo de desarrollo le asigna un número a cada stakeholder para su identificación, iniciando con el 1.

Al grupo de todos los (involucrados) stakeholders se le asigna el 0.

En la intersección de la fila de la conducta (a-l) con la línea vertical punteada, se registra un evento producido por un stakeholder, hacia quién I quiénes dirige ese evento y con la flecha punteada, qué tipo de conducta (a-l) evidencia. Por ejemplo:

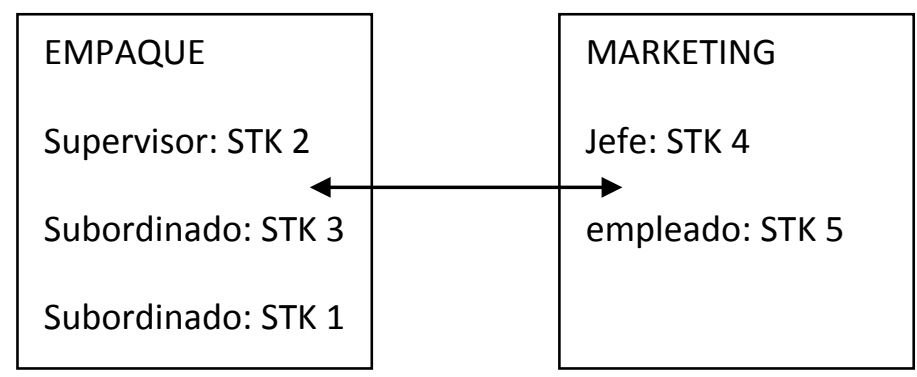

Figura 9: Conductas de los Involucrados 
En la tabla se registra el debate. El primero en tomar la palabra fue el involucrado stk 2 , supervisor del sector empaque, quien dirigiéndose a todo el grupo (2-0) pidió orientación sobre si el sistema de gestión de ventas a implementar remplazaba los formularios impresos por formularios de correo electrónico.

A continuación el involucrado stk 3 , del mismo sector, pidió opinión al grupo (3-0) si ese cambio podía producir despidos en la división imprenta, dependiente de ese sector.

Al ser afirmativa la respuesta, otro representante del mismo sector, le pidió sugerencias al grupo (1-0) para que en lugar de despidos se reubicara al personal.

El involucrado stk 4, jefe del Departamento Marketing, le sugirió al 1 (4-1), que la gerencia de esa organización pretendía imponer un cambio tecnológico a fin de incrementar la competitividad.

Por su parte el involucrado stk 5 , subordinado del stk 4, dio su opinión al grupo (5-0) reafirmando la necesidad de incorporar tecnología debido a que si se mantenían los niveles de producción actual, el próximo año podrían producirse grandes pérdidas con despidos masivos.

Al analizar esta última afirmación, el stk 3 de empaque coincidió con el jefe de marketing, stk 5, y le expresó al grupo (3-0) que en lugar de provocar despidos, el formulario electrónico debería incorporar una mejora productiva.

En contraposición a lo expresado por su empleado, el supervisor de empaque stk 3, quien originó la discusión, le expresó al jefe de Marketing (2-4) su desacuerdo con la implementación del nuevo sistema de ventas.

Como puede apreciarse en el ejemplo son amplias las posibilidades que ofrece este método de observación como herramienta para elicitar la comunicación entre el usuario y su entorno.

La fiabilidad del método presenta correlaciones que van del 0,75 al 0,95, resulta de fácil instrumentación y genera información de alta sensibilidad para el equipo de desarrollo. [Huici Casal et al., 2004] 


\section{Análisis Cognitivo}

Otra de las herramientas provenientes del área de la psicología social que permite mejorar la comunicación usuario-equipo de desarrollo es el análisis cognitivo. La aplicación de este tipo de análisis es una propuesta de solución para enfrentar a los problemas de comunicación entre personas que interactúan en dominios diferentes, especialmente cuando el proceso de elicitación de requerimientos debe realizarse en ambientes distribuidos. [Aranda, 2005].

La propuesta consiste en seleccionar la técnica de elicitación en función del estilo cognitivo en que un individuo procesa la información proveniente del entorno.

Remontémonos a los orígenes.

El término estilo cognitivo fue acuñado por Alport (1937) para designar los abordajes individuales para resolver problemas, recibir y recuperar información memorizada.

Para este autor los estilos cognitivos son componentes de la personalidad que identifican a los individuos por el modo de procesar la información que reciben del ambiente.

A diferencia de los teóricos de la personalidad, los psicólogos especializados en educación, en lugar de utilizar el término estilo cognitivo, comenzaron en muchos casos a denominarlo "estilo de aprendizaje". [Alonso Pantoja Ospina, 2005]

Para establecer una definición conceptual, es necesario reconocer que el término "estilo cognitivo" tiene bases biológicas como culturales.

Y continúa afirmando [Alonso Pantoja Ospina, 2005]: "Se sabe que los sujetos perciben el conocimiento de manera diferente. Cada individuo evidencia un patrón o estilo particular, que involucra tanto los procesos de enseñanza como los de aprendizaje. Dicho patrón se extiende a lo social, a lo laboral, a la toma de decisiones y a las relaciones en el trabajo de equipo."

Desde un perspectiva más técnica, este autor afirma que "el estilo cognitivo es la forma más habitual y permanente en la que un individuo responde a los estímulos de información que genera su entorno."

Estas preferencias de respuesta, estilos, son generalmente inconscientes 
y asumidas por el individuo dentro de su propia naturaleza. Por esa razón, es difícil que cambie su tendencia de respuesta, es decir, que pase de un estilo a otro ante diferentes situaciones que se le presentan. [Alonso Pantoja Ospina, 2005].

Uno de los trabajos más conocidos sobre el análisis cognitivo aplicado al ámbito de la implementación de proyectos de software es el denominado "Elicitación Basada en Psicología Cognitiva: Un Caso de Estudio". De [Martinez Carod et al., 2004]. En él las autoras sostienen que la utilización de los métodos de elicitación de requerimientos está influenciada por las percepciones cognitivas de los usuarios. Para demostrarlo realizaron un estudio comparativo entre la aplicación de técnicas de elicitación teniendo en cuenta los estilos cognitivos y omitiéndolos.

Para realizar el estudio [Martinez Carod et al., 2004] utilizó el modelo de Felder-Silverman [Felder et al., 2005], el cual sostiene que las personas aprenden mejor una tarea o labor cuando se les enseña respetando sus categorías cognitivas.

En sus conclusiones, las autoras sostienen que en los grupos con fuerte predominancia cognitiva se percibió mayor consenso y mejor clima laboral, cuando se utilizaron las técnicas de elicitación considerando los perfiles cognitivos.

Determinación del valor cognitivo ILS para técnicas de elicitación de requerimientos

El Index Learning Styles (ILS) de [Soloman et al., 2006], utilizado como índice para medir los estilos de aprendizaje, establece cuatro (4) estilos cognitivos básicos de cada individuo:

- Perceptivo / intuitivo.

- Visual / verbal.

- Activo / reflexivo.

- Secuencial / global.

Además, cuantificó la intensidad de esos estilos como:

- Fuertes.

- Moderadas, o

- Leves.

El ILS es un test compuesto por 44 preguntas que permite identificar el 
estilo cognitivo predominante de las personas.

En la siguiente tabla extraída de [Martínez Carod et al., 2007] se ejemplifica un reporte ILS para un grupo de personas fuertemente activas y visuales con su preferencia respecto a tres técnicas de elicitación.

Tabla 8: Estilos cognitivos / técnicas de elicitación

\begin{tabular}{|l|l|c|}
\hline Predominancia & \multicolumn{1}{|c|}{ Técnica de elicitación } & Valor \\
\hline \multirow{2}{*}{ Activo } & Casos de uso & 0.53 \\
& Documentación & 0.78 \\
& Entrevistas & 0.27 \\
\cline { 2 - 3 } & & 0.83 \\
& Casos de uso & 0.65 \\
& Documentación & 0.42 \\
\hline
\end{tabular}

El cálculo del valor cognitivo por técnica de elicitación surge promediando todos aquellos stakeholders con fuertes preferencias por un estilo cognitivo, por ejemplo, visual y restando los que evidencian fuertes rechazos por ese mismo estilo, desestimándose aquellos individuos con tendencias neutras o moderadas.

$$
V\left(F C_{c}\left[t e c_{j}\right]\right)=\frac{1}{n}\left(\sum_{i=1}^{n} F C_{c}\left[+t e c_{j}\right]-\sum_{i=1}^{n} F C_{c}\left[-t e c_{j}\right]\right)
$$

donde [+tecj] significa fuerte preferencia por la técnica de elicitación "j" y [-tecj] significa fuerte rechazo por dicha técnica de elicitación.

Según [Martinez Carod et al., 2004], cuanto más cercano a 1 sea el valor de $V\left(F C_{C}\left[t_{e c}\right]\right.$, la aplicación de la técnica de elicitación j en individuos con estilo cognitivo c, permitirá obtener, mayor consenso y mejor clima laboral.

[Martínez Carod, 2007] propone entonces incorporar el análisis cognitivo como estrategia para mejorar el proceso de gestión de requerimientos.

El método parte de la determinación de las macro necesidades de los stakeholders (objetivos padre) y desde allí, se elicitan los requerimientos por prioridades, estableciendo, mediante negociación y consenso, sub- 
objetivos cada vez más específicos, siendo el equipo de desarrollo quien asume el rol de facilitador.

Para seleccionar qué técnica de elicitación aplicar a cada sub-objetivo [Martínez Carod, 2007] considera el estilo cognitivo predominante de cada stakeholder a través del índice ILS.

\section{Principales trabajos en la temática}

Gestión de Requerimientos basada en Técnicas Cognitivas para la implementación del Sistema de liquidación de Ingresos Brutos de la Provincia de Neuquén, Argentina. [Martínez Carod, 2007]

[Martínez Carod et al., 2005] parten del hecho que cada individuo tiene un abordaje cognitivo particular y predominante para percibir, entender y planear sus interacciones durante un proyecto de software.

Objetivo principal del sistema: "Inscribir una persona física o jurídica en el sistema de pago de ingresos brutos, como condición necesaria para ejercer una actividad comercial o profesional".

Objetivo particular: "calcular el monto a pagar de acuerdo a los ingresos de la actividad del negocio/servicio a inscribir."

Requisito: "Cada contribuyente debe completar un formulario de alta y pagar mensualmente un porcentaje proporcional a su facturación."

La siguiente figura muestra el grafo global AND/OR correspondiente a una instancia del proceso de elicitación de requerimientos. Se identifican los objetivos con elipses. Los rectángulos corresponden a las técnicas de elicitación hasta allí aplicadas. 


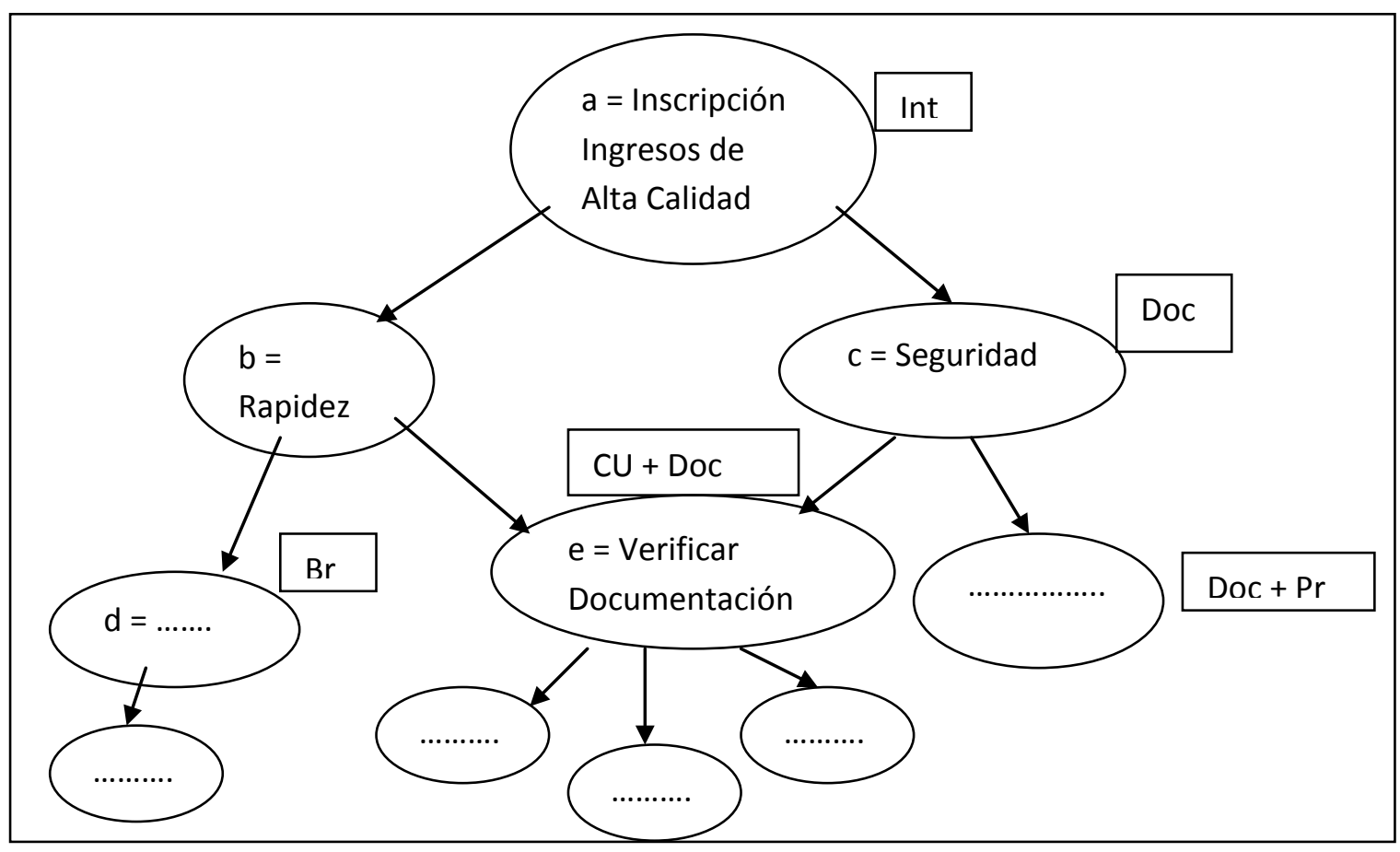

Figura 10: Objetivos / tecnicas de elicitación

Las técnicas de elicitación aplicadas fueron:

PR (prototipos)

Int (entrevistas)

$\mathrm{Br}$ (brainstorming)

$\mathrm{CU}$ (casos de uso)

Doc (documentación).

Por ejemplo, al objetivo e "Verificar documentación" se le aplicaron dos (2) técnicas de elicitación diferentes: casos de uso y documentación.

Los objetivos que no tienen adosada una técnica de elicitación, como el objetivo b "Rapidez", heredan la técnica de su objetivo padre (Int).

Utilizando la tabla siguiente de valores cognitivos promedio, analicemos del grafo global cuatro situaciones posibles con dos involucrados Stk1 y Stk2. Ambos, evidencian estilos cognitivos del tipo activo, visual o los dos combinados. 


\begin{tabular}{|l|l|c|}
\hline Predominancia & \multicolumn{1}{|c|}{ Técnica de elicitación } & Valor \\
\hline \multirow{2}{*}{ Activo } & Casos de uso & 0.53 \\
& Documentación & 0.78 \\
& Entrevistas & 0.27 \\
& & \\
\hline \multirow{2}{*}{ Visual } & Casos de uso & 0.83 \\
& Documentación & 0.65 \\
& Entrevistas & 0.42 \\
\hline
\end{tabular}

\section{Situación 1:}

Stk1: Objetivo del grafo global: a (Inscripción Ingresos de Alta Calidad)

- Estilo cognitivo de Preferencia de Stk1: Visual

- Técnica de elicitación adoptada para el objetivo a: entrevistas (Int)

- Afinidad de Stk1 con Entrevistas = Valor Cognitivo promedio de Entrevistas para Estilo cognitivo de Preferencia: Visual $=0.42$

Conclusión $\rightarrow$ La afinidad de Stk1 con la técnica adoptada para ese objetivo es moderada a baja. Se considera el valor 1 como lo óptimo.

Situación b:

Stk2: Objetivo del grafo global: a

- Estilo cognitivo de Preferencia de Stk2: Activo y Visual

- Técnica de elicitación adoptada para objetivo a: entrevistas (Int)

- Afinidad de Stk2 con Int = Max Valor Cognitivo promedio de Int para

Estilos cognitivos de Preferencia: Activo y Visual $=\operatorname{Max}(0.27$, $0.42)=0.42$, dado que una persona con preferencia por dos categorías cognitivas (visual, activa), utilizará generalmente la de mayor predominio, visual en este caso.

Conclusión $\rightarrow$ la afinidad de Stk2 con la técnica adoptada para ese objetivo resulta también moderada a baja.

Situación 2:

Stk1: Objetivo del grafo global: e (Verificar Documentación) 
- Estilo cognitivo de Preferencia de Stk1: Visual.

- Técnicas de elicitación adoptadas para objetivo e: Casos de Uso (CU) y Documentación (Doc).

- Afinidad de Stk1 con CU y Doc = Media aritmética de los valores cognitivos promedios de las técnicas utilizadas $=(0.83+0.65) / 2=$ 0.74 .

Si bien una de las técnicas (Casos de Uso) es la preferida por ser una técnica preferentemente del tipo visual, coincidiendo además con el estilo cognitivo de Stk1, al utilizarse también otra técnica (Documentación), la información extraída de Stk1 posiblemente se verá afectada por la aplicación de ésta última técnica.

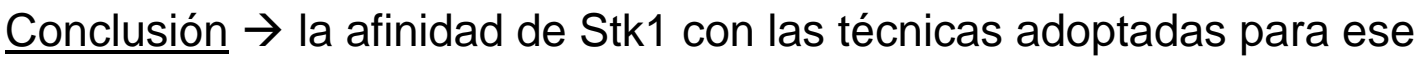
objetivo resulta moderada a alta.

\section{Situación 3:}

Stk2: Objetivo del grafo global: e

- Estilo cognitivo de Preferencia de Stk2: Activo y Visual.

- Técnicas de elicitación adoptadas para objetivo e: Casos de Uso (CU) y Documentación (Doc).

- Afinidad de Stk2 con CU y Doc = Media Aritmética de los mayores valores cognitivos promedios presentes de las técnicas de elicitación que intervienen $=(0.83+0.78) / 2=0.805$.

Esto indica que en cada una de las técnicas de elicitación para ese objetivo, la persona utiliza aquellas características de mayor afinidad cognitiva acorde a la técnica.

Conclusión $\rightarrow$ la afinidad de Stk2 con las técnicas adoptadas para ese objetivo resulta alta.

El análisis propuesto por [Martínez Carod et al., 2005] es un claro ejemplo de incorporación de la psicología social en el proceso de elicitación de 
requerimientos. Su objetivo es optimizar la compatibilización de los objetivos del proyecto con la afinidad cognitiva de los involucrados.

Como condición necesaria se requiere la realización de un test cognitivo.

\subsection{Nivel de Consenso para implementar el proyecto de software}

En términos generales las dificultades más comunes que presenta la gestión de requerimientos para la implementación de proyectos de software derivan de dos (2) cuestiones fundamentales [Hanyuda E., 2005]:

- Los usuarios no saben lo que realmente necesitan.

- Los requerimientos cambian continuamente.

Para este autor, la aplicación exclusiva de herramientas de ingeniería de requerimientos, no garantiza por sí sola, el éxito de una implementación. Durante la etapa de requerimientos, la construcción de consenso en las interacciones entre los involucrados con el proyecto resulta ser un factor clave, especialmente entre los sectores medios de la organización, sectores éstos determinantes en el resultado final de toda implementación de software.

[Wong, F, 2005] sostiene que el surgimiento de conflictos disfuncionales durante la etapa de requerimientos ocurre por perspectivas, objetivos e interpretaciones diferentes de los stakeholders. Esto sucede en gran parte porque aún perdura una importante brecha tecnológica-generacional en las organizaciones.

Con el objeto de detectar, resolver y registrar conflictos durante el proceso de desarrollo de software se diseñó [Wong, 2007] (CONflict Free Editing in a Replicated architecture). Esta herramienta de software incluye soporte colaborativo para la construcción de consenso y resolución de conflictos promoviendo la sinergia de grupo.

Pongamos un ejemplo. Dadas las categorías propias de la escala de Likert (FA, A, N, D y FD - Fuerte Acuerdo, Acuerdo, Neutralidad, Desacuerdo y Fuerte Desacuerdo), en donde cada una de esas magnitudes se asocian a un valor numérico, es posible medir estadísticamente la opinión de stakeholders sobre un determinado aspecto a través del cálculo del consenso. Si la mitad de los involucrados eligiera la alternativa FA y la otra mitad FD, entonces el nivel de consenso 
sería 0, ya que el grupo está igualmente distribuido hacia sus extremos. En cambio, otra sería la situación si todos los stakeholders convergieran hacia una única posición.

Veamos. La variable $X$ puede tomar cualquiera de los siguientes valores: $F A, A, N, D$ y FD; $d X=(X \max -X \min )$ y $\mu x$ es la media de $X$.

$$
\operatorname{Cns}(\mathbf{X})=1+\sum_{i=1}^{n} p_{i} \log _{2}\left(1-\frac{\left|X_{i}-\mu_{x}\right|}{d_{x}}\right)
$$

La función de Entropía de Shannon [Shannon, C., 1948] resulta una herramienta útil para estimar el consenso y medir el grado de dispersión entre las diferentes posiciones entre los involucrados con el proyecto.

El consenso sobre objetivos permite que todos los individuos perciban los mismos objetivos para la organización, lo cual es de suma importancia para la obtención de los resultados esperados. Compartir los objetivos otorga un sentido de pertenencia y de identificación con el grupo y con la organización. [Fernández Ríos et al., 1997]

Por lo tanto, si no resulta factible incrementar Csn a medida que el proyecto avanza, el equipo de desarrollo debería gestionar las medidas de mitigación adecuadas para resolver el problema antes que la implementación se encuentre comprometida.

\subsection{Estilo de mando: Estilos de Priorización de Requerimientos}

Existen diversos criterios para la toma de decisiones durante el proceso de priorización de requerimientos. Según la taxonomía de [Aurum et al., 2005], los requerimientos deben priorizarse en función de:

- La importancia: relación del requerimiento con el objetivo de la organización.

- El impacto negativo: implicaciones perjudiciales.

- El costo: esfuerzo económico, físico o humano.

- El riesgo: probabilidad de fallo en su aplicación.

Para [Olsina, L, 1999], el estilo de mando en el proceso de priorización de requerimientos es un mecanismo de naturaleza compleja en donde 
intervienen métodos cuantitativos, cualitativos y apreciaciones intuitivas del evaluador. Los métodos brindan el soporte de objetividad, mientras que las apreciaciones intuitivas y la experiencia del equipo de desarrollo aportan el sustento de subjetividad necesaria para una realista priorización de las decisiones.

El significado que se le atribuye aquí a la palabra "intuición" no es peyorativo: se lo asimila a un mecanismo mental, conocimiento claro, visión instantánea, a través de la cual el ser humano interpreta subjetivamente la realidad.

En este sentido, varios investigadores coinciden que en la métrica de un atributo debe existir un balance entre la objetividad que aporta un sistema numérico y la subjetividad que brinda la experiencia. [Fenton, 2005]

Por ejemplo [Olsina, L, 1999] argumenta: "Para establecer un conjunto de metas a alcanzar, $y$, a partir de éstas, especificar requerimientos de calidad, los componentes de subjetividad en la toma de decisiones, son partes necesarias.

"En cambio [Ruiz Gonzáles et al., 2000] sostiene: "Los miembros de un equipo necesitan comprender las bases de todas las decisiones que los afectan. Si encuentran que las decisiones están tomadas por razones arbitrarias, subjetivas o egoístas su rendimiento se verá penalizado."

Trataremos de explicar esta última posición con un ejemplo.

La Real Academia española define el término arbitrariedad como el "acto o proceder contrario a la justicia, la razón o las leyes, dictado solo por la voluntad."

Según [Braidot, 2011], el $40 \%$ de las empresas más grandes del mundo, son propiedad de familias o están controladas por ellas. Sin embargo, la mayoría de las organizaciones fundadas como familiares, entre el $70 \%$ y el $90 \%$, no han logrado atravesar su primera generación.

"En la mayoría de los casos, los factores de fracaso no son atribuibles a políticas macroeconómicas regresivas, cambios tecnológicos importantes, variaciones radicales en las preferencias de los clientes o errores en la estrategia comercial."

"Gran parte de ese fracaso se explica por decisiones gerenciales erróneas surgidas de arbitrariedades producto de conflictos emocionales. Este 
problema aún no ha sido resuelto por la gestión gerencial tradicional." [Braidot, 2011]

[Ferrari Márquez, 2006] sostiene: "Si reiteradamente las decisiones se basan en criterios arbitrarios, variables o contrarios a las necesidades reales de la organización o de sus partícipes, el proceso de comunicación será distorsionante."

\subsection{Nivel de estrés en la organización}

Como es habitual en la mayoría de los conceptos estudiados en las ciencias sociales, el término estrés ha sido analizado desde diferentes puntos de vista, dando lugar a distintas definiciones, incluso algunas de ellas contradictorias. Este carácter impreciso y ambiguo del estrés ha llevado a algunos autores a realizar un proceso de síntesis, agrupando múltiples interpretaciones en función de sus experiencias. Una de las definiciones que mejor se ha ajustado a nuestra investigación es la que aporta [Selye, 1956]. Para este autor el término estrés se refiere a "las respuestas psicológicas y fisiológicas que tiene el individuo ante ciertos estímulos del ambiente". Este aspecto adquiere importancia en el contexto de las organizaciones en general, y en nuestro caso en las organizaciones que se encuentran en proceso de implementar un proyecto de software. A continuación esbozaremos algunas definiciones adicionales en sintonía con el enfoque de este trabajo.

Según [Eduards, 1998], la experiencia de estrés ocurre cuando se produce un desajuste entre las características o circunstancias del entorno y las preferencias o deseos del individuo.

Por su parte [McGrath, 1970] sostiene que se produce una experiencia de estrés cuando una persona desea responder a las demandas planteadas por el ambiente, pero percibe que no dispone de los recursos necesarios para resolverlas.

[Muñoz, C, 1970] asevera que las consecuencias negativas del estrés no solo afectan a la salud física y psicológica del individuo, sino que también inciden en la organización, ya que los recursos humanos juegan un rol fundamental en su devenir. Por lo tanto, si no existe una política organizacional dirigida a prevenir y controlar las múltiples fuentes de estrés laboral, la falta de motivación e ineficiencia serán los resultados más previsibles. 
Como el área de implementación de software impone cambios rápidos y profundos en la forma de trabajar de las organizaciones, afectando amplios sectores de su estructura, la probabilidad de aparición de situaciones estresantes es alta. Es por esto último que la herramienta "CMMI® for Development, Version 1.3" [SEl, 2010], en varias de sus secciones (pp. $25,65,106,268$, etc.) diferencia explícitamente la situación cuando una organización, se encuentra bajo situación de estrés.

Por su parte, [Pose, G., 2005], resalta que cuando las demandas del medio resultan excesivas, intensas y/o prolongadas, superando la capacidad de resistencia y de adaptación del organismo de un individuo, se está en presencia de lo que se denomina estrés disfuncional laboral.

En relación a los proyectos de software, se produce "tecno-ansiedad" cuando un individuo experimenta elevados niveles de activación fisiológica no placentera e incremento de la tensión, por el uso, actual o futuro de algún tipo de sistema y/o herramienta tecnológica en el trabajo. Este síntoma psicosocial generalmente lo condiciona al individuo a adoptar actitudes escépticas respecto al uso de la tecnología y genera en él reducción de la autoestima respecto a su capacidad y competencia laboral.

Ahora bien, continúa argumentando Pose, "si la exposición al estrés no se produce de manera constante y prolongada, la misma puede tener efectos positivos, ya que favorece la activación física y mental del organismo, permitiendo al individuo responder eficazmente a las demandas de la organización y su entorno". Es por ello que conseguir cierto nivel de activación mediante estimulación ambiental puede resultar una estrategia a tener en cuenta para elevar el rendimiento. En ese sentido, la ley de Yerkes-Dodson [Yerkes et al., 1908] lo reafirma al describir la relación entre nivel de activación y el rendimiento.

Por su parte [Ivanisevich, 1985] postula: "Cuando se trata de abordar el fenómeno del estrés en las organizaciones, el objetivo principal debe ser encontrar el nivel de intensidad adecuado para producir incrementos, tanto en el nivel de rendimiento individual, como de la propia organización".

Según esta ley, la relación entre el nivel de activación y el rendimiento toma la forma de $U$ invertida. Para cada tarea se define un nivel de activación en la cual el rendimiento es óptimo. A la izquierda o derecha de ese nivel de activación óptimo, el rendimiento decrecerá en función de cuánto más lejos se encuentre de él.

Por otro lado el estrés disfuncional extremo no sólo desencadena 
problemas en la economía de las organizaciones, sino que también afecta a salud mental y física de los individuos que trabajan en ellas, afectados por los agentes estresantes.

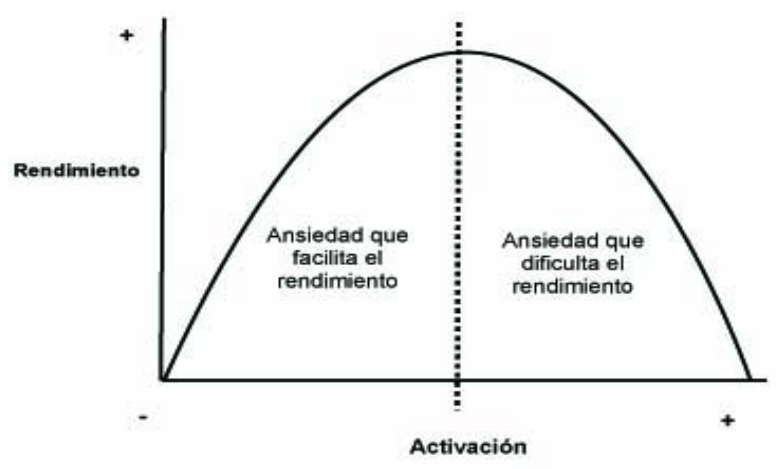

Figura 11: Estrés. Curva de Yerkes - Dodson

Según [Pose, G., 2005] los agentes estresantes son circunstancias del entorno que inciden negativamente en las personas.

Y continúa afirmando: "Estamos en presencia de estrés disfuncional cuando la reacción psicosocial del individuo ante los agentes estresantes, se caracteriza por ser, negativa, insuficiente o exagerada en relación con el nivel de activación, provocando falta de adaptación."

Si se aplica estrictamente el concepto de estrés disfuncional al ámbito laboral, el mismo se puede entender como un desequilibrio percibido entre las demandas del medio y la incapacidad de la persona para enfrentarlas.

Según [Doval G.et. al, 1998] existen los siguientes tipos de factores estresantes:

Factores $\left\{\begin{array}{l}\text { Intrínsecos a la tarea. } \\ \text { Interpersonales. } \\ \text { Relacionados con el desarrollo de la carrera profesional. } \\ \text { Relacionados con la estructura y el clima organizacional. }\end{array}\right.$

Intentaremos demostrar relación estadística significativa entre la presencia de estrés disfuncional en la organización respecto a otras métricas propias de la ingeniería de software como por ejemplo, la implementación exitosa de proyectos o la cantidad de involucrados con el software o el nivel de 
satisfacción del usuario. En esa línea de pensamiento [Andriano, N., 2006]) argumenta que el estrés impacta negativamente sobre los proyectos de software.

\subsection{Participación - Actitud de los Usuarios Claves}

La introducción de las tecnologías de la información ha causado, y continúa causando un impacto muy fuerte en las relaciones de poder y en las metodologías de trabajo en las organizaciones. [Vaughan, 2001]

Al igual que sucede con las obras de arte, los valores y creencias de los diseñadores de software se encuentran embebidos en el proyecto a implementar.

Durante la implementación de un proyecto, la organización en la que finalmente funcionará el software se expone al reajuste que le imprime la dinámica de la gestión del equipo de desarrollo. Este proceso de transformación no involucra únicamente a determinados niveles de la organización sino que, por lo general, la modifica integralmente, ya sea por los distintos niveles jerárquicos o transversalmente. En ambos casos, nunca debe pasarse por alto la organización informal, la cual convive a la sombra de la formal, pero no necesariamente coincide con ésta.

Ahora bien, la intensidad del cambio que instala el proyecto en la organización a través de nuevas herramientas y metodologías puede alterar la percepción de roles. Y es allí donde la actitud de resistencia 0 apoyo de los usuarios claves juega un papel fundamental en el éxito o fracaso de la implementación.

Sostiene [Vaughan, 2001]: "No sólo los usuarios pueden perder de vista que son engranajes de la gran rueda que es la organización, sino que confundidos, es posible que pierdan el marco de referencia y no logren reconocer a ésta como un todo".

Y continúa: "Mientras que los usuarios, no acepten, convencidos o forzados, los nuevos roles que produce el cambio, la aceptación del nuevo sistema será difícil".

Por su parte [Baronas et al., 1988] afirman que los usuarios aceptan mejor el nuevo sistema cuando:

- Se anticipan los cambios por fuentes creíbles.

- Se contrastan opiniones a través de libre expresión. 
- Se minimizan las sorpresas que impone el nuevo sistema a través de pruebas con prototipos.

- Se planifica y ejecuta la capacitación / entrenamiento con el nuevo sistema.

En un estudio de campo realizado por [Hunton et al., 1997] se confirmó que involucrar a los usuarios claves de manera mandataria o coercitiva en un proyecto, representa una estrategia ineficaz, particularmente si a éstos no se les asigna sentido de control o responsabilidad sobre el proyecto a implementar.

Y concluyen afirmando que resulta un factor de éxito clave para la implementación de software la identificación de los usuarios con el proyecto, mediante la asignación de responsabilidades.

Para [Markus, 1983] en cambio, la resistencia al proyecto por parte de los usuarios claves puede jugar a favor o en contra, y su resultado depende de la gestión del equipo de desarrollo. Las causas principales a tener en cuenta son los factores:

- relacionados con los usuarios.

- técnicos inherentes del proyecto.

- vinculaos a la interacción del usuario con el proyecto.

Para este autor, de los tres (3) factores arriba citados, la interacción usuario-proyecto introduce una variable política crítica: la distribución del poder dentro de la organización.

Si se implementa el proyecto, algunas personas reducirían su espacio de poder y por lo tanto, su actitud será poco colaborativa, de manera explícita u oculta.

En la otra vereda se encuentran los usuarios que creen que con la implementación obtendrán mas espacio de poder y por lo tanto demuestran actitud colaborativa.

Entre ambas posiciones, se encuentran ubicados aquellos usuarios que no perciben ventajas o desventajas con la implementación, y por ende, se mantienen en una posición neutral.

Como ya dijimos antes, todas estas posiciones a favor o en contra de la implementación representan potenciales agentes de cambio y volatilidad en los requerimientos, generalmente originados en la organización informal. 
Es por esto último que resulta prioritario que el equipo de desarrollo cuente con métodos de diagnóstico eficaces para mapear la organización informal durante el proceso de elicitación con el fin de:

- identificar el poder real de los usuarios claves,

- identificar los factores que facilitan y dificultan el cambio que introduce el proyecto,

- resolver los conflictos emergentes.

[Markus, 1983] sostiene que si se dispusiera de tales métodos, el diseño y la implementación del proyecto serían más viables.

A tenor de ello, surge necesario definir primero qué se entiende por estructura informal de una organización, para luego entonces sí proponer un método que resuelva el tema.

Se define como estructura informal de un grupo, a las posiciones, estatus y roles que, sin estar prefijados con anterioridad, han surgido de manera espontánea y gradual a partir de la interacción de sus integrantes. [Huici Casal et al., 2004]

Aunque cualquier grupo tenga una estructura formal, ésta puede subsistir junto a otra informal, que no tiene por qué coincidir con la anterior.

En la estructura informal, la posición de cada persona depende de sus habilidades y de su liderazgo. A diferencia de lo que ocurre en la estructura formal, en la informal, los estatus y los roles son aspectos relativos y dependen del significado que se les asigne en una instancia, por lo cual pueden cambiar en cualquier momento. [Huici Casal et al., 2004]

El sociograma, ideado por [Moreno, 1953], es uno de los métodos de la psicología que proponemos como buena práctica a incluir durante el proceso de elicitación de requerimientos, con el fin de registrar las relaciones informales de los stakeholders de la organización donde finalmente funcionará el software.

Este método parte de la idea que lo que realiza un stakeholder puede afectar al grupo al que pertenece. Lo relevante aquí consiste en el concepto que las relaciones interpersonales tienen un efecto determinante 
sobre el grupo. Básicamente, el método registra las relaciones con los demás integrantes, las preferencias, rechazos e indiferencias.

Las relaciones de los involucrados se registran en lo que se denomina socio - matriz. En la siguiente figura, las filas representan las elecciones de los involucrados con el proyectos (quienes) y las columnas, los involucrados elegidos (a quienes).

Tabla 9: Socio matriz

\begin{tabular}{|l|l|l|l|l|l|}
\hline & STK A & STK B & STK C & STK D & STK E \\
\hline STK A & & 1 & 2 & 3 & \\
\hline STK B & 3 & & 1 & & 2 \\
\hline STK C & 2 & 1 & & 3 & \\
\hline STK D & & & & & \\
\hline STK E & 1 & 2 & 3 & & \\
\hline
\end{tabular}

Por ejemplo, El involucrado stk B eligió como favorito al C (1), en segundo lugar al E (2) y en el último lugar al A (3). No eligió al D. Las columnas representan al estatus de cada involucrado. Por ejemplo, los stk A, B y C fueron elegidos cada uno en tres oportunidades. El stk B parecería ser el más popular, mientras que el E con solo una elección y en segundo lugar, sería el más aislado. También se pueden ver cadenas de amistades, por ejemplo el $B$ elige al $C$ en primer lugar y el $C$ elige al $B$ en primer lugar.

Si bien el método presenta limitaciones sobre el contenido de la información grupal, el mismo aporta información sobre la dirección e intensidad de la comunicación y un gran volumen de datos psicosocial grupal.

Como en la implementación de proyectos de software intervienen tanto los grupos formales como los informales, cualquier herramienta que evalúe la influencia de ambos grupos y sus interrelaciones, aportará atributos de valor para su gestión. 


\subsection{Nivel de conflictos en la organización}

Es bien sabido que todo proyecto de software se expone a riesgos cuya responsabilidad recae en el equipo de desarrollo aunque su origen provenga del contexto de la organización en donde finalmente funcionará el software.

Para [Jiang, J et al., 1999], los factores de riesgo que más impactan sobre la probabilidad de éxito de un proyecto provienen de:

- La envergadura del proyecto.

- El tamaño de los grupos se usuarios y gerentes afectados.

- El cambio de tecnología.

- Las innovaciones que impone el cambio.

- Los cambios en los roles que impone el sistema.

- La carencia de soporte.

- Cronogramas y presupuestos poco realistas.

- Interfaces de usuario poco amigables.

- Funcionalidad defectuosa.

- Cambios continuos en los requerimientos.

- Déficit de personal.

- Conflictos en la organización, equipo de desarrollo y entre ambos.

De los factores de riesgo mencionados, esta sección tratará especialmente los que mencionamos en último orden.

[Mclntyre, 1987] sostiene que los líderes del equipo de desarrollo deben optimizar las relaciones interpersonales resolviendo los conflictos, promoviendo conductas cooperativas y colaborativas entre ellos y con los stakeholders. Es decir, deben priorizarse el comportamiento socio-afectivo interpersonal con el fin de mejorar las relaciones en la organización.

Por su parte, la herramienta "CMMI® for Development, Version 1.3" [SEI, 2010] en la sección "Prácticas y Objetivos Genéricos", establece la necesidad de introducir, en el área de elaboración y gestión de requerimientos, entrenamiento en Negociación y Resolución de Conflictos".

Aunque los grupos de trabajo en la organización son de distinto tipo y competencias, es frecuente que se compartan actividades entre sí, generándose conflictos con distintos niveles de sensibilidad e intensidad. 
En la sección "Practicas Específicas por Objetivos" de [SEI, 2010] (SP 1.4, pp. 166) se requiere que se identifiquen las estrategias para resolver los conflictos existentes entre los involucrados con el proyecto considerados claves".

En lo que respecta a las tecnologías ágiles de desarrollo de software, la perspectiva es ambiciosa. Para [Sutherland, 2010], la consideración del conflicto se sustenta en los siguientes puntos de apoyo:

- Mejora de proceso a través de determinación y resolución de obstáculos.

- Innovación como resultado del libre intercambio de ideas inicialmente conflictivas.

- Monitoreo por parte del equipo de desarrollo detrás de la exploración e identificación de agendas conflictivas.

- Compromiso de trabajo individual y colectivo luego de acordar objetivos comunes.

Por lo tanto, para las tecnologías ágiles, el conflicto no es considerado como un factor psicosocial "disfuncional" que perjudique la implementación de proyectos de software. Todo lo contrario, se lo utiliza al conflicto como escala para sincerar posiciones de disenso entre los distintos grupos de involucrados. Con ello, se busca llegar a una especificación de requerimientos "más limpia".

En esa misma dirección, la herramienta [PMBOK, 2003] incorporó la gestión de conflictos como un instrumento necesario para mejorar la dirección del equipo del proyecto.

Una herramienta que esta investigación propone para evaluar el nivel de conflictos antes y durante la implementación de un proyecto de software es el denominado "Sistema de Observación de Múltiples Niveles" o SYMLOG. [Bales et al., 1979].

Este sistema, además de ser un instrumento de medición de las interacciones grupales, explica ciertos fenómenos propios de la psicología social, como son el liderazgo, la dinámica grupal y el desarrollo de los equipos de trabajo. 
Elaborado por [Bales et al., 1979], es una mejora al Interaction Process Analysis (IPA) [Bales, 1950], el cual omitía analizar la conducta no verbal o no explícita. A diferencia de éste, el SYMLOG incluye en su heurística los actos de comunicación no verbal y el contenido de la misma, a través de cuestionarios de adjetivos, interacciones y valores.

El método permite obtener una línea base de medida que sirve como referencia de medidas posteriores determinando si se han producido evoluciones o involuciones sobre la medida inicial, siendo a nuestro criterio especialmente útil como herramienta de elicitación para modelos de desarrollo iterativo.

Para representar los diferentes comportamientos de los stakeholders en el grupo se dispone de lo que se denomina "diagrama del cubo" el cual representa los indicadores en un espacio tridimensional.

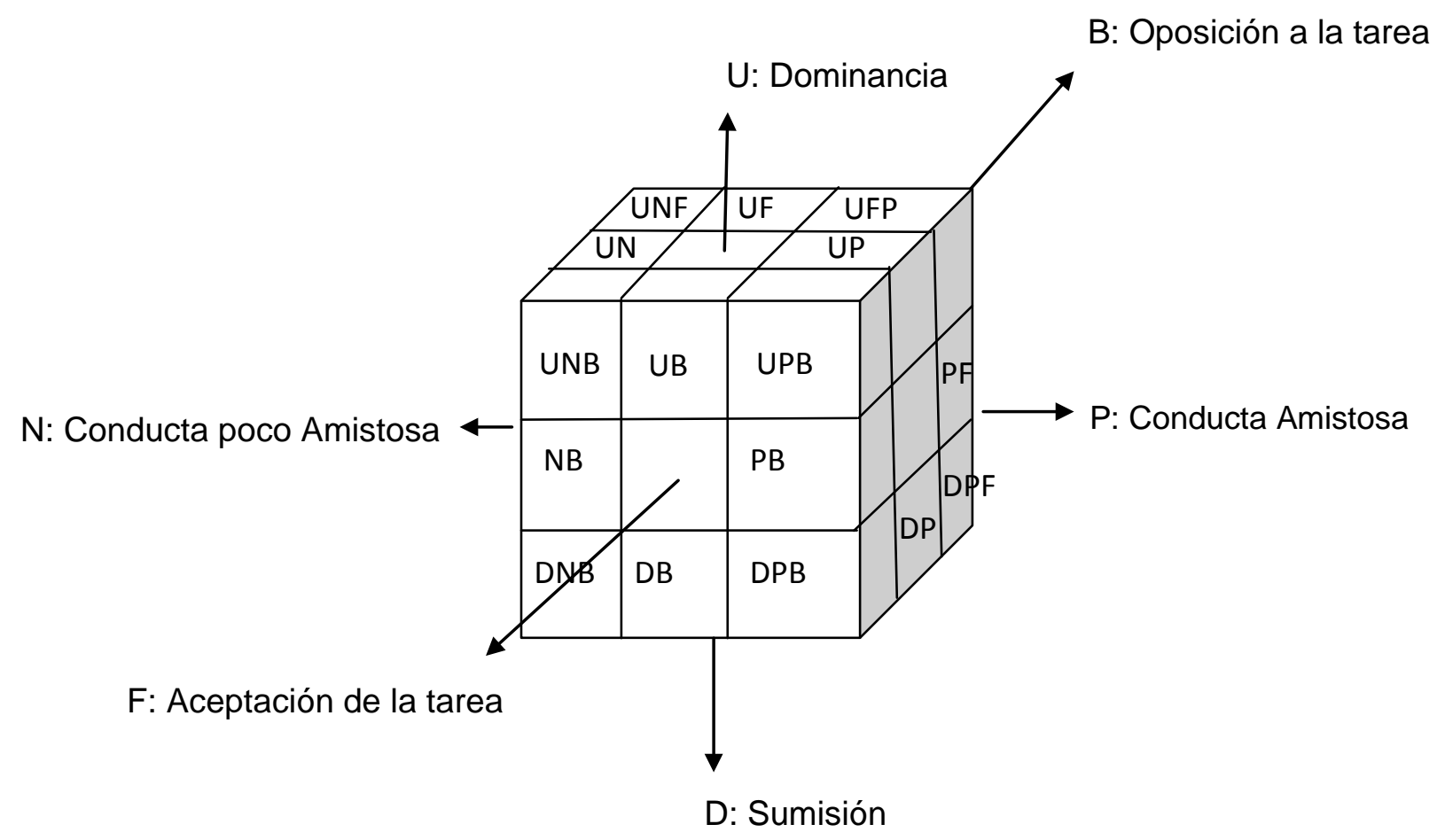

Figura 12: Diagrama del cubo

Como se aprecia en la figura anterior, los valores de dominancia (U) se encuentran en la parte superior del cubo y los de sumisión (D), en la inferior. 
En la parte delantera del cubo se indica el comportamiento de aceptación a la autoridad (F). En la cara posterior, se indica el rechazo (B) a la autoridad, respecto a la tarea por ésta encomendada.

Por último, los valores de conducta amistosa o abierta de los stakeholders aparecen del lado derecho del cubo $(P)$. Las conductas que denotan una actitud poco amistosa o cerrada se ubican del lado izquierdo $(\mathrm{N})$.

El diagrama del cubo está compuesto de veintisiete (27) $(3 \times 3 \times 3)$ cubos más pequeños que codifican la totalidad de valores, características y conductas posibles. El cubo central se toma como origen y no representa ninguna de las tres dimensiones. En total son veintiséis (26) códigos de letras.

Para dimensionar las interacciones individuales y grupales, se diseñaron 3 cuestionarios que permiten valorizar a un individuo evaluándolo respecto a cada una de las 26 situaciones contempladas en el cubo.

Los cuestionarios disponibles son:

- de adjetivos.

- de valores.

- de interacciones.

Por razones de espacio se muestra únicamente el cuestionario de valores.

Los números son los pesos que asigna el método en relación a la frecuencia de la observación.

Tabla 10: Cuestionario de valores

\begin{tabular}{|l|l|l|l|l|l|l|}
\hline Cód & Descripción & Nunca & Poco & $\begin{array}{l}\text { A } \\
\text { veces }\end{array}$ & Mucho & Siempre \\
\hline U & $\begin{array}{l}\text { Éxito financiero individual y } \\
\text { poder }\end{array}$ & 0 & 6 & 12 & 18 & 24 \\
\hline UP & Éxito social y popularidad & 0 & 3 & 6 & 9 & 12 \\
\hline UPF & $\begin{array}{l}\text { Cooperación y trabajo en } \\
\text { equipo }\end{array}$ & 0 & 2 & 4 & 6 & 8 \\
\hline
\end{tabular}




\begin{tabular}{|c|c|c|c|c|c|c|}
\hline UF & $\begin{array}{l}\text { Eficiencia, administración } \\
\text { imparcial }\end{array}$ & 0 & 3 & 6 & 9 & 12 \\
\hline UNF & $\begin{array}{l}\text { Autoridad, cumplimiento de } \\
\text { normas }\end{array}$ & 0 & 2 & 4 & 6 & 8 \\
\hline UN & Agresivo crecimiento personal & 0 & 3 & 6 & 9 & 12 \\
\hline UNB & $\begin{array}{l}\text { Resistencia a la autoridad, } \\
\text { individualismo }\end{array}$ & 0 & 2 & 4 & 6 & 8 \\
\hline UB & Relajamiento del control & 0 & 3 & 6 & 9 & 12 \\
\hline UPB & Cooperación y Protección & 0 & 2 & 4 & 6 & 8 \\
\hline$P$ & $\begin{array}{l}\text { Igualdad, toma de decisiones } \\
\text { democrática }\end{array}$ & 0 & 6 & 12 & 18 & 24 \\
\hline PF & $\begin{array}{l}\text { Idealismo responsable, trabajo } \\
\text { colaborativo }\end{array}$ & 0 & 3 & 6 & 9 & 12 \\
\hline $\mathrm{F}$ & $\begin{array}{l}\text { Formas conservadoras, } \\
\text { establecidas y correctas de } \\
\text { efectuar las tareas }\end{array}$ & 0 & 6 & 12 & 18 & 24 \\
\hline NF & $\begin{array}{l}\text { Restricción de Objetivos } \\
\text { personales en pos de metas } \\
\text { de la organización }\end{array}$ & 0 & 3 & 6 & 9 & 12 \\
\hline $\mathrm{N}$ & $\begin{array}{l}\text { Autoprotección, } \\
\text { autosuficiencia }\end{array}$ & 0 & 6 & 12 & 18 & 24 \\
\hline NB & $\begin{array}{l}\text { Rechazo de los } \\
\text { procedimientos establecidos }\end{array}$ & 0 & 3 & 6 & 9 & 12 \\
\hline$B$ & $\begin{array}{l}\text { Innovación de nuevos } \\
\text { procedimientos, creatividad }\end{array}$ & 0 & 6 & 12 & 18 & 24 \\
\hline PB & $\begin{array}{l}\text { Compatibilidad social, } \\
\text { recreación }\end{array}$ & 0 & 3 & 6 & 9 & 12 \\
\hline $\mathrm{DP}$ & Confianza en los demás & 0 & 3 & 6 & 9 & 12 \\
\hline DPF & $\begin{array}{l}\text { Lealtad a la organización, } \\
\text { fidelidad, dedicación }\end{array}$ & 0 & 2 & 4 & 6 & 8 \\
\hline DF & $\begin{array}{l}\text { Obediencia a la línea de } \\
\text { mando complaciendo a la } \\
\text { autoridad }\end{array}$ & 0 & 3 & 6 & 9 & 12 \\
\hline
\end{tabular}




\begin{tabular}{|l|l|l|l|l|l|l|}
\hline DNF & $\begin{array}{l}\text { Sacrificio personal en pos de } \\
\text { la organización }\end{array}$ & 0 & 2 & 4 & 6 & 8 \\
\hline DN & $\begin{array}{l}\text { Rechazo a la popularidad, } \\
\text { aislamiento }\end{array}$ & 0 & 3 & 6 & 9 & 12 \\
\hline DNB & Aceptación del fracaso, apatía & 0 & 2 & 4 & 6 & 8 \\
\hline DB & $\begin{array}{l}\text { Falta de cooperación con la } \\
\text { autoridad }\end{array}$ & 0 & 3 & 6 & 9 & 12 \\
\hline DPB & Satisfacción, tranquilidad & 0 & 2 & 4 & 6 & 8 \\
\hline D & Pasividad, dejadez & 0 & 6 & 12 & 18 & 24 \\
\hline
\end{tabular}

Para la comparación entre 2 involucrados, "A" y "B", una opción sería la gráfica de los resultados.

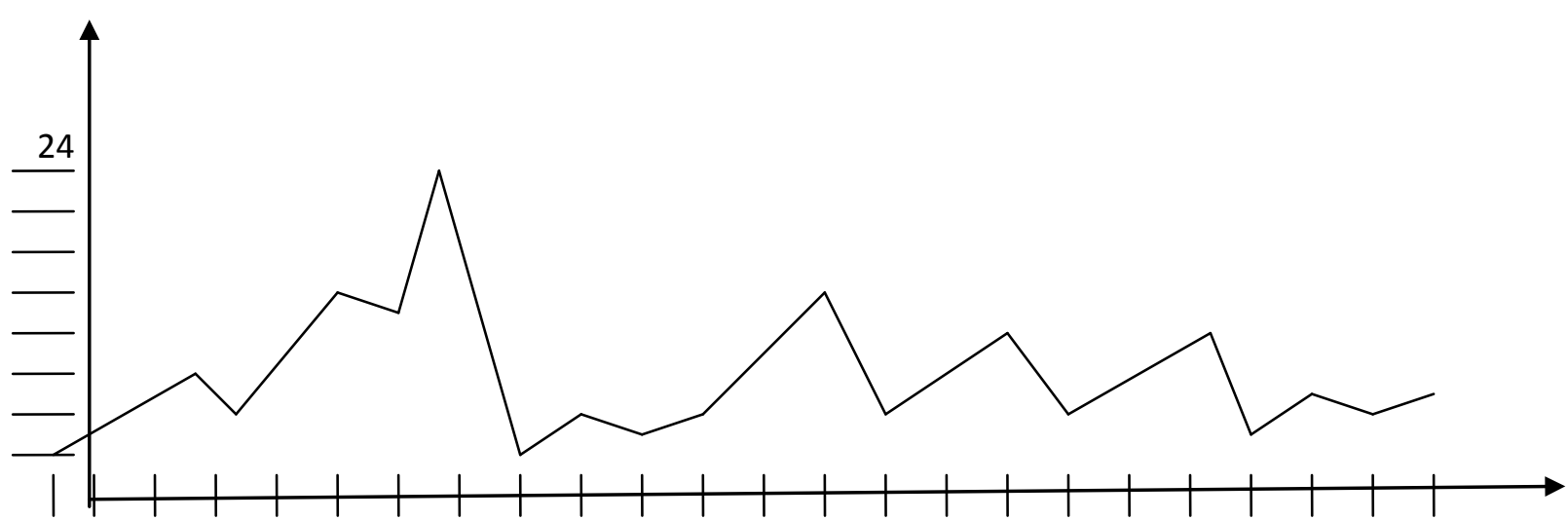

D DPB DB

...NB.

UPF UP U

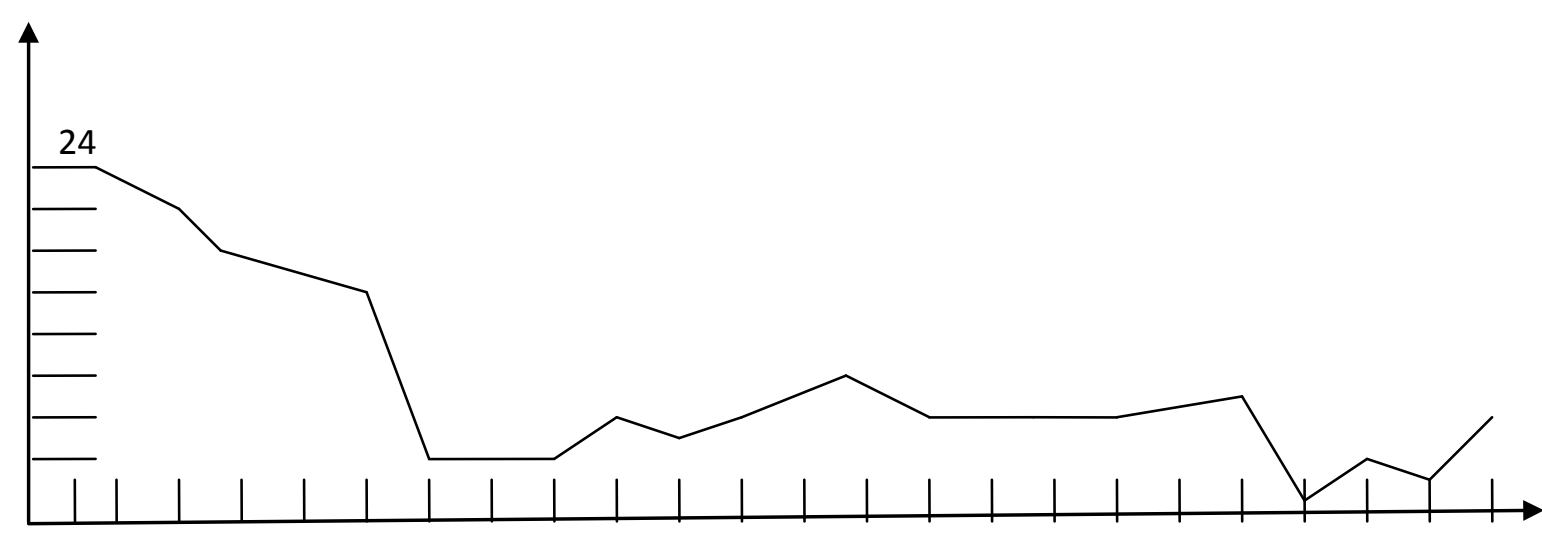

D DPB DB. NB..........

Figura 13: Perfil Psicosocial 
Mientras que el involucrado stk A evidencia bajos niveles de pasividad (D), es decir alta hiperactividad, y autosuficiencia, el stk B muestra altos niveles de pasividad y muy bajos valores en cooperación y trabajo en equipo (UPF).

Por otro lado, el método permite evaluar al grupo como un todo mediante lo que [Huici Casal et al., 2004] denomina "diagrama de campo".

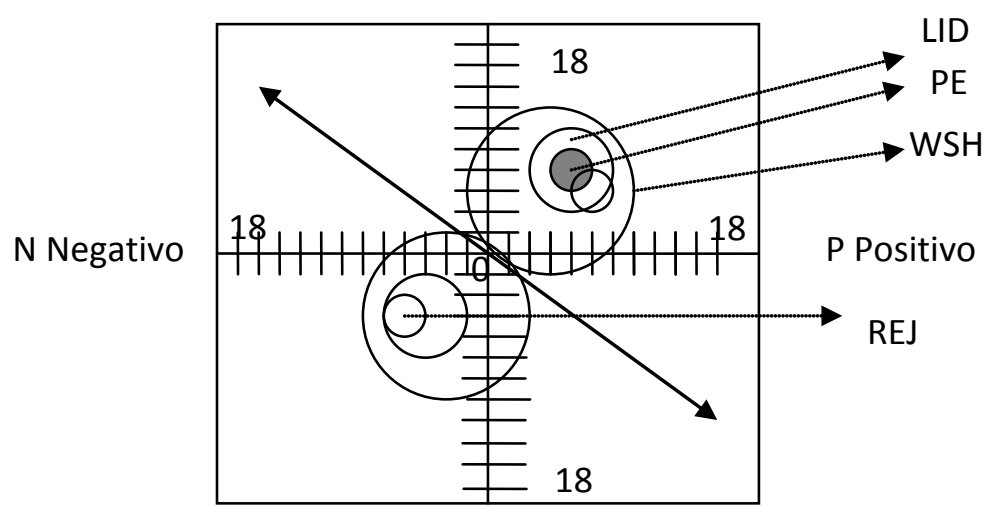

Figura 14: Diagrama de Campos

A partir de los valores extraídos del cuestionario, en la parte superior de la figura anterior, se representan los valores relacionados con la "Aceptación a la tarea" del stakeholder analizado. En la inferior, "la Oposición" (primera dimensión). A la derecha, "los síntomas Positivos" y a la izquierda, "los Negativos" (segunda dimensión). El centro representa un valor adimensional, 0, y partiendo de allí, tanto para la línea horizontal como para la vertical se establece una escala que oscila entre 0 y 18 para representar los valores de ambas dimensiones mencionadas. Estos valores surgen a partir de la tabla de conversión de pesos a unidades de diagrama de campo en cada dimensión.

Tabla 11: Cuantificación del diagrama de campo

\begin{tabular}{|l|l|l|l|}
\hline Peso & $\begin{array}{l}\text { Unidades } \\
\text { en el } \\
\text { Diagrama } \\
\text { de Campo }\end{array}$ & Peso & $\begin{array}{l}\text { Unidades } \\
\text { en el } \\
\text { Diagrama } \\
\text { de Campo }\end{array}$ \\
\hline
\end{tabular}




\begin{tabular}{|l|l|l|l|}
\hline $3-8$ & 1 & $55-60$ & 10 \\
\hline $9-14$ & 2 & $61-66$ & 11 \\
\hline $15-20$ & 3 & $67-72$ & 12 \\
\hline $21-25$ & 4 & $73-77$ & 13 \\
\hline $26-31$ & 5 & $78-83$ & 14 \\
\hline $32-37$ & 6 & $84-89$ & 15 \\
\hline $38-43$ & 7 & $90-95$ & 16 \\
\hline $44-49$ & 8 & $96-101$ & 17 \\
\hline $50-54$ & 9 & $102-104$ & 18 \\
\hline
\end{tabular}

Hasta aquí, con dos dimensiones, se tenía un punto en el diagrama de campo por cada involucrado. Al incorporar los valores del cuestionario correspondientes a Dominancia y Sumisión (tercera dimensión) el punto se transforma en círculo. El radio del mismo depende del valor de la tercera dimensión. Cuánto más grande sea el círculo, el stakeholders evidenciará mayor dominancia. [Huici Casal et al., 2004]

Los círculos WSH y REJ representan a los:

- valores que los involucrados desearían mostrar en su comportamiento (WSH).

- valores que los involucrados desearían ocultar (REJ).

En el cuadrante superior derecho aparece un tercer círculo (en gris) que representa al perfil más efectivo (PE).

El círculo más grande comprende una región en la que estarían las personas que comparten valores relacionados con el trabajo eficaz. A su vez, el círculo que incluye a PE (gris) representa el área en donde se ubicaría el líder del grupo.

Los dos círculos equivalentes a éstos pero ubicados en el cuadrante inferior izquierdo ubican a los stakeholders que se oponen al trabajo en equipo. Aquí se encontraría el stakeholder B del ejemplo anterior. 
La línea diagonal originada en del cuadrante inferior derecho y dirigida hacia el superior izquierdo, se denomina "línea de balance". Esta línea divide a los valores (y por ende a las personas) que favorecen al trabajo en equipo de los que lo dificultan (los ubicados por debajo).

Además de servirle al equipo de desarrollo para determinar cómo perciben los involucrados las normas y la cultura organizacional, este método es útil para mejorar los puntos conflictivos una vez éstos detectados.

De aplicarse este método en forma sistemática como buena práctica durante la etapa de elicitación, la gestión de requerimientos contará con información psicosocial grupal de los involucrados que conforman la organización donde funcionará el software. Con esos datos, el equipo de desarrollo estará en condiciones de evaluar el nivel de conflictos y gestionar la estrategia de mitigación, si dichos conflictos implican alto riesgo para la implementación del proyecto de software.

\subsection{Información - Apertura a las iniciativas}

El tema que se tratará a continuación forma parte de los indicadores que describen el comportamiento de los niveles gerenciales de la organización respecto a iniciativas y estímulos ascendentes generados por stakeholders de jerarquías inferiores. Las principales fuentes consultadas le asignan a la innovación y la participación de los usuarios gran preponderancia como variables descriptivas de la organización, variables éstas que para nosotros debería tener en cuenta el equipo de desarrollo, antes y durante la implementación de un proyecto de software.

[Baronas et al., 1988] sostienen que cuando la gerencia favorece la participación de los empleados de la organización en la implementación de un sistema, éstos lo aceptan más rápido y se adaptan más fácilmente a sus cambios.

Los autores afirman que para cumplir con este propósito, es necesario que la gerencia promueva la generación de iniciativas innovadoras por parte de los empleados, mediante:

- Su participación en las decisiones significativas. 
- La asignación de responsabilidades específicas, sentando las bases para la toma de conciencia que el proyecto será una herramienta de gestión compartida.

- La eliminación del estrés disfuncional producto del cambio organizacional que introduce la implementación del proyecto.

Por su parte, [Barki et al., 1994] argumentan que el equipo de desarrollo debe procurar durante la elicitación de requerimientos que la gerencia sea permeable a las innovaciones que incorpora el proyecto, facilitando la participación activa de los usuarios a todo nivel.

Una forma de medir estas cuestiones se logra evaluando lo "trascendente $y$ personalmente relevante" que resulta ser el proyecto, tanto para la gerencia como para los usuarios. Si un individuo cree que el sistema es personalmente relevante, es probable que adopte una actitud positiva hacia el mismo.

[Fishbein et al., 1975] sostiene que: "existe relación directa entre la actitud del usuario respecto al sistema y su participación durante la etapa de requerimientos". Y lo ejemplifica: "las percepciones de baja autoestima por parte de los usuarios en relación a su eficacia para desarrollar las tareas, generalmente lo inhiben de participar activamente."

Ahora bien, esta última afirmación nos lleva a plantear el siguiente interrogante:

¿El éxito en la implementación de proyectos de software depende del grado de apertura que adopte la gerencia en relación a la aceptación de ideas innovadoras provenientes de sus empleados?

Según [Vaughan, 2001] los indicadores relevantes para evaluar el grado de apertura de la gerencia ante la inminente implementación de un proyecto de software dependen de:

\begin{tabular}{|l|ll|}
\hline \multicolumn{1}{|c|}{ Indicador de Apertura gerencial } & & \multicolumn{2}{c|}{ Grado } \\
\hline Recepción de ideas innovadoras & Abierta & Cerrada \\
\hline Estilo de Participación & Voluntario & Coercitivo \\
\hline Dirección de la Participación & Directa & Indirecta \\
\hline Oportunidad de la Participación & Permanente & A requerimiento \\
\hline Cobertura de la Participación & Global & Parcial \\
\hline
\end{tabular}

Tabla 12: Apertura gerencial 
Una organización cuyo estilo gerencial priorice el intercambio de ideas innovadoras a nivel global, premie la participación voluntaria y directa de manera permanente, será más flexible al cambio que impone un proyecto de software.

En el otro extremo, una gerencia cerrada a las nuevas ideas de los empleados, suele utilizar métodos coercitivos de participación y lo hace de manera parcial y discontinua. Por lo tanto, la probabilidad de implementación exitosa no será alta en este caso.

La información de alta sensibilidad que generan estos indicadores de apertura gerencial debería ser recopilada durante el proceso de elicitación de requerimientos y registrada por el equipo de desarrollo para su posterior análisis cuando se intente implementar el proyecto de software en otra organización. Su utilidad recae en la posibilidad de adoptar un plan estratégico para la implementación del proyecto en función del estilo de apertura gerencial.

\subsection{Motivación para implementar el proyecto}

Si bien la infraestructura, los recursos, el personal y la tecnología, representan aspectos esenciales en cualquier proyecto, la motivación, especialmente la organizacional, representa un aspecto determinante para su implementación. Los siguientes autores coinciden con esta línea de pensamiento.

[Langford et al., 1995]P sostiene "problemas como el ausentismo, la rotación del personal y la baja productividad están profundamente relacionados con la motivación y la satisfacción laboral."

Fue Víctor Vroom quien expuso por primera vez en 1964 el "modelo de las expectativas o modelo cognitivo de la motivación en el trabajo". [Vroom, 1964].

Esencialmente el modelo de Vroom establece que "la gente está motivada si cree que su conducta producirá los resultados que desea". [Spector, 2003] 


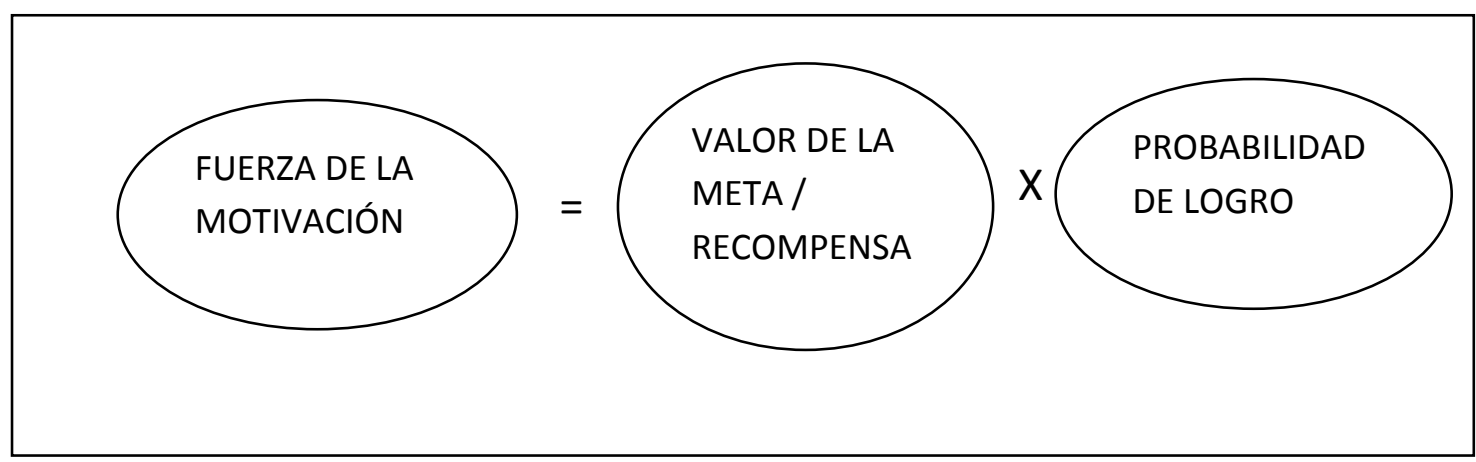

Figura 15: Motivación

Para el individuo, la motivación resultará nula, tanto cuando la meta / recompensa resultase indiferente, o cuando la expectativa del logro fuera dudosa o poco probable.

Como en varias otras disciplinas, en el ámbito de la ingeniería de software se consideraron válidas estas teorías.

[Markus, 1983] respalda esta esa idea: "Introducir una mejor solución metodológica de desarrollo de software no es suficiente para garantizan resultados favorables en la implementación de un proyecto de software. La motivación del individuo puede producir un cambio dramático en la implementación, ya sea, para bien o para mal."

En febrero de 2001, diecisiete (17) desarrolladores de software se reunieron en Snowbird, Utah EEUU para diseñar métodos que permitieran motivar a los involucrados manteniendo la calidad y mejorando la productividad en términos de reducción de tiempos de desarrollo de software.

Como condición, se debía respetar el cumplimiento de los estándares de calidad. Se publicó entonces el denominado "Manifiesto para el Desarrollo Ágil de Software" [Beck, 2001].

Dicho acuerdo, fue el origen de las metodologías de desarrollo rápido de software. El Manifiesto estableció cuatro (4) lineamientos fundamentales que introdujeron una diferencia de fondo respecto al entonces plenamente vigente Modelo de Capacidad y Madurez (SW-CMM®) [Paulk, 1993]. Los lineamientos principales del Manifiesto priorizaron:

- Individuos e interacciones sobre procesos y herramientas.

- Codificación de software sobre documentación detallada.

- Colaboración con el cliente sobre contratos.

- Respuestas al cambio sobre estricto plan del proyecto. 
La implementación de estos lineamientos se instrumentó mediante doce (12) principios fundamentales, entre los cuales el $8^{\circ}$ destacó: "Los proyectos de software se construyen en torno a individuos motivados, quienes además deberían ser de confianza."

Por su parte, el Project Management Institute (PMI), en su guía para la administración de proyectos "Project Management Body of Knowledge" [PMBOK, 2003], incorporó en su Apéndice G el factor "motivación" como un aspecto indispensable para obtener valor agregado en la organización, definiendo como "stakeholders relevantes", a todas aquellas personas u organizaciones cuyas acciones estén motivadas a provocar un impacto directo sobre el proyecto.

\subsection{Apertura a las tecnologías}

La importancia de la aceptación de la tecnología como paso previo a su uso ha sido foco de atención de varias investigaciones. El Modelo de Aceptación de la Tecnología (TAM) [Davis, 1989] ha sido ampliamente aceptado como un método válido para predecir la conducta individual de admisión de nuevas tecnologías de información y sus diferentes usos.

El modelo sugiere que cuando se les presenta a los usuarios una nueva tecnología, un número de factores influyen en su decisión acerca de cómo y cuándo ésta se usará.

Fred Davis definió los términos de utilidad percibida (PU) y facilidad de uso percibida (PEOU), y los propuso como indicadores principales de la aceptación de nuevas tecnologías por parte de los usuarios.

Facilidad de Uso Percibida (PEOU): "evaluación subjetiva del usuario respecto al esfuerzo que implica la utilización de un sistema determinado."

Utilidad percibida (PU): "medida por la cual una persona cree que el uso de un determinado sistema mejoraría su desempeño laboral."

Su teoría establece que los sistemas útiles, primero como requisito, deben ser fáciles de usar. 


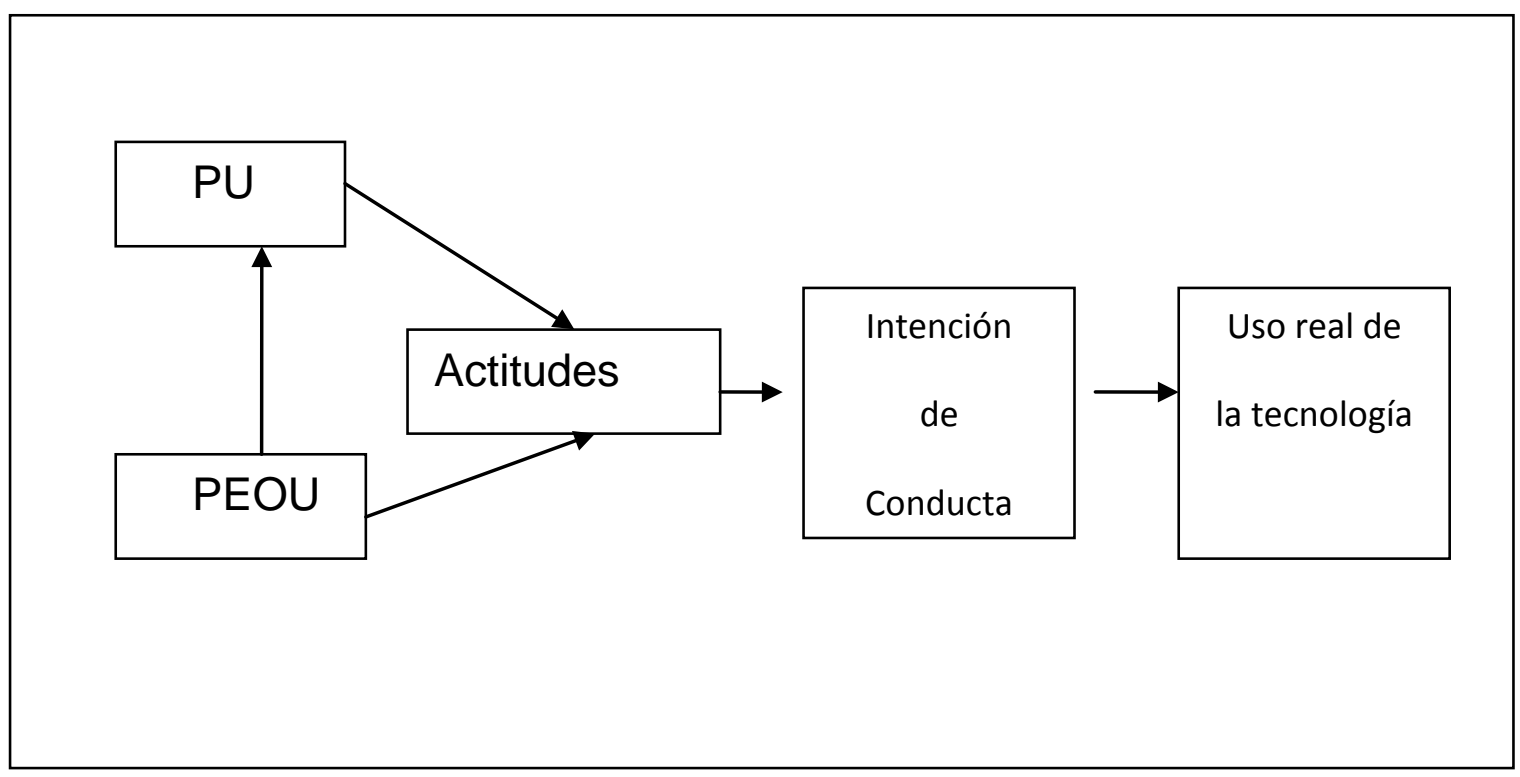

Figura 16: Uso real de la tecnología

Otro factor importante que [Davis, 1989] propone como variable a considerar en el esquema cuando se analiza el uso real de la tecnología, es la intención de conducta del usuario, la cual se ve afectada directamente por las actitudes psicosociales de éste.

Existen numerosos trabajos que validaron este modelo. TAM ha sido expandido a TAM 2 [Venkatesh et al., 2000] y a TAM 3 [Venkatesh et al., 2002]

[Betz, 1998], por su parte, define a la tecnología como "el conocimiento de la manipulación de la naturaleza para propósitos humanos".

Por su parte, [Abukhzam et al., 2010 ] sostiene que: "Entender por qué los usuarios aceptan o rechazan a las nuevas tecnologías ha sido y es un desafío psicosocial a resolver en las organizaciones."

En este mismo sentido [Manross et al.,1986] lo reafirma: "La introducción, plena implementación y adopción con éxito de nuevas tecnologías en las organizaciones, se alcanza sólo si primero éstas son aceptadas por quienes las van a utilizar."

[Chou, 2001], [Harris et al., 1999] y [Todman, 2000] postulan que: "los valores, creencias, edades y experiencias previas del sistema social de los usuarios constituyen aspectos complejos de resistencia a la tecnología que suelen ser condicionantes en un proyecto de software." 


\subsection{Formación - Acceso de los usuarios a la capacitación}

El significado del término "capacitación" lo define [Bramley, 1996] como: "desarrollo sistemático de un patrón de comportamiento, actitud, conocimiento, habilidad requerido por un individuo para realizar adecuadamente una tarea o trabajo."

Y continúa afirmando: "la capacitación es la tarea de adquisición de habilidades, consideradas necesarias por la gerencia, para que los miembros de una organización mejoren la probabilidad de consecución de los objetivos institucionales."

"Es por ello, que la gerencia de una organización deberá adoptar las medidas de entrenamiento y capacitación necesarias para disminuir la brecha entre el rendimiento productivo esperado y el rendimiento real, a través del cambio en las actitudes y habilidades específicas requeridas a los empleados".

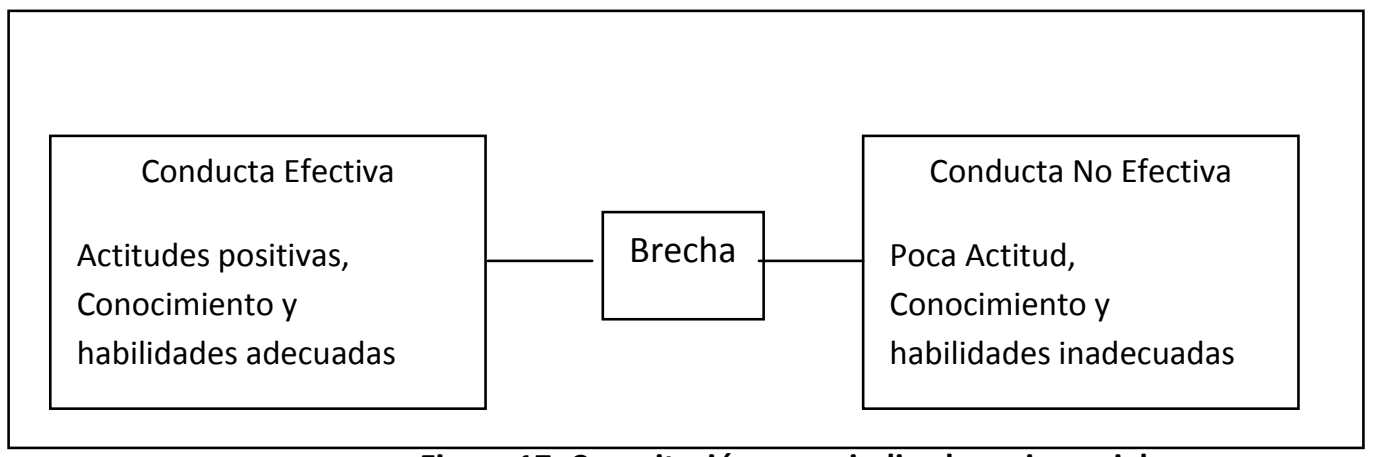

Figura 17: Capacitación como indicador psicosocial

El Software Engineering Institute, a través de la herramienta "People Capability Maturity Model ${ }^{\circledR}$ (P.CMM $\left.{ }^{\circledR}\right)$ [Curtis et al.,2001], sostiene que por lo general los gerentes que trabajan en organizaciones con bajo nivel de madurez, se sensibilizan más por cubrir aspectos reglamentarios de la capacitación que por convencimiento que la misma representa un medio indispensable para lograr los objetivos.

Por su parte en CMMI ${ }^{\circledR}$ for Development, Version 1.3, el área de proceso de formación organizativa (OT) identifica las necesidades de formación estratégicas de la organización, así como las tácticas que son comunes a los proyectos y a los grupos de soporte. [Chrissis, 2010] 


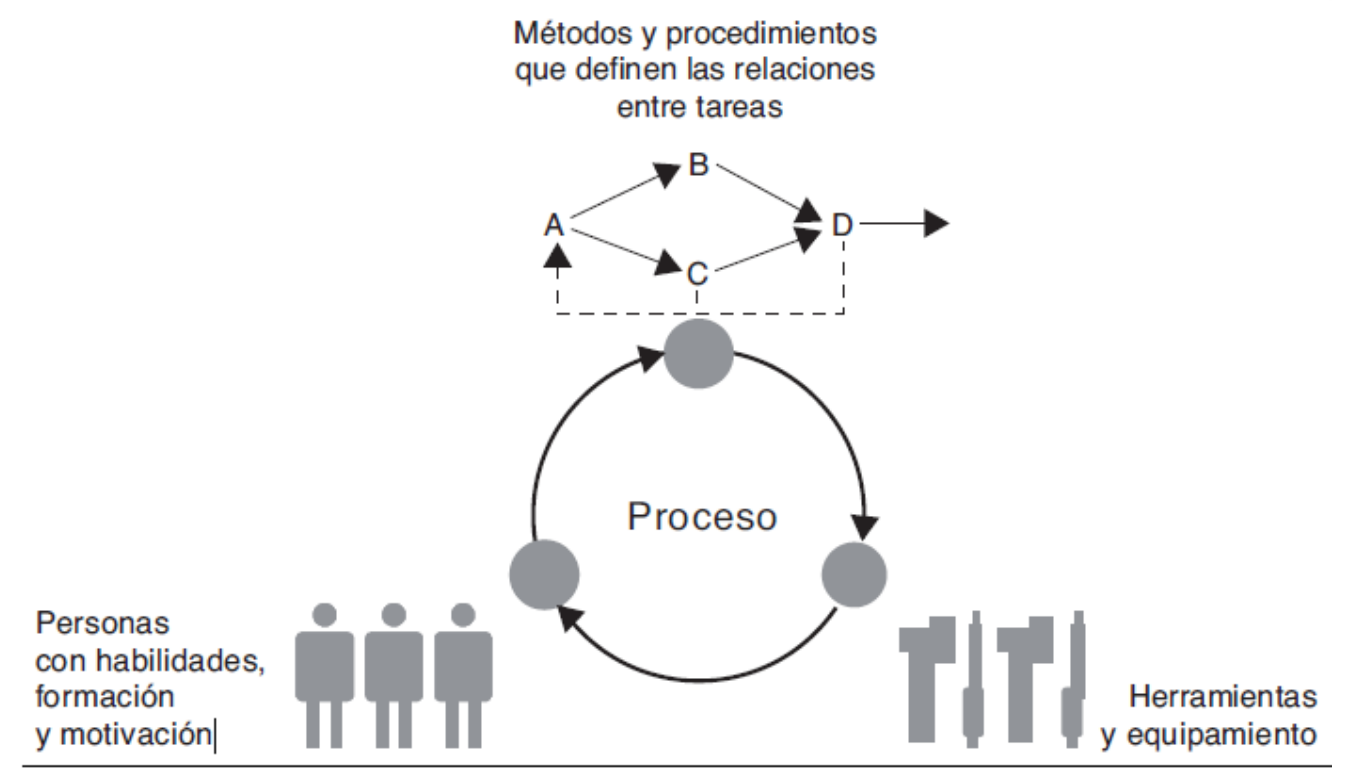

Figura 18: Necesidades estratégicas de formación

La Figura anterior ilustra las tres dimensiones que [Chrissis, 2010] considera críticas sobre las cuales se concentran las organizaciones: las personas, los métodos y procedimientos, y las herramientas y equipamiento.

Aunque a veces resulta difícil obtener la información requerida, una forma pragmática de estimar la prioridad que la gerencia le asigna a la capacitación es hacerlo a través del método ROI (Retorno de la Inversión) [Phillips et al.,2007]

$\mathrm{ROI}=$ Beneficios $/$ Costos o B $/ \mathrm{C}$.

Donde ROI representa la relación entre los beneficios económicos obtenidos gracias a la inversión en capacitación realizada por la organización.

Si B / C >1, la capacitación produjo ganancia.

$B / C=1$, la capacitación no produjo ganancia ni pérdida.

B / C <1, la capacitación produjo pérdida.

Por su parte [Rowden, 2005] sostiene que "los empleados capacitados satisfacen mejor las necesidades de sus clientes. Para este autor los empleados comprometidos con el aprendizaje evidencian un mayor nivel de satisfacción en el trabajo, con un efecto positivo en su calidad y rendimiento." 
Según la Real Academia Española el término "reciprocidad" denota correspondencia mutua de una persona o cosa, con otra.

Llevado al ámbito organizacional, el significado del término expresa la actitud positiva del empleado hacia la organización, en respuesta a similar actitud de ésta respecto a él. [Brum, 2007]

En este sentido, Brum intenta diferenciarse del resto de las opiniones respecto a los beneficios que produce la capacitación. Mientras que la mayoría se enfocan en el resultado final: el producto, este autor realza a la capacitación como un medio para crear un sentimiento de compromiso entre los empleados y la organización. El objetivo de tal estrategia es desarrollar conexiones psicológicas de reciprocidad hacia la organización como un medio para alcanzar los objetivos. 


\section{Capítulo 3}

\section{Materiales y Métodos}

Cuando describimos en el Capítulo I el Objetivo General de esta investigación, mencionamos como meta "el desarrollo de una herramienta de diagnóstico destinada al proceso de elicitación de requerimientos para identificar el riesgo proveniente del área sociológica y psicosocial de la Organización, y su impacto sobre el proyecto de software."

Como paso metodológico necesario para lograr lo mencionado precedentemente definimos como objetivo específico la necesidad de corroborar, mediante encuestas de opinión y entrevistas, "la utilidad de incorporar instrumentos de la psicología social al proceso de elicitación de requerimientos, como una herramienta más de análisis."

En virtud de ello, tanto en el diseño de la herramienta de diagnóstico sociológico y psicosocial como en la encuesta de opinión y las entrevistas formuladas en los objetivos específicos, se incorporaron materiales y métodos sustentando a los factores psicosociales descriptos en el Capitulo II.

\subsubsection{Arquitectura de la encuesta de opinión}

El propósito de la encuesta ha sido corroborar estadísticamente la existencia de relación significativa entre los factores psicosociales descriptos en el Capítulo II y la implementación de proyectos de software.

Para lograr arribar con éxito a esa instancia, la arquitectura de la encuesta se focalizó en satisfacer los siguientes requisitos:

- Establecer el propósito, la bibliografía base utilizada y el canal de comunicaciones con los encuestados.

- Recabar la opinión entre los desarrolladores de software centrándose en las cuestiones de interés medular para la corroboración de la hipótesis. 
- Determinar la concordancia de los participantes con los objetivos del trabajo (general y específicos).

\subsubsection{Implementación de la encuesta y métodos de análisis}

La premisa principal fue elaborar un cuestionario en internet que abordara directamente las cuestiones de interés, evitando incluir en lo posible factores que incrementen la deserción en las encuestas, como por ejemplo, excesiva cantidad de preguntas, ambigüedad y un entorno poco amigable.

El tiempo establecido de exposición de la encuesta fue de tres (3) meses: desde el 5 de febrero de 2012 al 5 de mayo del mismo año, con un tiempo promedio para completar la misma de quince (15) minutos.

Con el fin que la audiencia fuera lo más heterogénea posible se incluyó en la encuesta a todo el espectro de roles que intervienen en los equipos de desarrollo e implementación de proyectos de software. Fue así, que a través de la publicación de la encuesta en sitios web de Argentina y Chile, fue posible conocer qué opinaban los ingenieros en requerimientos, analistas, diseñadores, programadores y testers, respecto a la incorporación de la psicología social en el proceso de elicitación de requerimientos de software.

\subsubsection{Operalización de las Variables}

Excepto las preguntas sobre datos particulares del participante o sus comentarios al final de la encuesta, el resto de las preguntas fueron cerradas.

La información obtenida fue registrada utilizando dos (2) clases de variables:

- Variables cualitativas categorizadas ordinales, donde la asignación de valores identifican un grupo de pertenencia, permitiendo establecer un orden sobre cómo es una categoría respecto a las otras.

Como ejemplo de este tipo de variables, en la pregunta 8 de la encuesta se requirió: "en la etapa de requerimientos, ¿como era el nivel de estrés laboral que usted percibió entre los empleados, intenso, normal o bajo?" 
- Variables cualitativas categorizadas nominales: en ellas, la asignación de valores identifican un grupo de pertenencia. A diferencia de las anteriores aquí no es posible establecer un orden.

Como ejemplo, en la pregunta 7 se demandó: “¿cuál era el estilo más asiduamente utilizado en la priorización de requerimientos por parte de la gerencia, el objetivo o el subjetivo?".

\subsubsection{Esquema de evaluación de los resultados de la encuesta}

El esquema de evaluación fue previsto para que una vez finalizada la captura de datos, los mismos se vuelquen de inmediato en cuadros comparativos y tablas de contingencia destinadas a corroborar la hipótesis, utilizando el método de contraste de Chi Cuadrado.

Para evitar respuestas sesgadas, en el diseño de la encuesta se intercalaron preguntas no relacionadas con los factores psicosociales descriptos en el Capítulo II. Esas preguntas, a las que definimos como factores de contraste, se focalizaron deliberadamente en aspectos técnicos, económicos - financieros del proyecto y de infraestructura de la organización.

Como premisa, se les requirió a los participantes que establecieran durante toda la encuesta dos (2) únicos proyectos de software en los que hayan intervenido directamente con algún rol. Los proyectos debían cumplir las siguientes condiciones:

- un (1) proyecto implementado con éxito al que denominados proyecto implementado $(\mathrm{Pl}), \mathrm{y}$;

- un (1) proyecto que haya fracasado por completo o proyecto no implementado (PNI).

Si bien inicialmente se analizó la posibilidad de incluir una tercer categoría, "proyecto aún no completado", se decidió finalmente no hacerlo, debido a que dicha categoría podría agregar ambigüedad o redundancia en las respuestas, afectando los objetivos de corroboración.

El total de variables estudiadas fue de diecinueve (19).

De las diecinueve (19) variables, once (11) corresponden a los factores psicosociales tratados en el Capítulo II, los cuales están relacionados 
directamente con corroboración de la hipótesis. De esas once (11) variables, dos (2) se especializaron en evaluar la gestión psicosocial del equipo de desarrollo y nueve (9) en la organización cliente (donde funciona el software una vez implementado el proyecto).

A su vez, de las nueve (9) variables que se utilizan para evaluar la organización desde el punto de vista psicosocial, cuatro (4) de ellas se enfocaron en la interacción grupal de los involucrados con el proyecto y cinco (5) evaluaron psicosocialmente las políticas gerenciales de la organización.

De las restantes ocho (8) variables no dedicadas a la corroboración de la hipótesis: tres (3), miden los factores de contraste (cuestiones no relacionadas con los factores psicosociales), cuatro (4), categorizan a los encuestados, y finalmente una (1), mide la concordancia con el objetivo general propuesto en esta investigación.

\subsubsection{Instrumentación de la encuesta}

El método Chi Cuadrado de Pearson constituye uno de los procedimientos más asiduamente utilizados de contraste de hipótesis. Sin embargo, esta prueba estadística, cuando el tamaño de la muestra es menor que veinte (20), pierde eficacia [Rodríguez, 2012]. Por lo tanto, para asegurar la confiabilidad en la corroboración de la hipótesis, el tamaño de la muestra que estipulamos fue sensiblemente superior a ese número: cien (100) proyectos de software.

Para los fines de administración y publicación de la encuesta se recurrió a una plataforma web de encuestas de experiencia en el mercado hispanoamericano (encuestafacil.com). En el Anexo IV se presenta la página de administración de la encuesta y la publicación de la misma en los portales nacionales e internacionales que brindaron su apoyo para la realización de este trabajo.

\subsubsection{Estructura de las entrevistas}

[Royo Beberide] sostiene que la entrevista es un método de probada eficiencia para medir opiniones. Junto con la observación y el cuestionario, la entrevista constituye la herramienta más adecuada para evaluar cuestiones abstractas como son los factores psicosociales. 
La entrevista, como técnica de recopilación, puede ser estructurada con formato de interrogación estandarizada, o implementarse a través de una conversación libre.

Para el tratamiento de nuestra temática las entrevistas se realizaron mediante una guía estructurada de preguntas de distinto tipo.

\subsubsection{Objetivo de las entrevistas}

El objetivo de las entrevistas estuvo orientado en recabar información detallada acerca de las cuestiones de interés que consideramos relevantes respecto a la problemática "Incorporación de la Psicología Social al proceso de elicitación de requerimientos de software".

En ese sentido, y como queda de manifiesto al analizar el titulo del presente trabajo de tesis, existe un hilo conductor que involucra grupos de personas pertenecientes a tres (3) dominios diferentes:

- Psicólogos sociales y/o sociólogos.

- Profesionales y técnicos que integran equipos de desarrollo de software, y;

- Usuarios.

Si bien los grupos están diferenciados, en la problemática tratada existen temas que afectan de manera transversal a todos ellos. Por lo tanto, en el diseño de las entrevistas se tuvieron en cuenta preguntas:

- específicas de cada grupo, y;

- comunes a los tres (3) grupos.

Por otro lado, desde el punto de vista de la interrelación entre las disciplinas que involucra este trabajo, se aprecia un hecho elocuente en nuestra propuesta: la inserción de la psicología social dentro del proceso de elicitación de requerimientos. Como todo proceso de incorporación implica cierta resistencia al mismo, se quiso evaluar en las entrevistas las distintas reacciones que evidenciaron los tres (3) grupo de involucrados.

\subsubsection{Selección de los entrevistados}

El criterio adoptado para la selección de los entrevistados fue encontrar en las tres (3) audiencias personas con la suficiente experiencia para reconocer la problemática aquí planteada. 
Se estableció un mínimo de veinte (20) años como tiempo requerido para ser seleccionado para la entrevista, considerando que transcurrido ese lapso de tiempo un individuo se encuentra en condiciones óptimas profesionales para aportar sus puntos de vista en su dominio de aplicación ya sean las áreas de desarrollo, de usuarios o de profesionales de la psicología.

Las entrevistas fueron diagramadas para que no excedieran una (1) hora de duración y en ningún caso se superaran las diez (10) preguntas.

El cuerpo de la entrevista se conformó con un grupo de preguntas introductorias sobre la incorporación de la psicología en el desarrollo e implementación de proyectos de software, una segunda sección de identificación de los problemas más comunes que ocurren en la implementación de los proyectos de software y una última parte destinada a medir la opinión de los entrevistados sobre la mejora que aportaría la inclusión de una herramienta de diagnóstico de la gestión del área sociológica y psicosocial de la Organización, y su impacto sobre el proyecto de software (objetivo general del presente trabajo de tesis).

\subsubsection{Herramienta de diagnóstico psicosocial sobre el proyecto}

En relación al objetivo general de la tesis de desarrollar una herramienta de diagnóstico, el Anexo II propone un cuestionario y guía de evaluación para brindarle al equipo de desarrollo la posibilidad de identificar y calificar, durante la elicitación de requerimientos, el riesgo proveniente del área sociológica y psicosocial de la Organización, y su impacto sobre el proyecto de software.

La fuente a la que se recurrió para el diseño de tal herramienta de diagnóstico fue el cuestionario publicado en Internet por [Martín, et al., 2002], denominado "FACTORES PSICOSOCIALES - IDENTIFICACIÓN DE SITUACIONES DE RIESGO" desarrollado por el Instituto Navarro de Salud Laboral de España (ISNL). El mencionado trabajo trata la afectación que produce el estrés laboral sobre la salud de los empleados y el rendimiento en las actividades.

Por su flexibilidad, hemos tomado como modelo instrumental el trabajo del ISNL, especializándolo para investigar cómo influyen los aspectos sociológicos y psicosociales sobre la implementación del proyecto de software. 
La arquitectura de dicho trabajo se sustenta sobre tres (3) funcionalidades principales:

- Evaluación inicial del estado de la organización en relación al riesgo psicosocial.

- Identificación de las situaciones de riesgo mediante la aplicación del cuestionario de factores psicosociales.

- Aporte de medidas preventivas.

En la primera y segunda funcionalidades los autores describen las variables (factores psicosociales) de incidencia. El sistema de evaluación que adoptó ISNL fue de hasta cuatro (4) opciones por pregunta que se califican de cero (0) a seis (6) puntos cada uno. El cuestionario consta de treinta (30) preguntas.

Según el puntaje obtenido en el cuestionario el método representa la gestión psicosocial representándola en la siguiente escala:

Muy poco adecuada / Inadecuada / Adecuada y Muy Adecuada.

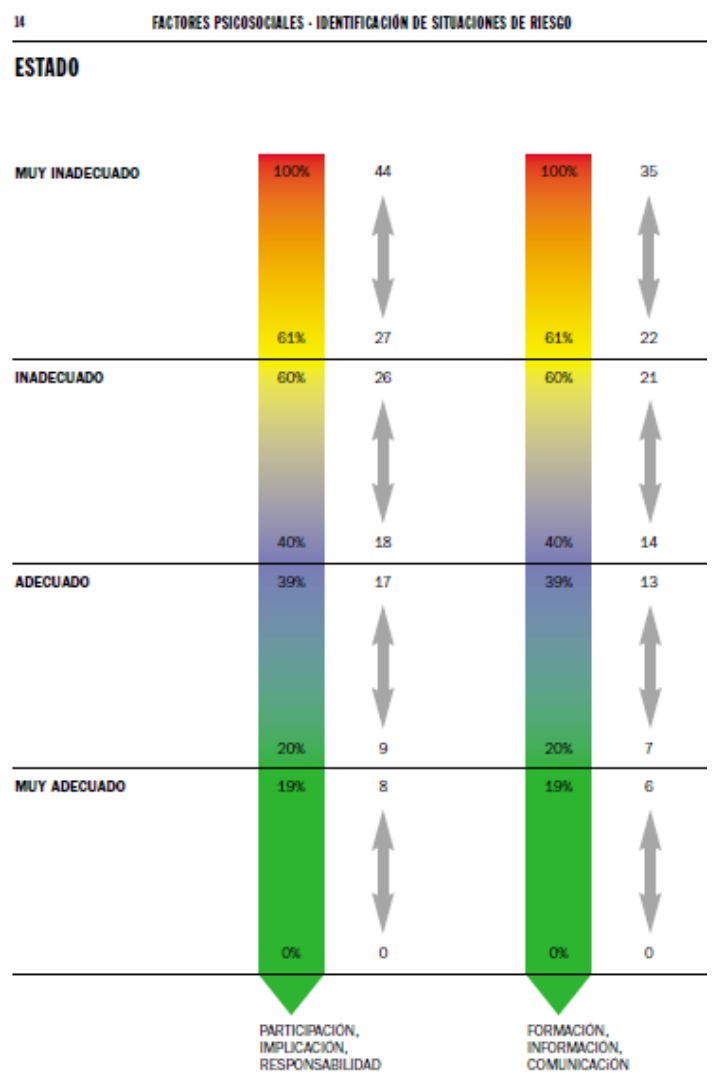

Figura 19: Calificación del riesgo psicosocial

Si la calificación obtenida es inadecuada o inferior, el método propone la 
aplicación de recomendaciones específicas.

Atendiendo a los requisitos impuestos por el objetivo general de esta investigación, en el Anexo II se presenta en detalle una herramienta de diagnóstico para identificar el riesgo proveniente del área sociológica y psicosocial de la Organización, y su impacto sobre el proyecto de software. En dicho anexo, nuestra propuesta aporta un cuestionario especializado, un esquema de representación visual de la calificación y una sección de medidas de mitigación del riesgo psicosocial al que se enfrenta el proyecto de software durante el proceso de elicitación de requerimientos.

\subsubsection{Descripción de las variables: riesgo psicosocial}

En el siguiente cuadro se detalla cada factor psicosocial tratado en el Capítulo Il y el área de riesgo psicosocial que involucra. (Ver Anexo II).

Tabla 13: áreas del riesgo psicosocial

\begin{tabular}{|c|c|c|}
\hline \multicolumn{2}{|c|}{$\frac{\text { Áreas del Riesgo }}{\text { psicosocial }}$} & Factor Psicosocial \\
\hline \multicolumn{2}{|c|}{$\begin{array}{l}\text { Del equipo de desarrollo } \\
\text { (E) }\end{array}$} & $\begin{array}{l}\text { Cohesión->Interacción de estilos de } \\
\text { personalidad dentro del equipo de desarrollo. } \\
\text { Comunicación entre el equipo de desarrollo y } \\
\text { el usuario. }\end{array}$ \\
\hline \multirow{7}{*}{$\begin{array}{c}\text { De la } \\
\text { Organización } \\
\text { donde } \\
\text { funcionará el } \\
\text { software }\end{array}$} & \multirow{4}{*}{$\begin{array}{l}\text { De la } \\
\text { interacción } \\
\text { grupal }\end{array}$} & $\begin{array}{l}\text { Nivel de consenso para implementar el } \\
\text { proyecto de software. }\end{array}$ \\
\hline & & Nivel de estrés en la organización. \\
\hline & & Participación - Actitud de los usuarios claves. \\
\hline & & $\begin{array}{l}\text { Nivel de Conflictos en la organización. } \\
\text { Estilo de mando - Estilos de priorización de } \\
\text { requerimientos. }\end{array}$ \\
\hline & \multirow{3}{*}{$\begin{array}{l}\text { De sus } \\
\text { políticas }\end{array}$} & Información - Apertura a las iniciativas. \\
\hline & & $\begin{array}{l}\text { Motivación de la gerencia para la implementar } \\
\text { el proyecto. }\end{array}$ \\
\hline & & $\begin{array}{l}\text { Apertura a las Tecnologías. } \\
\text { Formación - Acceso de los usuarios a la } \\
\text { capacitación }\end{array}$ \\
\hline
\end{tabular}




\section{Capítulo 4}

\section{Análisis e Interpretación de los resultados de la encuesta de opinión}

En el presente capítulo se analizan los resultados de la encuesta de opinión completada por los desarrolladores de software. Su objetivo es corroborar la siguiente hipótesis general:

"Existe relación estadísticamente significativa entre los factores psicosociales y la implementación de proyectos de software".

La prueba de hipótesis se realizará por cada uno de los factores psicosociales detallados en el capítulo 2. En relación a ello, los encuestados emitieron su opinión considerando únicamente dos (2) proyectos de software por ellos seleccionados, uno de los cuales fue implementado con éxito y el otro, no.

De acuerdo a la taxonomía de [Cequea, et al., 2011], por cada factor psicosocial se ha asignado con (I), (G), u (O), la categoría al cual pertenece: Individual, Grupal u Organizacional.

Tabla 14: Análisis de Factores psicosociales

\section{Factores Psicosociales}

4.1 Cohesión->Interacción de estilos de personalidad dentro del equipo de desarrollo. (I)

4.2 Comunicación entre el equipo de desarrollo y el usuario (I)

4.3 Nivel de consenso para implementar el proyecto de software (G)

4.4 Estilo de mando - Estilos de priorización de requerimientos (O)

4.5 Nivel de estrés en la organización (G)

4.6 Participación - Actitud de los usuarios claves (G)

4.7 Nivel de Conflictos en la organización (G)

4.8 Información - Apertura a las iniciativas $(\mathrm{O})$ 
4.9 Motivación de la gerencia para la implementar el proyecto (O)

4.10 Apertura a las Tecnologías (O)

4.11 Formación - Acceso de los usuarios a la capacitación (O)

Para el análisis, generación de gráficos e interpretación de los resultados de la encuesta se utilizaron los siguientes instrumentos:

- El estimador de contraste de hipótesis Chi Cuadrado de Pearson.

$$
\mathrm{X}^{2}=\sum \mathrm{H}_{\mathrm{N}=1} \sum \mathrm{K}_{\mathrm{N}=1} \frac{(\mathrm{fo}-\mathrm{fe})^{2}}{\mathrm{fe}} \quad \begin{aligned}
& \begin{array}{l}
\text { Donde: } \\
\mathrm{x}^{2}=\text { valor estadistico de ji cuadrada. } \\
\text { f }=\text { frecuencia observada. } \\
\text { fe }=\text { frecuencia esperada. }
\end{array}
\end{aligned}
$$

- El software InfoStat [Di Rienzo et al., 2011], en su versión de distribución gratuita en Internet.

A continuación, se presenta el análisis de los resultados con la verificación de la hipótesis.

Cabe agregar que, por cada factor psicosocial, el análisis se realiza en primera instancia a nivel global, es decir considerando los 100 proyectos de software. Luego, se analizan separadamente los proyectos de acuerdo a las categorías: implementados y los no implementados.

Evaluación de la cohesión. Interacción de estilos de personalidad dentro del equipo de desarrollo

Se describe a continuación la verificación de la hipótesis según las opiniones de los encuestados respecto a la pregunta 18 de la encuesta: “¿Cómo era la interacción grupal interna del equipo de desarrollo a lo largo del proyecto?"

Opciones:

GRUPO ALTAMENTE COHESIONADO

CON DIFERENCIAS SALVABLES

CON DIFERENCIAS INSALVABLES. 
Como se observa en la siguiente tabla de contingencia, el valor de $\mathrm{p}=$ 0,0029, correspondiente al estadístico Chi Cuadrado de Pearson, es inferior a 0,05, por lo que se corrobora nuestra hipótesis, es decir existe relación estadísticamente significativa entre las variables: implementación de proyectos de software e interacción de personalidades dentro del equipo de desarrollo de software.

Tabla 15 : de contingencia (Cohesión de personalidades)

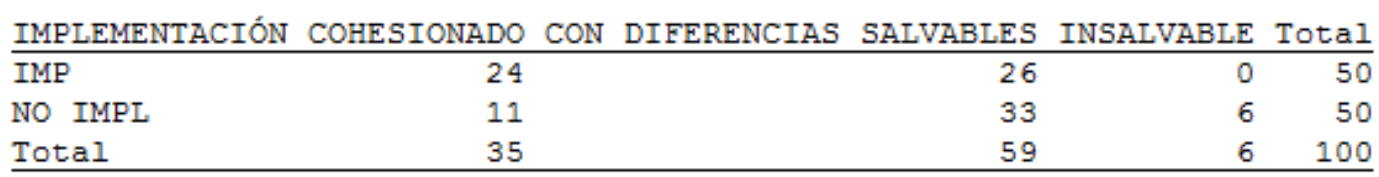

\begin{tabular}{lrrr}
\multicolumn{1}{c}{ Estadistico } & Valor & gl & p \\
\hline Chi Cuadrado Pearson & 11,66 & 2 & 0,0029 \\
Chi Cuadrado MV-G2 & 14,10 & 2 & 0,0009 \\
Coef. Conting. Cramer & 0,24 & & \\
Coef. Conting. Pearson & 0,32 & \\
\hline
\end{tabular}

Si consideramos el total de proyectos (100) en forma conjunta, implementados y no implementados:

- Las opiniones sobre interacción producida por personalidades altamente cohesionadas en el equipo de desarrollo se distribuyeron, en un $69 \%$ sobre los proyectos implementados, y en un $31 \%$ sobre los no implementados.

- En cambio, las opiniones sobre interacción con diferencias insalvables de personalidades se distribuyeron todas (100\%) sobre los proyectos no implementados. No hubo opiniones a favor de proyectos implementados con problemas insalvables de personalidad dentro del equipo de desarrollo. 

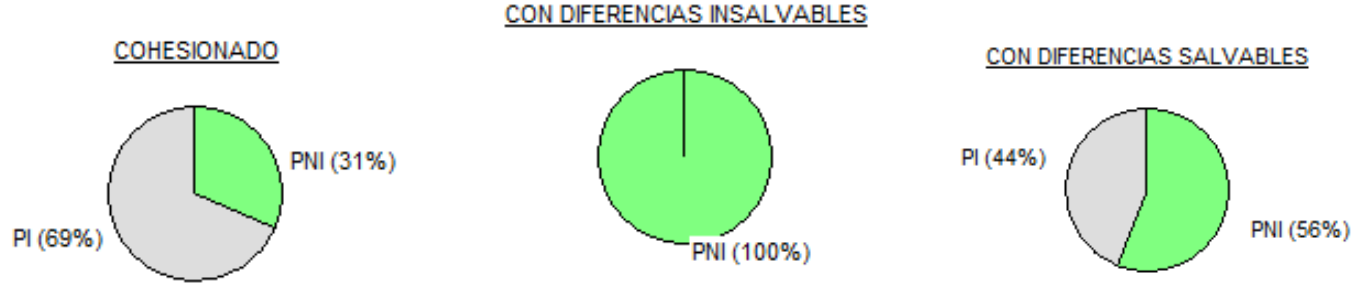

Figura 20: Cohesión respecto al total de proyectos- PI: Proyectos Implementados PNI: Proyectos No Implementados

Por otro lado, si queremos medir cómo se distribuyó la interacción por resultado final del proyecto:

- En los proyectos implementados (50), para el $48 \%$ de las opiniones, el éxito se logró con grupos altamente cohesionados.

- En cambio, en los proyectos no implementados (50), solo el $22 \%$ de las opiniones detectaron grupos altamente cohesionados.

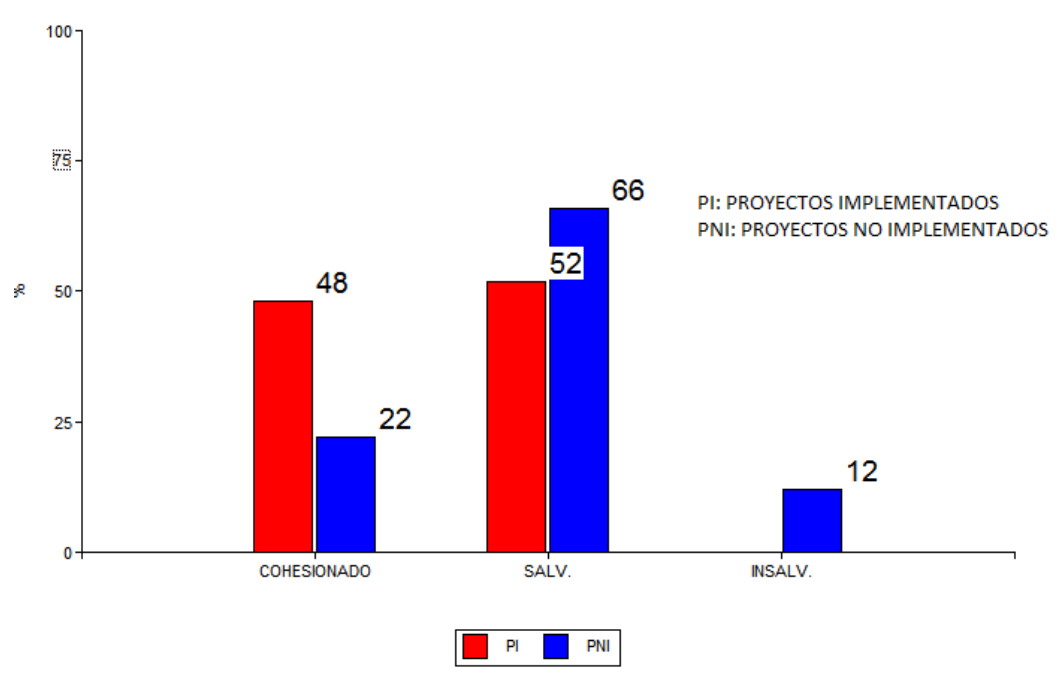

Figura 21: Cohesión por tipo de proyectos

En síntesis. Los resultados obtenidos reflejan lo explicado en el capítulo 2 durante la descripción del framework SimOrg. "el rendimiento de las actividades está influenciado por la personalidad individual de los miembros del equipo de desarrollo de software."

La clave parece estar en encontrar un equipo de desarrollo cohesionado integrado por personalidades compatibles. 
Evaluación de Is Comunicación entre el equipo de desarrollo y el usuario

Se presenta a continuación la verificación de la hipótesis y la interpretación de las opiniones de los encuestados respecto a la pregunta 17 de la encuesta: "Durante la etapa de requerimientos, ¿cómo era la comunicación entre el equipo de desarrollo con los futuros usuarios de cada proyecto?"

Opciones:

\section{FLUIDA / NORMAL / DEFICIENTE}

Como se observa en la siguiente tabla de contingencia, el valor de $p<$ 0,0001 correspondiente al estadístico Chi Cuadrado de Pearson es inferior a 0,05 , por lo que se corrobora nuestra hipótesis, es decir existe una relación estadísticamente significativa entre las variables: implementación de proyectos de software y comunicación del equipo de desarrollo con los usuarios.

Resultado Final del Proyecto $\rightarrow$ PI: Proyecto Implementado - PNI: Proyecto No Implementado.

Tabla 16: de contingencia (Comunicación con el usuario)

Frecuencias absolutas

En columnas: COMUNICACION

\begin{tabular}{lrr} 
Proyecto DEFICIENTE FLUIDA NORMAL Total \\
\hline TMP
\end{tabular}

$\begin{array}{lllll}\text { NO IMPL } & 21 & 4 & 25 & 50\end{array}$

\begin{tabular}{lllll} 
Total & 25 & 30 & 45 & 100 \\
\hline
\end{tabular}

\begin{tabular}{lrrrc}
\multicolumn{1}{c}{ Estadistico } & Valor & gl & p \\
\hline Chi Cuadrado Pearson & 28,25 & $2<0,0001$ \\
Chi Cuadrado MV-G2 & 31,26 & $2<0,0001$ \\
Coef. Conting. Cramer & 0,38 & & \\
Coef. Conting. Pearson & 0,47 & & \\
\hline
\end{tabular}

Si consideramos el total de proyectos (100),

- Las opiniones sobre comunicación fluida entre ambos grupos se distribuyeron, en un $87 \%$ sobre los proyectos implementados, y en un $13 \%$ sobre los no implementados.

- En cambio, las opiniones sobre comunicación deficiente se distribuyeron en un $84 \%$ sobre los proyectos no implementados y en un $16 \%$ sobre los implementados. 


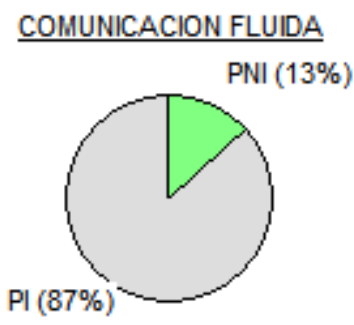

COMUNICACION DEFICIENTE

$\mathrm{PI}(16 \%)$

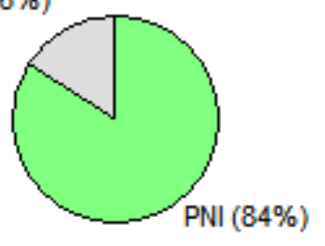

COUUNICACION NORMAL

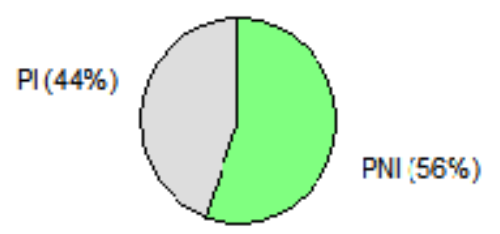

Figura 22: Comunicación con el usuario respecto al total de proyectos PI: Proyectos Implementados PNI: Proyectos no Implementados

Por otro lado, si se quiere medir cómo se distribuyó la comunicación por resultado final del proyecto:

- En los proyectos implementados (50), para el $52 \%$ de las opiniones, se produjo comunicación fluida.

- En cambio, en los proyectos no implementados (50), solo el $8 \%$ de las opiniones detectaron comunicación fluida.

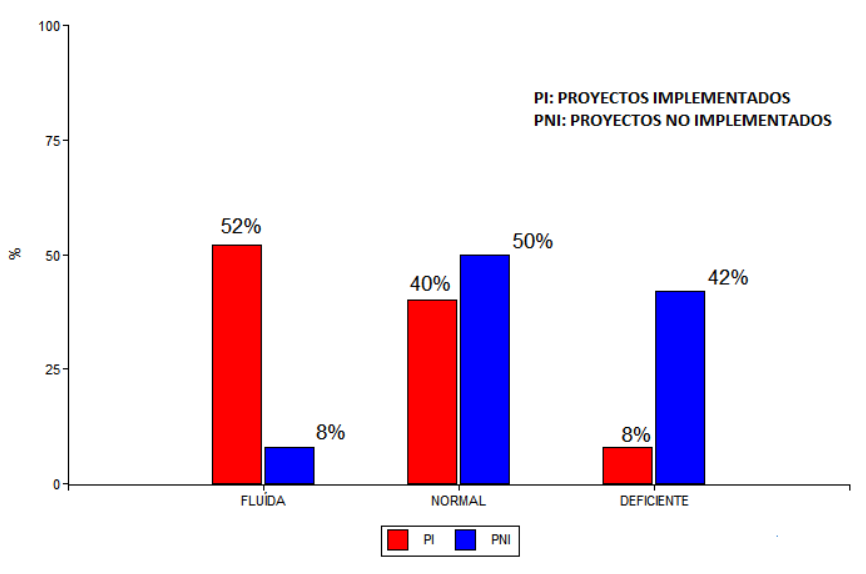

Figura 23: Comunicación con el usuario por tipo de proyectos PI/PNI

Los gráficos reflejan el fenómeno descripto en el capítulo 2 acerca de la brecha existente en la comunicación entre desarrolladores y usuarios. Si el 
equipo de desarrollo no logra entablar una buena comunicación con los usuarios, el riesgo de implementación deficiente aumenta.

\section{Evaluación del consenso para implementar el proyecto de software}

En el presente punto se verifica la hipótesis componente y se analiza cómo opinaron los encuestados respecto a la pregunta 6 de la encuesta: "entre los sectores medios de la organización, ¿predominaba una actitud de consenso para implementar el proyecto?".

\section{Opciones: SI / NO /NO SABE}

Como se aprecia en la siguiente tabla de contingencia, se corrobora la hipótesis que: "existe relación estadísticamente significativa entre la implementación de proyectos de software y el consenso para implementar el proyecto". El valor de $\mathrm{p}<0,0001$ correspondiente al estadístico Chi cuadrado de Pearson es $<$ que 0.05 .

Tabla 17: de contingencia (Consenso para la implementación)

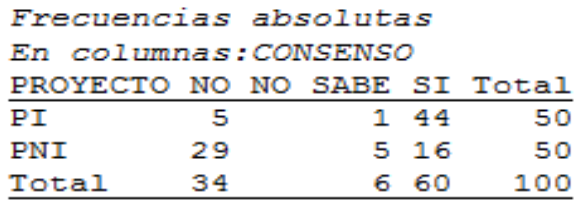

\begin{tabular}{lrrrc}
\multicolumn{1}{c}{ Estadistico } & Valor & g1 & p \\
\hline Chi Cuadrado Pearson & 32,67 & 2 & $<0,0001$ \\
Chi Cuadrado MV-G2 & 35,24 & 2 & $<0,0001$ \\
Coef. Conting. Cramer & 0,40 & & \\
Coef. Conting. Pearson & 0,50 & & \\
\hline
\end{tabular}

Si consideramos el total de proyectos (100),

- Las opiniones sobre predominio de consenso se distribuyeron en un $73 \%$ sobre los proyectos implementados, y un $27 \%$ sobre los no implementados.

- En cambio, las opiniones sobre ausencia de "consenso" se distribuyeron en un $85 \%$ sobre los proyectos no implementados y un $15 \%$ sobre los implementados. 

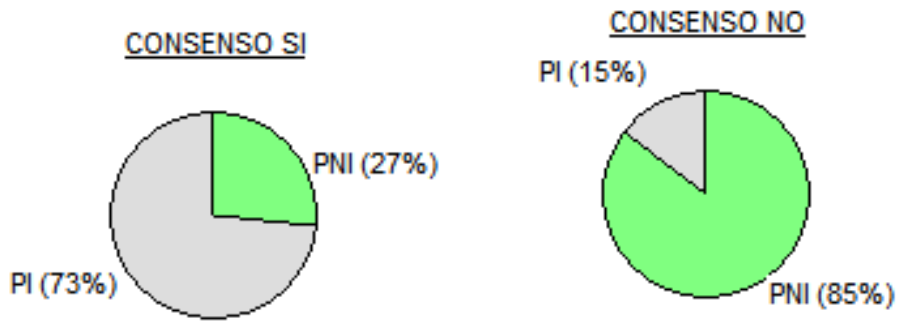

\section{CONSENSO NO SABE}

$\mathrm{PI}(17 \%)$

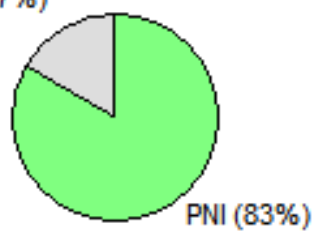

Figura 24: (Consenso para la implementación respecto al total de proyectos PI: Proyectos Implementados - PNI: Proyectos No Implementados)

Ahora bien, si queremos medir cómo se distribuyó el predominio del consenso por resultado final del proyecto:

- En los proyectos implementados (50), para el $88 \%$ de las opiniones, predominaba el consenso.

- En cambio, en los proyectos no implementados (50), solo el $32 \%$ de las opiniones detectaron ese síntoma.

- La diferencia es significativa.

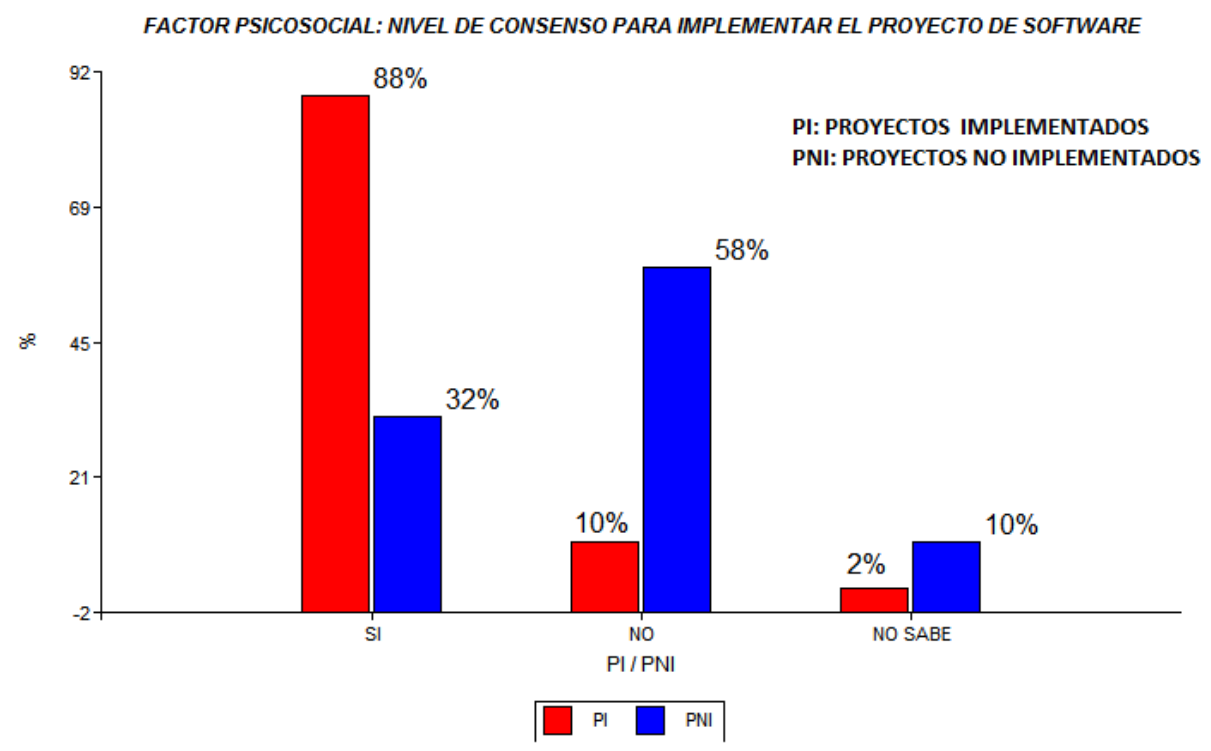

Figura 25: (Comunicación con el usuario por tipo de proyecto PI / PNI) 
El análisis realizado refleja un hecho obvio pero frecuentemente desestimado: el nivel de consenso representa una medida del riesgo psicosocial que enfrenta un proyecto de software. La mayoría de los proyectos de software que no se implementan evidencian un bajo nivel de consenso, especialmente en los stakeholders pertenecientes a los niveles jerárquicos medios de las organizaciones.

\section{Evaluación de Estilo de Mando. Estilos de Priorización de Requerimientos}

A continuación se presenta el análisis de los resultados y se verifica la hipótesis componente relacionada con la pregunta 7 de la encuesta: "En la etapa de priorización de requerimientos por parte de la gerencia, ¿que estilo era más asiduamente utilizado: el subjetivo o el objetivo?"

\section{Opciones: ESTILO SUBJETIVO / ESTILO OBJETIVO.}

Como se observa en la siguiente tabla de contingencia, el valor de $p$ correspondiente al estadístico Chi Cuadrado de Pearson supera al valor 0,05 . Por lo tanto, no resulta posible rechazar la hipótesis nula, la cual sostiene la independencia entre las variables: implementación de proyectos y estilos de priorización de requerimientos por parte de la gerencia (objetivo / subjetivo).

Resultado Final del Proyecto $\rightarrow$ PI: Proyecto Implementado - PNI: Proyecto No Implementado.

Tabla 18: de contingencia (estilo de mando / priorización de requerimientos)

Frecuencias absolutas
En columnas: ESTILO
\begin{tabular}{llrr} 
Proyecto & OBJETIVO & SUBJETIVO & Total \\
\hline IMP & 34 & 16 & 50 \\
NO IMPL & 28 & 22 & 50 \\
Total & 62 & 38 & 100 \\
\hline
\end{tabular}

\begin{tabular}{lrrc}
\multicolumn{1}{c}{ Estadistico } & Valor & gl & p \\
\hline Chi Cuadrado Pearson & 1,53 & 1 & 0,2164 \\
Chi Cuadrado MV-G2 & 1,53 & 1 & 0,2157 \\
Irwin-Fisher bilateral & 0,12 & & 0,2259 \\
Coef.Conting.Cramer & 0,09 & & \\
Coef.Conting.Pearson & 0,12 & & \\
Coeficiente Phi & 0,12 & & \\
\hline
\end{tabular}

Si consideramos el total de proyectos (100),

- Las opiniones sobre objetividad se distribuyeron en la encuesta de la siguiente manera. Un $55 \%$ consideraron que predominaba objetividad en los proyectos implementados, y un $45 \%$ percibieron 
el mismo síntoma sobre los no implementados.

- Similarmente, las opiniones sobre subjetividad se distribuyeron en un $42 \%$ sobre los proyectos no implementados y un $58 \%$ sobre los implementados.

Como puede apreciarse, tanto la objetividad como la subjetividad en los estilos de priorización de requerimientos, evidenciaron valores altos.

\section{ESTILO SUBJETNO}

$\mathrm{PI}(42 \%)$

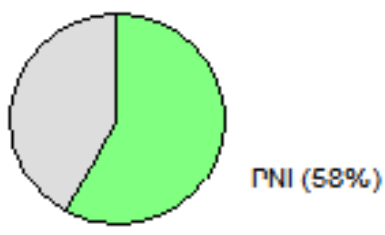

ESTILO OBJETINO

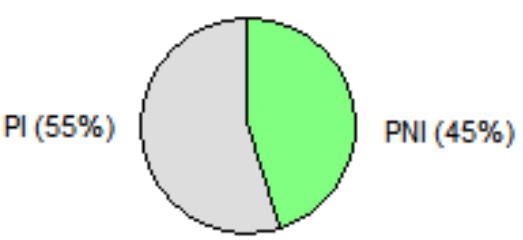

Figura 26: (Estilo de mando/Priorización de requerimientos respecto al total de proyectos) PI: Proyectos No Implementados - PNI: Proyectos No Implementados

Por otro lado, si se desea medir cómo se distribuyó la subjetividad en el proceso de priorización de requerimientos por resultado final del proyecto, se tiene que:

- En los proyectos implementados (50), para el $32 \%$ de las opiniones, hubo subjetividad.

- En los proyectos no implementados (50), el $44 \%$ de las opiniones detectaron ese síntoma. 


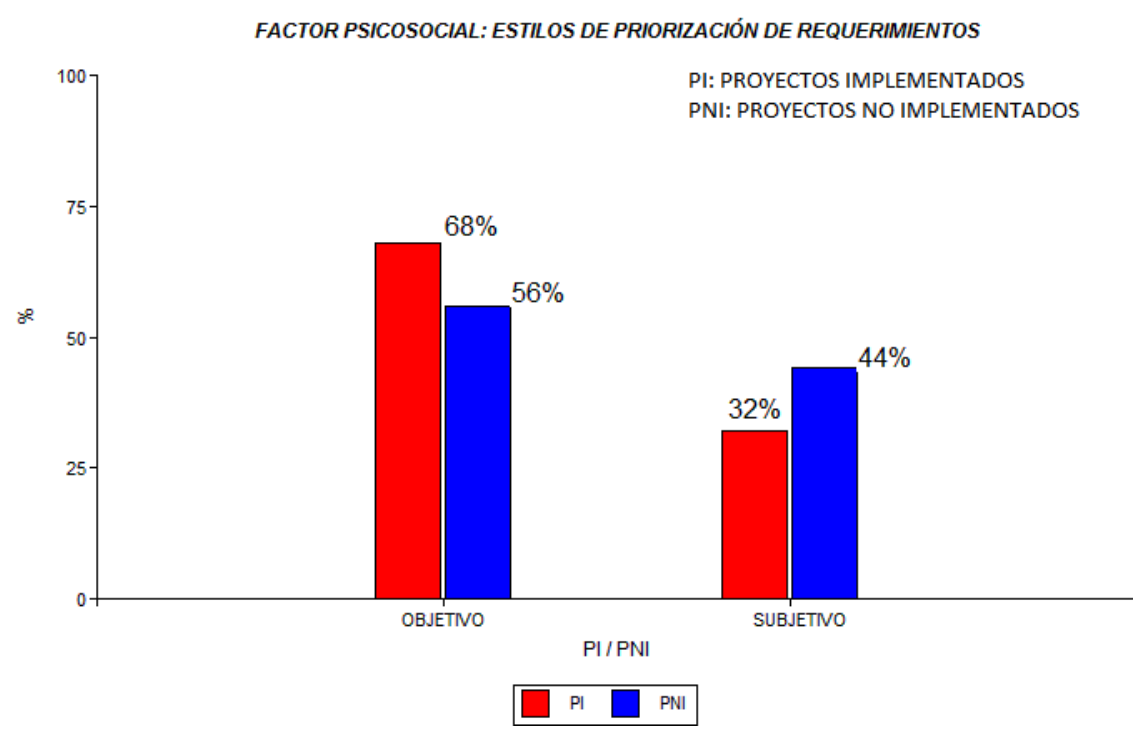

Figura 27: (Estilo de mando/priorización de requerimientos por tipo de proyecto $\mathrm{PI} / \mathrm{PNI}$ )

Los valores obtenidos no han sido lo suficientemente categóricos como para corroborar nuestra hipótesis, ya que no fue posible observar una relación estadísticamente significativa entre las variables: implementación de los proyectos de software y estilos de priorización de requerimientos.

Nuestra postura aquí concuerda con lo vertido en el capítulo 2, el cual sostiene que durante la gestión de requerimientos se combinan aspectos positivos y negativos inherentes a la subjetividad. En ella, se compensan por ejemplo cuestiones como la intuición de los desarrolladores para captar requerimientos o la arbitrariedad vigente en la toma de decisiones. Estas virtudes y defectos terminan por debilitar la existencia de una relación significativa entre estilos de priorización e implementación.

\section{Evaluación del nivel de estrés en la organización}

Se describe a continuación la verificación de la hipótesis componente y la interpretación de las opiniones de los encuestados respecto a la pregunta 8 de la encuesta: "en la etapa de requerimientos, ¿cómo era el nivel de estrés laboral de los involucrados que usted percibió entre los empleados?

Opciones: INTENSO / NORMAL /BAJO.

Como se observa en la siguiente tabla de contingencia, el valor de $p=$ 0,0159, correspondiente al estadístico Chi Cuadrado de Pearson, es inferior a 0,05, por lo que se corrobora nuestra hipótesis, es decir existe relación estadísticamente significativa entre las variables: implementación 
de proyectos de software y nivel de estrés laboral de la organización donde funcionará el software.

Resultado Final del Proyecto $\rightarrow$ PI: Proyecto Implementado - PNI: Proyecto No Implementado.

Tabla 19: de contingencia (nivel de estrés en la organización.)

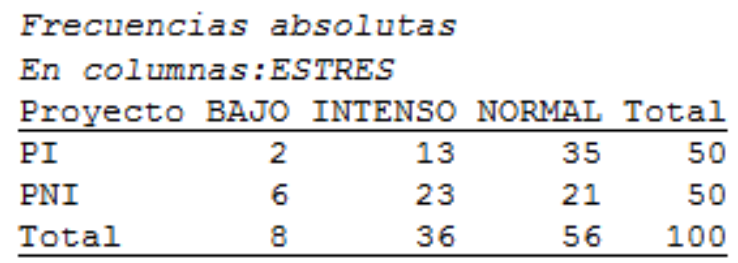

\begin{tabular}{lrrrc}
\multicolumn{1}{c}{ Estadístico } & Valor & gl & p \\
\hline Chi Cuadrado Pearson & 8,28 & 2 & 0,0159 \\
Chi Cuadrado MV-G2 & 8,45 & 2 & 0,0147 \\
Coef. Conting.Cramer & 0,20 & & \\
Coef.Conting.Pearson & 0,28 & & \\
\hline
\end{tabular}

Si consideramos el total de proyectos (100), y medimos el nivel de estrés laboral, se tiene que:

- Las opiniones que detectaron intensos niveles de estrés fueron percibidas en un $36 \%$ sobre los proyectos implementados, y un 64 $\%$, sobre los no implementados.

- Similarmente, las opiniones que detectaron bajos niveles de estrés lo hicieron en un $25 \%$ sobre los implementados y en un $75 \%$ sobre los proyectos no implementados.

Es decir, según la opinión de los encuestados, los proyectos de software implementados no estuvieron expuestos a altos y bajos niveles de estrés.

En cambio, los proyectos que no lograron implementarse tuvieron considerable influencia proveniente tanto de los altos niveles de estrés como de los bajos. 


\section{ESTRES INTENSO}

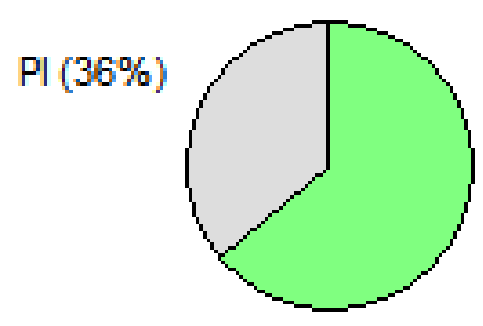

PNI (64\%)

\section{ESTRES NORMAL}

$\mathrm{PI}(63 \%)$

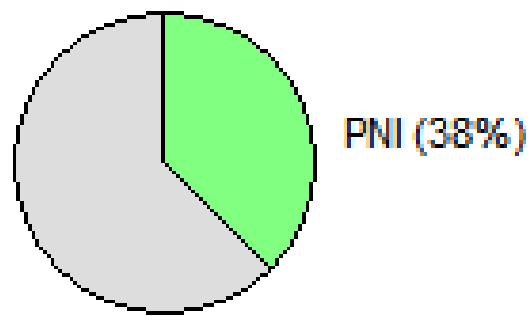

\section{ESTRES BAJO}

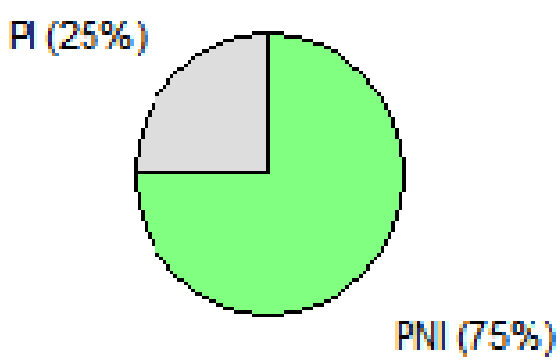

Figura 28: Nivel de estrés en la organización respecto al total de proyectos- PI: Proyectos Implementados PNI: Proyectos No Implementados

Por otra parte, si queremos medir cómo se distribuyó el nivel de estrés por resultado final del proyecto:

- En los proyectos implementados (50), el $26 \%$ de las opiniones detectaron intensos niveles de estrés.

- En cambio, en los proyectos no implementados (50), el $46 \%$ de las opiniones percibieron ese síntoma. 


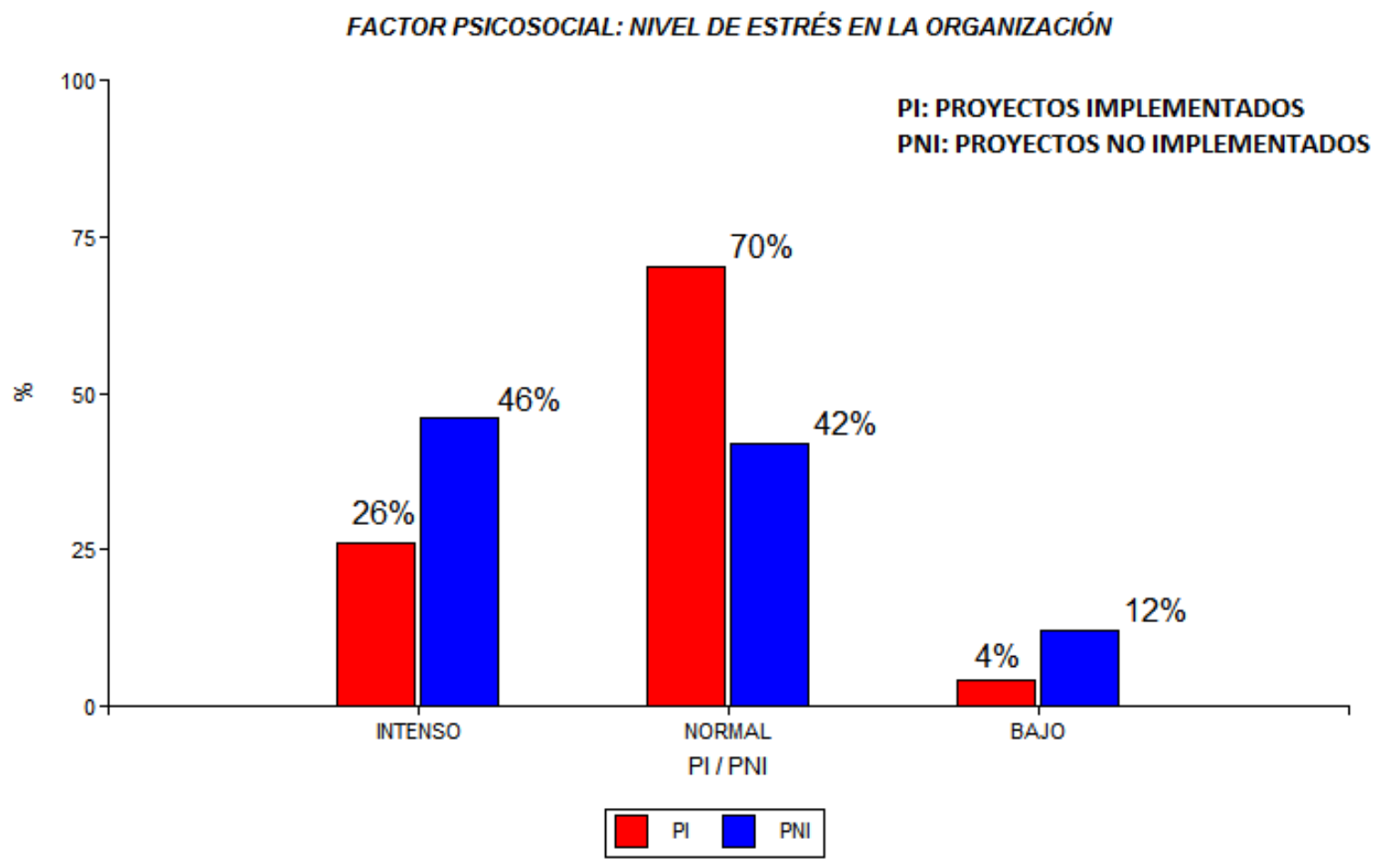

Figura 29: Nivel de estrés en la organización por tipo de proyecto PI/PNI

Los resultados confirman las teorías descriptas en el capítulo 2 sobre cómo condiciona el estrés el rendimiento de las personas en su trabajo.

Los datos aportados por la encuesta, nos deja una importante conclusión: "es tan perjudicial para la implementación de proyectos de software, que exista exposición de los stakeholders a intensos niveles de estrés, como a bajos niveles".

Parece ser que la clave está en gestionar el estrés en su justa medida.

No sería una idea descabellada que durante la etapa de requerimientos el equipo de desarrollo efectúe consultas a profesionales de la psicología para establecer el estrés presente en una organización como una medida del riesgo que afronta un proyecto de software.

\section{Evaluación de la participación. Actitud de los usuarios claves}

Seguidamente se exhibe la corroboración de la hipótesis y el análisis de las opiniones de los encuestados relacionadas con la pregunta 10 de la encuesta: "en la etapa de requerimientos, ¿cómo era la actitud de los usuarios claves que conocían en detalle las funcionalidades que se pretendían implementar con el proyecto?"

Opciones: COLABORATIVA - NORMAL - POCO COLABORATIVA. 
Como se aprecia en la siguiente tabla de contingencia, el valor de $p<$ 0,0001 correspondiente al estadístico Chi Cuadrado de Pearson es notablemente inferior a 0,05 , por lo que se corrobora hipótesis componente, es decir: "existe relación estadísticamente significativa entre la implementación de proyectos y la actitud de los usuarios claves".

Resultado Final del Proyecto $\rightarrow$ PI: Proyecto Implementado - PNI: Proyecto No Implementado.

Tabla 20: de contingencia (Participación. Actitud de los usuarios claves)

\begin{tabular}{|c|c|c|c|c|c|}
\hline \multicolumn{6}{|c|}{ Frecuencias absolutas } \\
\hline \multicolumn{6}{|c|}{ En columnas:ACTITUD } \\
\hline PROYECTO & COLABORATIVA & NORMAL & $\mathrm{POCO}$ & COLABORATIVA & Total \\
\hline $\mathrm{PI}$ & 29 & 17 & & 4 & 50 \\
\hline PNI & 10 & 14 & & 26 & 50 \\
\hline Total & 39 & 31 & & 30 & 100 \\
\hline
\end{tabular}

\begin{tabular}{lrrr}
\multicolumn{1}{c}{ Estadistico } & Valor & gl & p \\
\hline Chi Cuadrado Pearson & 25,68 & 2 & $<0,0001$ \\
Chi Cuadrado MV-G2 & 27,98 & $2<0,0001$ \\
Coef. Conting. Cramer & 0,36 & & \\
Coef. Conting. Pearson & 0,45 & & \\
\hline
\end{tabular}

Si se considera el total de proyectos (100), y se evalúa la actitud de los usuarios claves, surge que:

- Las opiniones que percibieron actitudes colaborativas por parte de los usuarios claves recayeron en un $74 \%$ sobre los proyectos implementados, y en un $26 \%$ sobre los no implementados.

- En cambio, las opiniones sobre actitudes poco colaborativas se distribuyeron en un $87 \%$ afectando a los proyectos no implementados y en un $13 \%$ sobre los implementados. 


\section{ACTITUD COLABORATINA}
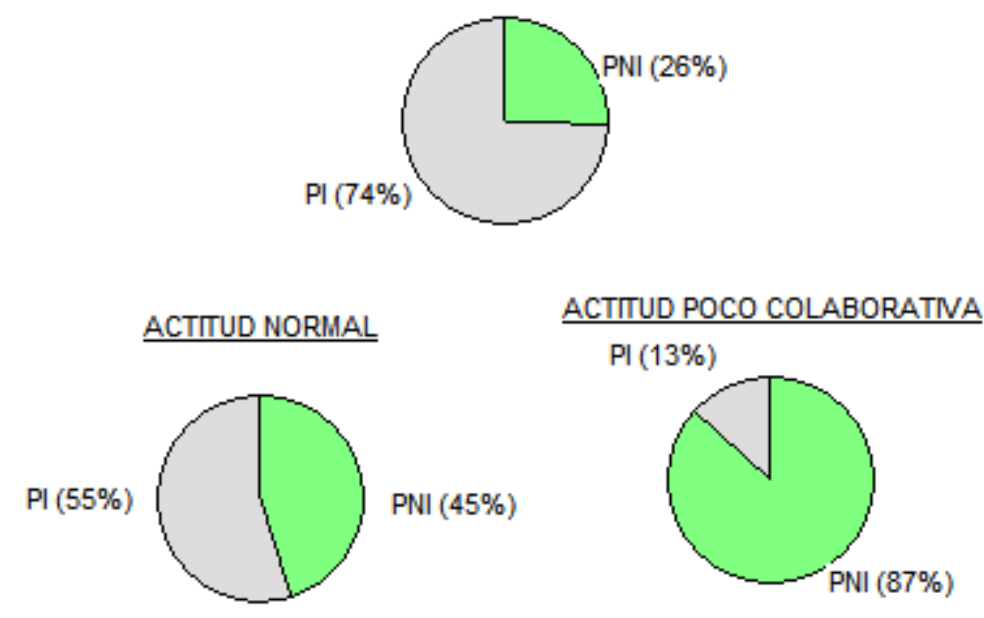

Figura 30: Participación. Actitud de los usuarios claves respecto al total de proyectos- PI: Proyectos Implementados PNI: Proyectos No Implementados

Por otra parte, si se requiere medir cómo se distribuyó el nivel de colaboración por resultado final del proyecto, se tiene que:

- En los proyectos implementados (50), para el $58 \%$ de las opiniones predominaba una actitud colaborativa de parte de los usuarios claves.

- En cambio, en los proyectos no implementados (50), solo el $20 \%$ de las opiniones detectaron colaboración.

FACTOR PSICOSOCIAL: PARTICIPACIÓN. ACTITUD DE LOS USUSARIOS CLAVES

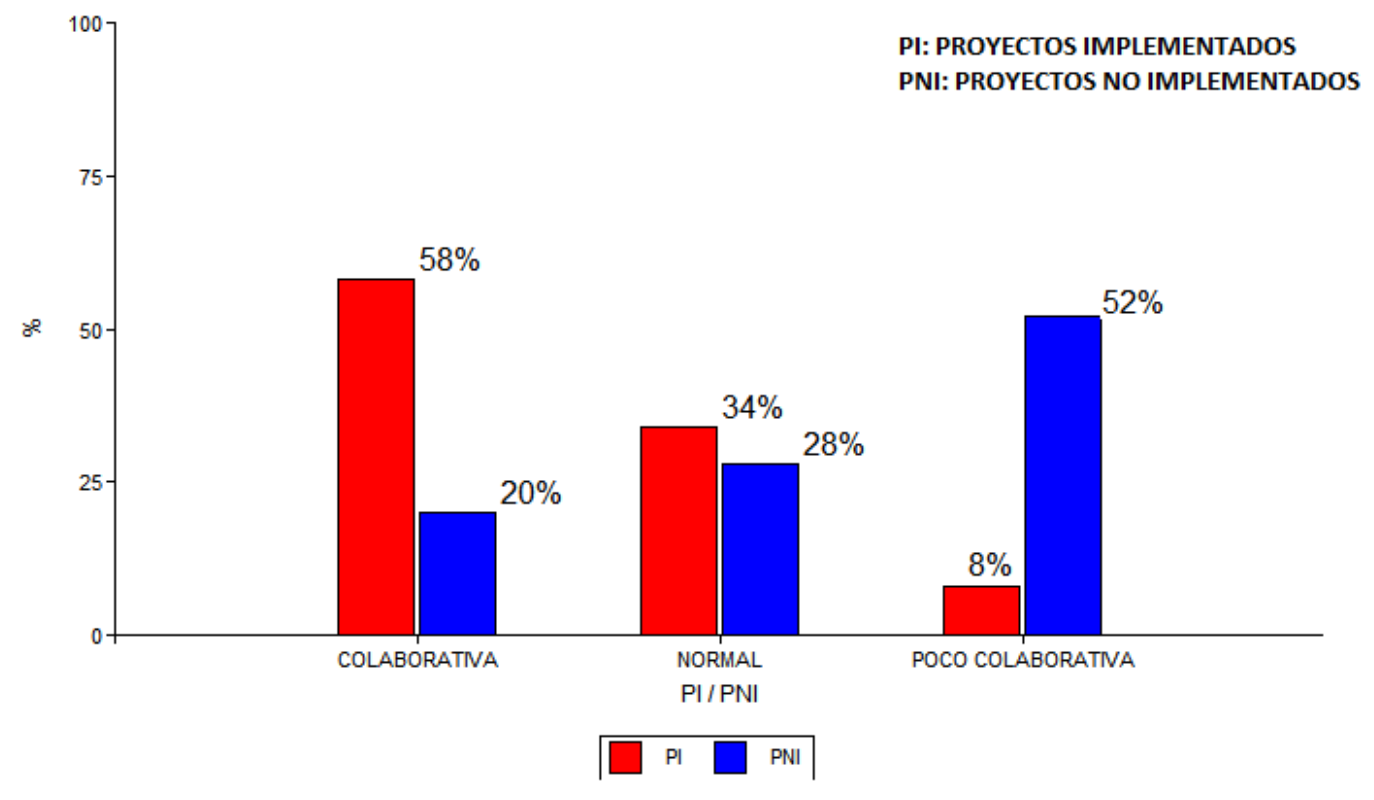

Figura 31: Participación. Actitud de los usuarios claves por tipo de proyecto PI/PNI 
Los resultados reflejan lo descripto en el capítulo 3, punto 3.1.4, en lo referente a que determinados usuarios obstaculizan el proyecto para no exponerse a una potencial pérdida de poder. En la otra vereda se ubican los stakeholders que aprecian una oportunidad con la implementación del proyecto para incrementar las posibilidades de incrementar su protagonismo. En síntesis, se aprecia en las opiniones una marcada escasez de colaboración de los usuarios claves en aquellos proyectos que no lograron implementarse $\mathrm{e}$, inversamente, una actitud altamente colaborativa en los proyectos implementados con éxito.

\section{Evaluación del nivel de conflictos en la organización}

Se describe a continuación la verificación de la hipótesis componente y la interpretación de las opiniones de los encuestados respecto a la pregunta 12 de la encuesta: "en la etapa de requerimientos, ¿cómo era el nivel general de conflictos en la organización?"

\section{Opciones: ALTO / MEDIO / BAJO.}

Como se observa en la siguiente tabla de contingencia, el valor de $\mathrm{p}<$ 0,0001 correspondiente al estadístico Chi Cuadrado de Pearson, es inferior a 0,05 , por lo que se corrobora nuestra hipótesis, es decir existe relación estadísticamente significativa entre las variables: implementación de proyectos de software y nivel de conflictos de la organización donde funcionará el software. 
Tabla 21: de contingencia (Nivel de conflictos en la organización)

\begin{tabular}{|c|c|c|c|c|}
\hline $\begin{array}{l}\text { Frecuenc } \\
\text { En colum. }\end{array}$ & $\begin{array}{l}\text { ias a } \\
\text { has :C }\end{array}$ & ONFLI & $\begin{array}{l}\text { tas } \\
\operatorname{ctos}\end{array}$ & \\
\hline PROYECTO & ALTO & BAJO & MEDIO & Total \\
\hline PI & 5 & 27 & 18 & 50 \\
\hline PNI & 21 & 9 & 20 & 50 \\
\hline Total & 26 & 36 & 38 & 100 \\
\hline
\end{tabular}

\begin{tabular}{lrrr}
\multicolumn{1}{c}{ Estadistico } & Valor & gl & \multicolumn{1}{c}{$\mathrm{p}$} \\
\hline Chi Cuadrado Pearson & 18,95 & 2 & 0,0001 \\
Chi Cuadrado MV-G2 & 20,11 & 2 & $<0,0001$ \\
Coef. Conting. Cramer & 0,31 & \\
Coef. Conting. Pearson & 0,40 & \\
\hline
\end{tabular}

Si se considera el total de proyectos (100), y se mide el nivel de conflictos presente en la organización donde se implementará el proyecto de software, resulta que:

- Las opiniones sobre detección de alto nivel de conflictos se distribuyeron con marcadas diferencias. Solo un $19 \%$ de los encuestados detectaron niveles altos de conflictos en los proyectos implementados, mientras que el restante $81 \%$ lo hizo sobre los no implementados.

- En cambio, las opiniones sobre bajo nivel de conflictos se distribuyeron inversamente, es decir un $75 \%$ de los encuestados detectaron bajo nivel sobre de conflictos en los proyectos implementados, mientras que un $25 \%$ lo percibió sobre los no implementados. 

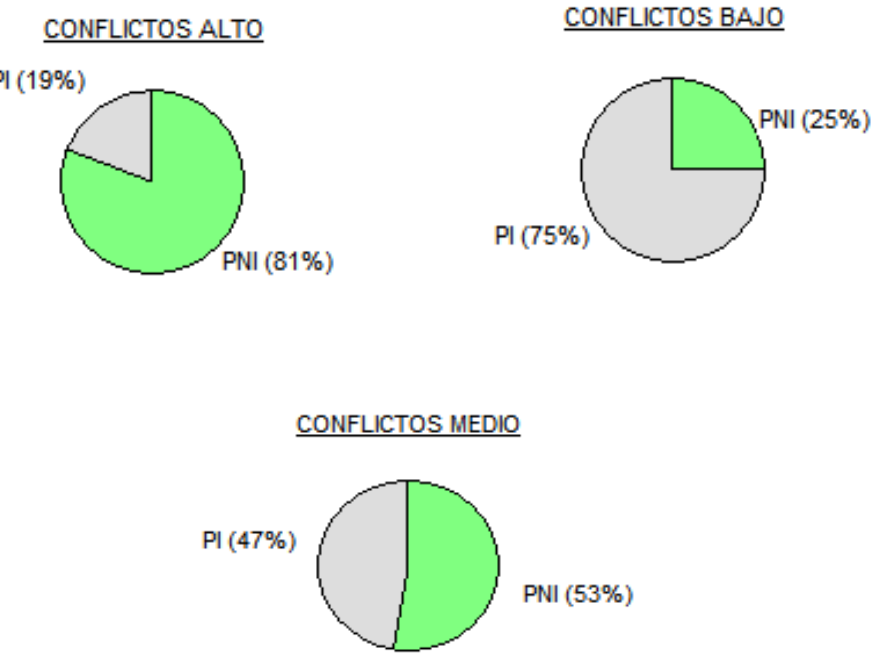

Figura 32: Nivel de conflictos en la organización respecto al total de proyectos- PI: Proyectos Implementados PNI: Proyectos No Implementados

Por otra parte, si se requiere evaluar cómo se distribuyó el nivel de conflictos de manera separada y por relación al resultado final del proyecto, se tiene que:

- En los proyectos no implementados (50), el $42 \%$ de las opiniones detectaron altos niveles de conflictos en la organización donde funcionará el software.

- En cambio, en los proyectos implementados (50), solo el $10 \%$ de las opiniones detectaron ese síntoma.

FACTOR PSICOSOCIAL: NIVEL DE CONFLICTOS EN LA ORGANIZACIÓN

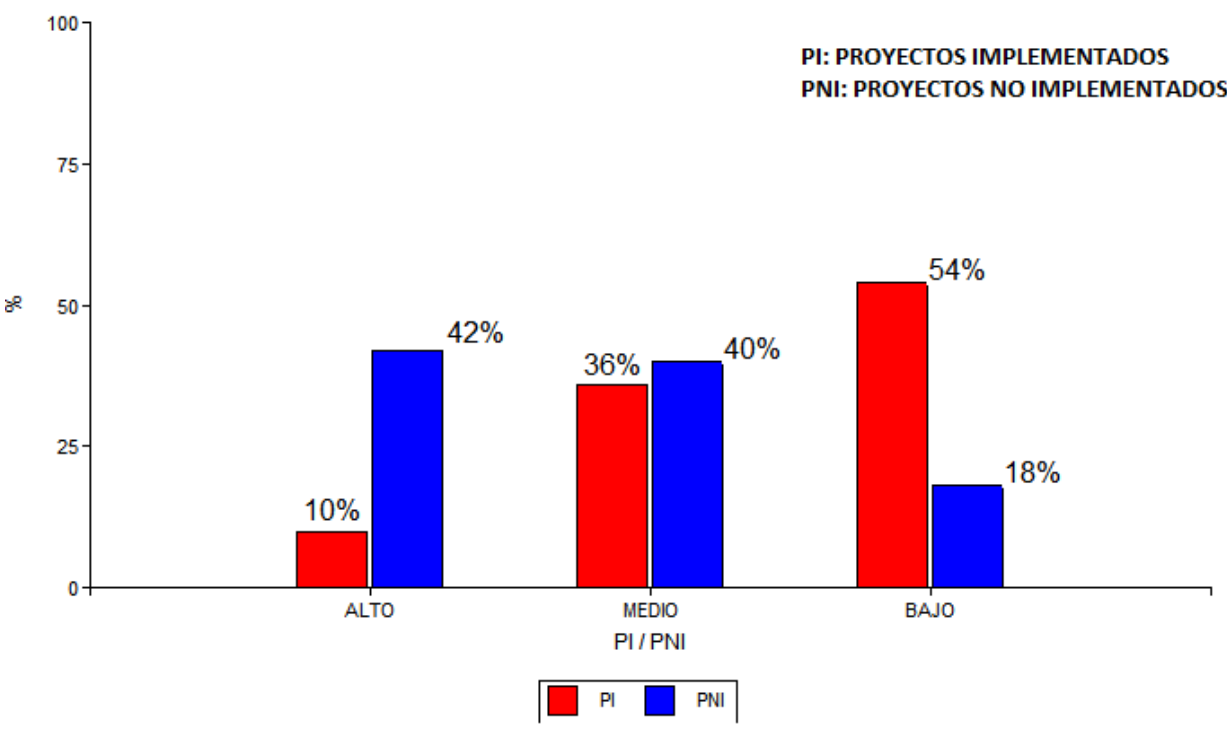

Figura 33: Nivel de conflictos en la organización por tipo de proyecto PI/PNI 
En síntesis, en función de las opiniones de los desarrolladores, todo parece indicar que el nivel de conflictos en la organización se encuentra relacionado de manera inversa a la tasa de implementación de proyectos de software. Es por ello, que este factor psicosocial podría ser utilizado por el equipo de desarrollo durante la etapa de requerimientos como un buen indicador del riesgo de implementación al que se expondrá el proyecto.

Evaluación de la información. Apertura a las iniciativas

Se presenta seguidamente la verificación de la hipótesis componente y la interpretación de las opiniones de los encuestados respecto a la pregunta 13 de la encuesta: "durante la etapa de requerimientos, ¿eran tenidas en cuenta por parte de la gerencia, las iniciativas innovadoras generadas por los empleados?"

Opciones: SI, NO, NO SABE.

Como se aprecia en la siguiente tabla de contingencia, el valor de $p<$ 0,0001 correspondiente al estadístico Chi Cuadrado de Pearson es inferior a 0,05, por lo que se corrobora nuestra hipótesis, es decir: existe relación estadísticamente significativa entre las variables: implementación de proyectos y apertura de la gerencia a las iniciativas de los empleados.

Resultado Final del Proyecto $\rightarrow$ PI: Proyecto Implementado - PNI: Proyecto No Implementado.

Tabla 22: de contingencia (Información. Apertura a las iniciativas)

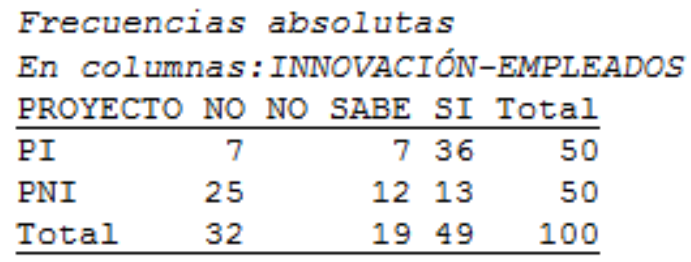

\begin{tabular}{lrrrc}
\multicolumn{1}{c}{ Estadístico } & Valor & gl & p \\
\hline Chi Cuadrado Pearson & 22,24 & $2<0,0001$ \\
Chi Cuadrado MV-G2 & 23,30 & $2<0,0001$ \\
Coef. Conting. Cramer & 0,33 & & \\
Coef. Conting. Pearson & 0,43 & & \\
\hline
\end{tabular}

Si se analiza el total de proyectos (100), y se evalúa cuál fue la opinión de los encuestados respecto al nivel de apertura de la gerencia a las iniciativas de sus empleados durante la etapa de requerimientos, se tiene que: 
- El porcentaje de opiniones que detectaron apertura fue del $73 \%$ para los proyectos implementados y del $27 \%$ para los no implementados.

- En cambio, la detección de escasa apertura fue del $78 \%$ para los proyectos no implementados y del $22 \%$ para los implementados.

\section{APERTURA A LAS INICIATINAS - SI}

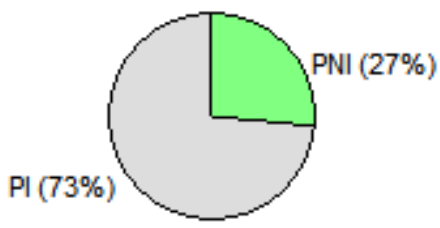

APERTURA A LAS INICIATIVAS - NO

$\mathrm{PI}(22 \%)$

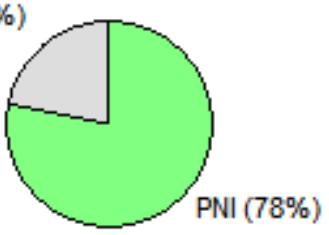

APERTURA A LAS INICIATIVAS: NO SABE

$\mathrm{PI}(37 \%)$

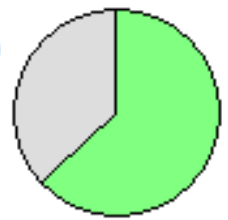

PNI (63\%)

Figura 34: Información. Apertura a las iniciativas respecto al total de proyectos- PI: Proyectos Implementados PNI: Proyectos No Implementados

Por otro lado si se requiere evaluar cómo se distribuyeron las opiniones de los encuestados pero sobre el resultado final del proyecto, se tiene que:

- En los proyectos implementados (50), el $72 \%$ de las opiniones detectaron alto nivel de apertura de la gerencia a las iniciativas innovadoras de los empleados.

- En cambio, en los proyectos no implementados (50), solo el $26 \%$ de las opiniones detectaron ese síntoma. 


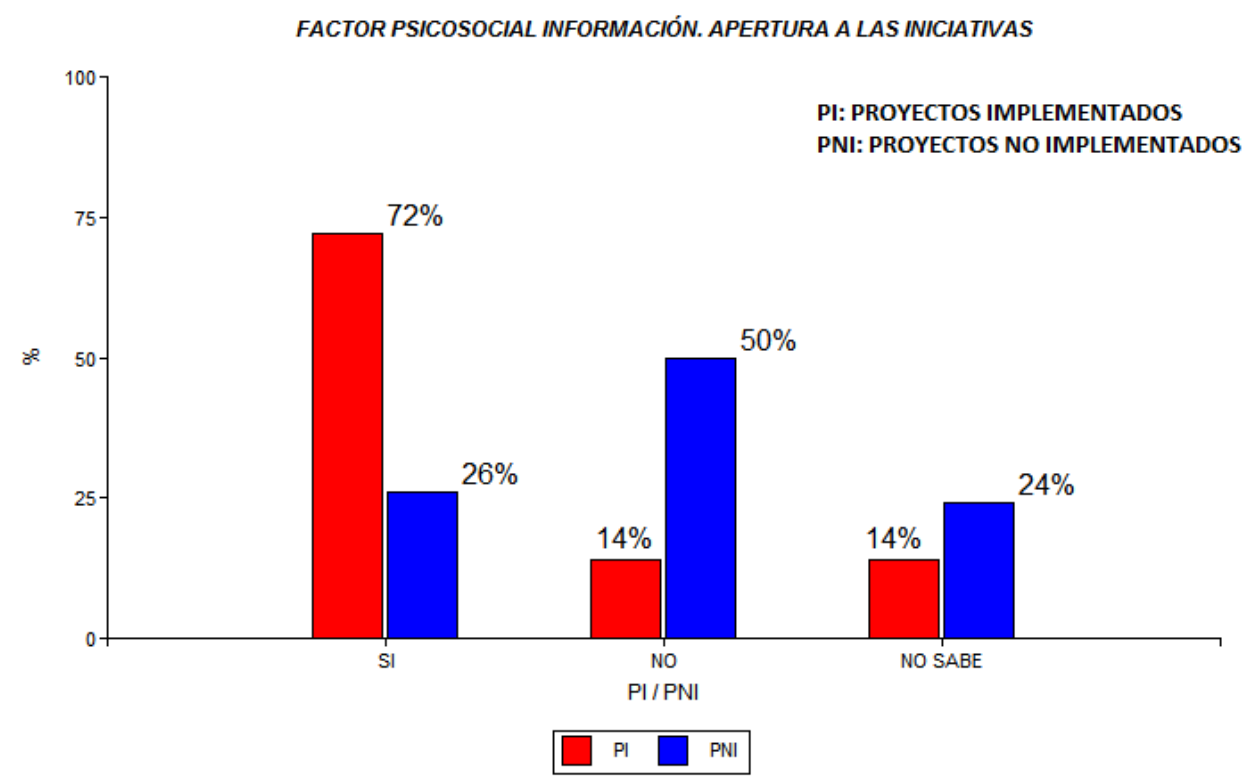

Figura 35: Información. Apertura a las iniciativas por tipo de proyecto PI/PNI

Parece confirmarse con la encuesta lo descripto en el capítulo 2, por [Baronas et al., 1988]: "cuando la gerencia favorece la participación de los empleados de la organización en la implementación de un sistema, éstos lo aceptarán más rápido y se adaptarán más fácilmente a sus cambios."

Nuestra posición coincide plenamente con la anterior: "Cuánto mayor sea la apertura de la gerencia a las iniciativas innovadoras de los empleados, mejores serán los resultados que se obtienen en las implementaciones de los proyectos de software."

\section{Evaluación de la motivación para implementar el proyecto}

Seguidamente se describe la corroboración de la hipótesis y el análisis de las opiniones de los encuestados relacionadas con la pregunta 14 de la encuesta: "en la etapa de requerimientos, ¿la gerencia se involucró activamente en el proyecto?"

Opciones: SI, NO, NO SABE.

Como se puede apreciar en la siguiente tabla de contingencia, el valor de $p$ $<0,0001$ correspondiente al estadístico Chi Cuadrado de Pearson es inferior a 0,05, con lo que se corrobora la hipótesis, es decir: existe relación estadísticamente significativa entre las variables: implementación de proyectos de software y motivación para lograrlo. 
Tabla 23: de contingencia (Motivación para implementar el proyecto)

\begin{tabular}{|c|c|c|c|c|}
\hline \multicolumn{5}{|c|}{ Frecuencias absolutas } \\
\hline PROYECTO & NO NO & $S A B E$ & SI & Total \\
\hline$\overline{\mathrm{PI}}$ & 6 & 2 & 42 & 50 \\
\hline PNI & 29 & 6 & 15 & 50 \\
\hline Total & 35 & 8 & 57 & 100 \\
\hline
\end{tabular}

\begin{tabular}{lrrrc}
\multicolumn{1}{c}{ Estadístico } & Valor & gl & p \\
\hline Chi Cuadrado Pearson & 29,90 & $2<0,0001$ \\
Chi Cuadrado MV-G2 & 31,86 & $2<0,0001$ \\
Coef. Conting. Cramer & 0,39 & & \\
Coef. Conting. Pearson & 0,48 & & \\
\hline
\end{tabular}

Si se enfoca el análisis el total de proyectos (100), y se evalúa cuál fue la opinión de los encuestados respecto al nivel de motivación de la gerencia para implementar el proyecto durante la etapa de requerimientos, resulta que:

- Las opiniones que detectaron motivación alcanzaron los porcentajes de $74 \%$ para los proyectos implementados y de $26 \%$ para los no implementados.

- En cambio, la detección de carencia de motivación fue del 83 \% en los proyectos no implementados y del $17 \%$ en los implementados.

MOTIVACIÓN SI
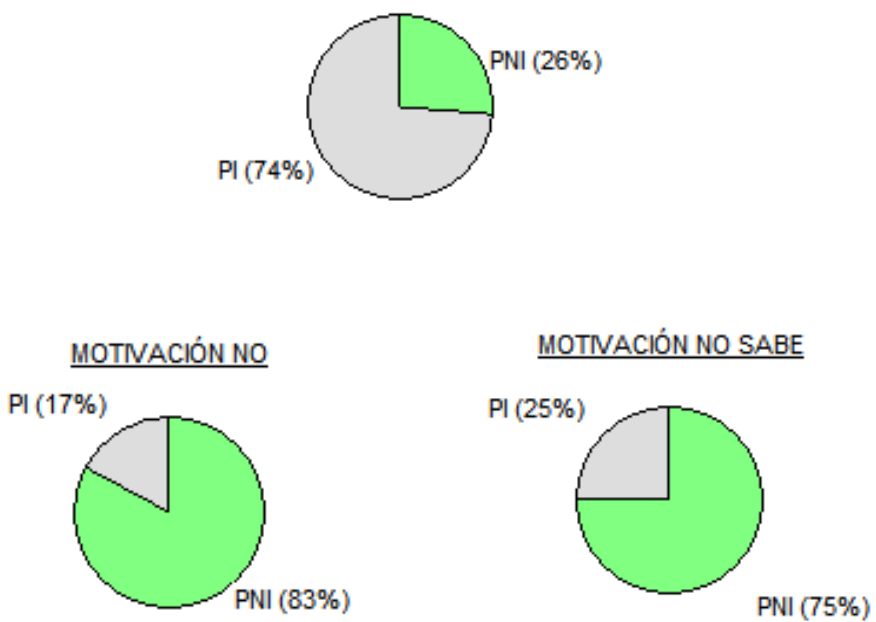

Figura 36: Motivación para implementar el proyecto sobre el total de proyectos- PI: Proyectos Implementados PNI: Proyectos No Implementados 
Por otro lado, si se requiere evaluar cómo se distribuyeron las opiniones de los encuestados sobre el mismo ítem pero en relación al resultado final del proyecto por separado, se tiene que:

- En los proyectos implementados (50), el $84 \%$ de las opiniones detectaron evidente motivación de la gerencia para implementar el proyecto.

- En cambio, en los proyectos no implementados (50), solo el $30 \%$ de las opiniones detectaron ese síntoma.

FACTOR PSICOSOCIAL MOTIVACIÓN PARA IMPLEMENTAR EL PROYECTO

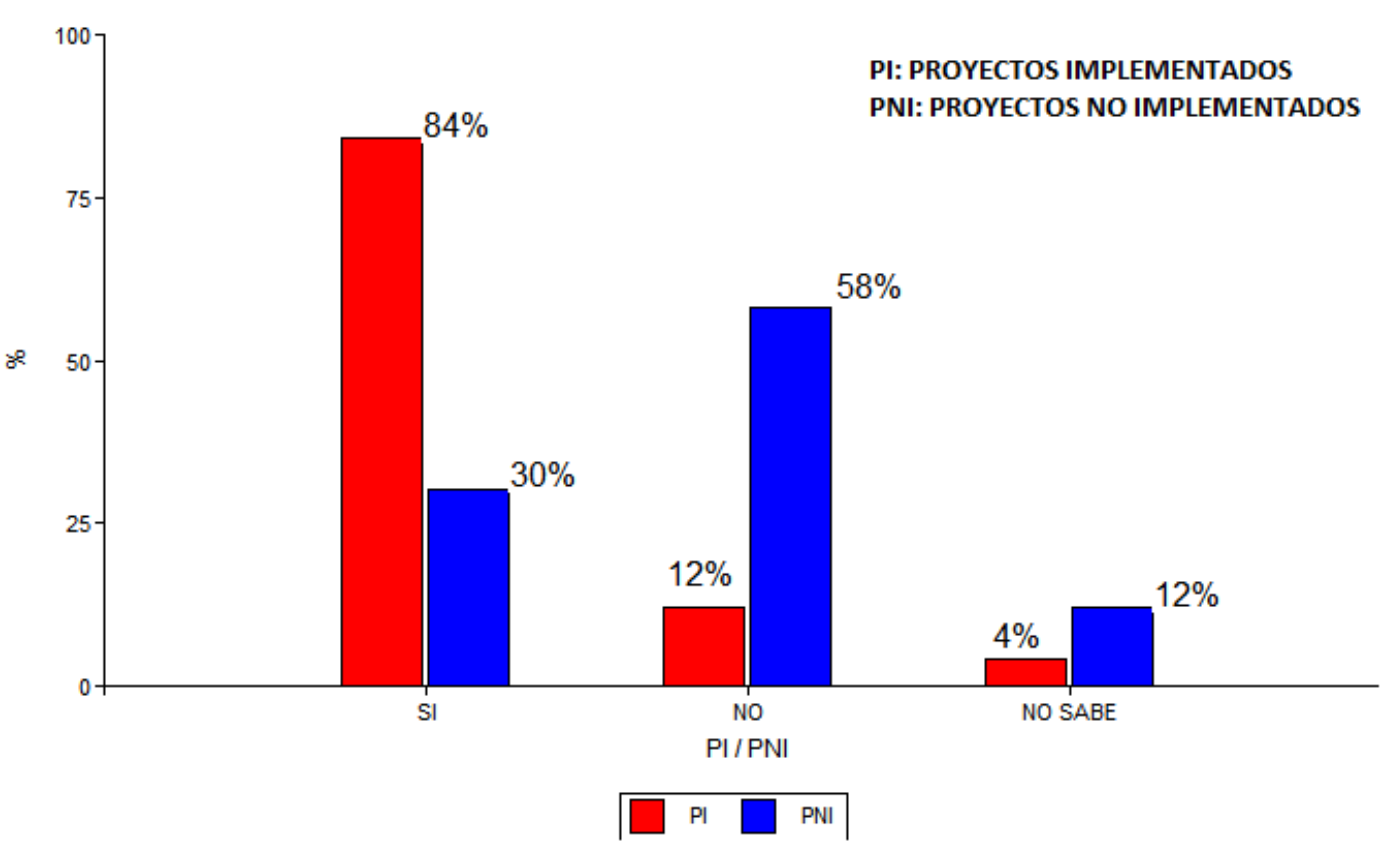

Figura 37: Motivación para implementar el proyecto por tipo de proyecto PI/PNI

Según las opiniones de los desarrolladores, cuánto más motivada e involucrada esté la gerencia de la organización con el proyecto de software, mejores serán los resultados de su implementación.

A mayor motivación, mayor chance de implementación.

En concordancia con lo descripto en el capítulo 3, punto 3.1.7, esta investigación coincide con [Markus, 1983] cuando sostiene que "la motivación del individuo puede producir un cambio dramático en la implementación por lo que, para bien o para mal, introducir una mejor solución metodológica de desarrollo de software no es suficiente para garantizan resultados favorables." 
El hecho de detectar, durante la gestión de requerimientos, el nivel de motivación que evidencia la gerencia para implementar el proyecto, puede constituirse en un recurso de utilidad para estimar el riesgo que éste afronta.

\section{Evaluación de la apertura a las tecnologías}

Se presenta a continuación la verificación de la hipótesis y la interpretación de las opiniones de los encuestados respecto a la pregunta 15 de la encuesta: "en la etapa de requerimientos, "¿en general cuál era la actitud de los futuros usuarios respecto a las nuevas funcionalidades que traía consigo el proyecto de software?

\section{Opciones: A GUSTO, LO ACEPTARON CON ESFUERZO, SE OPUSIERON}

Como muestra la siguiente tabla de contingencia, el valor de $p<0,0001$ correspondiente al estadístico Chi Cuadrado de Pearson es inferior a 0,05, con lo que se corrobora la hipótesis, es decir: "existe relación estadísticamente significativa entre la implementación de proyectos de software y la actitud de los usuarios respecto a las nuevas tecnologías"

Resultado Final del Proyecto $\rightarrow$ PI: Proyecto Implementado - PNI: Proyecto No Implementado.

Tabla 24: de contingencia (Apertura a la tecnología)

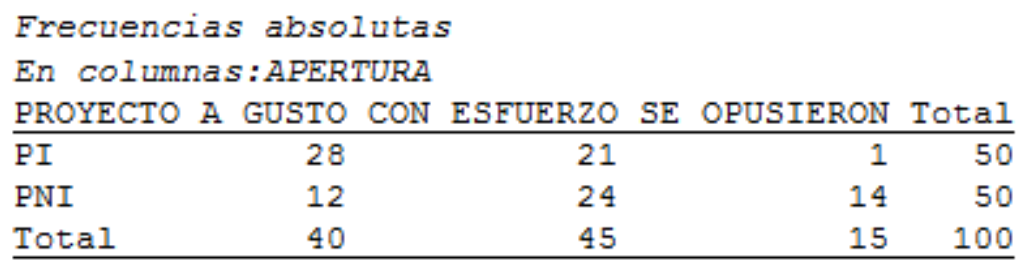

\begin{tabular}{lrrr}
\multicolumn{1}{c}{ Estadístico } & Valor & gl & \multicolumn{1}{c}{$p$} \\
\hline Chi Cuadrado Pearson & 17,87 & 2 & 0,0001 \\
Chi Cuadrado MV-G2 & 20,23 & 2 & $<0,0001$ \\
Coef. Conting. Cramer & 0,30 & & \\
Coef. Conting. Pearson & 0,39 &
\end{tabular}

Si se toman en cuenta el total de proyectos (100), y se evalúa cuál fue la opinión de los encuestados, resulta ser que:

- Se detectó para los proyectos implementados un porcentaje del 70 $\%$ de opiniones "a gusto" de los usuarios con las nuevas 
tecnologías que traía consigo el proyecto. Para los proyectos no implementados ese porcentaje fue del $30 \%$.

- En cambio, la detección de actitud "de oposición" fue del 93 \% para los proyectos no implementados y del $7 \%$ para los implementados.
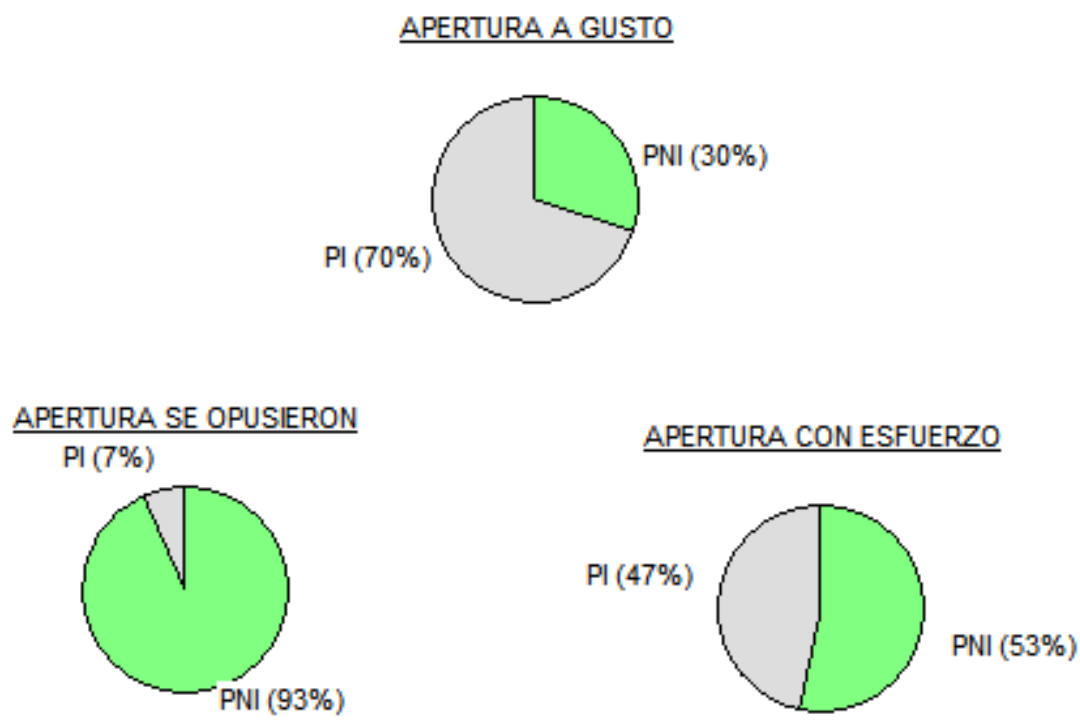

Figura 38: Apertura a la tecnología respecto al total de proyectos- PI: Proyectos Implementados PNI: Proyectos No Implementados

Desde otra perspectiva, si se evalúa cómo se distribuyeron las opiniones de los encuestados sobre el mismo ítem pero en relación al resultado final del proyecto por separado, se tiene que:

- En los proyectos implementados (50), el $56 \%$ de las opiniones detectaron que los usuarios se sentían "a gusto" con las nuevas tecnologías que traía consigo el proyecto.

- En cambio, en los proyectos no implementados (50), esa sensación alcanzó solo el $24 \%$ de las opiniones. 


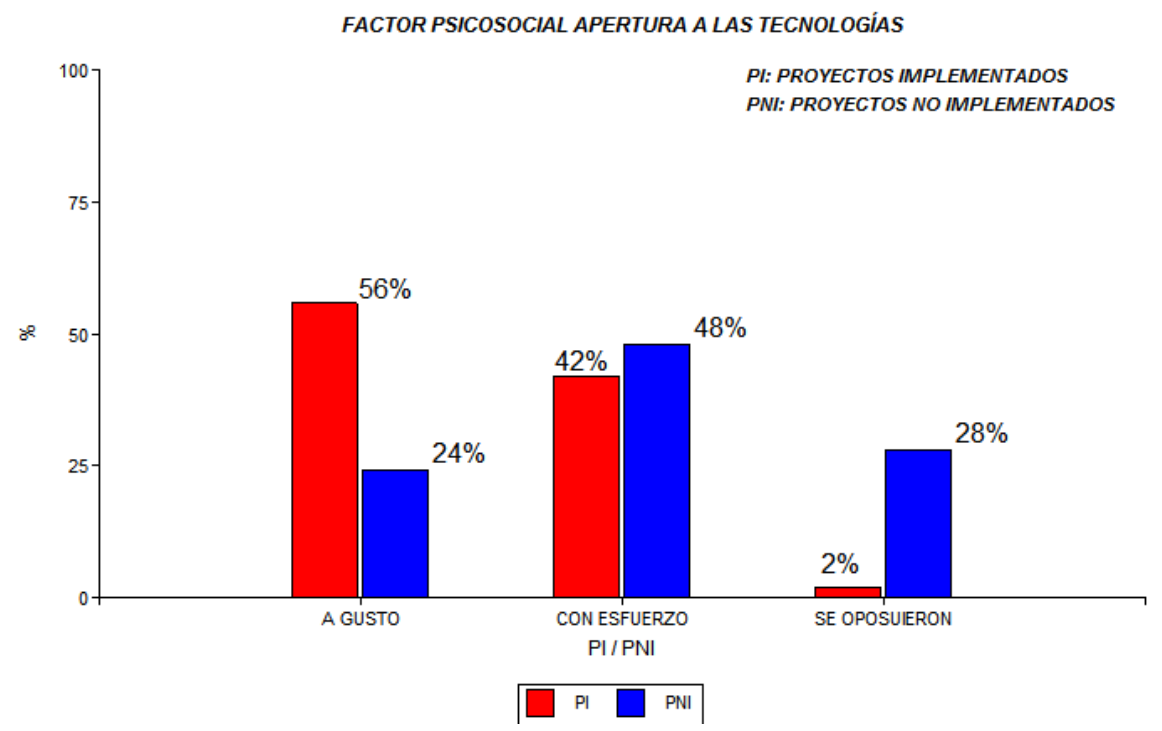

Figura 39: Apertura a la tecnología por tipo de proyecto PI/PNI

Es notorio que a medida que se acrecienta el nivel de oposición de los usuarios a las tecnologías que se incorporan, mayor riesgo de implementación afrontará el proyecto de software. Como se mencionó en el capítulo 3, punto 3.1.8, esta investigación coincide con [Manross et al.,1986] cuando afirma que: "La introducción, plena implementación y adopción con éxito de nuevas tecnologías en las organizaciones se logrará sólo si primero éstas son aceptadas por quienes las van a utilizar."

\section{Evaluación de la formación. Acceso de los usuarios a la capacitación}

Se presenta a continuación la verificación de la hipótesis y la interpretación de las opiniones de los encuestados respecto a la pregunta 16 de la encuesta: "en la etapa de requerimientos, "¿cómo era la actitud de la gerencia en relación a la capacitación que debían recibir los empleados?"

Como se aprecia en la siguiente tabla de contingencia, el valor de $p=0,0001$, correspondiente al estadístico Chi Cuadrado de Pearson es inferior a 0,05, con lo que se corrobora la hipótesis, es decir: "existe relación estadísticamente significativa entre las variables: implementación de proyectos de software y actitud de la gerencia en relación a la capacitación de los empleados".

\section{Opciones: LO CONSIDERABA INDISPENSABLE / SOLO CUMPLÍA POR OBLIGACIÓN / NO CUMPLÍA}

Resultado Final del Proyecto $\rightarrow$ PI: Proyecto Implementado - PNI: Proyecto No Implementado. 
Tabla 25: de contingencia. Formación. (Acceso de los usuarios a la capacitación)

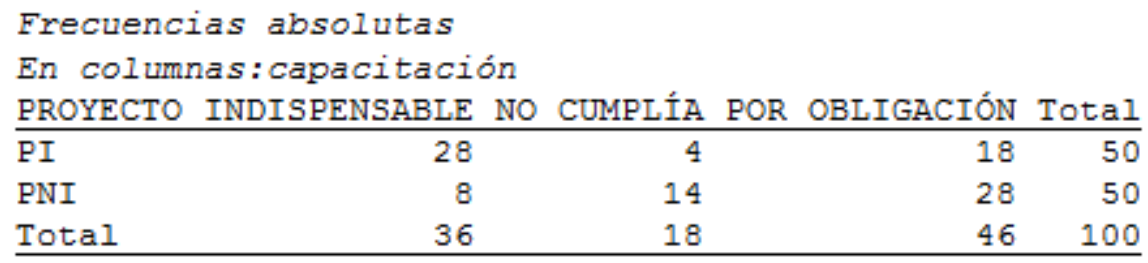

\begin{tabular}{lrrrr}
\multicolumn{1}{c}{ Estadístico } & Valor & gl & \multicolumn{1}{c}{ p } \\
\hline Chi Cuadrado Pearson & 18,84 & 2 & 0,0001 \\
Chi Cuadrado MV-G2 & 19,84 & 2 & $<0,0001$ \\
Coef. Conting. Cramer & 0,31 & & \\
Coef. Conting. Pearson & 0,40 & & \\
\hline
\end{tabular}

Tabla 22

Si se toman en cuenta el total de proyectos (100), y se mide cuál fue la opinión de los encuestados respecto a la actitud de la gerencia en relación a la capacitación de los empleados, se observa que:

- Para los proyectos implementados, el porcentaje de opiniones vertidas por los desarrolladores en relación a que la gerencia consideraba a la capacitación como "indispensable" fue del $78 \%$ y del $22 \%$ para los no implementados.

- Similar número pero en orden inverso se dio en el porcentaje de opiniones vertidas en relación a que la gerencia "no cumplía" con los planes de capacitación: $78 \%$ para los proyectos no implementados y del $22 \%$ para los implementados.
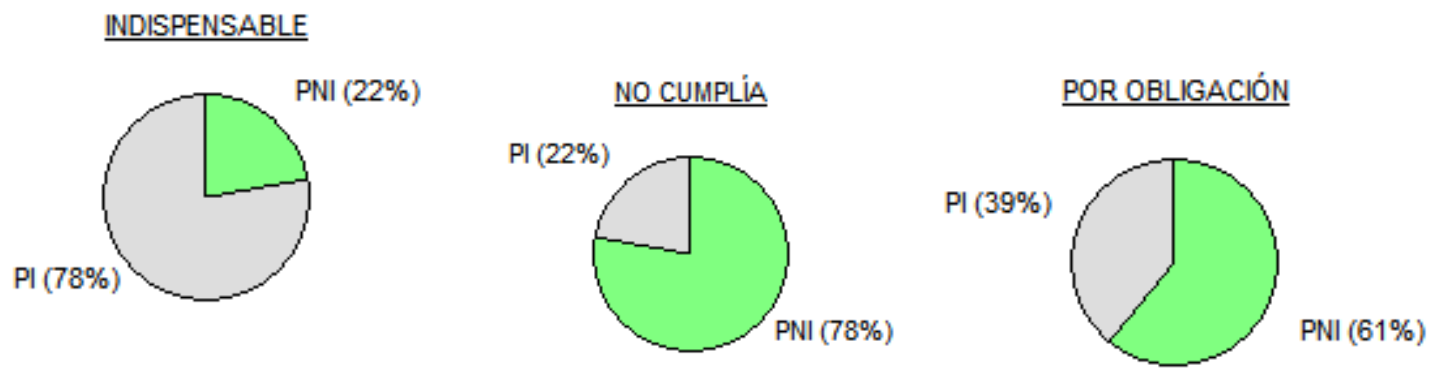

Figura 40: Formación. Acceso de los usuarios a la capacitación respecto al total de proyectos- PI:

Proyectos Implementados PNI: Proyectos No Implementados 
Si se evalúa cómo se distribuyeron las opiniones de los encuestados pero en relación al resultado final del proyecto por separado, se tiene que:

- En los proyectos implementados (50), el $56 \%$ opinaba que la gerencia consideraba "indispensable" a la capacitación de los empleados.

- En cambio, en los proyectos no implementados (50), solo fue del 16 $\%$ el porcentaje de opiniones que detectaron "indispensable" para la gerencia a la capacitación de los empleados.

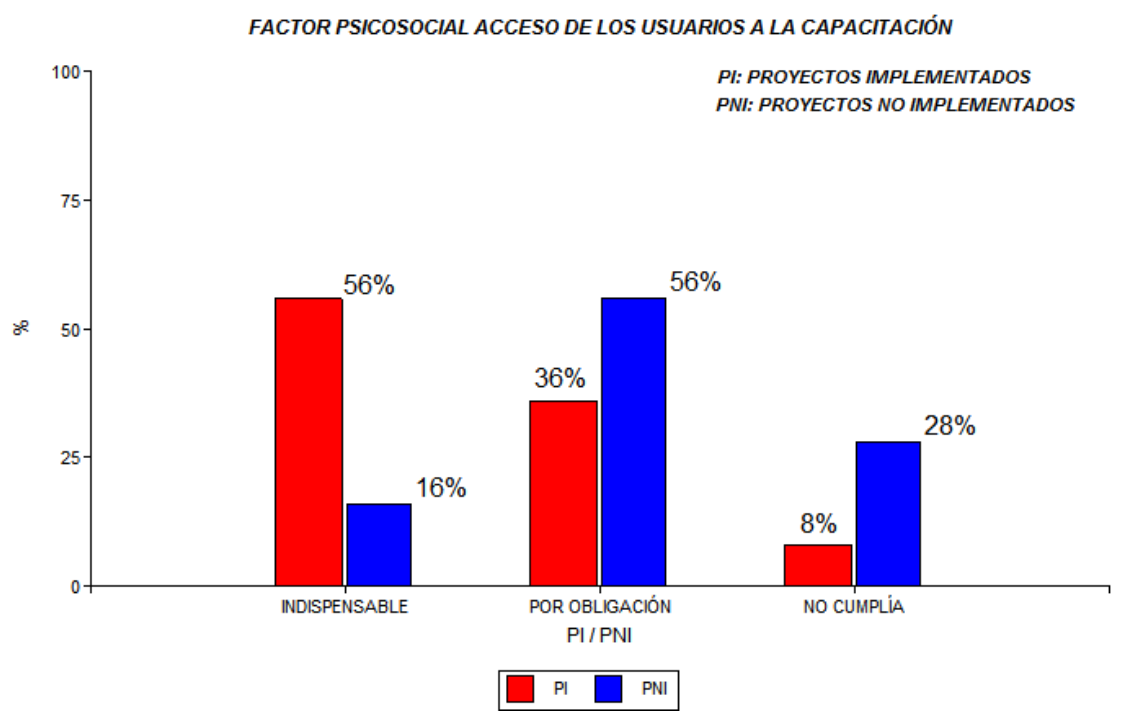

Figura 41: Formación. Acceso de los usuarios a la capacitación por tipo de proyecto PI/PNI

La opinión de los encuestados es coincidente con el pensamiento de los autores mencionados en el capítulo 3, punto 3.1.9: sobre el sentimiento de reciprocidad que genera en los empleados la capacitación. "Si la organización me ayuda a mi, yo ayudo a la organización”. [Brum, S, 2007]

Es por ello que resulta para nosotros indispensable evaluar, durante la elicitación de requerimientos, cuánta importancia le asigna la gerencia a la gestión de capacitación de sus empleados. Con los instrumentos de medición propuestos, resulta posible estimar el riesgo de implementación al que se expone un proyecto de software cuyas causas se relacionan con falencias en la gestión de capacitación. 


\section{Factores de contraste}

La intención de incorporar en la encuesta de opinión factores de contraste no relacionados con los factores psicosociales estuvo inspirada en dos motivos principales:

- Por un lado, incrementar el espacio muestral y evitar introducir sesgo por saturación del encuestado con la temática psicosocial y por el otro,

- evaluar en qué medida estos factores de contraste son causales de éxito o de fracaso en la implementación de proyectos de software.

Los factores introducidos se presumen trascendentes y comprenden aspectos económicos - financieros, de infraestructura y recursos técnicos.

El análisis efectuado a estos factores de contraste fue similar al que realizamos con los 11 factores psicosociales. Es decir, se evaluó el comportamiento del estimador Chi cuadrado de Pearson al introducir preguntas en la encuesta que referenciaban a estos 3 factores de contraste.

Incidencia de aspectos de naturaleza técnica sobre el resultado final de la implementación

Se presenta a continuación la verificación de la hipótesis y la interpretación de las opiniones de los encuestados respecto a la pregunta 9 de la encuesta: ¿ ¿Hubo aspectos de naturaleza técnica que fueron determinantes en el resultado final de la implementación?"

\section{Opciones: SI / NO /NO SABE}

Como se aprecia en la siguiente tabla de contingencia, el valor de $p=$ 0,0994 correspondiente al estadístico Chi Cuadrado de Pearson es superior a 0,05 , por lo que se puede afirmar que para los encuestados "no existe relación estadísticamente significativa entre el resultado final de la implementación y los aspectos de naturaleza técnica involucrados con el proyecto de software". 
Tabla 26 de contingencia (Incidencia de aspectos de naturaleza técnica)

\begin{tabular}{|c|c|c|c|c|c|}
\hline \multicolumn{6}{|c|}{ Frecuencias absolutas } \\
\hline ROYECTO & NO & NO & SABE & SI & Total \\
\hline PI & 31 & & 0 & 19 & 50 \\
\hline ENI & 22 & & 2 & 26 & 50 \\
\hline Total & 53 & & 2 & 45 & 100 \\
\hline
\end{tabular}

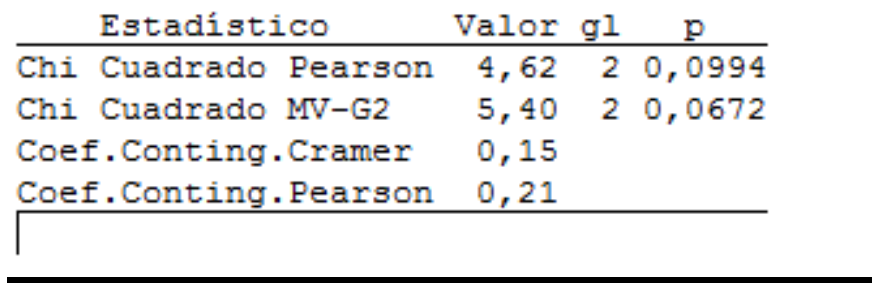

Tabla 23

Como puede apreciarse en el siguiente gráfico, prácticamente no existieron diferencias de significación entre las opiniones a favor y en contra respecto a que hubo aspectos de naturaleza técnica que fueron determinantes para el resultado final de la implementación.

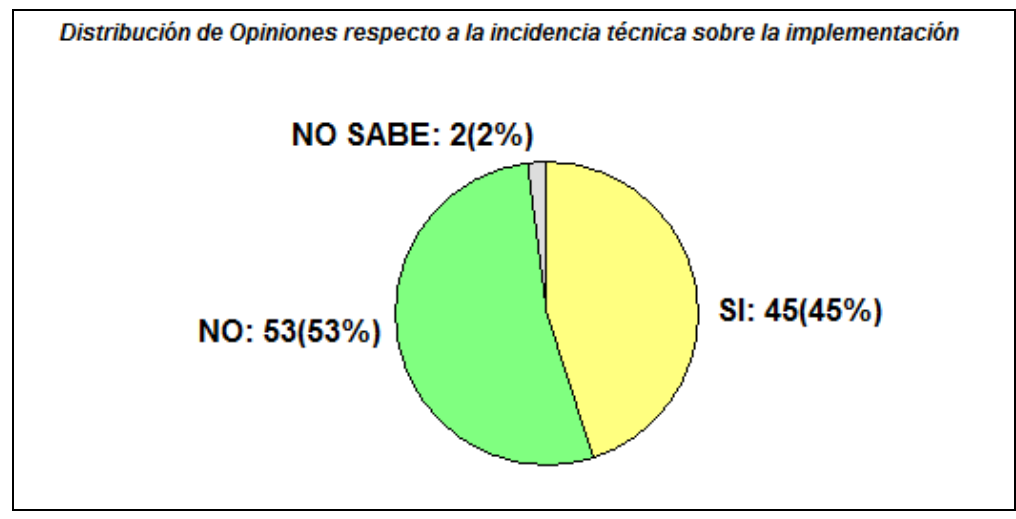

Figura 42: Incidencia de aspectos de naturaleza técnica sobre PI/PNI

Incidencia de aspectos de naturaleza económica financiera sobre el resultado final de la implementación

Se presenta seguidamente la verificación de la hipótesis y la interpretación de las opiniones de los encuestados respecto a la pregunta 11 de la encuesta: "¿Hubo aspectos de naturaleza económica - financiera que fueron determinantes en el resultado final de la implementación?" 


\section{Opciones: SI / NO /NO SABE}

Como se aprecia en la siguiente tabla de contingencia, el valor de $\mathrm{p}=0,1129$ correspondiente al estadístico Chi Cuadrado de Pearson es superior a 0,05 , por lo que se puede afirmar que "no existe relación estadísticamente significativa entre el resultado final de la implementación y los aspectos de naturaleza económico - financiera involucrados con el proyecto de software".

Resultado Final del Proyecto $\rightarrow$ PI: Proyecto Implementado - PNI: Proyecto No Implementado.

Tabla 27: de contingencia (Incidencia de aspectos de naturaleza económica/financiera sobre PI/PNI)
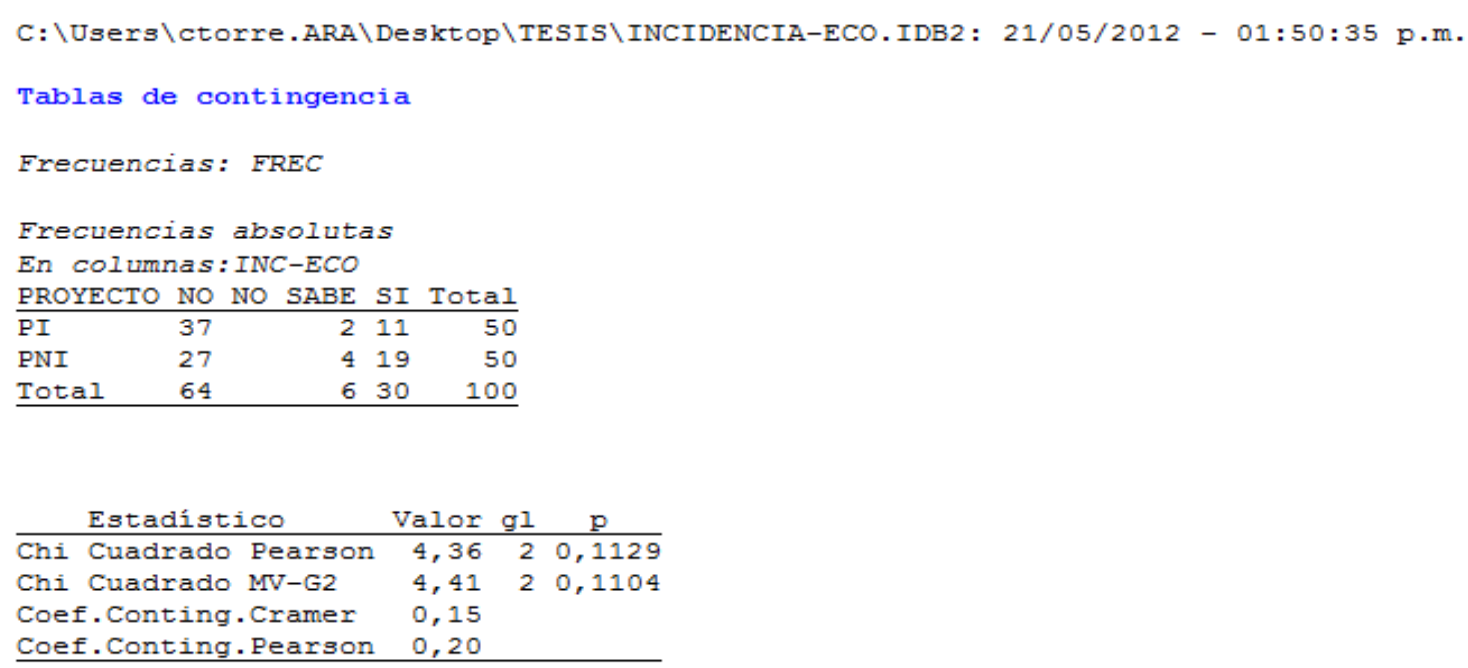

Si bien existen diferencias entre las opiniones respecto a que hubo aspectos de naturaleza económico-financiera que fueron determinantes en el resultado final de la implementación, dichas diferencias no logran ser significativas.

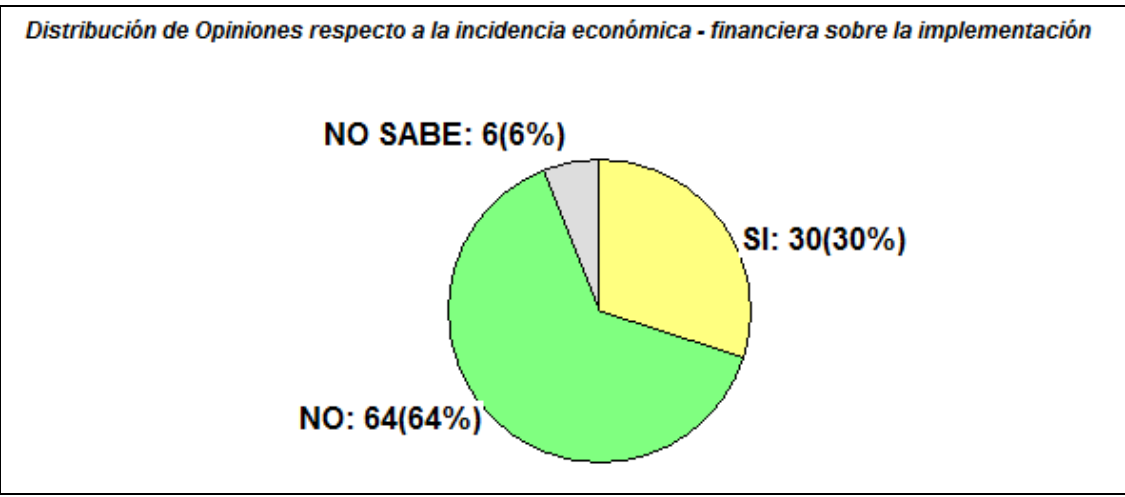

Figura 43: Incidencia de aspectos de naturaleza económica/financiera sobre PI/PNI 
Incidencia del tamaño de la organización sobre el resultado final de la implementación

Se presenta a continuación la verificación de la hipótesis y la interpretación de las opiniones de los encuestados respecto a la pregunta 5 de la encuesta: “¿De qué tamaño eran las organizaciones para las cuáles se desarrollaron ambos proyectos de software, el proyecto que no pudo desarrollarse y el implementado con éxito?"

\section{Opciones:}

PEQUEÑA (MENOS DE 50 PERSONAS)

MEDIANA (ENTRE 50 Y 200 PERSONAS)

GRANDE (MÁS DE 200 PERSONAS)

Resultado Final del Proyecto $\rightarrow$ PI: Proyecto Implementado - PNI: Proyecto No Implementado.

Tabla 28: de contingencia (Incidencia del tamaño de la organización sobre PI/PNI)

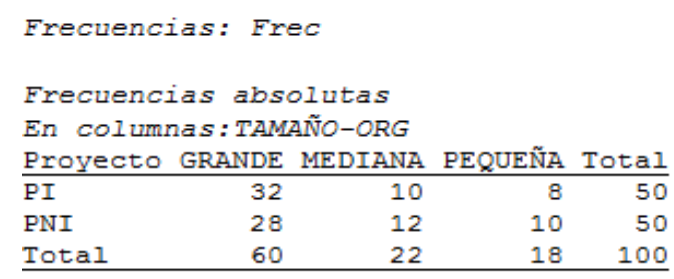

\begin{tabular}{lrrr}
\multicolumn{1}{c}{ Estadistico } & Valor & gl & p \\
\hline Chi Cuadrado Pearson & 0,67 & 2 & 0,7151 \\
Chi Cuadrado MV-G2 & 0,67 & 2 & 0,7148 \\
Coef. Conting.Cramer & 0,06 & & \\
Coef. Conting. Pearson & 0,08 & & \\
\hline
\end{tabular}

Si bien existen diferencias a favor de la implementación de proyectos en organizaciones grandes (más de 200 personas), dichas diferencias no logran ser significativas respecto a las demás categorías.

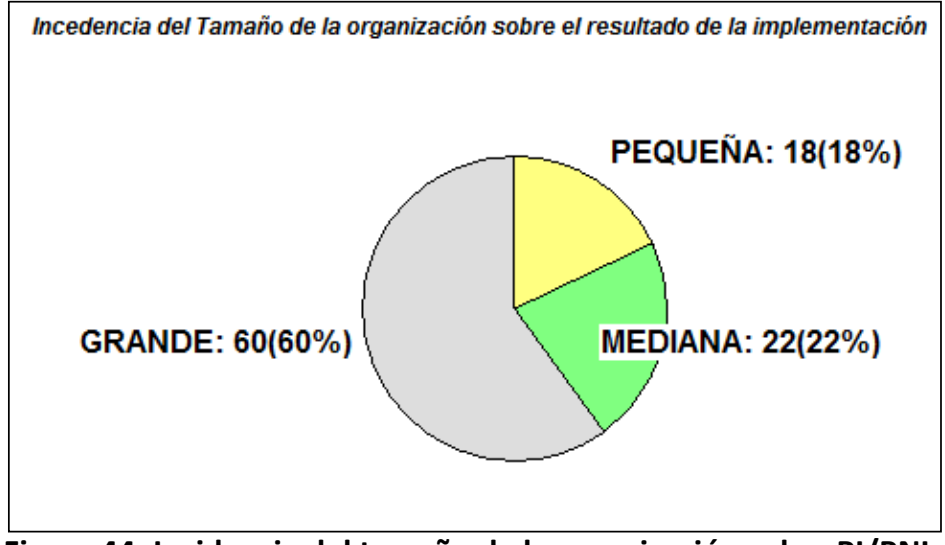

Figura 44: Incidencia del tamaño de la organización sobre PI/PNI 
Al analizar los resultados que arrojaron los factores de contraste surge que los mismos resultan un tanto sorprendentes. A diferencia de lo que se presumía antes de la encuesta, los factores psicosociales aquí descriptos parecen ser para los encuestados aspectos más determinantes para la implementación de proyectos de software que los recursos técnicos, económicos o de infraestructura.

Según los datos relevados, los factores psicosociales podrían ser considerados indicadores muy representativos del riesgo que afronta un proyecto de software socio-técnico cuando se expone a la compleja diversidad del factor humano.

En el siguiente gráfico se describirá, a modo de resumen totalizador, cómo influyeron los factores psicosociales y los de contraste respecto a los proyectos implementados y los no implementados.

\section{Corroboración de la hipótesis}

A partir de los resultados de la encuesta, el siguiente gráfico de barras resume la relación estadística (significativa o no) entre la implementación de proyectos de software y los factores psicosociales propuestos en este trabajo.

En el eje $X$ del valor 1 al 11, se consideraron la totalidad de los factores psicosociales analizados. Desde el valor 12 y hasta el 14, se incluyeron para contraste, aspectos no relacionados con los factores psicosociales (cuestiones técnicas y económicas - financieras y de infraestructura).

Por su parte, en el eje $Y$ se representan las frecuencias expresadas en porcentajes, extraídas de las tablas de contingencia de cada factor psicosocial, discriminadas por proyecto implementado y no implementado. Por ejemplo, en $\mathrm{x}=3$, los porcentajes 88 y 32 surgen de los resultados de la encuesta correspondiente al factor psicosocial consenso. (Anexo I pregunta 6) 
Tabla 29: de contingencia (ejemplo para cálculo de proporciones)

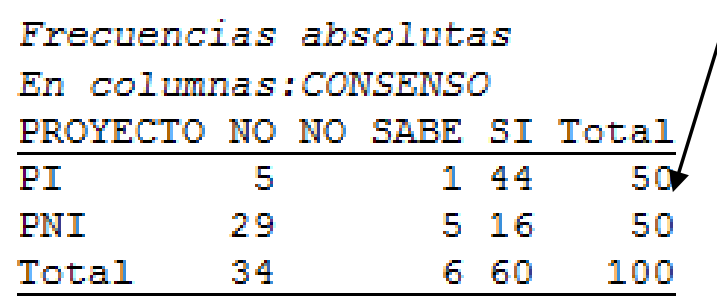

\begin{tabular}{lrrr}
\multicolumn{1}{c}{ Estadistico } & Valor & gl & p \\
\hline Chi Cuadrado Pearson & 32,67 & 2 & $<0,0001$ \\
Chi Cuadrado MV-G2 & 35,24 & $2<0,0001$ \\
Coef. Conting. Cramer & 0,40 & & \\
Coef. Conting. Pearson & 0,50 & & \\
\hline
\end{tabular}

El porcentaje $88 \%(x=3$, barra roja) se obtiene, al dividir el número de opiniones favorables de los encuestados que detectaron predominio de consenso para implementar (44) el proyecto respecto los proyectos que finalmente se implementaron (50). Ver tabla anterior.

El porcentaje $32 \%(x=3$, barra azul) se obtiene al efectuar el mismo análisis pero en relación a los proyectos no implementados: 16/50. 


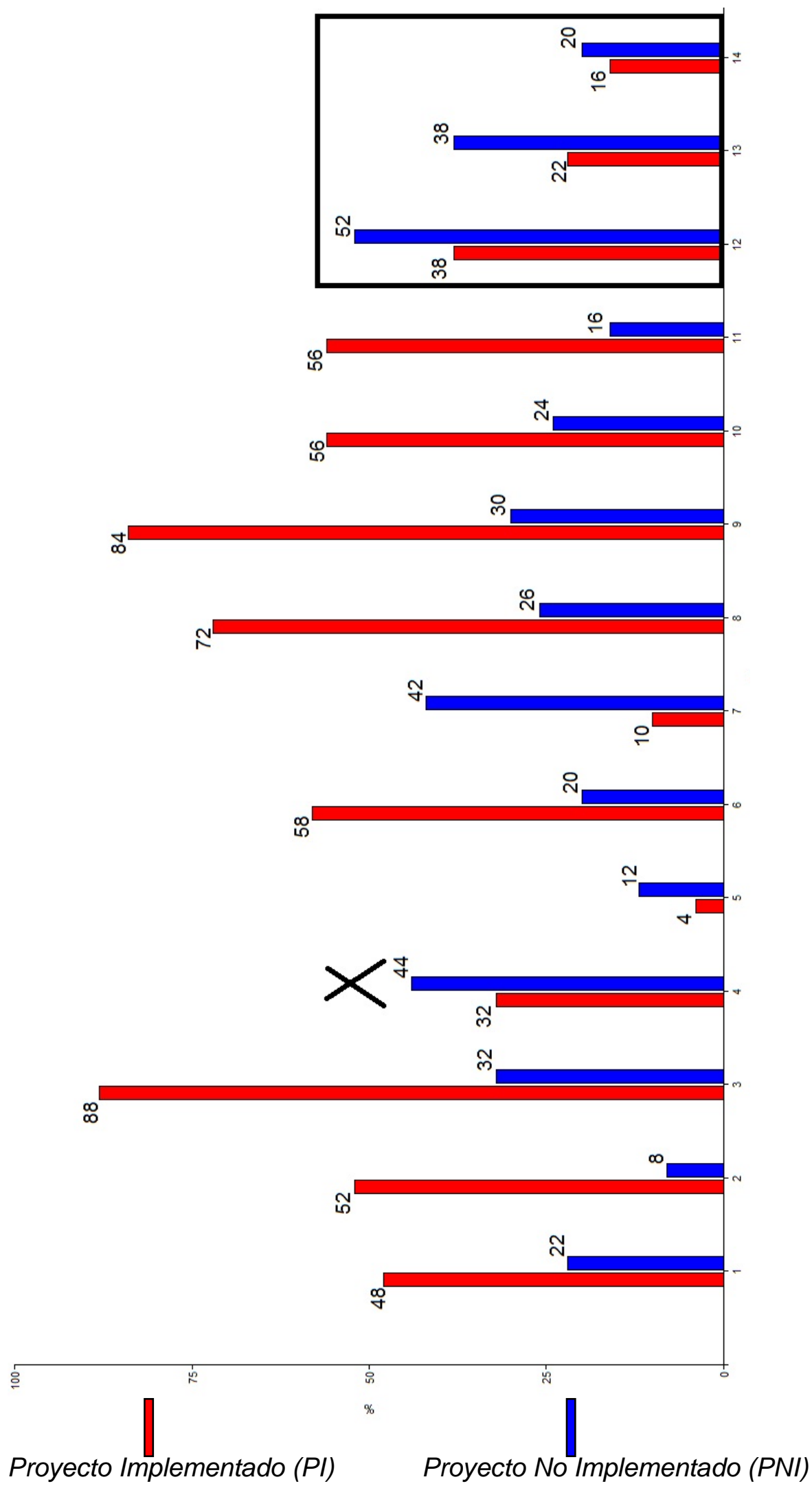

Los valores del 1 al 14 en el eje x representan los puntos 4.1 a 4.14 de la tabla 12.

Figura 45: Resumen de valores de contraste de hipótesis 
Como se apuntó oportunamente, el valor de Chi cuadrado de Pearson $<$ a $0,0001$ ( 0.05$)$ confirma la existencia de una relación estadísticamente significativa entre la implementación de proyectos de software y el factor psicosocial considerado.

Corroboración: del total de once (11) factores psicosociales tratados, los resultados han permitido corroborar las hipótesis componentes en diez de ellos, por lo que el porcentaje de cumplimiento de la hipótesis general supera el $90 \%$.

En el gráfico anterior se señala con una $X$ al factor psicosocial, "Estilo de Priorización de Requerimientos" (4.4), como el único factor psicosocial que no guarda una relación estadísticamente no significativa con la implementación de proyectos de software.

Como se aprecia nítidamente en los valores 5 y 7 del eje $x$ del gráfico, correspondientes a los factores psicosociales "Nivel de estrés" y "Nivel de Conflictos en la organización", los porcentajes son superiores en los proyectos no implementados. Esto ocurre porque, a diferencia con los restantes factores psicosociales, en ellos se produce una relación inversa con la implementación, es decir a mayor estrés y conflictos, menores serán las tasas de implementación exitosa.

Por otra parte, es importante resaltar el comportamiento de los valores 12 , 13 y 14 del gráfico. Dichos valores representan en el eje $X$ cuestiones no relacionadas con los factores psicosociales (aspectos económicos financieros, técnicos y de infraestructura). Los datos de la encuesta reflejan por Chi Cuadrado, que para los encuestados, estas cuestiones no guardan relación estadísticamente significativa con la implementación de proyectos de software. A nuestro entender estos resultados refuerzan la propuesta de incluir el análisis del contexto psicosocial cuando se pretende implementar un proyecto de software. 


\section{Análisis de los Factores Psicosociales como una buena práctica para la Implementación de Proyectos de Software}

Un desafío interesante fue preguntarle a los encuestados cuál era su opinión respecto a incluir como buena práctica, la evaluación de los factores psicosociales sobre la implementación. Los resultados estuvieron a favor con su incorporación.

En tal sentido, como se aprecia en la siguiente tabla de contingencia, al ser el estimador Chi Cuadrado de Pearson $<0,05$, se confirma en las opiniones, que para aquellos que desarrollan y gestionan proyectos de software, sería de utilidad disponer de una buena práctica.

Tabla 30: de contingencia (Análisis de opiniones de incorporar como buena práctica al análisis de los factores psicosociales)

\begin{tabular}{lrr} 
Frecuencias absolutas \\
BUENA PRÁCTICA \\
\hline NO & 1 & 2,00 \\
NO SABE & 7 & 14,00 \\
SI & 42 & 84,00 \\
Total & 50 & 100,00 \\
\hline
\end{tabular}

\begin{tabular}{lrrrr}
\multicolumn{1}{c}{ Estadistico } & Valor & gl & p \\
\hline Chi Cuadrado Pearson & 58,84 & $2<0,0001$ \\
Chi Cuadrado MV-G2 & 59,87 & $2<0,0001$ \\
Coef. Conting. Cramer & 1,08 & & \\
Coef. Conting. Pearson & 0,74 & & \\
\hline
\end{tabular}

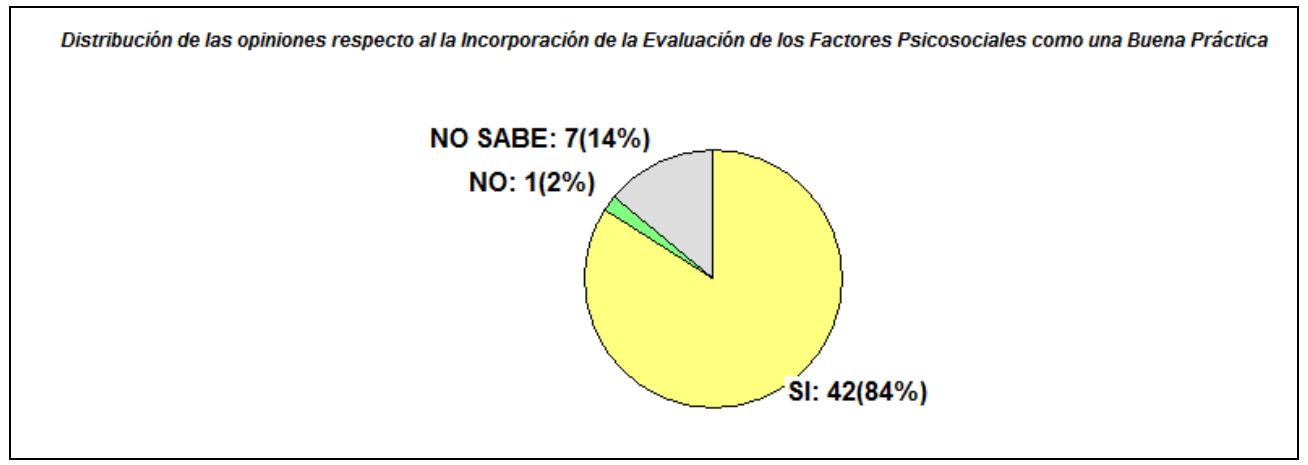

Figura 46: Análisis de opiniones sobre incorporar como buena práctica al análisis de los factores psicosociales 


\section{$\underline{\text { Trabajos futuros }}$}

La motivación principal que inspiró este trabajo fue haber vivido en reiteradas oportunidades, al implementar sistemas informáticos, problemas críticos relacionados con la gente, los cuales podrían haberse atenuado o evitado si se hubiera aplicado previamente alguna herramienta de diagnóstico que incluya su perfil psicosocial.

No es frecuente la presencia de profesionales de la psicología en los equipos de desarrollo, pero no es de extrañar que en un futuro próximo sea un hecho bastante común su asesoramiento en las primeras etapas de un proyecto de desarrollo de software socio técnico.

Una posible aplicación de lo visto en esta investigación podría ser el diseño de un marco de trabajo similar al SimOrg, descripto en el capítulo 2, pero ampliando su ámbito de aplicación a las personalidades de los involucrados que conforman la organización donde funcionará el software. Cabe recordar que el SimOrg se aplica únicamente a la simulación de personalidades del equipo de desarrollo.

También admite un posible campo de continuidad en el futuro profundizar en el diseño y aplicación de buenas prácticas y heurísticas que especialicen con más detalle en la herramienta de diagnóstico propuesta en el Anexo II.

\section{$\underline{\text { Síntesis final y Conclusiones }}$}

En el presente trabajo se intentó investigar por qué determinados proyectos de software se pueden implementar en algunas organizaciones, mientras que en otras no resulta posible hacerlo.

Para arribar con probabilidades de éxito al objetivo descripto en el párrafo anterior, se decidió incorporar conocimiento proveniente del campo de la psicología social y aplicarlo al ámbito de la gestión de proyectos de software. 
El argumento sobre el cual giró el estudio se resume en determinar si los factores psicosociales afectan, o no, al éxito de las implementaciones de software.

El análisis se realizó en dos (2) direcciones bien definidas:

- El equipo de desarrollo de software.

- La organización donde funcionará el software.

Las premisas básicas que se siguieron fueron:

- Plantear la problemática de la relación entre los factores psicosociales y la implementación de proyectos de software.

- Postular una hipótesis general que incluya esa problemática.

- Describir el estado del arte y los principales trabajos en la temática a fin de volcar conocimiento relevante.

- Corroborar la hipótesis postulada, a través de una encuesta de opinión y un método de contraste, y finalmente;

- Diseñar una herramienta de diagnóstico psicosocial como punto de partida para avanzar en la resolución de la problemática planteada.

Tanto por la corroboración estadística de la hipótesis realizada, como por las opiniones de los desarrolladores en las entrevistas (Anexo III), existe coincidencia en un punto: "la existencia de relación entre los factores psicosociales aquí tratados y la implementación de proyectos de software".

$Y$ en ese sentido algunas cuestiones resultaron decisivas en los proyectos que tuvieron éxito que no ocurrieron en los que fracasaron: la conformación cohesionada del equipo de desarrollo, la buena comunicación con el usuario, la participación de los usuarios calves, la apertura a las iniciativas, la motivación de la dirección y el consenso de los usuarios para dejar de lado los obstáculos para sostener el emprendimiento. No menos importante fue confirmar que el manejo de la tecnología y la capacitación son aspectos que inclinan la balanza a favor cuando las dudas abundan, al igual que algunas políticas organizacionales como el manejo del estrés, el conflicto y la objetividad en la toma de decisiones. 
En definitiva, todo lo anterior nos permite argumentar que prestar atención al riesgo psicosocial puede ser una alternativa útil cuando los métodos y técnicas tradicionales, no parecen ser suficientemente.

Contar con tales instrumentos no significa haber descubierto "balas de plata" que solucionan la mayoría de los problemas en la gestión de los proyectos de software. Su contribución apunta a abrir el juego para que ciertas disciplinas de las ciencias sociales aporten conocimiento complementario del factor humano, aspecto éste para nosotros crítico en el proceso de desarrollar e implementar sistemas. 


\title{
Anexo I
}

\section{Encuesta publicada}

\author{
FACTORES PSICOSOCIALES QUE INFLUYEN EN LA IMPLEMENTACIÓN DE PROYECTOS DE SOFTWARE
}

Se sabe que determinados proyectos de software socio-técnico que se implementan sin inconvenientes en algunas organizaciones, fracasan en otras. La presente encuesta de opinión tiene por objeto corroborar que existe relación entre los factores psicosociales de la organización (ej. la motivación, el estrés, el consenso, las actitudes) y la implementación de proyectos de software. Como la gente es diferente, la cuestión es: "evaluar los factores psicosociales para reducir ese riesgo",

EN EL MARCO DE LA PROPUESTA DE TESIS DE MAESTRÍA DE INGENIERÍA DE SOFTWARE : " INCORPORACIÓN DE LA PSICOLOGÍA SOCIAL AL PROCESO DE ELICITACIÓN DE REQUERIMIENTOS DE SOFTWARE ", PROPUESTA ÉSTA ACEPTADA POR LA COMISIÓN ASESORA DE INVESTIGACIONES Y POSTGRADO DE LA FACULTAD DE INFORMÁTICA DE LA UNIVERSIDAD NACIONAL DE LA PLATA (UNLP), LOS INVITAMOS A PARTICIPAR DE LA SIGUIENTE ENCUESTA PARA CONOCER LA OPINIÓN DE PROFESIONALES Y TÉCNICOS DEL ÁREA DE GESTIÓN / DESARROLLO DE PROYECTOS DE SOFTWARE RESPECTO A LA INFLUENCIA DE LOS FACTORES PSICOSOCIALES DE LA ORGANIZACIÓN SOBRE LAS IMPLEMENTACIONES INFORMÁTICAS

...-.. PARA PRESERVAR LA PRIVACIDAD DE LOS ENCUESTADOS NO SE LES REQUERIRÁ INGRESAR SUS DATOS PERSONALES. ÚNICAMENTE SE LES SOLICITARÁ LA DIRECCIÓN DE CORREO ELECTRÓNICO PARA CONTACTARLOS Y OFRECERLES PARTICIPAR EN UN SORTEO DE UN RADIO RELOJ DESPERTADOR SONY EN AGRADECIMIENTO A SU PARTICIPACIÓN EN LA ENCUESTA. EL TIEMPO PROMEDIO PARA COMPLETARLA ES DE 15 MINUTOS APROXIMADAMENTE, UNA VEZ COMPLETADA LA MISMA HAGA CLICK EN EL BOTÓN Fin -..-.;

\section{Bibliografía básica consultada:}

... Andriano N. (2006) "Comparación del Proceso de Elicitación de Requerimientos en el desarrollo de Sottware a Medida y Empaquetado" Tesis de Magister en Ingeniería de Sotware UNLP dissponible en http://postgrado,info,unlp,edu,ar/Carrera/Magister/IIngenieria\%202de\%205otware/Tesis/Andriano,pdf ... Campos, A, (2007) "Simulting Working Environments through the use of Personality Based Agents", en

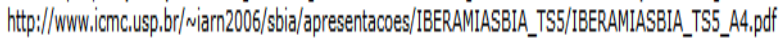
... Doval, Y., Moleiro, O., Rodriguez, R. (2004) "Estrés Laboral, Consideraciones sobre sus caracteristicas y formas de afrontamiento" disponible en http://www.psicologiacientifica.com /publicaciones/biblioteca/articulos/ar-gonnoo1_.h.htm.

-.. 2nd IEEE International Conference on Requirements Engineering, Colorado Springs,USA, 15-18 April 1996, pp. 136-144.

... Huici Casal, C. (2004) "Psicología de Grupos II, Métodos, Técricas y Aplicaciones", pp 87 - 118.

... Tastle,W. (2010)"A New Approach in Requirements Elicitation Análisis" disponible en httpi///0js.academypublisher.com/index.php/jetwi/article/viewFile/20203221231/2081

... Suarez, F (1971) "Introduccion al Estudio de la Sociología de las Organizaciones" disponible en hitp://es.scribd.com/doc/26166702/

...... INVESTIGADOR: CLAUDIO TORRE -....

POSTGRADO EN LA ESPECIALIDAD DE INGENEERIA DE SOFTWARE (UNLP) ...... CORREO ELECTRÓNICO:Claudio_torre@̣hotmail.com

\section{*1. CONSIDERACIONES A TENER EN CUENTA PARA COMPLETAR LA ENCUESTA:}

Para contestar el siguiente cuestionario usted debe TENER EN MENTE durante las siguientes preguntas, solo DOS (2) PROYECTOS DE SOFTWARE, uno que NO PUDO IMPLEMENTAR su equipo de desarrollo y otro que FUE IMPLEMENTADO CON ÉXITO. Ambos proyectos pueden haber sido desarrollados en organizaciones distintas.

Antes de cada pregunta se citan ejemplos extraídos de la experiencia del investigador relacionados con el impacto negativo de factores psicosociales de la organización (Ej. consenso, estrés, conflictos, etc.) sobre los proyectos de software. El objetivo es ofrecer una muestra para que el encuestado tenga un marco de referencia para calificar objetivamente la relación entre cada factor y los proyectos seleccionados.

Se recomienda calificar cada factor psicosocial caso por caso en un orden de pensamiento causa - $>$ efecto sobre el proyecto, y no a la inversa, es decir calificar el factor erróneamente en función del resultado ya conocido del proyecto (éxito o frcaso), asumiendo que:

-."como el proyecto de software no se implementó, todos los factores psicosociales de la organiación se califican como negativos", e inversamente,

-."como el proyecto de software pudo implementarse con éxito, se califican todos los factores psicosociales de la organización como positivos".

Por favor, para comenzar, ingrese su CORREO ELECTRÓNICO. 
*2. Ingrese CARG0 o FUNCIÓN que desempeña en el Equipo de Desarrollo de Software. Ej. Jefe de Proyecto / Analista / Programador / Tester, etc.

*3. LUGAR DE RESIDENCIA

*4. Cuál es el número de integrantes que componen el equipo de desarrollo que usted dirige 0 al cual usted pertenece ? CMENOR QUE 5 C ENTRE 5 Y 20 CMAYOR QUE 20

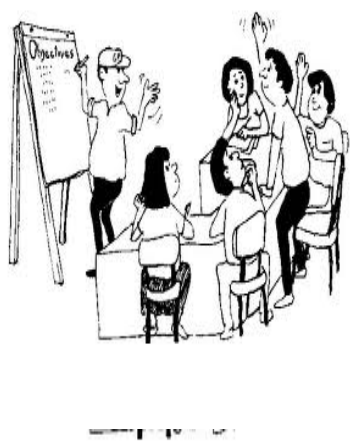

*5. ¿ De qué TAMAN̉O eran las ORGANIZACIONES para las cuáles se desarrollaron ambos proyectos de software, el proyecto que no se pudo implementar y el implementado con éxito

PEQUEÑA (MENOS DE MEDIANA (ENTRE 50 Y GRANDE (MÁS DE 200

PROYECTO NO IMPLEMENTADO

50 PERSONAS) 200 PERSONAS) PERSONAS)

PROYECTO IMPLEMENTADO

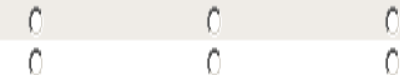

CONSENSO PARA IMPLEMENTAR EL PROYECTO EN LOS SECTORES MEDIOS DE LA ORGANIZACIÓN (JEFES DE DEPARTAMENTO 0 EQUiVALENTES).

[Tastle, W., 2010]

Ejemplos de FALTA DE CONSENSO para implementar el proyecto a nivel de Jefes de Departamento o equivalentes (extraídos de experiencias propias del encuestador):

- Los usuarios presentan como prioritarios requerimientos dificiles de implementar con el objeto de obstaculizar el avance del proyecto y conservar el espacio de poder. - No pueden decidirse sobre lo que desean.

-Existen demasiadas fuentes de requerimientos.

Pregunta:

¿ ENTRE LOS SECTORES MEDIOS DE LA ORGANIZACIÓN PREDOMINABA UNA ACTITUD DE CONSENSO PARA IMPLEMENTAR EL PROYECTO?

Elija la opción de abajo que mejor se ajuste a lo sucedido en cada proyecto.

\begin{tabular}{|c|c|c|c|}
\hline & SI & NO & NO SABE \\
\hline PROYECTO NO IMPLEMENTADO …...... & $\mathrm{C}$ & 0 & C \\
\hline PROYECTO IMPLEMENTADO & 0 & 0 & 0 \\
\hline
\end{tabular}


*7.

ESTILOS EN LA ASIGNACIÓN DE PRIORIDADES POR PARTE DE LA GERENCIA

[Suarez, F., 1971]

Características principales de ambos estilos

-El estilo SUBJETIVO privilegia los puntos de vista de las personas, asignándose las prioridades a los requerimientos de acuerdo a los intereses y deseos particulares de los individuos.

-El estilo OBJETIVO asigna las prioridades a los requerimientos independientemente de la manera de pensar o de sentir de los individuos. Se prioriza según las normas establecidas por la organización.

Pregunta:

EN LA PRIORIZACIÓN DE REQUERIMIENTOS POR PARTE DE LA GERENCIA, i QUÉ ESTILO ERA MÁS ASIDUAMENTE UTILIZADO: El SUBJETIVO 0 EL OBJETIVO ?

Elija la opción de abajo que mejor se ajuste a lo sucedido en cada proyecto.

\begin{tabular}{|c|c|c|}
\hline & ESTILO SUBJETIVO & ESTILO OBJETIVO \\
\hline 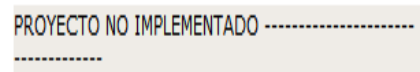 & C & $\mathrm{c}$ \\
\hline PROYECTO IMPLEMENTADO & 0 & 0 \\
\hline
\end{tabular}

*8.

NIVEL DE ESTRÉS LABORAL

[Doval, Y, 2004]

Se citan abajo ejemplos de INTENSO ESTRÉS LABORAL presente en la organización donde se implementa un proyecto de software (extraídos de experiencias propias del encuestador):

-Elevado ausentismo por licencias por tratamiento médico.

-Descontento con el clima laboral reinante en la organización por las condiciones ambientales y/o edilicias.

-Excesiva presión ejercida por las jerarquías superiores.

Pregunta:

EN LA ETAPA DE REQUERIMIENTOS, ¿CÓMO ERA EL NIVEL DE ESTRÉS LABORAL QUE USTED PERCIBIÓ ENTRE LOS EMPLEADOS?

Elija la opción de abajo que mejor se ajuste a lo sucedido en cada proyecto.

$\begin{array}{lccc} & \text { INTENSO } & \text { NORMAL } & \text { BAJO } \\ \text { PROYECTO NO IMPLEMENTADO } \ldots \ldots \ldots \ldots . . . . & C & C & 0 \\ \text { PROYECTO IMPLEMENTADO } & 0 & 0 & 0\end{array}$


${ }^{*} g_{1}$.

INCIDENCIA DE ASPECTOS DE NATURALEZA TÉCNICA SOBRE El RESULTADO FINAL DE LA IMPLEMENTACIÓN

[Andriano, N., 2006]

Ejemplos de problemas de naturaleza técnica (extraídos de experiencias propias del encuestador):

-La actual infraestructura informática y de comunicaciones de la organización no satisface las exigencias que el proyecto demanda.

-Las aplicaciones críticas residuales del sistema anterior que aún se ejecutan no están debidamente documentadas para migrarlas al nuevo sistema y comprometen el cronograma del proyecto.

-Por inexperiencia del equipo de desarrollo con las nuevas tecnologías, no se diseñaron las interfaces de software necesarias para cubrir todos los requerimientos funcionales.

Pregunta:

HUBO ASPECTOS DE NATURALEZA TÉCNICA QUE FUERON DETERMINANTES EN EL RESULTADO FINAL DE LA IMPLEMENTACIÓN ?

Elija la opción de abajo que mejor se ajuste a lo sucedido en cada proyecto.

$\begin{array}{lccc} & \text { SI } & \text { NO } & \text { NO SABE } \\ \text { PROYECTO NO IMPLEMENTADO } & \mathrm{C} & \mathrm{C} & \mathrm{C} \\ \text { PROUECTO IMPLEMENTADO } & \mathrm{N} & 0 & 0\end{array}$

*10.

ACTITUD DE USUARIOS CLAVES SOBRE LA IMPLEMENTACIÓN

[Andriano, N., 2006]

Ejemplos de conductas POCO COLABORATIVAS de Supervisores, jefes de división, etc. (extraídos de experiencias propias del encuestador):

-Ocultan la documentación de procedimientos críticos (datagramas, hojas de ruta, etc.) con el objetivo que el nuevo sistema no comparta esa información con otras áreas. -Ejercen influencia para que el personal a su cargo no detalle el conocimiento específico que lograron con la experiencia acumulada.

-Pretenden formar opinión en sus superiores argumentando que el nuevo sistema disminuirá su peso estratégico en el proceso de toma de decisiones.

Pregunta:

EN LA ETAPA DE REQQUERIMIENTOS, ¿CÓMO ERA LA ACTITUD DE LOS "USUARIOS CLAVES" QUE CONOCÍAN EN DETALLE LAS FUNCIONALIDADES QUE SE PRETENDÍan IMPLEMENTAR CON EL PROYECTO?

Elija la opción de abajo que mejor se ajuste a lo sucedido en cada proyecto.

\begin{tabular}{|c|c|c|c|}
\hline & COLABORATIVA & NORMAL & $\begin{array}{c}\text { POCO } \\
\text { COLABORATIVA }\end{array}$ \\
\hline 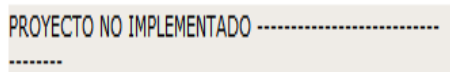 & C & C & C \\
\hline PROYECTO IMPLEMENTADO & 0 & 0 & 0 \\
\hline
\end{tabular}




\section{${ }^{*} 11$. INCIDENCIA DE ASPECTOS ECONÓMICOS FINANCIEROS SOBRE EL RESULTADO FINAL DE LA IMPLEMENTACIÓN [Andriano, N., 2006] \\ Ejemplos de problemas de naturaleza Económica-Financiera (extraídos de experiencias propias del encuestador): \\ -Pagos extras al personal para cumplir el cronograma del proyecto afectado por inconvenientes ajenos al ámbito técnico (problemas sindicales, etc.). -Retrasos en el pago por parte del Contratista por servicios ya entregados. \\ - Mayores costos para remplazar personal altamente calificado que dejó el equipo de desarrollo.}

Pregunta:

HUBO ASPECTOS DE NATURALEZA ECONÓMICA-FINANCIERA QUE FUERON DETERMinANTES EN EL RESULTADO FINAL DE LA IMPLEMENTACIÓN ?

Elija la opción de abajo que mejor se ajuste a lo sucedido en cada proyecto.

\begin{tabular}{lccc} 
& SI & NO & NO SABE \\
PROYECTO NO IMPLEMENTADO & $\mathrm{C}$ & $\mathrm{C}$ & $\mathrm{C}$ \\
\hdashline PROYECTO IMPLEMENTADO & 0 & 0 & 0
\end{tabular}

${ }^{*} 12$.

NIVEL DE CONFLICTOS EN LA ORGANIZACIÓN

[Huici Casal et al., 2004]

Ejemplos de conductas típicas cuando existe ALTO NIVEL DE CONFLCTOS en la organización en donde se pretende implementar un proyecto de software (extráidos de experiencias propias del encuestador):

- Los requerimientos relevados en diferentes áreas de la organización se oponen entre si.

-El equipo de desarrollo requiere mediación politica para atenuar posiciones enfrentadas entre diferentes sectores que dificultan la negociación de prioridades en los requerimientos. -Se detectan usuarios claves con poca o nula intervención grupal (aislamiento crítico).

Pregunta:

EN LA ETAPA de REQUERIMIENTOS, iCÓMO ERA El NIVEL GENERAL DE CONFLICTOS EN LA ORGANIZACIÓN ?

Elija la opción de abajo que mejor se ajuste a lo sucedido en cada proyecto.

\begin{tabular}{|c|c|c|c|}
\hline & ALTO & MEDIO & BAJO \\
\hline PROYECTO NO IMPLEMENTADO -........ & 0 & 0 & 0 \\
\hline PROYECTO IMPLEMENTADO & 0 & 0 & 0 \\
\hline
\end{tabular}


${ }^{*} 13$.

APERTURA DE LA GERENCIA A LAS INICIATIVAS DE LOS EMPLEADOS

[Suarez, $\left.F_{1}, 1971\right]$

A continuación se citan ejemplos de INICIATIVAS DESESTIMADAS por falta de apertura de la Gerencia (extraídos de experiencias propias del encuestador):

-Se niega sistemáticamente la Gerencia a admitir nuevas funcionalidades originadas en los empleados para no elevar el costo de la implementación. -La Gerencia no incorpora normas de calidad en los procedimientos parar no apartarse de una cultura organizacional fuertemente arraigada.

- La Gerencia no estimula la creatividad, ni se premia al personal que aporta soluciones para el proceso de mejora continua de la organización.

Pregunta:

EN LA ETAPA DE REQUERIMIENTOS, $i$ ERAN TENIDAS EN CUENTA POR PARTE DE LA GERENCIA LAS INICIATIVAS INNOVADORAS GENERADAS POR LOS EMPLEADOS ?

Elija la opción de abajo que mejor se ajuste a lo sucedido en cada proyecto.

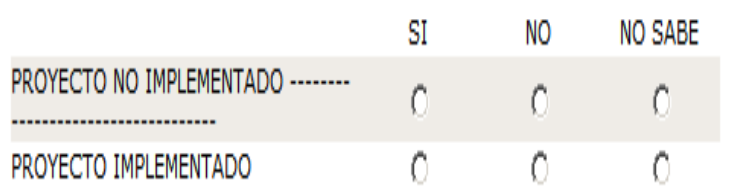

*14.

MOTIVACIÓN DE LA GERENCIA PARA IMPLEMENTAR EL PROYECTO

[Huici Casal et al., 2004]

Ejemplos de POBRE MOTIVACIÓN de la Gerencia respecto al proyecto de software (extraídos de experiencias propias del encuestador):

-La gerencia no transmite explicitamente al resto de la organización su decisión política de apoyar totalmente la implementación del proyecto. -No requiere, por iniciativa propia, reuniones con el equipo de desarrollo para controlar la evolución del cronograma.

-No interviene en los conflictos intergrupales cuando se negocian las prioridades.

Pregunta:

EN LA ETAPA DE REQUERIMIENTOS, i LA GERENCIA SE INVOLUCRÓ ACTIVAMENTE CON EL PROYECTO ?

Elija la opción de abajo que mejor se ajuste a lo sucedido en cada proyecto.

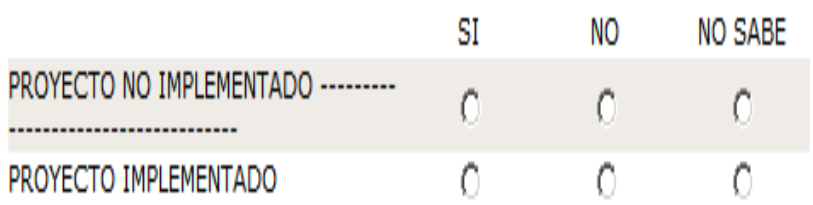




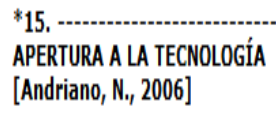

Ejemplos de conductas típicas de OPOSICIÓN respecto al salto tecnológico que traía consigo el proyecto de software (extraídos de experiencias propias del encuestador):

-Cuando el proyecto de software se implementa para remplazar un sistema antiguo, los usuarios de niveles inferiores (Supervisores, jefes de división) frecuentemente exageren las bondades del viejo sistema minimizando sus limitaciones. Con esta conducta se pretende mantener espacios de poder consolidados en el tiempo.

-En usuarios de edad elevada (de cualquier nivel jerárquico) es frecuente cierta aversión a la imposición de nuevas tecnologías.

-Es frecuente que en la etapa de testeo del sistema, ante las primeras fallas detectadas se produzca un vuelco y disminuya la confianza respecto al nuevo sistema.

\section{Pregunta:}

EN GENERAL, ¿ CUÁL ERA LA ACTITUD DE LOS FUTUROS USUARIOS RESPECTO A LAS NUEVAS FUNCIONALIDADES Y TECNOLOGÍAS QUE INCORPORABA EL PROYECTO?

Elija la opción de abajo que mejor se ajuste a lo sucedido en cada proyecto.

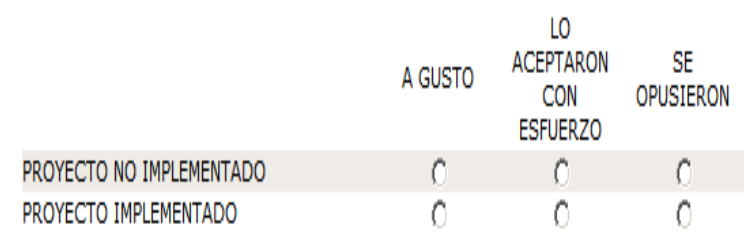

*16.

CAPACITACIÓN DEL PERSONAL

[IEEE, 1996]

Se citan a continuación ejemplos en la falta de compromiso de la Gerencia en las políticas de CAPACITACIÓN DE PERSONAL (extraídos de experiencias propias del encuestador):

-La gerencia no está convencida que el capital intelectual es determinante en un mundo en el que la tecnología se encuentra cada vez más accesible.

- No planifica regularmente en su presupuesto partidas destinadas a incorporar a la organización capital intelectual.

- Las políticas de ascensos en los cargos a cubrir priorizan la antigüedad de su personal en detrimento de sus antecedes académicos, sintoma éste muy común en empresas familiares.

Pregunta:

CÓMO ERA LA ACTITUD DE LA GERENCIA EN RELACIÓN A LA CAPACITACIÓN QUUE DEBÍAN RECIBIR LOS EMPLEADOS?

Elija la opción de abajo que mejor se ajuste a lo sucedido en cada proyecto.

\section{LO CONSIDERABA SOLO CUMPLIA}

INDISPENSABLE POR OBLIGACIÓN

\section{NO CUMPLÍA}

PROYECTO NO IMPLEMENTADO

PROYECTO IMPLEMENTADO

C


${ }^{*} 17$.

COMUNICACIÓN DEL EQUIPO DE DESARROLLO CON LOS USUARIOS

[Andriano, N., 2006]

Ejemplos de COMUNICACIÓN DEFICIENTE (extraídos de experiencias propias del encuestador):

-Se producen por diferentes estilos de interacción entre el desarrollador y los usuarios.

-Ocurren errores de interpretación cuando el desarrollo se realiza en ambientes distribuidos en diferentes áreas geográficas.

-Se presentan dificultades cuando los usuarios no saben transmitir su conocimiento del dominio.

Pregunta:

DURANTE LA ETAPA DE REQUERIMIENTOS, i CÓMO ERA LA COMUNICACIÓN ENTRE EL EQUIPO DE DESARROLLO CON LOS FUTUROS USUARIOS DE CADA PROYECTO ?

Elija la opción de abajo que mejor se ajuste a lo sucedido en cada proyecto.

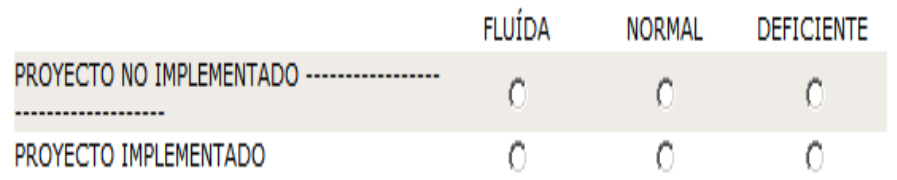

*18.

INTERACCIÓN GRUPAL DENTRO DEL EQUIPO DE DESARROLLO

[Campos,A ., 2007]

Ejemplos de interacción grupal negativa (extraídos de experiencias propias del encuestador):

-Líderes de proyectos con rasgos de personalidad con dificultades de relación.

-Rasgos de personalidad similar en la mayoría de los miembros del equipo de desarrollo (falta de complementariedad).

-Conflictos entre los miembros del grupo de desarrollo por profundas diferencias en valores fundamentales.

Pregunta:

¿ CÓMO ERA LA INTERACCIÓN GRUPAL INTERNA DEL EQUIPO DE DESARROLLO A LO LARGO DEL PROYECTO ?

Elija la opción de abajo que mejor se ajuste a lo sucedido en cada proyecto.

$\begin{array}{lccc}\text { GRUPO ALTAMENTE } & \begin{array}{c}\text { CON DIFERENCIAS } \\ \text { SALVABLES }\end{array} & \begin{array}{c}\text { CON DIFERENCIAS } \\ \text { INSALVABLES }\end{array} \\ \text { PROYECTO NO IMPLEMENTADO } & 0 & 0 & 0 \\ \text { PROYECTO IMPLEMENTADO } & 0 & 0 & 0\end{array}$


*18.

INTERACCIÓN GRUPAL DENTRO DEL EQUIPO DE DESARROLLO

[Campos,A ., 2007]

Ejemplos de interacción grupal negativa (extraídos de experiencias propias del encuestador):

-Líderes de proyectos con rasgos de personalidad con dificultades de relación.

-Rasgos de personalidad similar en la mayoría de los miembros del equipo de desarrollo (falta de complementariedad).

-Conflictos entre los miembros del grupo de desarrollo por profundas diferencias en valores fundamentales.

Pregunta:

¿ CÓMO ERA LA INTERACCIÓN GRUPAL INTERNA DEL EQUIPO DE DESARROLLO A LO LARGO DEL PROYECTO ?

Elija la opción de abajo que mejor se ajuste a lo sucedido en cada proyecto.

\begin{tabular}{|c|c|c|c|}
\hline & $\begin{array}{l}\text { GRUPO ALTAMENTE } \\
\text { COHESIONADO }\end{array}$ & $\begin{array}{c}\text { CON DIFERENCIAS } \\
\text { SALVABLES }\end{array}$ & $\begin{array}{l}\text { CON DIFERENCIAS } \\
\text { INSALVABLES }\end{array}$ \\
\hline PROYECTO NO IMPLEMENTADO & 0 & $\mathrm{C}$ & $\mathrm{C}$ \\
\hline PROYECTO IMPLEMENTADO & $\mathrm{C}$ & 0 & 0 \\
\hline
\end{tabular}

*19.

INCORPORACIÓN DE LA EVALLACIÓN DE LOS FACTORES PSICOSOCIALES COMO UNA BUENA PRÁCTICA PARA LA GESTIÓN DE REQUERIMIENTOS

Ejemplos en el uso de buenas prácticas recomendadas para la gestión de requerimientos [Andriano, N, 2006]:

Recolectar requerimientos desde múltiples puntos de vista.

Reutilizar requerimientos.

Tener en cuenta las restricciones del ambiente.

Pregunta:

¿ TENIENDO EN CUENTA SU EXPERIENCIA PROFESIONAL, i PIENSA USTED QUE SERÍA VENTAJOSO INCORPORAR LA EVALUACIÓN DE LOS FACTORES PSICOSOCIALES AQQUí MENCIONADOS COMO UNA BUENA PRÁCTICA A INCLUIR DURANTE LA ETAPA DE REQQUERIMIENTOS?

Elija la opción de abajo que mejor se ajuste a lo sucedido en cada provecto.

\section{CSI CNO CNOSABE}


SI DESEA AGREGAR ALGÚN COMENTARIO, POR FAVOR HÁGALO EN EL SIGUIENTE CUADRO. 


\section{Anexo II}

Herramienta para diagnosticar riesgos psicosociales en el desarrollo e implementación de proyectos de software

Esta herramienta de diagnóstico debe ser usada como primera aproximación a la gestión psicosocial del proyecto de software. Las áreas que presenten deficiencias representan el punto de partida para el consecuente análisis de riesgo más específico.

A partir del "Cuestionario de diagnóstico de riesgo psicosocial en proyectos de software" que debe completar el responsable del proyecto se procura:

- Registrar la situación psicosocial inicial del equipo de desarrollo y de la organización donde funcionará el proyecto de software.

- Identificar situaciones de riesgo causadas por factores psicosociales examinados.

- Aportar una serie de medidas mitigadoras supeditadas a una evaluación posterior más rigurosa.

Tabla 31: Áreas de riesgo psicosocial

\begin{tabular}{|c|c|c|c|}
\hline \multicolumn{2}{|r|}{$\frac{\text { Áreas del Riesgo }}{\text { psicosocial }}$} & Factor Psicosocial & $\frac{\begin{array}{c}\text { Pregunta del } \\
\text { custionario que lo }\end{array}}{\text { identifica }}$ \\
\hline \multirow{2}{*}{\multicolumn{2}{|c|}{$\begin{array}{l}\text { Del equipo de desarrc } \\
\text { (E) }\end{array}$}} & $\begin{array}{l}\text { Cohesión->Interacción } \\
\text { de estilos de } \\
\text { personalidad dentro del } \\
\text { equipo de desarrollo. }\end{array}$ & 1 у 2 \\
\hline & & $\begin{array}{l}\text { Comunicación entre el } \\
\text { equipo de desarrollo y el } \\
\text { usuario. }\end{array}$ & $3,4,5$ y 6 \\
\hline \multirow{2}{*}{\multicolumn{2}{|c|}{$\begin{array}{l}\text { De la } \\
\text { interacción } \\
\text { grupal }\end{array}$}} & $\begin{array}{l}\text { Nivel de consenso para } \\
\text { implementar el proyecto } \\
\text { de software. }\end{array}$ & 7. \\
\hline & & Nivel de estrés en la & $10,11,12$ у 13. \\
\hline
\end{tabular}




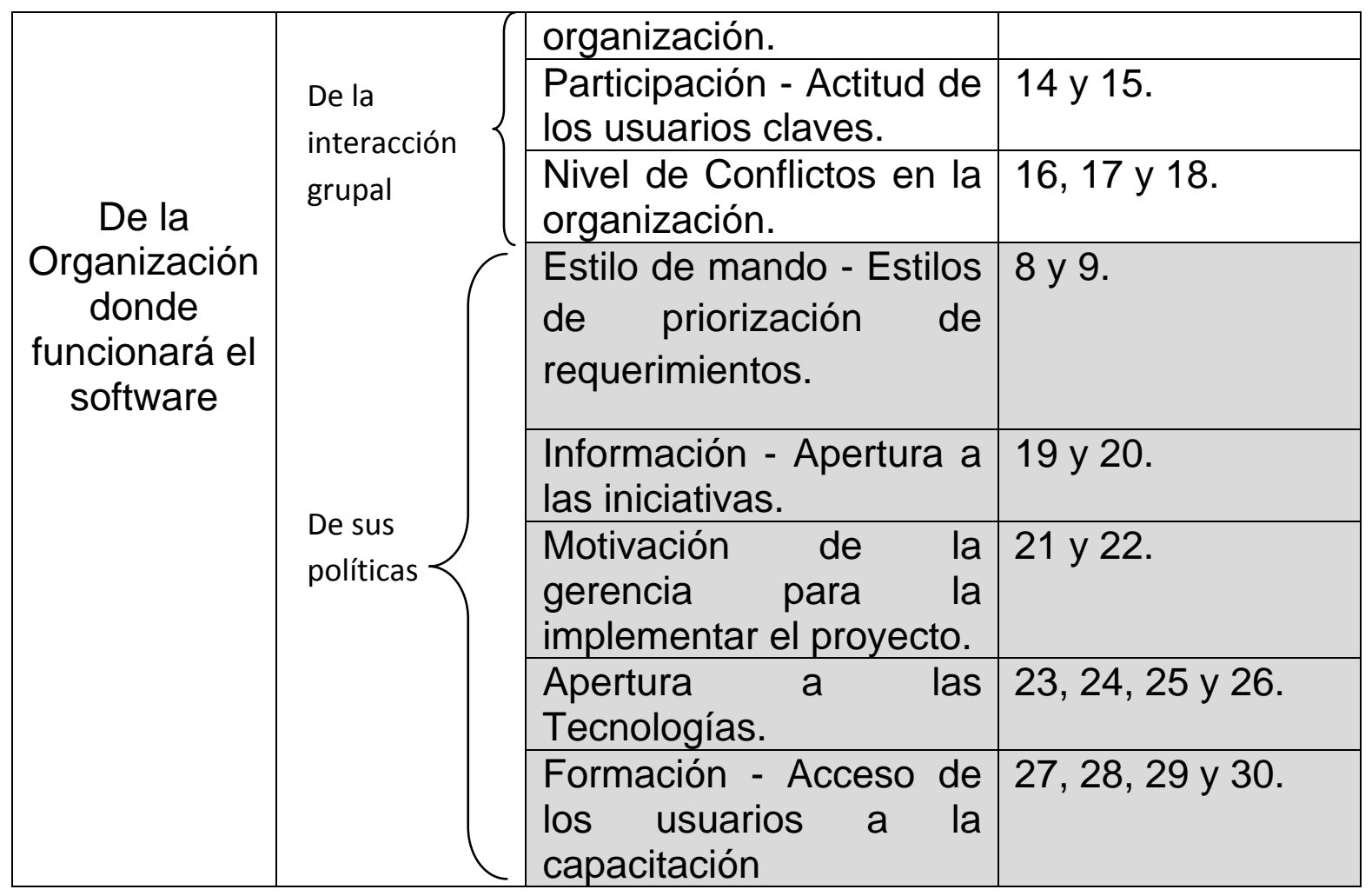

Momento de Aplicación del Cuestionario

Durante el proceso de elicitación de requerimientos.

Frecuencia: por hitos o tiempos. Es recomendable realizarlo de manera iterativa con el fin de medir la evolución de las variables a lo largo del ciclo de vida del proyecto.

Sujeto de aplicación

Responsable técnico del proyecto de software.

\section{$\underline{\text { Condiciones de evaluación }}$}

Las respuestas del cuestionario deben cuantificarse de acuerdo a la Planilla de Valoración Psicosocial, a partir de la cual surgirá el diagnóstico sobre el estado general del proyecto de software analizado desde el punto de vista psicosocial. A partir del puntaje obtenido, se califican las dos (2) áreas del riesgo psicosocial, las cuales varían desde óptima adecuación a máxima inadecuación.

Para que el procedimiento sea válido, quien lo complete debe asegurarse que: 
- las preguntas se interpreten correctamente.

- se maximice la objetividad.

- No se dejen preguntas sin contestar.

- Se respeta la confidencialidad de los datos.

El cuestionario está compuesto de treinta (30) preguntas, con tres (3) opciones de respuesta $(\mathrm{a}, \mathrm{b}$ y $\mathrm{c}$ ) y un campo Observaciones que permite aclarar la respuesta aportada. 


\section{Cuestionario de diagnóstico de riesgo psicosocial en proyectos de software}

Este cuestionario tiene como objetivo diagnosticar el riesgo psicosocial al que está expuesto el proyecto de software del cual usted es responsable.

Seguidamente le presentamos un conjunto de preguntas con varias opciones. Seleccione la que más se identifique con la situación por la que atraviesa su proyecto. Si necesita efectuar alguna aclaración, hágalo en observaciones.

El tiempo promedio para la finalización del cuestionario no excede los quince (15) minutos.

Muchas gracias.

\section{Datos del contexto del proyecto}

a) Nombre de la organización donde funcionará el software del cual es responsable:

b) Cantidad estimada de personas que la integran:

c) Nombre del Proyecto:

d) Fecha de inicio del proyecto:

e) Fecha en el que le fue asignado el proyecto.

f) Cantidad de integrantes del equipo de desarrollo que usted lidera:

g) Cantidad de proyectos asignados hasta la fecha en los que fue líder:

\section{Desarrollo del cuestionario}

1. ¿En general, el equipo de desarrollo asignado al proyecto de software está conformado por personalidades que lo distinguen como un grupo cohesionado?

a. No, sus integrantes frecuentemente colisionan por motivos laborales y/o personales. 
b. Aunque el equipo no se muestra como un grupo cohesionado, las disputas se producen únicamente por puntos de vista diferentes respecto al proyecto.

c. Si, la relación laboral entre los miembros del equipo se encuadra como de buena a óptima.
$\mathrm{A}$
B
$c \square$

Observaciones:

2. ¿Las cualidades que evidencia la personalidad de los miembros del equipo de desarrollo pueden desarrollarse en los roles que tienen asignados?

a. No. La mayoría de los roles deberían cambiar de personas. Otros miembros del equipo los podrían cumplir más naturalmente.

b. Se podrían hacer cambios mínimos como reajuste.

c. Si. Existe coincidencia entre las capacidades requeridas para cumplir los roles y las personas a ellos asignadas.
A
B
$c \square$

Observaciones:

3. ¿En la etapa de requerimientos, la comunicación entre el equipo de desarrollo y los usuarios es continua y fluida?

a. No. Los usuarios en general se resisten a brindar cualquier tipo de información clave relacionada con el proyecto. 
b. Si bien los usuarios comunican las necesidades relacionadas con el proyecto, la información clave la aportan fuera del ámbito de las técnicas de elicitación utilizadas.

c. Si. Los usuarios transmiten la información requerida en tiempo y forma con la técnica de elicitación que está siendo utilizada.
$\mathrm{A}$
B
$c \square$

Observaciones:

4. ¿Las técnicas de elicitación aplicadas por el equipo de desarrollo cambian en función de los resultados obtenidos en la interacción con los usuarios?

a. No, son fijas y se aplican siempre las mismas hasta que finaliza la gestión de requerimientos.

b. No, solo se cambian cuando se renueva el equipo encargado de la gestión de requerimientos.

c. Si, se cambian cuando se percibe que con la técnica aplicada no se obtiene la información necesaria.
A
B
$c \square$

Observaciones:

5. ¿Puede el equipo de desarrollo manejar sin inconvenientes la cantidad de requerimientos que demanda el proyecto de software? 
a. No. La alta tasa de cambio en los requerimientos genera volatilidad.

b. Ocasionalmente se producen inconvenientes puntuales pero en general se pueden gestionar los requerimientos.

c. Si. Los requerimientos se gestionan sin inconvenientes.
A
$\mathrm{B}$
$C \square$

Observaciones:

6. ¿En las áreas claves de la organización, se han implementado con éxito proyectos de software desarrollados "a medida".

a. No. Se utiliza únicamente software del tipo empaquetado.

b. Algunas aplicaciones son "a medida" y otras del tipo "empaquetado".

c. Si.
A
B
$C \square$

Observaciones:

7. ¿En la organización donde finalmente funcionará el software, el nivel general de consenso para implementar el proyecto es el suficiente?

a. No, hay demasiadas posiciones encontradas entre los involucrados lo que dificulta el avance. 
b. No, pero como hay firme decisión de implementar el proyecto, el consenso se logra paulatinamente.

c. Si. La mayoría de los involucrados están de acuerdo con los objetivos del proyecto y colaboran con la implementación.
A
B
$\subset \square$

Observaciones:

8. ¿En la organización donde finalmente funcionará el software, el estilo de mando utilizado prioriza la objetividad en la toma de decisiones importantes?

a. No. En la mayoría de las medidas prevalece la arbitrariedad.

b. Ocasionalmente se toman decisiones importantes arbitrarias.

c. Si. La objetividad está presente en todas las decisiones trascendentes.
A
B
$c \square$

Observaciones:

9. ¿Se respetan las cuestiones de género, raza o religión, entre otros derechos?

a. No. Se perciben altos índices de discriminación.

b. Ocasionalmente se detectan empleados aislados.

c. La organización es muy cuidadosa en respetar esas cuestiones.
A
B
C $\square$ 
Observaciones:

10. ¿Considera usted que el nivel general de estrés presente en la organización genera ansiedad que favorece el rendimiento?

a. No. Lo perjudica.

b. No incide.

c. Si. Lo Estimula.
A
B
$c \square$

Observaciones:

11. ¿El ausentismo por licencias por tratamiento médico y psicológico es poco frecuente?

a. Es muy frecuente.

b. Los niveles son normales. Como los de cualquier organización.

c. La gente generalmente no falta.
A
B
$c \square$

Observaciones: 
12. ¿El ambiente de trabajo posibilita relaciones amistosas entre los empleados?

a. En general, no se aprecia una buena relación.

b. Las relaciones entre los empleados son normales.

c. Si, en general la vida social de los empleados es buena también fuera del trabajo.
$\mathrm{A}$
B
$c \square$

Observaciones:

13. ¿Los empleados tienen la posibilidad de regular su ritmo de trabajo?

a. No. La organización controla exhaustivamente los horarios de los empleados.

b. No, porque el control es compartido. Los empleados están supervisados por los niveles superiores.

c. Si, mientras alcancen los rendimientos, los empleados autorregulan su ritmo de trabajo.
A
B
C

Observaciones: 
14. ¿Los usuarios claves brindan la información necesaria que se les requiere para la implementación del proyecto de software? O (PU)

a. No. Generalmente son reticentes.

b. Algunos se resisten, otros no tanto.

c. Si. En su gran mayoría cooperan y colaboran para que el proyecto prospere.
A
B
$C \square$

Observaciones:

15. ¿Los usuarios claves de la organización donde funcionará el software aceptan sin resistencia los nuevos roles que incorpora el proyecto de software?

a. No. En general, se quejan argumentando que los cambios introducidos le producirán graves problemas a la organización.

b. Algunos usuarios están en contra pero otros a favor.

c. En su gran mayoría lo aceptan sin inconvenientes.
A
B
$c \square$

Observaciones:-

16. ¿Las relaciones entre los empleados se ajustan a la orgánica formal de la organización donde funcionará el software? 
a. No. En los lugares comunes de descanso (café, pasillos, etc.) generalmente se establecen acuerdos transversales que no respetan las jerarquías naturales.

b. No. Porque hay determinados empleados que pueden imponer sus puntos de vista independientemente del puesto que ocupan.

c. Si. La organización es muy estricta con su orgánica.
A
B
$C \square$

Observaciones:

17. ¿Es frecuente la organización del trabajo intergrupal?

a. No. Cada grupo hace solo la tarea que le corresponde.

b. No. Únicamente en periodos de vacaciones por la escasez de personal.

c. Si. La organización promueve que determinadas tareas se realicen en forma compartida con la intervención de distintos equipos de trabajo.
A
B
$C \square$

Observaciones:

18. Las situaciones de conflictividad entre los empleados de un mismo grupo, ¿̇e intentan resolver de manera abierta?

a. No. Generalmente se resuelve informalmente con algún perjuicio para alguna de las partes. 
b. No. La organización no resuelve dos (2) conflictos iguales de la misma forma. No hay previsibilidad en el manejo del conflicto.

c. Si. La organización gestiona el conflicto a través de normas que evalúan las conductas en función de la ética.
A
B
$c \square$

Observaciones:

19. ¿Existe un procedimiento de atención a las posibles sugerencias y/o mejoras presentadas por los empleados?

a. No. La organización tiene sus propias normas y no admite desvíos.

b. Generalmente no. En forma excepcional se atienden sugerencias si provienen de determinados empleados.

c. Si. La organización valora las iniciativas de los empleados y de ser convenientes se adoptan.
A $\square$
B
$c \square$

Observaciones:

20. ¿La asignación de premios en la gestión de personal se realiza priorizando la idoneidad profesional?

a. No, en general prevalecen aspectos no relacionados con la idoneidad.

b. Se reparten las decisiones. Muchos estímulos se asignan por idoneidad profesional y otros por motivos diferentes. 
c. Casi siempre las decisiones se toman priorizando la idoneidad profesional.
A $\square$
B
$C \square$

Observaciones:

21. Los niveles directivos transmiten explícitamente al resto de la organización su decisión política de apoyar el proyecto de software.

a. No. Los empleados ignoran por completo que el proyecto de software que se está desarrollando es prioritarios para la dirección.

b. Sólo algunos empleados conocen la motivación de la dirección para que el proyecto se implemente.

c. Si. Toda la organización está motivada porque la dirección de la organización se ha manifestado públicamente a favor del proyecto de software.
A
B
$C \square$

Observaciones:

22. ¿Los niveles directivos participan en la negociación de requerimientos prioritarios que realizan el resto de los involucrados con el proyecto de software?

a. No. Se mantienen al margen completamente.

b. Solo algunos jefes intervienen en la negociación. 
c. Si. Los directores y gerentes de máximo nivel intervienen activamente.
A
B
$C \square$

Observaciones:

23. ¿En general, la edad promedio de los potenciales usuarios del proyecto de software es menor a 40 años?

a. No. Excede en promedio esa edad.

b. Si, pero muy estrecho margen.

c. Es una organización integrada por gente en su mayoría más joven.
A
B
$c \square$

Observaciones:

24. ¿Desde el punto de vista tecnológico, es una organización actualizada?

a. No. Supera los cinco (6) años de antigüedad.

b. No. La última actualización fue hace más de tres (3) años.

c. Si. La tecnología adquirida data de menos de tres (3) años.
$\mathrm{A} \square$
B
$c \square$

Observaciones: 
25. ¿Todas las áreas de la organización se encuentran informatizadas?

a. No, en su gran mayoría.

b. Solo las áreas claves.

c. Si.
A
B
$c \square$

Observaciones:

26. La organización donde funcionará el software tiene certificaciones de calidad y/o madurez (por ejemplo ISO, CMMI, etc.) acreditadas por instituciones de nivel internacional o nacional reconocido.

a. No.

b. Comenzó el proceso de certificación pero lo abandonó.

c. Si.
$\mathrm{A}$
B
$c \square$

Observaciones:

27. ¿Han recibido los directivos y empleados la formación para cumplir con sus roles y tareas?

a. No, fue insuficiente. 
b. Sólo la necesaria.

c. Si. La organización tiene como objetivo incrementar el capital intelectual.
$\mathrm{A}$
B
$C \square$

Observaciones:

28. ¿En general, los empleados han exteriorizado síntomas de reciprocidad hacia la organización?
a. No, todo lo contrario.
b. No, de indiferencia.
c. Si.
$\mathrm{A}$
B
$c \square$

Observaciones:

29. ¿En el año anterior se cumplieron los planes de capacitación del personal previstos?

a. No, hubo planes.

b. No, por cuestiones presupuestarias.

c. Si.
A
$\mathrm{B}$
$C \square$ 
Observaciones:

30. ¿Todos los empleados disponen de la información documentada para realizar su tarea?

a. No. Hay áreas de la organización que trabajan siguiendo pautas que se transmiten oralmente a través del tiempo.

b. No. Si bien la información sobre normas y procedimientos está documentada, no se la utiliza.

c. Si. Se respetan estrictamente las normas documentadas en todos los niveles.
A $\square$
B
c $\square$

Observaciones: 


\section{Evaluación}

\begin{tabular}{|c|c|c|}
\hline \multicolumn{3}{|c|}{ Planilla de Valoración Psicosocial } \\
\hline \multirow{2}{*}{\multicolumn{3}{|c|}{$\begin{array}{l}\text { Organización: } \\
\text { Hito del Plan: }\end{array}$}} \\
\hline & & \\
\hline $\begin{array}{l}\text { Nro. de la } \\
\text { respuesta }\end{array}$ & \multicolumn{2}{|c|}{$\begin{array}{l}\text { Puntaje asignado de acuerdo a la opción } \\
\text { seleccionada del cuestionario: } \\
\begin{array}{l}\mathrm{a}=6 \\
\mathrm{~b}=3 \\
\mathrm{c}=0\end{array}\end{array}$} \\
\hline Pregunta 1 & \multirow{6}{*}{$\begin{array}{l}\text { Del equipo } \\
\text { de } \\
\text { desarrollo }\end{array}$} & \\
\hline Pregunta 2 & & \\
\hline Pregunta 3 & & \\
\hline Pregunta 4 & & \\
\hline Pregunta 5 & & \\
\hline \multicolumn{2}{|l|}{ Pregunta 6} & \\
\hline \multicolumn{2}{|c|}{$\begin{array}{l}\text { Factores psicosociales que involucran } \\
\text { al Equipo de Desarrollo }\end{array}$} & $\begin{array}{l}\text { Puntaje } \\
\text { Total = }\end{array}$ \\
\hline \multicolumn{2}{|c|}{ Nro. de la respuesta } & $\begin{array}{l}\text { Puntaje asignado de acuerdo } \\
\text { a la opción seleccionada del } \\
\text { cuestionario: } \\
a=6 \\
b=3 \\
c=0\end{array}$ \\
\hline
\end{tabular}




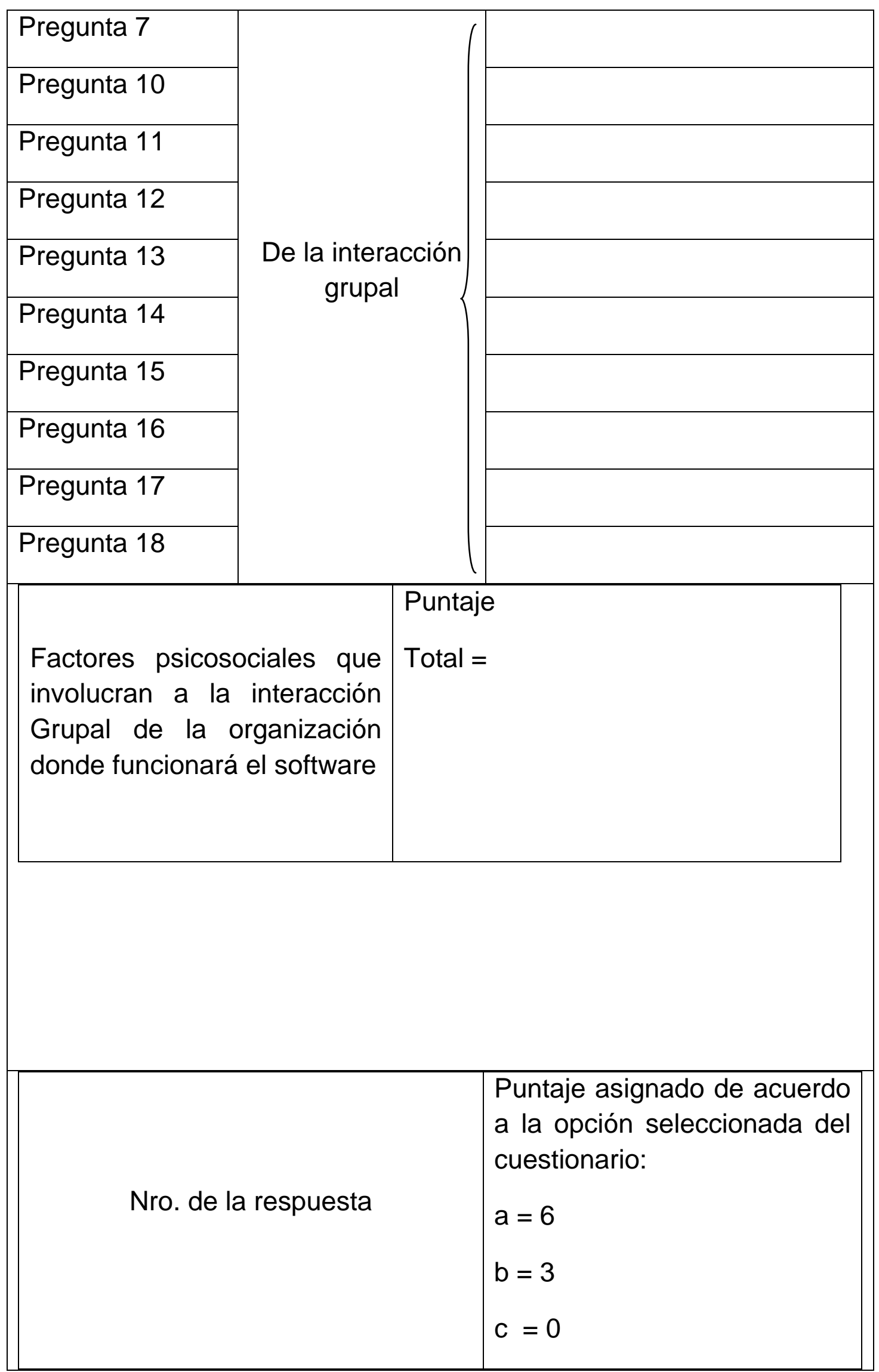




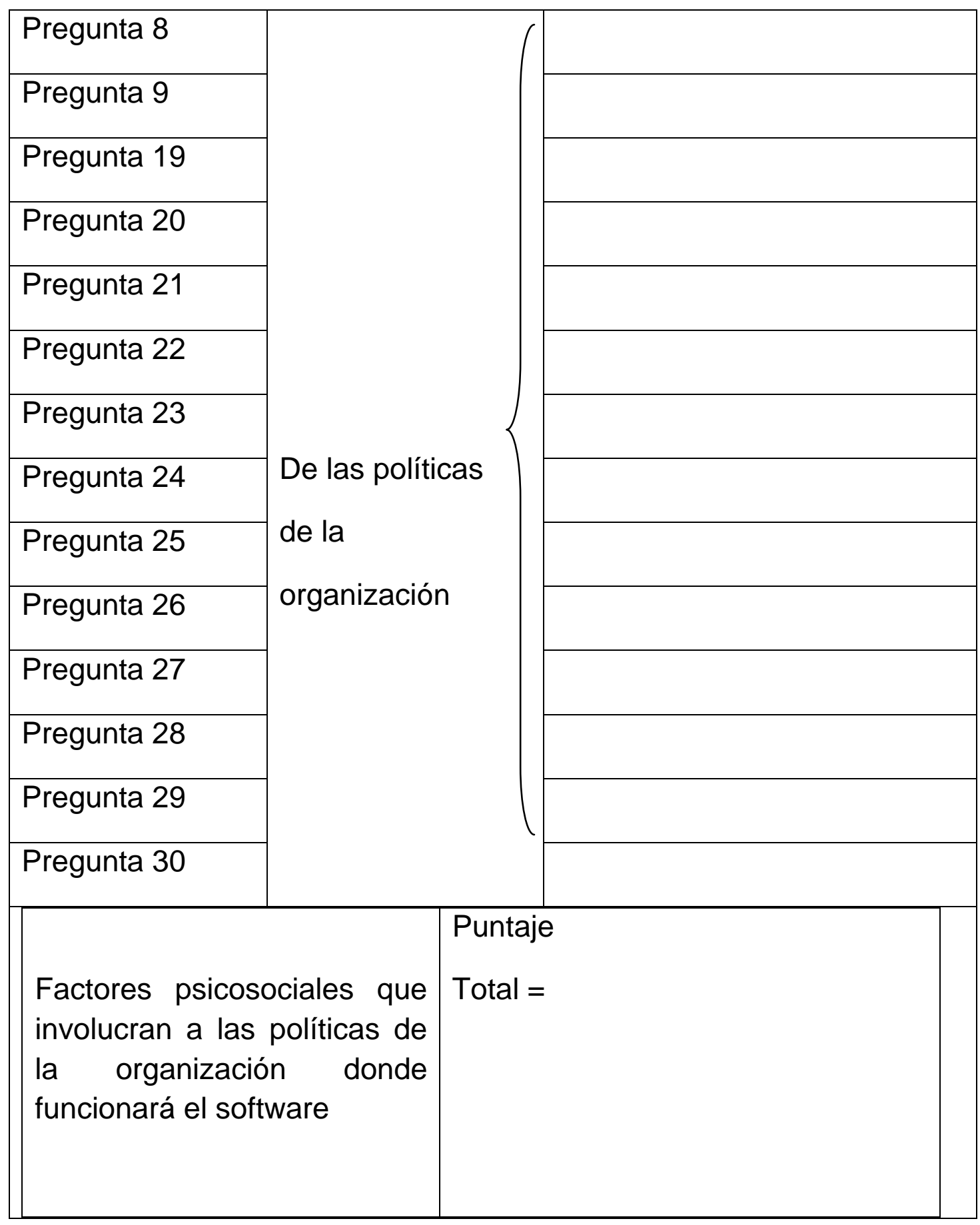

En función del puntaje obtenido en las tres (3) áreas de riesgo será posible el ubicar el riesgo psicosocial que enfrenta el proyecto de software, el cual variará de MUY INADECUADO - INADECUADO - ADECUADO ADECUADO. 


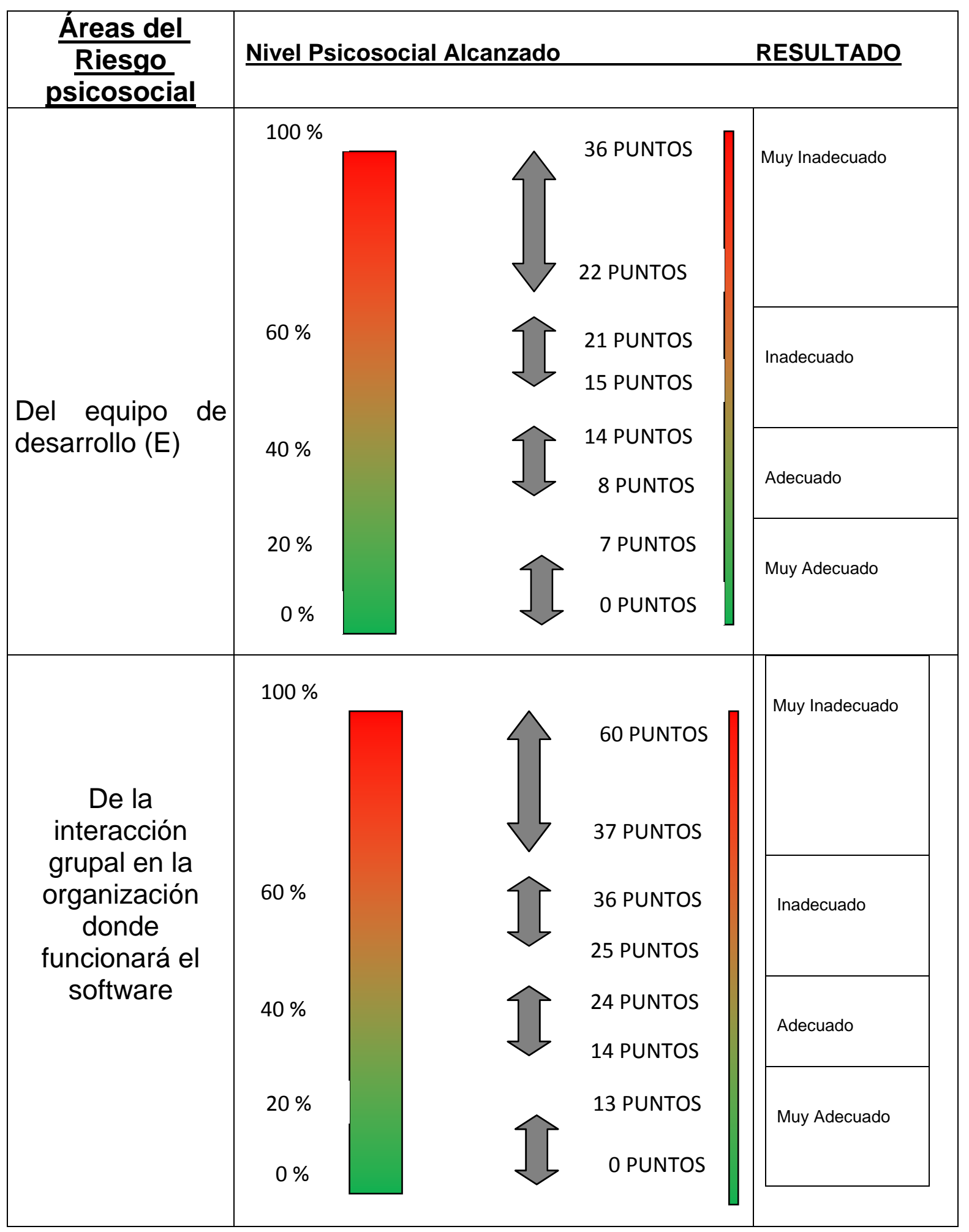




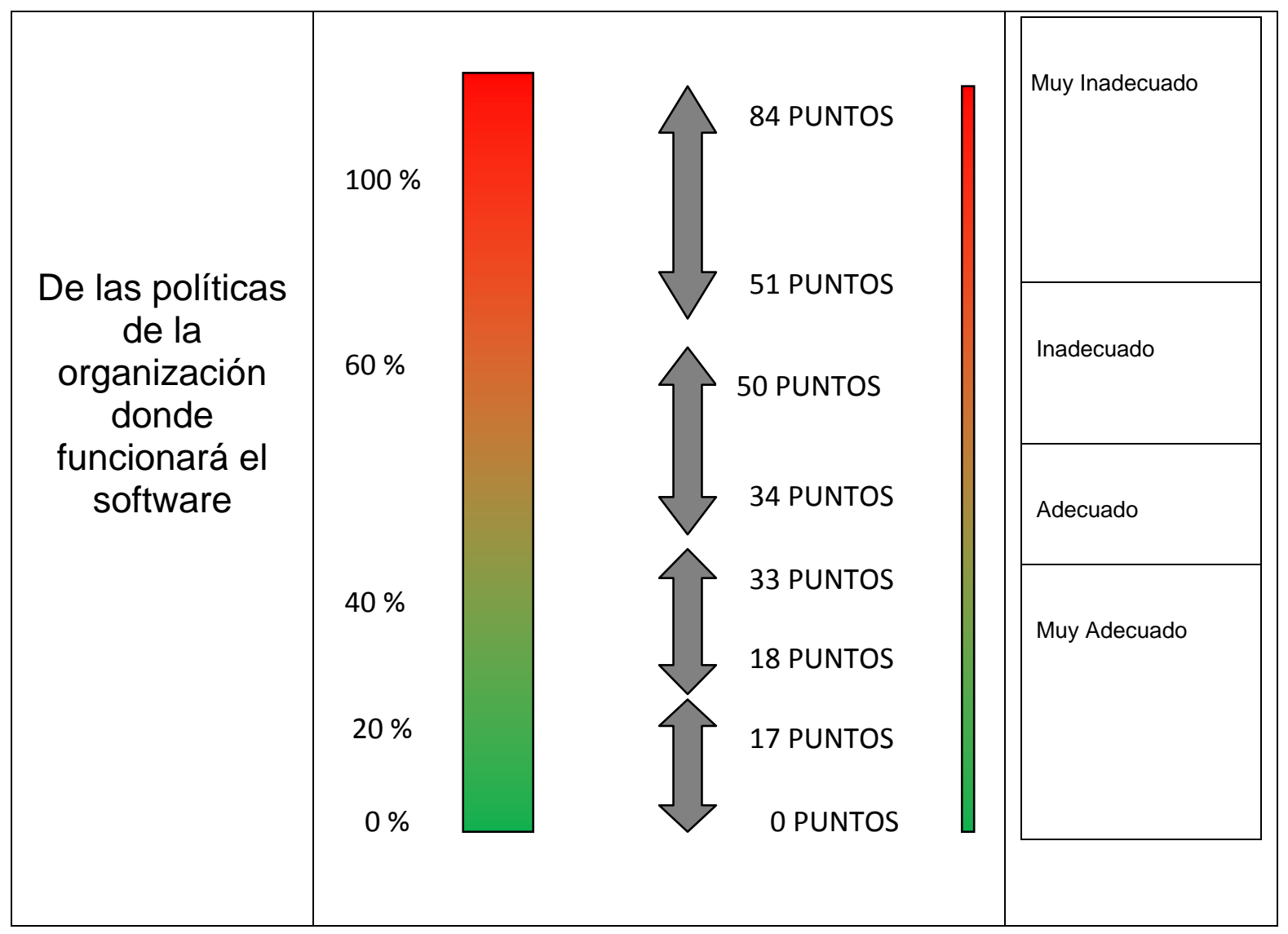

\section{Medidas Mitigadoras del Riesgo Psicosocial}

Si el resultado del cuestionario resulta ser INADECUADO o MUY INADECUADO, el responsable del proyecto de software deberá analizar cuál será la mejor manera de aplicar las recomendaciones siguientes con el fin de comenzar a revertir la situación del área psicosocial en cuestión.

Cómo ayuda para la identificación de situaciones psicosociales problemáticas se describen una serie de síntomas representativos.

1. Síntomas: - Incompatibilidad entre las personalidades de los miembros del equipo con las actividades de desarrollo de software. - Rendimiento en las tareas reducido por falta de cohesión entre las personalidades de los integrantes del equipo.

\section{Recomendación:}


OPTIMIZAR LA INTEGRACIÓN DE LOS ESTILOS DE PERSONALIDAD DEL EQUIPO DE DESARROLLO DE SOFTWARE

2. Síntomas: -Las técnicas de elicitación no se adecuan a los estilos cognitivos de los usuarios. - El equipo de desarrollo no detecta el impacto social que introduce el software en los usuarios de la organización.

Recomendación:

MEJORAR LA COMUNICACIÓN EQUIPO DE DESARROLLO - USUARIO

3. Síntomas: Exceso de requerimientos prioritarios para conservar el espacio de poder por parte de los stakeholders. -Existen requerimientos contradictorios $\mathrm{y} / \mathrm{o}$ demasiadas fuentes de requerimientos que dificultan su priorización.

Recomendación:

INCREMENTAR EL CONSENSO PARA IMPLEMENTAR EL PROYECTO

4. Síntomas: se aplican prácticas de tipo discriminatorio hacia determinados stakeholders por diferencias de género, edad, raza, religión, ideología, familia, entre otras.

Recomendación:

\section{$\underline{\text { REDUCIR LA ARBITRARIEDAD EN LA TOMA DE DECISIONES }}$}

5. Síntomas: Elevado ausentismo por licencias por tratamiento médico. Descontento con el clima laboral reinante en la organización por las condiciones de infraestructura informática, ambientales y/o edilicias. Elevado recambio de personal. 
Recomendación:

\section{REDUCIR EL NIVEL DE ESTRÉS DISFUNCIONAL EN LA ORGANIZACIÓN}

6. Síntomas: los usuarios claves no aceptan los nuevos roles que incorpora el proyecto de software y se resisten al cambio. - Generalmente originados en la organización informal, las posiciones a favor o en contra de la implementación representan potenciales agentes de cambio y volatilidad en los requerimientos. - No se aplican métodos para determinar cuál es la organización informal.

Recomendación:

\section{INCREMENTAR LA PARTICIPACIÓN DE LOS USUARIOS CLAVES}

7. Síntomas: Los requerimientos relevados en diferentes áreas de la organización se oponen entre si. -Se detectan usuarios claves con poca o nula intervención grupal. Presencia de grupos antagónicos.

Recomendación:

\section{REDUCIR EL NIVEL DE CONFLICTOS DISFUNCIONALES EN LA}

\section{ORGANIZACIÓN}

8. Síntomas: La Gerencia se niega sistemáticamente a admitir nuevas funcionalidades originadas en los empleados para no elevar el costo de la implementación. -La Gerencia no incorpora normas de calidad en los procedimientos parar no apartarse de su cultura organizacional. -Se aprecia carencia de estímulos en los empleados. Falta de actitud creadora e innovación.

Recomendación:

ESTIMULAR LA APERTURA A LAS INICIATIVAS DE LOS EMPLEADOS 
9. Síntomas: La gerencia no transmite explícitamente al resto de la organización su decisión política de apoyar totalmente la implementación del proyecto. -La Gerencia no controla la evolución del cronograma. -No interviene en los conflictos intergrupales cuando se negocian las prioridades.

Recomendación:

MOTIVAR A LA GERENCIA PARA IMPLEMENTAR EL PROYECTO

10. Síntomas: Son deficientes las políticas de calidad en la organización. Capital intelectual degradado. Falta de entrenamiento del personal.

Recomendación:

INCREMENTAR EL NIVEL DE CAPACITACIÓN DEL USUARIO

11. Síntomas:-Aversión a la imposición de nuevas tecnologías por excesiva antigüedad del personal o por inversiones que no rindieron el resultado esperado.

Recomendación

INCENTIVAR EL USO DE LA TECNOLOGÍA EN LA ORGANIZACIÓN 


\section{Anexo III}

\section{Entrevistas}

El objetivo de la entrevistas ha sido corroborar con profesionales de la psicología, desarrolladores y usuarios, si para ellos la incorporación de la psicología social en el proceso de elicitación de requerimientos puede aportar resultados significativos a la implementación de proyectos de software.

\section{Entrevistas a psicólogos}

Extracto de la entrevista realizada con las Licenciadas en Psicología Verónica AUMANN y Marisa BARRERA, el día 1 de Noviembre de 2011.

Claudio Torre: ¿En su ámbito de trabajo, cuáles son las razones que la llevaron a aplicar métodos de evaluación de los estilos de personalidad individual?

Verónica Aumann: La necesidad de tener que asignar especialidades laborales a capacitaciones. El objetivo es lograr que la persona más idónea cubra el puesto adecuado.

Marisa Barrera: Lo primero es definir el perfil laboral. A partir de allí evaluamos la personalidad del individuo para contrastarlo con el perfil requerido y determinamos si reúne las condiciones y requisitos.

C.T: ¿Está de acuerdo en que el rendimiento en las actividades en una organización puede mejorarse si se conoce la tipología de las personalidades?

V.A: Sí, sin embargo considero que la evaluación tiene que ser amplia, teniendo en cuenta por ejemplo como se enfrenta al estrés, a lo grupal, a los conflictos, etc.

M.B: : Si, a través de las técnicas proyectivas y psicometrías.

$\underline{\mathbf{C} \text { T: }}$ Teniendo en cuenta que en una organización la implementación de 
software socio-técnico puede implicar transformaciones significativas en el acceso a los datos y al proceso de toma de decisiones, ¿la aplicación de test, podría anticipar la presencia de estilos de personalidad proclives a obstaculizar dicho proceso de cambio?

$\underline{\text { V.A: }}$ Si, pero la persona es mucha más compleja y hay que pensar que esa información es un dato más que se complementa con otras informaciones.

M.B: Si. Es un buen indicador.

C.T.: En caso de ser afirmativa la respuesta a la pregunta anterior, y sin entrar en el campo de las patologías, cla psicología social cuenta con instrumentos de gestión individual o colectivo para reducir el riesgo que produce la resistencia al cambio. ?

V.A: Si, es muy importante el trabajo de campo, con monitoreo y asistencia que permita identificar dificultades y conflictos.

M.B: Si, tanto a nivel individual como grupal, mediante técnicas grupales.

C.T.: Como contracara a la primer pregunta, la aplicación de test en el mismo escenario, puede detectar la presencia de personalidades que alienten dicho proceso de cambio. ?

$\underline{\text { V.A: }}$ Si, pero siempre con un dato complementario mas.

M.B: SI.

C.T.: Se sabe que la dinámica de grupos cuenta con métodos para evaluar la conducta grupal (IPA, SYMLOG, Sociograma, etc.). Usted piensa que el uso de tales herramientas aplicadas desde el principio en un proyecto de software podría detectar la presencia de:

a. líderes positivos que encaminan el proceso de cambio al implementarse un nuevo sistema;

b. líderes negativos que lo dificultan; e individuos altamente influenciables e impredecibles cuya conducta difiere si los mismos se encuentran en soledad o si forman parte de un grupo.

V.A: Si. Los roles de liderazgo y la asignación de los mismos son 


\section{datos muy útiles que pueden brindar las técnicas grupales mencionadas.}

M.B: Si, sin duda se pueden utilizar en ambos casos.

C.T.: Como usted sabrá, existen sistemas informáticos que se implementan sin inconvenientes en algunas organizaciones mientras que los mismos proyectos en otras fracasan rotundamente. ¿Usted piensa que la intervención de un profesional de la psicología con la aplicación de los métodos antes mencionados puede ser un elemento de diagnóstico para evaluar la factibilidad de implementación de un proyecto de software?

V.A: Si. Siempre como un elemento de diagnóstico previo, que puede alertar sobre posibles dificultades. La psicología no es una ciencia exacta por lo que debe tomarse como un asesoramiento que debe ser corroborado a lo largo del proceso. Siempre es un dato más a tener en cuenta.

M.B: Si. Los proyectos de software socio-técnicos no fracasan solos, el perfil del hombre que lo gestiona y lo usa tiene gran injerencia en ello.

C.T.: Muchas gracias Licenciadas por su colaboración y su tiempo. 


\section{Entrevistas a desarrolladores}

Por razones de espacio se reproduce un extracto de entrevista realizada a desarrolladores de software. Tanto Alberto Piba como Silvio Arijón son analistas programadores con más de 20 años de experiencia. Piba trabaja en "TeVe Compras" en la Ciudad Autónoma de Buenos Aires y Arijón lo hace en la Administración Pública Nacional.

Claudio Torre : Durante la implementación de proyectos de software socio-técnico en los que usted participó, ¿pudo comprobar entre los stakeholders algún tipo de resistencia al cambio motivada por la introducción del nuevo sistema en la organización. ?

Alberto Piba: Si, muy frecuentemente.

Silvio Arijón: Si, generalmente hay resistencia.

C.T. ¿Cuáles de los siguientes síntomas usted percibió con mayor frecuencia en implementaciones que fracasaron o tuvieron dificultades serias? :
a. Falta de apertura debido a relaciones conflictivas entre stakeholders por diferencias de personalidad.
b. Confrontaciones entre los stakeholders por metas diferentes.
c. Negación a brindar información por temor a perder trabajo I poder.
d. Negación a brindar información por desconocimiento de lo que usted necesitaba saber.

\section{A.P: El punto $C$. \\ S.A: El punto $a$.}

C.T.: ¿En implementaciones que fracasaron o tuvieron dificultades serias, cómo percibió la relación entre los stakeholders. ?
a. Normal
b. Relación conflictiva
c. Buena relación/ buena armonía en el trabajo 
A.P: El punto b.

S.A: El punto b.

C.T.: En caso de haber percibido una relación conflictiva entre los stakeholders, ¿usted piensa que la aplicación de métodos propios de la psicología social, los cuales pueden brindarle al equipo de desarrollo información sobre la personalidad de los stakeholders y las relaciones grupales, podrían ser instrumentos de ayuda para la implementación del proyecto?

A.P: Si, absolutamente.

S.A: Si, dado que va a permitir identificar fácilmente a los usuarios claves problemáticos.

C.T.: ¿Usted cree que se mejora la afinidad equipo de desarrollo usuario clave, el hecho de utilizar técnicas de elicitación de requerimientos acordes con el estilo cognitivo del usuario, es decir de acuerdo a la forma de procesar la información del entorno ?

A.P: $\mathrm{Si}$, estoy convencido. Ello permitiría encarar cada uno de los temas con mayor compatibilidad.

S.A: Si, porque unifica la comunicación entre ambos.

C.T.: A su criterio, ¿podría gestionar mejor un proyecto de software si tuviera una herramienta para simular y modelar los estilos de personalidad de los stakeholders que intervienen en él?

A.P: Si, sería una herramienta adicional que incrementaría la probabilidad de implementación exitosa de los proyectos de software.

S.A: Si, porque podría conocer de antemano la composición psicológica de la organización, anticipándome a los obstáculos y potenciando a favor las ventajas.

C.T.: En los proyectos de software exitosos en los que le tocó participar, ¿podría mencionar cuáles de las siguientes conductas era la más frecuente entre los usuarios clave?

a. Innovación y libertad de acción brindada por la gerencia. 
b. Confianza y buena comunicación con el equipo de desarrollo.

c. Ambiente de trabajo informal pero productivo.

d. Si es otra causa especificarla.

A.P: El punto b.

S.A: El punto $\mathrm{C}$.

C.T.: Muchas gracias por su colaboración y su tiempo.

\section{Entrevistas a usuarios}

Claudio Torre: ¿Participó como usuario en la implementación de algún proyecto de software en su lugar de trabajo?

Usuario: $\mathrm{Si}$, varias veces.

C.T: Durante el proceso de implementación, ¿apreció entre los empleados algún tipo de resistencia al cambio producido por modificaciones que introducía el nuevo sistema?

Usuario: $\mathrm{Si}$, varias veces.

C.T.: ¿A cuál de las siguientes causas usted le atribuye esa resistencia?:

a. por conflictos producidos por personalidades diferentes.

b. por intereses y metas diferentes

c. por temor a perder información o espacio de poder

d. por edad.

e. A todas ellas.

Usuario: La causa e.

C.T.: Cuando fracasó o costó demasiado la implementación implementar un proyecto de software, cómo percibió la relación entre los empleados involucrados? 

a. Normal.
b. Mala relación / relación conflictiva
c. Buena relación / armonía en el trabajo
d. Indiferente

Usuario: la opción b. La relación se resentía por un tiempo.

C.T.: En caso de haber presenciado una implementación exitosa de un proyecto de software, ¿a cuál/es de las siguientes causas usted atribuye el éxito?
a. Innovación y libertad de acción.
b. Capacitación y buena comunicación.
c. Ambiente de trabajo informal pero productivo.
d. Si es otra causa especificarla.

Usuario: La opción b.

C.T.: En caso de haber vivido una relación conflictiva en la que no se pudo implementar un proyecto de software, ¿podría usted mencionar cuál/es de los siguientes síntomas percibió como más frecuente?
a. Subjetividad arbitraria, clima de presión, sobrecarga laboral e Irritabilidad, estrés.
b. Indiferencia, parálisis, superficialidad.
c. Aislamiento, negatividad.

Usuario: La opción a.

C.T.: Muchas gracias por su colaboración y su tiempo. 


\section{Anexo IV}

\section{Administración y publicación de la encuesta}

Se muestra los sitios nacionales e internacionales que brindaron su apoyo para la realización de este trabajo.

\section{Mis encuestas}

Utiliza este cuadro para editar tus encuestas, abrirlas o cerrarlas al público, determinar el método de envío y ver los resultados.

Cuenta :

Suscripción mensual desde el 18/08/2012 hasta el 17/09/2012

$\mathrm{N}^{0}$ de encuestas y respuestas: Ilimitadas

Límite de visualización:

Ilimitados cuestionarios por encuesta.

Visita la pagina de Funcionalidades para conocer en detalle las características de cada cuenta.

\begin{tabular}{|c|c|c|c|c|c|c|c|c|c|c|}
\hline (2) Nueva & $\begin{array}{l}\text { (6) Editar } \\
\text { encuesta }\end{array}$ & Popciones & $\begin{array}{l}\text { Links a } \\
\text { encuesta }\end{array}$ & if Compartir & (N) Resultados & Vaciar & X Eliminar & \multicolumn{2}{|c|}{$\begin{array}{l}\text { (4) Transferir } \\
\text { encuesta }\end{array}$} & \\
\hline \multicolumn{3}{|c|}{ Carpeta: } & & & & & & & & \\
\hline \multicolumn{2}{|l|}{ Título } & & & & & Entreq. (2) & Contestados (2) & Eliminados & Alta & Abrir/Cerrar \\
\hline \multicolumn{2}{|c|}{ FACTORES PSIC } & QUE INFLUYEN EI & LA IMPLEMENTA & N DE PROYECT & S DE SOFTWARE & 310 & 50 & 0 & $\begin{array}{l}14 / 0 \\
6: 36\end{array}$ & $\frac{\text { Cerrada al }}{\text { público }}$ \\
\hline
\end{tabular}




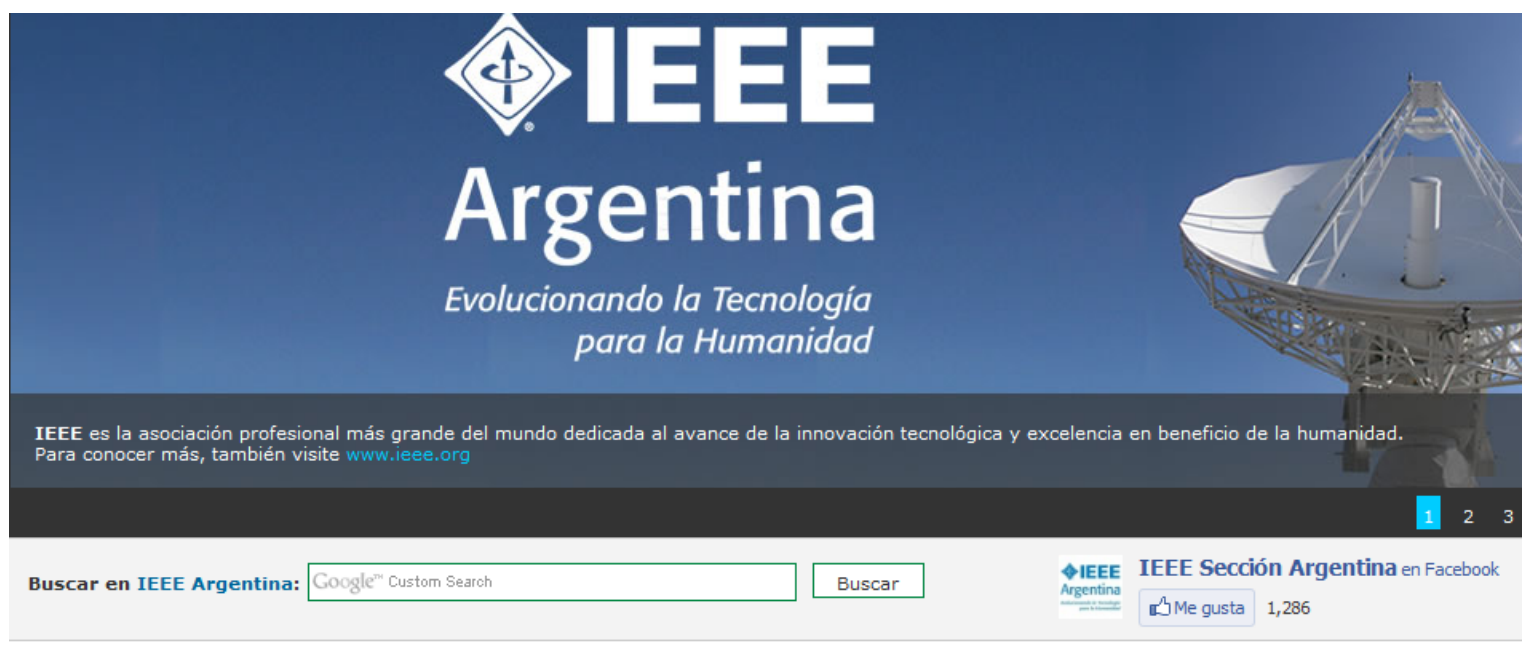

\section{Noticias y Actividades}

\begin{tabular}{l|l|l|l|} 
Actuales & Buscador & Histórico & Documentación
\end{tabular}

\section{Actuales}

Haga click en el evento elegido para conocer más detalles

12/04/2012 FI UNLP - Encuesta: 'Factores Psicosociales que Influyen en la Implementación de Proyectos de Software Invitación a participar

Descubra los beneficios

$$
\text { de ser miembro IEEE }
$$

- acceso a más de 200 e-books - IEEE memberNet

- IEEE Job Site

- y muchos beneficios más!

Para más información, haga clíck aqui

No deje de visitar los siguientes sitios IEEE:

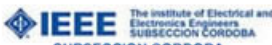

10.

14. -.- FI UNLP - Encuesta: 'Factores Psicosociales que Influyen en la Implementación de Proyectos de Software'

Se sabe que determinados proyectos de software socio-técnico que se implementan sin inconvenientes en algunas organizaciones, fracasan en otras.

La presente encuesta de opinión tiene por objeto corroborar que existe relación entre los factores psicosociales de la organización (ej. la motivación, el estrés, el consenso, las actitudes) y la implementación de proyectos de software. La cuestión es: "evaluar los factores psicosociales para reducir ese riesgo".

Esta encuesta se inserta en el marco de la propuesta de Tesis de Maestria de Ingeniería de Software : 'Incorporación de la psicolói social al proceso de elicitación de requerimientos de software ', aceptada por la Comisión Asesora de investigaciones y postorado de la Facultad de Informática de la Universidad Nacional de La Plata (UNLP)

Los invitamos a participar de la misma para conocer la opinión de profesionales y técnicos del área de gestión L desarrollo de proyectos de software respecto a la influencia de los factores psicosociales de la organización sobre las implementaciones informáticas.

Entre quienes participen de la encuesta, en agradecimiento por la colaboración brindada, se sorteará un radio reloj despertador Sony.

La encuesta está disponible en

http:/lwww.encuestafacil.com/RespWeb/Cuestionarios.aspx?EID=1163296\&MSJ=NO\#Inicio

Para más información comunicarse con Claudio Torre claudio torre@hotmail.com

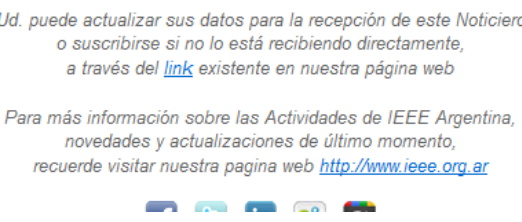




\section{Glosario de Definiciones, Términos y abreviaturas}

Apertura / preservación: trata de establecer en qué medida la conducta del sujeto está motivada por el deseo de obtener un refuerzo positivo (apertura) o evitar una estimulación negativa procedente del entorno (preservación).

Conductas Interpersonales: establecen en qué medida el estilo de relacionarse con los demás tiene que ver con el retraimiento o la comunicatividad, la vacilación o firmeza, la discrepancia o el conformismo, el sometimiento o el control y la insatisfacción o la concordancia.

Dinámica de Grupos: es una disciplina de la psicología, consistente en la aplicación de métodos, para establecer las causas del comportamiento grupal, es decir, procura averiguar por qué los grupos se comportan de la manera en que lo hacen.

Elicitación de requerimientos: es el proceso que consiste en adquirir todo el conocimiento relevante, necesario para producir un modelo de requerimientos (especificación) de un dominio de problema.

Estilos cognitivos: son componentes de la personalidad que identifican a los individuos por el modo de procesar la información que reciben del ambiente. El término fue introducido por G. W. Allport en los años 30.

Extraversión / introversión y sensación / intuición: repara en las estrategias empleadas para recolectar información.

Framework: En el desarrollo de software, un framework representa una estructura conceptual y tecnológica de soporte definida, normalmente con artefactos o módulos concretos, con base en la cual otro proyecto de software puede ser organizado y desarrollado.

Individualismo / Protección: evalúa en qué medida el sujeto está motivado por metas relacionadas con él (individualismo) o relacionadas con los demás (protección).

IPA: Interaction Process Analisis. 
Interacción Grupal: Conjunto de relaciones que ocurren entre los miembros de un mismo grupo. [Huici Casal et al., 2004]

Metas Motivacionales: evalúan la tendencia del individuo a obtener refuerzo del medio ambiente.

MIPS: Inventario Millon de Personalidades. [Millon, 2008]

Modificación / Acomodación: analiza cómo las actividades del sujeto reflejan una disposición a modificar el mundo (modificación) o adaptarse a él (acomodación).

Personalidad: Diferencia individual que constituye a cada persona y la distingue de otra.

Psicología Social: es el estudio científico de cómo los pensamientos, sentimientos y comportamientos de las personas son influidos por la presencia real, imaginada o implicada de otras personas. Según esta definición, científico refiere al método empírico de investigación. Los términos pensamientos, sentimientos y comportamientos incluyen todas las variables psicológicas que se pueden medir en un ser humano.

Reflexión / afectividad y sistematización / innovación: apuntan a establecer los estilos de procesamiento de la información obtenida.

Requerimiento: es la condición o capacidad que debe tener un sistema, producto, servicio o componente para satisfacer un contrato, estándar, especificación, u otros documentos formalmente establecidos. [Thomas, 2005]

Stakeholder: Término inglés utilizado por primera vez por R. E. Freeman, en su obra "Strategic Management", para referirse a quienes pueden afectar o ser afectados por las actividades de una empresa.

Desde el punto de vista de desarrollo de sistemas, un Stakeholder es aquella persona o entidad que esta interesada en la realización de un proyecto o tarea, auspiciando el mismo ya sea mediante su poder de decisión o de financiamiento.

SYMLOG: SYstem for the Multiple Level Observation of Groups.

Técnicas de grupos: conjunto de procedimientos sistematizados cuyo objeto es determinar qué procesos suceden dentro de un grupo. 


\section{$\underline{\text { Referencias Bibliográficas }}$}

1. Abukhzam A. , Lee A. (2010) "Workforce Attitude on Technology Adoption and Diffusion". School of the Built Environment, University of Salford, UK. <available at: http://tbher.org/index.php/tbher/article/viewFile/27/28>

2. Acuña, E. (2005) "Análisis de Datos Categóricos" Departamento de Matemáticas, Universidad de Puerto Rico <available at: http://academic.uprm.edu/eacuna/miniman8sl.pdf>

3. Alonso Pantoja Ospina, M. (2005) "Estilos Cognitivos" Universidad Nacional de Colombia - Sede Manizales <available at: http://www.manizales.unal.edu.co/modules/unrev creando/documentos/EstilosCognitivos.pdf>

4. Andriano N. (2006) "Comparación del Proceso de Elicitación de Requerimientos en el desarrollo de Software a Medida y Empaquetado" Tesis de Magíster en Ingeniería de Software UNLP pp. 28. <available at: http://postgrado.info.unlp.edu.ar/Carreras/Magisters/Ingenieria de Software/Tesis/Andriano Natalia.pdf>

5. Alvarez, R. (2002) "Discourse Analysis of Requirements and Knowledge Elicitation Interviews". Proceedings of the 35th Hawaii International Conference on System Sciences (HICSS-35). Jan. 710, Big Island.

6. Aparicio, E., García y Sánchez-López P. (1999) "Los estilos de personalidad: su medida a través del Inventario Millon de Estilos de Personalidad". Anales de Psicología 1999, vol. 15, nº 2, pp. 191-211 Universidad de Murcia, España.

7. Antón, A. (1996) "Goal Based Requirements Analysis". 2nd IEEE International Conference on Requirements Engineering, Colorado Springs,USA, 15-18 April 1996, pp. 136-144.

8. Aranda, G., Vizcaíno, A., Cechich, A. y M. Piattini ( 2005) "A Cognitive Based Approach to Improve Distributed Requirements Elicitation Processes". Universidad Nacional del Comahue Argentina. <available at: http://wer.inf.puc-rio.br/WERpapers/artigos/artigos WER05/gabriela aranda.pdf >

9. Aurum, A., Wohlin, C. (2005) "Engineering and Managing Software Requirements". Ed. Springer.

10. Barañano, M. (2005) "Gestión De La Innovación Tecnológica: Estudio exploratorio de nueve Pymes españolas"<available at: http://www.madrimasd.org/revista/revista30/tribuna/tribuna2.asp>

11. Bales, R. (1950) "Interaction Process Analysis: a method for the study of small groups. Cambridge, Addison-Wesley.

12. Bales, R y Cohen, S. (1979) "SYMLOG: a system for the multiple level observation of groups". New York. Free Press.

13. Barki, H. y Hartwick, J. (1994) "Measuring User Participation, User Involvement, and User Attitude." MIS Quarterly, Vol. 18, pp. 59-82.

14. Baronas, A. y Louis, M. (1988). "Restoring A Sense of Control During Implementation: How User Involvement Leads to System 
Acceptance." MIS Quarterly, Vol. 12, pp. 111-123.

15. Beck, K. (2000) "Extreme Programming Explained. Embrace Change", Pearson Education.

16. Beck, K. et. al. (2001) "Manifesto for Agile Software Development". available at < http://agilemanifesto.org/>

17. Betz, F. (1998). "Managing technological innovation: Competitive advantage from change" (pp. 9).New York: John Wiley \& Sons, Inc.

18. Bice, B. (2010) "Bridging The Communication Gap Between Customers and Developers" available at < http://www.leveltendesign.com/blog/brent/user-stories-bridging-communication-gapbetween-customers-and-developers

19. Boehm, B., Egyed, A., Kwan, J., Port, D. y Shah, A. (1998) "Using the WinWin Spiral Model: A Case Study, Computer". University of Southern California. <available at: http://sunset.usc.edu/ aegyed/publications/Using the WinWin Spiral Model-A Case Study.pdf>

20. Braidot. N (2011). "Toma de decisiones: el rol de las emociones en la empresa familiar". Brain Decision Braidot Centre, available at: http://www.materiabiz.com/mbz/entrepreneur/nota.vsp?nid=43081>

21. Bramley, $\mathrm{P}(1996)$ "Evaluating training effectiveness" Segunda Edición, London: McGraw-Hill.

22. Briggs, K. y Myers, I.(1921) "The Myers-Briggs Type Indicator"

23. Brooks Jr., Frederick P., (1995) "The Mythical Man-Month, AddisonWesley".

24. Brum, S.(2007) "What impact does training have on employee commitment and Employee turnover?" .University of Rhode Island. <available at: http://mww.uri.edu/research//rc/research/papers/Brum-Commitment.pdf>

25. Campos, A., Santos, E., Canuto, A., Soares, R., Alchieri, J. (2007) "Simulting Working Environments through the use of Personality Based Agents". <available at: http://www.icmc.usp.br//iarn2006/sbia/apresentacoes/IBERAMIASBIA_TS5/IBERAMIASBIA_TS5_A4.pdf.

26. Canós, J. (2005) "Metodologías Ágiles en el Desarrollo de Software" <available at: http://www.willydev.net/descargas/prev/TodoAgil.Pdf >

27. Cataldo, M., Wagstrom, P., Herbsleb, J. y K. Carley. (2006)."Identification of Coordination Requirements: Implications for the Design of Collaboration, and Awareness Tools". Computer Supported Cooperative Work '06, Banff, Alberta, Canada.

28. Cequea, M., Núñez Bottini M, y Rodríguez Monroy C. (2011) "Factores grupales que inciden en la productividad". Universidad Nacional Experimental Politécnica Antonio Sucre Venezuela. Revista: Universidad, Ciencia y Tecnología. Volumen XV, $n^{\circ} 61, p p$ 223 - 231. <available at: http://oa.upm.es/10785/1/INVE MEM 2011 96697.pdf>

29. Cooper, M. y Sheldon, M. (2002) "Seventy years of research on personality and close relationships: Substantive and 
methodological trends over time". Journal of Personality. 70(6):pp 783, December 2002.

30. Chou, H. (2001). "Effects of training method and computer anxiety on learning performance and self-efficacy". Computers in Human Behavior, Vol. 17, pp. 51-69.

31. Chrissis, M., Konrad, M. y Shrum, S. (2009) "CMMI® Guía para la integración de procesos y la mejora de productos". Traducción: Cátedra de Mejora de Procesos de Software en el Espacio Iberoamericano de la Universidad Politécnica de Madrid Segunda edición.

32. Christel, M. y Kang, K. (1992) "Issues in Requirements Elicitation". Technical Report CMU/SEI-92-TR-012, ADA258932. Pittsburgh: Software Engineering Institute, Carnegie Mellon University.

33. Curtis, B., Hefley, w. y Miller, S. (2001) "People Capability Maturity Model ${ }^{\circledR}(P . C M M \circledast)$ Version 2.0.Software Engineering Institute.

34. Davis, F. (1989) "Perceived Usefulness, Perceived Ease of Use, and User Acceptance of Information Technology," MIT, Cambridge, MA.

35. Deetz, S., Tracy, S. y Jennifer Lyn Simpson. (2000) "Leading Organizations Through Transition", Thousand Oaks, London, New Delhi, Sage Publications, Inc.

36. Digman, J. (1990) "Personality Structure: Emergence of the FiveFactor Model". Annual Review of Psychology, 41 pp 417-440, November 1990.

37. Di Rienzo, J., Balzarini, M., Casanoves, F., Gonzalez, L., Tablada, M. (2011) "I S - InfoStat". Postgrado de la Maestría en Estadística Aplicada. Universidad Nacional de Córdoba. Argentina.

38. Durán Toro, A y Bermudez Jimenes, B. (2002) "Metodología para la Elicitación de Requisitos de Sistemas Software". Departamento de Lenguajes y Sistemas Informáticos. Escuela Técnica Superior de Ingeniería Informática. Universidad de Sevilla. . <available at: http://www.infor.uva.es/ mlaguna/is1/materiales/metodologia elicitacion.pdf $>$

39. Felder, R., Brent, A (2005) "Understanding Student Differences" North Carolina State University.<available at: http://www4.ncsu.edu/unity/lockers/users//ffelder/public/Papers/Understanding Differences.pdf. >

40. Fenton, N. y Neil, M. (2005) "Software Metrics: Roadmap " Queen Mary and Westfield College, London.<available at: http:// citeseerx. ist. psu. edu/viewdoc/ download?doi=10.1.1.98.374\&rep=rep1\&type =pdf $>$

41. Fernández Ríos, M. y Sánchez, J. (1997) "Eficacia organizacional. Concepto, desarrollo y evaluación”. Madrid, Díaz de Santos, pp.340, ISBN: 84-7978-312-5.

42. Ferrari Márquez, J. (2006). "Dirección de equipos humanos en la gestión de la calidad total". Gerencia Regional del Catastro de Andalucía Occidental. España. <available at: http://www.catastro.meh.es/documentos/publicaciones/ct/ct43/J Ferrari.pdf>

43. Fichman, R., Kemerer, C. (1999), "The illusory diffusion of 
innovation: an examination of assimilation gaps", Information Systems Research, Vol.10 pp. 255-75.

44. Fishbein, M. y Ajzen, I. (1975) "Belief, Attitude, Intentions and behavior: An Introduction to Theory and Research", AddisonWesley, Boston, MA.

45. Fleishman, E. y Quaintance, M. (1984). "Taxonomies of human performance". New York: Academic Press.

46. Frese, M. y Hesse, W. (1995) "The Work Situation in Software Development" .University of Giessen - University of MarburgHans, Germany. <available at: http://www.methodsandtools.com/archive/archive. $p h p$ ?id=87>

47. Gómez Álvarez, J. (2005) "Sistemas de Información Multiagente". Departamento de Inteligencia Artificial de la Universidad Politécnica de Madrid. <available at: http://www.irisel.com/ imgomez/IT/doctorate/taller 2.htm

48. Geoergeff, M., Pell, B., Pollack, M., Tambe, M., y Wooldridge M. (1998) "The Belief-Desire-Intention model of agengy", Proceedings of the 5th International Workshop on Intelligent Agent. Agent Theories, Architectures and Languages, 1998.

49. Grudin, J. (1994). "Computer-Supported Cooperative Work: History and Focus". Computer 27 (5): pp 19-26.

50. Grudin, J. (1994) "Groupware and Social Dynamics: Eight Chalenges for developers" Communications of the ACM. pp 37, 92105.

51. Grünbacher, P., Halling, M., S. Biffl, Kitapci, H. y Boehm B. (2002) "Repeatable Quality Assurance Techniques for Requirements Negotiations". Proceedings of the 36th Hawaii International Conference on System Sciences (HICSS'03) IEEE.

52. Hickey, A. y Davis A. (2004) "A Unified Model of Requirements Elicitation". Journal of Management Information Systems, Vol. 20, No. 4, pp. 65-84.

53. Harris, R. y Davidson, R. (1999), "Anxiety and involvement: cultural dimension of attitudes toward computers in developing societies", Journal of Global Information Management, Vol.7. pp. 26-38.

54. Hayes-Roth, B., y Rousseau D. (1998) "A social-psychological model for synthetic actors". Proceedings of the 2 nd International Conference on Autonomous Agents (Agents'98), Minneapolis, US, pp.165-172.

55. Highsmith, J. (2002) "Agile Software Development Ecosystem", The Agile Software Development Series, Addison Wesley, Ed. 2002.

56. Huici Casal, C. y Domínguez, J. (2004) "Psicología de Grupos II. Métodos, Técnicas y Aplicaciones". U.D. pp $87-118$.

57. Hunter, A. y Nuseibeh, B. (1998) "Managing Inconsistent Specifications: Reasoning, Analysis and Action", ACM 
Transactions on Software Engineering and Methodology, Vol. 7 No. 4. pp 335-367.

58. Huntun, J. y Beeler, J. (1997) "Effects of User Participation in Systems Development: A longitudinal Field Experiment." MIS Quarterly, Vol 21, pp. 359-388.

59. Jacobson, I. (1992) "Object-Oriented Software Engineering: A Use Case Driven Approach". Boston: Addison-Wesley.

60. Jennings, N. (1998) "A road map of agent research and development". Autonomous Agents and Multi-agents, pp 7-38.

61. Jiang, J. y Klein, G. (1999) "Risks to different aspects of system success." Information \& Management, Vol. 36, pp. 263-272.

62. Kaiya, H. (2005) "Improving the detection of requirements discordances among stakeholders" Requirements Engineering, vol.10, no.4, pp.289-303.

63. Karlsson, J. (1997) "Cost-Value method based on analytical techniques". University of Limerick. <available at: http://files.itslearning.com/data/ntnu/open/CO33719/1424182.pdf>

64. Krzemien D. (2007) "Estilos de Personalidad y Afrontamiento Situacional Frente al Envejecimiento en la Mujer" Revista Interamericana de Psicología/ Interamerican Journal of Psychology 2007, Vol. 41, Num. 2 pp. 139-150.

65. Kwan, I. y Damain, D. (2006) "Connecting Peaople in Social Networks using Requiring Explorer" CSCW Workshop November 2006. Bnaff. Canadá. Available at: http://research.microsoft.com/pubs/75413/ssslssdproceedings.pdf

66. Langford, D., Hancock, M.R., Fellows R. y Gale, A.W. (1995): "Motivation". En Human Resources Management in Construction, Longman, pp.80-92.

67. Loucopoulos, P y Karakostas, V. (1995) "System Requirements Engineering" London: McGraw-Hill Companies. pp. 160.

68. Marguerison, C. y Mc.Cann, D. (1996) "Team Management System” Prado System Ltd. <available at: http://www.agence-tm.com/Fichiers PDF/tmi\%20EN.pdf

69. Markus, M. (1983) "Power, Politics and MIS Implementation." Communications of the ACD, Vol. 26, pp. 430-444.

70. Martínez Carod, N., Martín, A., Aranda, G., Cechich, A. (2005) "A Cognitive Approach to Improve Software Engineering Processes" Universidad Nacional del Comahue Argentina.

71. Manross, G. y Rice, R. (1986) "Don"t Hang Up: Organisational Diffusion of the Intelligent Telephone," Information and Management Magazzine Vol 10, pp.161-175.

72. Martín, M. y Góngora Yerro, J. (2002) "Factores Psicosociales Identificación de Situaciones de Riesgo" Instituto Navarro de Salud Laboral (I.S.N.L). Gobierno de Navarra. <available at: http://www.ual.es/GruposInv/Prevencion/evaluacion/procedimiento/F.\%20Factores\%2 
OPsicosociales.pdf>

73. Martínez Carod,N. y Cechich, A. (2004) "Elicitación Basada en Psicología Cognitiva: Un Caso de Estudio". Departamento de Ciencias de la Computación Universidad Nacional del Comahue, Neuquén, Argentina. <available at:

http://sedici.unlp.edu.ar/bitstream/handle/10915/21815/Documento completo.pdf?se quence $=1$

74. Martínez Carod, N. y Cechich A. (2007) "Gestión de

Preferencias de Requerimientos basada en Técnicas Cognitivas". XIII Congreso Argentino de Ciencias de la Computación - CACIC 2007. 01 - 05 de Octubre de 2007, Corrientes y Resistencia, Argentina.

75. Mclntyre, R. y Salas, E. (1995). "Measuring and managing for team performance: Lessons from complex environments". Team effectiveness and decision making in organizations, pp. 9-45. San Francisco: Jossey-Bass.

76. Millon, T. (2008) "Inventario Millon de Estilos de Personalidad" Paidos. pp 13 - 153.

77. Moreno, J. (1953) "Who will survive", Beacon House. Versión en castellano Editorial Paidos: Fundamentos de Sociometría.

78. Mullen, B. y Baumeister, R. (1987) "Group effects on self-attention and performance: Social loafing, social facilitation, and social impairment". Review of personality and social psychology, pp. 189206). Beverly Hills,CA: Sage.

79. Mullery, G. (1979) "CORE: A Method for Controlled Requirements Specification". Proceedings of the $4^{\text {th }}$ International Conference on Software Engineering (ICSE-4). Sep. 17-19, Munich.

80. Mylopoulos J., Chung L., Liao S., Wang H. y Yu E. (2001) "Exploring Alternatives During Requirements Analysis", IEEE Software, Jan/Feb 2001, Vol: 18 pp 92-96.

81. Olsina, L. (1999) "Metodología Cuantitativa para la Evaluación y Comparación de la Calidad de Sitios Web" Facultad de Ciencias Exactas UNLP Argentina, < available at: http://gidis.ing.unlpam.edu.ar/home/downloads/pdfs/Web-site QEM VF.pdf>

82. Paulk, M., Weber, C., Curtis, B. y Chrissis, M. (1993). "Capability Maturity Model for Software, Version 1.1". Technical Report (Carnegie Mellon University / Software Engineering Institute). CMU/SEI-93-TR-024 ESC-TR-93-177.

83. Parry, P., Ozcan, M. y Siddiqui, J. (1995) "The application visualitation to Requirements Engineering". Computing Reserch Centre. Shefield Hallam University. England.

84. Phillips, J., Phillips, P., Stone, R., y Burkett, H. (2007) “ The ROI Field Book: Strategies for Implementing ROI in HR and Training", S. A Massachusetts.

85. PMBOK (2003) "PMBOK A Guide to the Project Management Body 
of Knowledge" Project Management Institute. Fifth Edition. PMI.

86. Quijano S. (2006), "Dirección de Recursos Humanos y Consultoría en las Organizaciones. Barcelona, Ediciones. Icaria Editorial, pp. 425, ISBN: 84-7426-909-1.

87. Rodríguez, C. (2012) "Modelos Estocásticos". Escuela Profesional de Ingeniería Informática. Universidad Nacional de Piura. Perú. < available at: http://es.scribd.com/doc/94230363/Chi-Cuadrado-de-Pearson>

88. Royo Beberide, S. "Diseño y realización de entrevistas". Instituto Nacional de Seguridad e Higiene del Trabajo. < available at: http://www.insht.es/InshtWeb/Contenidos/Documentacion/FichasTecnicas/NTP/Ficher os/101a200/ntp 107.pdf

89. Rumbaugh, J. (1994) "Getting Started: Using Use Cases to Capture Requirements". Journal of Object-Oriented Programming, Vol. 7, No. 5, pp. 8-23.

90. Ramos, S. (2007) "Heurísticas y Problemas Combinatorios" < available at: http://materias.fi.uba.ar/7114/Docs/ApunteHeuristicas.pdf>

91. Robbins S y Judge T. (2009) "Comportamiento Organizacional". Decimotercera edición. México, Pearson Educación, pp.718, ISBN 978-60-7442-098-2.

92. Rodrigo M., Molina J. (2011) "Estadística Inferencial en Psicología" Universitat id Valencia" < available at:

http://ocw.uv.es/ciencias-de-la-salud/estadistica-estadistica-inferencial-enpsicologia/tema 5.pdf>

93. Ruiz González, F. y Molina Tejedor, M. (2000)" Planificación y Gestión de Sistemas de Información". Escuela Superior de Informática. Universidad de Castilla-La Mancha. < available at: http://alarcos.inf-cr.uclm.es/doc/pgsi/doc/esp/T9900 MAMolina.pdf>

94. Salgado, J. (2003) "Predicting job performance using personality measures". Journal of Occupational and Organizational Psychology. 76(3):pp 323-347, September 2003.

95. Salmon, P., Stanton, N., Houghton, R., Rafferty, L., Walker, G. y Jenkins D. (2008) "Developing Guidelines for Distributed Teamwork" , Human Factors Integration Defense Technology Centre. UK. <available at:

http://www.hfidtc.com/research/command/c-and-c-reports/phase-2/HFIDTC-2-8-6-2-1dis-teamwork-guidelines.pdf

96. Schwaber, Ken; Beedle, Mike (2002). "Agile software development with Scrum." Prentice Hall. ISBN 0-13-067634-9.

97. SEI (2010) "Improving processes for developing better products and services". CMMI ${ }^{\circledR}$ for Development, Version 1.3 Software Engineering Institute Carnigie Mellon. Determine risk sources: pp 351 < available at: http://www.sei.cmu.edu/reports/10tr033.pdf>

98. Sindre G. y Opdahl A. (2000) "Eliciting Security Requirements by 
Misuse Cases". Proceedings of the $37^{\text {th }}$ International Conference on Technology of Object-Oriented Languages Sydney, Australia.

99. Soloman, B. y Felder R. (2006) "Index of Learning Styles

Questionnaire" Department of Chemical Engineering North Carolina State University. <available at:

http://www.engr.ncsu.edu/learningstyles/ilsweb.html>

100. Sommerville, Ian y P. Sawyer (1997) "Requirements

Engineering: A Good Practice Guide" (1ra. edition edición). Wiley \&

Sons. pp. 404.

101. SommerVille, I. (2004) "Ingeniería de Software" Pearson, Addison Wesley. pp $10-25$.

102. Thomas, P. (2005) "Definición de un Proceso de Elicitación de Objetivos" Facultad de Informática, Universidad Nacional de La

Plata. <available at:

http://postgrado.info.unlp.edu.ar/Carreras/Magisters/Ingenieria de Software/Tesis/Th omas Pablo.pdf

103. Spector, P. (2003). "Industrial and organizational psychology Research and practice (3rd ed.). New York: John Wiley \& Sons, Inc.

104. Sun Public (2010) "Lightweight Scripting for Java" GNU Lesser Public. <available at: http://www.beanshell.org/contact.html> 105. Sutherland, J. (2010). "Agile Principles and Values". Microsoft Corporation <available at:

http://msdn.microsoft.com/en-us/library/dd997578.aspx

106. Todman, J. (2000). "Gender differences in computer anxiety among university entrants since 1992". Computers \& Education, Vol. 34 , pp. 27-35.

107. UNDP. (2010). "Igualdad de Género en las Empresas". United Nations Development Programme, <available at:

http://www.americalatinagenera.org/es/documentos/Manual Igualdad de Genero en las empresas.pdf>

108. Van Lamsweerde, A. (1998) "Goal-Oriented Requirements Analysis

with KAOS" Dept. Ingénierie Informatique, Univ.Louvain-la-Neuve Belgium. <available at:

http://www.policy-workshop.org/1999/policy-99/pdf/01-vanLamsweerde.pdf >

109. Vaughan, P. (2001) "System Implementation Success

Factors; It's not just the Technology". University of Colorado at Boulder. <available at:

http://spot.colorado.edu/ vaughan/SystemImplementationSuccessFactors files/frame.htm

110. Venkatesh, V. (1999) "Creation of Favorable User

Perceptions: Exploring the Role of Intrinsic Motivation," MIS

Quarterly (23:2) 1999, pp. 239-260.

111. Vroom, V. (1964). "Work and motivation". New York: John Wiley.

112. Venkatesh, V., and Davis, F. (2000) "A model of the 
antecedents of perceived ease of use: Development and test," Decision Sciences (27:10), Y: Self-Efficacy 1996, pp. 451-481.

113. Walsh, K. y Schneider, H. (2002) "The role of motivation and risk behaviour in software development success". Information Systems and Decision Sciences Department, Louisiana State University.

<available at:

http://www.informationr.net/ir/7-3/paper129.html>

Whitworth, E. y Biddle, R. (2007) "Motivation and Cohesion in Agile Teams". Human-Oriented Technology Laboratory Carleton University, Ottawa, Canada. <available at: http://www.google.com.ar/url?sa=t\&rct=j\&q=motivation\%20and\%20cohesion $\% 20$ in $\% 2$ 0agile\%20teams\%20\&source=web\&cd=1\&ved=0CDQQFjAA\&url=http\%3A\%2F\%2Fwww. agilealliance.org\%2Findex.php\%2Fdownload file\%2Fview\%2F23\%2F\&ei=9T-UOWHJleUiQLRsoCYDA\&usg=AFQjCNHcqriWrjPNVGYOg-qLSiZfRAD8UA

114. Wong, F., Fernandez, G. y McGovern, J. (2007) "CONFER: Towards Groupware for Building Consensus in Collaborative Software Engineering", School of Computer Science and Information Technology RMIT University Victoria, <available at: http://pdf.aminer.org/000/245/062/groupware support tools for collaborative softw are engineering.pdf

115. Yerkes. R. y Dodson, J. (1908). "The relation of strength of stimulus to rapidity of habit-formation". Journal of Comparative Neurology and Psychology 18: 459-482.

116. Zowghi, D. y C. Coulin,D. (2005) "Requirements Elicitation: A Survey of Techniques, Approaches, and Tools". Engineering and Managing Software Requirements. Heidelberg, Germany: SpringerVerlag. 